\begin{abstract}
UNIVERSIDADE DE SÃO PAULO
ESCOLA DE ENGENHARIA DE SÃO CARLOS

PROGRAMA DE PÓS-GRADUAÇÃO EM ENGENHARIA HIDRÁULICA E SANEAMENTO
\end{abstract}

MEHDI EL MANSSOURI

INFLUÊNCIA DA CARGA ORGÂNICA NA PRODUÇÃO DE BIOHIDROGÊNIO EM ASBBR COM AGITAÇÃO TRATANDO ÁGUA RESIDUÁRIA SINTÉTICA

VERSÃO CORRIGIDA

SÃo CARLOS, SP

2012 


\section{INFLUÊNCIA DA CARGA ORGÂNICA NA PRODUÇÃO DE BIOHIDROGÊNIO EM ASBBR COM AGITAÇÃO TRATANDO ÁGUA RESIDUÁRIA SINTÉTICA}

Dissertação apresentada à Escola de Engenharia de São Carlos da Universidade de São Paulo como parte dos requisitos necessários à obtenção do título de Mestre em Ciências.

Área de concentração: Engenharia Hidráulica e Saneamento

Orientador: Prof. Dr. José Alberto Domingues Rodrigues

VERSÃO CORRIGIDA

SÃO CARLOS, SP

2012 
Ficha catalografica preparada pela Seçao de Tratamento da Informacio do Servico de Biblioteca - EESC/USP

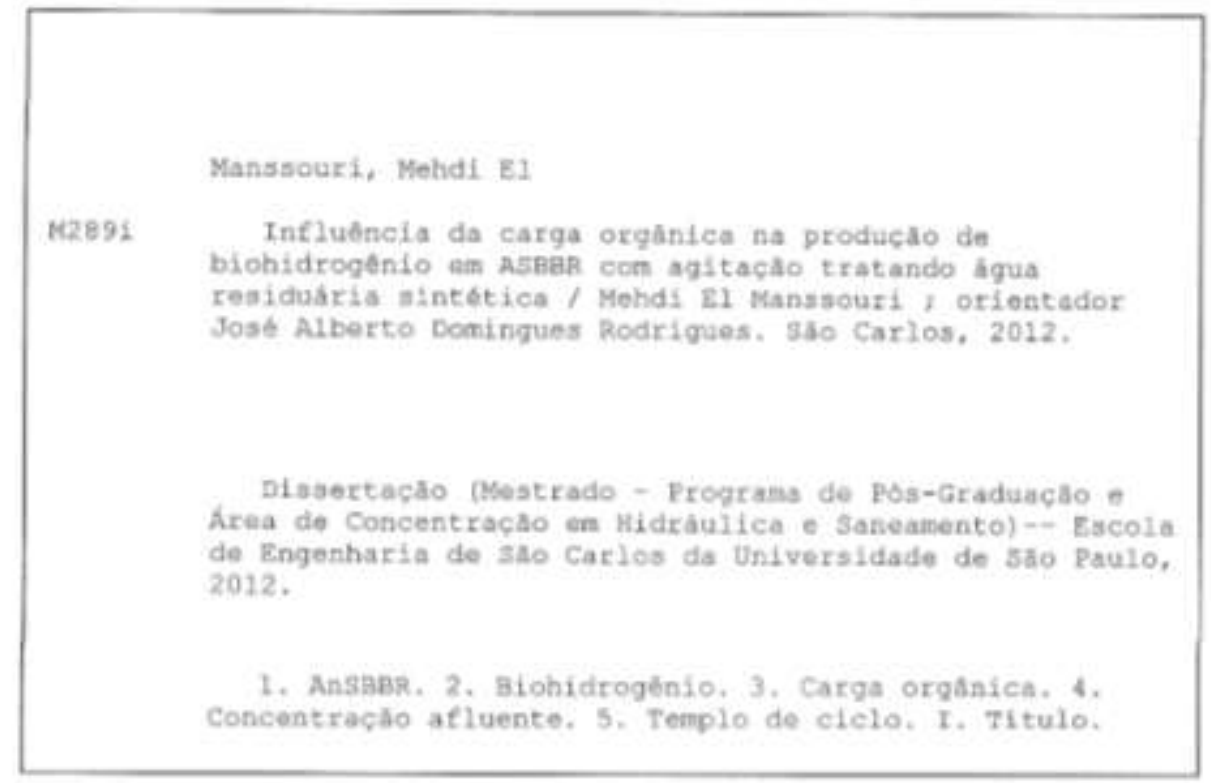




\section{FOLHA DE IULGAMENTO}

\section{Candidato: Engenheiro MEHDI EL MANSSOURI}

Título da dissertação: "Influência da carga orgânica na produção de biohidrogênio em ASBBR com agitação tratando água residuária sintética".

Data da defesa: 23/03/2012

\section{Comissão Julgadora:}

\section{Resultado:}

Prof. Associado José Alberto Domingues Rodrigues (Orientador)

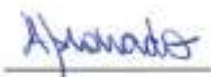

(Escola de Engenharia de Mauá/EEM)

Prof. Associado Marcelo Zaiat

(Escola de Engenharia de São Carlos/EESC)

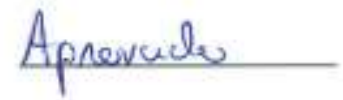

Prof. Dr. Luiz Olinto Monteggia

(Universidade Federal do Rio Grande do Sul/UFRGS)

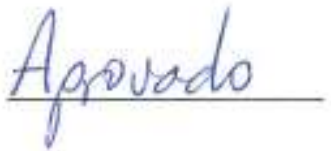

Coordenador do Programa de Pós-Graduação em Engenharia Hidráulica e Saneamento: Prof. Titular Edson Cezar Wendland

Presidente da Comissão de Pós-Graduação:

Prof. Associado Paulo Cesar Lima Segantine 
DEDICATORIA

A mon grand père, mon premier professeur. 


\section{AGRADECIMENTOS}

Em primeiro lugar, a minha família na França e no Brasil e a minha noiva Jennifer pelo apoio e o carinho, eles permitiram esta conquista.

Ao departamento de Hidráulica e Saneamento da Escola de Engenharia de São Carlos da Universidade de São Paulo SHS/EESC/USP e a Escola de Engenharia Mauá do Instituto Mauá de Tecnologia EEM/IMT que disponibilizaram o espaço e o apoio necessário a realização deste projeto.

Aos professores do SHS pela qualidade do ensino que constitui uma etapa importante deste trabalho.

Ao Dr. Marcelo Zaiat pelas sugestões no trabalho.

Aos meus colegas de sala e de laboratório.

Ao Daniel, ao Rafael e á Carol pela preciosa ajuda ao longo do trabalho.

Ao pessoal da oficina pelo apoio na montagem do reator.

Ao Danilo, um grande amigo que contribui muito a este trabalho, pelos conselhos, pelas conversas e pelo apoio.

Ao Dr. José Alberto Domingues Rodrigues e à Dra. Suzana Maria Ratusznei, pelas orientações, pela dedicação, pela disponibilidade, pelo profissionalismo e sobretudo pela amizade.

À CAPES pela bolsa de estudos concedida.

À FAPESP, pela bolsa de mestrado concedida (processo $n^{\circ}$ 10/03.876-6) e pelo auxílio financeiro no Projeto Temático "Produção de Bioenergia no Tratamento de Águas Residuárias e Adequação Ambiental dos Efluentes e Resíduos Gerados” (processo n 09/15.984-0).

Às pessoas que, cada um de sua maneira, contribuíram para realização destetrabalho, minha sincera gratidão. 
"If you think that education is expensive, try ignorance"

Derek Bok 


\section{RESUMO}

EL MANSSOURI, M. Influência da carga orgânica na produção de biohidrogênio em AnSBBR com agitação tratando água residuária sintética. Dissertação (Mestrado) - Escola de Engenharia de São Carlos Departamento de Hidráulica e Saneamento, Universidade de São Paulo, 2012.

Um reator anaeróbio com biomassa imobilizada e agitação mecânica foi operado em bateladas sequenciais com efluente sintético a base de sacarose visando à produção de biohidrogênio. $\mathrm{O}$ sistema foi inoculado com lodo proveniente de um reator anaeróbio metanogênico. Foram avaliados a produção de biohidrogênio, os rendimentos por carga aplicada e removida, a estabilidade e eficiência do reator quando submetido a diferentes cargas orgânicas volumétricas aplicada (COAV - 9,0;12,0;13,5; 18,0; 18,0 e 27,0 kgDQO. $\mathrm{m}^{-3} \cdot \mathrm{d}^{-1}$ ), as quais foram modificadas em função da concentração afluente (3600 e $5400 \mathrm{mgDQO} \cdot \mathrm{L}^{-1}$ ) e do tempo de ciclo (4, 3 e 2 h). O reator apresentou uma capacidade remoção da matéria orgânica (DQO) estável e próxima a um valor de $18 \%$, e uma boa capacidade de conversão de carboidratos (sacarose) a qual permaneceu entre 83 e 97\% ao longo da operação. Verificou-se uma diminuição do desempenho de remoção do reator com o aumento da carga orgânica aplicada e, além disso, valores crescentes de concentração afluente (e tempos de ciclo iguais) e tempos de ciclo menores (e concentrações afluente iguais) resultaram em eficiências menores de conversão. Houve predominância dos ácidos acético, butírico e propiônico com o aumento da carga orgânica, e de etanol em todas as condições. A maior concentração de biohidrogênio no biogás (24-25\%) foi atingida nas condições com COAV de 12,0 e 13,5 $\mathrm{kgDQO} \cdot \mathrm{m}^{-3} \cdot \mathrm{d}^{-1}$; a maior velocidade de produção diária $\left(0,139\right.$ mol.d $\left.\mathrm{d}^{-1}\right)$ foi atingida na condição com COAV de $18,0 \mathrm{kgDQO} \cdot \mathrm{m}^{-3} \cdot \mathrm{d}^{-1}$; e os maiores rendimentos de produção molares por carga aplicada e removida foram 2,83 e 3,04 $\mathrm{molH}_{2} \cdot \mathrm{kgSAC}^{-1}$, respectivamente, na condição com COAV de 13,5 $\mathrm{kgDQO} \cdot \mathrm{m}^{-3} \cdot \mathrm{d}^{-1}$. Não se verificou uma tendência de modificação do rendimento de biohidrogênio do reator em função da concentração afluente para tempos de ciclo iguais e do tempo de ciclo para concentrações afluente iguais, concluindo-se sobre a necessidade do estudo do comportamento do processo em função da carga orgânica aplicada e também das variáveis que definem a carga orgânica aplicada.

Palavras-chave: AnSBBR; biohidrogênio; carga orgânica; concentração afluente; tempo de ciclo. 


\begin{abstract}
EL MANSSOURI, M. Influence of influent concentration and feed time on biohydrogen production in an ansbbr with agitation treating sucrose based wastewater. Dissertation (Master in Hydraulic and Sanitary Engineering) - Engineering school of Sao Carlos, University of Sao Paulo, Sao Carlos, 2012

A mechanically stirred anaerobic sequencing batch reactor containing immobilized biomass treated sucrose-based synthetic wastewater to produce biohydrogen. The system was inoculated with sludge from an anaerobic methanogenic reactor. The following have been assessed: production of biohydrogen, yield per applied and removed load, reactor stability and efficiency under different applied volumetric organic loads applied (AVOL - 9.0, 12.0, 13.5, 18.0, 18. 0 and $27.0 \mathrm{kgDQO} . \mathrm{m}^{-3} \cdot \mathrm{d}^{-1}$ ), which were modified according to the influent concentration (3600 and $\left.5400 \mathrm{mgDQO} . \mathrm{L}^{-1}\right)$ and cycle time $(4,3$ and $2 \mathrm{~h}$ ). The reactor's ability to remove organic matter (COD) remained stable and close to a value of $18 \%$, and the system shows good ability to convert carbohydrates (sucrose) which remained between 83 and 97\% during the operation. There was a decrease in removal performance of the reactor with increasing applied organic load, and furthermore, increasing influent concentration (at constant cycle length) and cycle lengths (at constant influent concentrations) resulted in lower conversion efficiencies. Under all conditions, as organic load increased there was a predominance of acetic, propionic and butyric acid, as well as ethanol. The highest concentration of bio-hydrogen in the biogas (24-25\%) was achieved at conditions with AVOL of 12.0 and $13.5 \mathrm{kgDQO} . \mathrm{m}^{-}$ ${ }^{3} \cdot \mathrm{d}^{-1}$, the highest daily production rate $\left(0.139 \mathrm{~mol} \cdot \mathrm{d}^{-1}\right)$ was achieved at AVOL of $18.0 \mathrm{kgDQO} . \mathrm{m}^{-3} \cdot \mathrm{d}^{-1}$, and the highest production yields per removed and applied load were 2.83 and $3.04 \mathrm{molH}_{2} \cdot \mathrm{kgSAC}^{-1}$, respectively, at AVOL of $13.5 \mathrm{kgDQO} \cdot \mathrm{m}^{-3} \cdot \mathrm{d}^{-1}$. Biohydrogen yield showed no tendency to change with varying influent concentration at constant cycle length neither with varying cycle length at constant influent concentrations, indicating the need to study the behavior of the process as a function of applied organic load as well as of the variables which define the applied organic load.
\end{abstract}

Keywords: AnSBBR, agitation, biohydrogen, organic loading, influent concentration, cycle length. 


\section{RESUME}

EL MANSSOURI, M. Influence de la charge organique sur la production de bio-hydrogène d'un réacteur de type AnSBBR avec agitation mécanique appliqué au traitement d'effluent synthétique à base de saccharose. Dissertation (Master) - Ecole d'ingénierie de São Carlos - Département d'hydraulique e assainissement -Université de São Paulo, 2012.

Ce projet consiste en une étude de l'application d'un réacteur anaérobie séquentiel à agitation mécanique traitant un effluent synthétique à base de saccharose visant la production de bio-hydrogène. Le système a été initialement inoculé à partir de boues provenant d'un réacteur methanogénique. La capacité de production de biogaz, les rendements en fonction de la charge appliquée et retirée, la stabilité et l'efficacité du réacteur ont été évalués en fonction de la variation de la charge organique volumique appliquée (COVA - 9,0; 12,0 ; 13,$5 ; 18,0 ; 18,0$ e $27,0 \mathrm{kgDQO} \cdot \mathrm{m}^{-3} \cdot \mathrm{j}^{-1}$ ) induite par la modification de la concentration affluente (3600 e 5400 mgDQO. $\left.\mathrm{L}^{-1}\right)$ et du temps de cycle $(4,3,2 \mathrm{~h})$. Le système a montré une capacité d'éliminer la matière organique (DCO) stable et de l'ordre de $18 \%$ et une excellente capacité de conversion des glucides évoluant entre $83 \%$ à $97 \%$ au long de l'opération. Les données expérimentales ont permis de vérifier une tendance de diminution de la performance de conversion du réacteur en fonction de l'augmentation de la charge organique appliquée. L'analyse de paramètres intrinsèques à la charge organique a levé à la conclusion que l'augmentation de la concentration affluente (pour temps de cycles égaux) ou la diminution du temps de cycle (pour valeurs de concentrations égales) affecte négativement la performance du réacteur. L'augmentation de la charge organique a permis de révéler la prédominance de certains composés intermédiaire parmi lesquels l'éthanol et les acides acétique, propionique, butyrique Les plus hautes valeurs de concentrations de bio-hydrogène du biogaz (24-25\%) ont été atteintes au cours des conditions opérée sous COVA de 12 et $13,5 \mathrm{kgDQO} . \mathrm{m}^{-3} \cdot \mathrm{j}^{-1}$; le plus haut débit journalier de production de bio-hydrogène $(0,139$ mol. $\mathrm{d}^{-1}$ ) a été atteint au cours de la condition opérée sous COVA de 18,0 kgDQO. $\mathrm{m}^{-3} \cdot \mathrm{j}^{-1}$, et les meilleurs rendements par charge appliquée et retirée ont été de 2,83 et $3,04 \mathrm{molH}_{2} \cdot \mathrm{kgSAC}^{-1}$ respectivement et obtenus sous COVA de $13,5 \mathrm{kgDQO} . \mathrm{m}^{-3} \cdot \mathrm{j}^{-1}$. Aucune tendance de variation du rendement de production de biohydrogène en fonction de l'évolution des paramètres intrinsèques n'a été identifié justifiant la nécessité de réalisation d'études de comportement du procédés afin d'évaluer les meilleures conditions d'opération.

Mots clés: AnSBBR; bio-hydrogène; Charge organique; concentration affluente ; temps de cycle. 


\section{LISTA DE FIGURAS}

Figura 3.1 - Indicadores de produção de hidrogênio presentes na literatura 13

Figura 4.1 - Fotografia dos grânulos do material suporte 24

Figura 4.2 - Esquema do reator anaeróbio com agitação operado em bateladas seqüenciais contendo biomassa imobilizada 26

Figura 4.3 - Fotografia do aparato experimental 27

Figura 4.4 - Ciclos típicos de bateladas sequenciais. 34

Figura 5.1- Concentrações em carboidratos no afluente e efluente total e filtrado - Condição preliminar.

Figura 5.2 - Eficiências de conversão dos carboidratos na forma total e filtrada - Condição preliminar.

Figura 5.3 - Concentrações em DQO no afluente e efluente total e filtrado- Condição preliminar. 45

Figura 5.4 - Eficiências de remoção da DQO na forma total e filtrada- Condição preliminar. 45

Figura 5.5- Concentrações em ácidos volateís totais por titulação no afluente e efluente - Condição preliminar. 46

Figura 5.6 - pH afluente e efluente - Condição preliminar. 46

Figura 5.7 - Alcalinidades totais por titulação no afluente e efluente - Condição preliminar. 47

Figura 5.8- Concentrações em carboidratos no afluente e efluente total e filtrado - Condição I. ....51

Figura 5.9- Eficiências de conversão dos carboidratos na forma total e filtrada - Condição I......... 51

Figura 5.10- Concentrações em DQO no afluente e efluente total e filtrado - Condição I. 52

Figura 5.11- Eficiências de remoção da DQO na forma total e filtrada - Condição I 52

Figura 5.12- Concentrações em ácidos volateís totais por titulação no afluente e efluente Condição I. 53

Figura 5.13- pH afluente e efluente - Condição I. 55

Figura 5.14- Alcalinidades totais por titulação no afluente e efluente - Condição I. 55 
Figura 5.15 - Variação da produção volumétrica de biogás durante um ciclo - Condição I............56

Figura 5.16 - Perfil de evolução da concentração em carboidratos no reator - Condição I..............57

Figura 5.17 - Perfil de evolução da concentração em DQO no reator- Condição I.........................58

Figura 5.18 - Perfil de evolução da concentração em ácidos volateís totais por titulação no reator -

Condição I. 58

Figura 5.19 - Perfil de evolução das concentrações dos compostos intermediários - Condição I. ...59

Figura 5.20 - Perfil de evoluçãodo pH no reator- Condição I. .59

Figura 5.21 - Perfil de evolução da alcalinidade total por titulação no reator - Condição I. 60

Figura 5.22 - Perfil produção volumétrica acumulada de biogás - Condição I. 60

Figura 5.23 - Perfil produção volumétrica espécifica acumulada de gases - Condição I.

Figura 5.24 - Concentrações em carboidratos no afluente e efluente total e filtrado - Condição II. 64

Figura 5.25 - Eficiências de conversão dos carboidratos na forma total e filtrada - Condição II.....65

Figura 5.26- Concentrações em DQO no afluente e efluente total e filtrado - Condição II. .65

Figura 5.27- Eficiências de remoção da DQO na forma total e filtrada - Condição II. 66

Figura 5.28- Concentrações em ácidos volateís totais por titulação no afluente e efluente Condição II. .66

Figura 5.29- pH afluente e efluente - Condição II. 68

Figura 5.30- Alcalinidades totais por titulação no afluente e efluente - Condição II. .68

Figura 5.31- Variação da produção volumétrica de biogás durante um ciclo - Condição II. 69

Figura 5.32- Perfil de evolução da concentração em carboidratos no reator - Condição II. 70

Figura 5.33- Perfil de evolução da concentração em DQO no reator- Condição II. 71

Figura 5.34- Perfil de evolução da concentração em ácidos volateís totais por titulação no reator Condição II. .71

Figura 5.35 - Perfil de evolução das concentrações dos compostos intermediários - Condição II... 72

Figura 5.36- Perfil de evolução do pH no reator- Condição II. 72

Figura 5.37- Perfil de evolução da alcalinidade total por titulação no reator - Condição II. 73 
Figura 5.38 - Perfil produção volumétrica acumulada de biogás - Condição II. 73

Figura 5.39 - Perfil produção volumétrica espécifica acumulada de gases - Condição II. 74

Figura 5.40 - Concentrações em carboidratos no afluente e efluente total e filtrado - Condição III.

Figura 5.41 - Eficiências de conversão dos carboidratos na forma total e filtrada - Condição III. .. 77

Figura 5.42- Concentrações em DQO no afluente e efluente total e filtrado - Condição III.............78

Figura 5.43- Eficiências de remoção da DQO na forma total e filtrada - Condição III..... 78

Figura 5.44- Concentrações em ácidos volateís totais por titulação no afluente e efluente Condição III. 79

Figura 5.45- pH afluente e efluente - Condição III. 80

Figura 5.46- Alcalinidades totais por titulação no afluente e efluente - Condição III. 81

Figura 5.47- Variação da produção volumétrica de biogás durante um ciclo - Condição III. 81

Figura 5.48- Perfil de evolução da concentração em carboidratos no reator - Condição III. 83

Figura 5.49- Perfil de evolução da concentração em DQO no reator- Condição III. 83

Figura 5.50- Perfil de evolução da concentração em ácidos volateís totais por titulação no reatorCondição III. 84

Figura 5.51 - Perfil de evolução das concentrações dos compostos intermediários - Condição III. 84

Figura 5.52- Perfil de evolução do pH no reator- Condição III. 85

Figura 5.53- Perfil de evolução da alcalinidade total por titulação no reator - Condição III. 85

Figura 5.54- Perfil produção volumétrica acumulada de biogás - Condição III. 86

Figura 5.55 - Perfil produção volumétrica espécifica acumulada de gases - Condição III. 87

Figura 5.56 - Concentrações em carboidratos totais no afluente e efluente total e filtrado - Condição IV. 90

Figura 5.57 - Eficiências de conversão dos carboidratos totais na forma total e filtrada - Condição IV. 91

Figura 5.58- Concentrações em DQO no afluente e efluente total e filtrado - Condição IV. 91 
Figura 5.59- Eficiências de remoção da DQO na forma total e filtrada - Condição IV.

Figura 5.60- Concentrações em ácidos volateís totais por titulação no afluente e efluente Condição IV .93

Figura 5.61- $\mathrm{pH}$ afluente e efluente - Condição IV. 94

Figura 5.62- Alcalinidades totais por titulação no afluente e efluente - Condição IV

Figura 5.63- Variação da produção volumétrica de biogás durante um ciclo - Condição IV 95

Figura 5.64- Perfil de evolução da concentração em carboidratos totais no reator - Condição IV. . 96

Figura 5.65- Perfil de evolução da concentração em DQO no reator- Condição IV. 97

Figura 5.66- Perfil de evolução da concentração em ácidos volateís totais por titulação no reatorCondição IV

Figura 5.67 - Perfil de evolução das concentrações dos compostos intermediários - Condição IV. 98

Figura 5.68- Perfil de evolução do pH no reator- Condição IV 98

Figura 5.69- Perfil de evolução da alcalinidade total por titulação no reator - Condição IV. 99

Figura 5.70- Perfil produção volumétrica acumulada de biogás - Condição IV. 99

Figura 5.71 - Perfil produção volumétrica espécifica cumulada de gases - Condição IV. 100

Figura 5.72 - Concentrações em carboidratos no afluente e efluente total e filtrado - Condição V.

Figura 5.73 - Eficiências de conversão dos carboidratos na forma total e filtrada - Condição V. . 104

Figura 5.74- Concentrações em DQO no afluente e efluente total e filtrado - Condição V. 104

Figura 5.75- Eficiências de remoção da DQO na forma total e filtrada - Condição V 105

Figura 5.76- Concentrações em ácidos volateís totais por titulação no afluente e efluente Condição V. 106

Figura 5.77- $\mathrm{pH}$ afluente e efluente - Condição V. 107

Figura 5.78- Alcalinidades totais por titulação no afluente e efluente - Condição V 107

Figura 5.79- Variação da produção volumétrica de biogás durante um ciclo - Condição V...........108

Figura 5.80- Perfil de evolução da concentração em carboidratos no reator - Condição V. 109 
Figura 5.81- Perfil de evolução da concentração em DQO no reator- Condição V. 110

Figura 5.82- Perfil de evolução da concentração em ácidos volateís totais por titulação no reatorCondição V.

Figura 5.83 - Perfil de evolução das concentrações dos compostos intermediários - Condição V.111

Figura 5.84- Perfil de evolução do pH no reator- Condição V.

Figura 5.85- Perfil de evolução da alcalinidade total por titulação no reator - Condição V.

Figura 5.86- Perfil produção volumétrica acumulada de biogás - Condição V

Figura 5.87 - Perfil produção volumétrica espécifica cumulada de gases - Condição V.

Figura 5.88 - Concentrações em carboidratos no afluente e efluente total e filtrado - Condição VI.

Figura 5.89 - Eficiências de conversão dos carboidratos na forma total e filtrada - Condição VI. 117

Figura 5.90- Concentrações em DQO no afluente e efluente total e filtrado - Condição VI.

Figura 5.91- Eficiências de remoção da DQO na forma total e filtrada - Condição VI.

Figura 5.92- Concentrações em ácidos volateís totais por titulação no afluente e efluente Condição VI.

Figura 5.93- pH afluente e efluente - Condição VI.

Figura 5.94- Alcalinidades totais por titulação no afluente e efluente - Condição VI.

Figura 5.95- Variação da produção volumétrica de biogás durante um ciclo - Condição VI.

Figura 5.96- Perfil de evolução da concentração em carboidratos no reator - Condição VI 122

Figura 5.97- Perfil de evolução da concentração em DQO no reator- Condição VI.

Figura 5.98- Perfil de evolução da concentração em ácidos volateís totais por titulação no reator Condição VI. 123

Figura 5.99 - Perfil de evolução das concentrações dos compostos intermediários - Condição VI.

Figura 5.100- Perfil de evolução do pH no reator- Condição VI 124

Figura 5.101- Perfil de evolução da alcalinidade total por titulação no reator - Condição VI. 125 
Figura 5.102- Perfil produção volumétrica acumulada de biogás - Condição VI. 125

Figura 5.103 - Perfil produção volumétrica espécifica acumulada de gases - Condição VI 126

Figura 5.104 - Eficiências de remoção de matéria orgânica (DQO) nas formas não filtrada e filtrada - Todas Condições.

Figura 5.105 - Eficiências de conversão de carboidratos (sacarose) nas formas não filtrada e filtrada em função do aumento da carga orgânica aplicada - Todas Condições.

Figura 5.106 - Eficiências de conversão de carboidratos (sacarose) na forma não filtrada e filtrada em função do aumento da concentração afluente - Todas Condições.

Figura 5.107 - Eficiências de conversão de carboidratos (sacarose) na forma não filtrada e filtrada em função da diminuição do tempo de ciclo - Todas Condições.

Figura 5.108 - Repartição dos compostos intermedíarios - Todas Condições. 132

Figura 5.109 - Variação da produção volumétrica de biogás - Todas Condições. 133

Figura 5.110 - Variação da produção molar específica de biogás - Todas Condições. 134

Figura 5.111 - Diagrama de barra dos indicadores de produção molar em função do aumento da carga orgânica aplicada.- Todas Condições 138

Figura 5.112 -Rendimentos molar por carga aplicada na base do substrato em em função da variação da carga orgânica aplicada - Comparação com a literatura 142

Figura 5.113 - Microscopias por luz comum e contraste de fase e por fluorescência - Condições I e II 143

Figura 5.114 - Microscopias por luz comum e contraste de fase e por fluorescência - Condições III e IV. 144

Figura 5.115 - Microscopias por luz comum e contraste de fase e por fluorescência - Condições V e VI. 144

Figura 5.116 - Potencial energético por combustão - Todas Condições. 150

Figura 5.117 - Equivalente em grama de gasolina do potencial de energético por combustão Todas Condições. 


\section{LISTA DE TABELAS}

Tabela 3.1 - Avaliações da produção de biohidrogênio em função da carga orgânica ..................... 19

Tabela 4.1 - Características do material suporte da biomassa ......................................................24

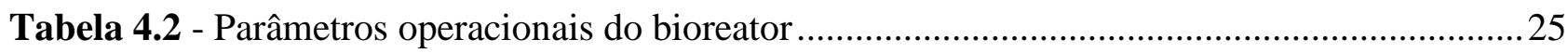

Tabela 4.3 - Composição da água residuária sintética a ser utilizada nos ensaios*........................29

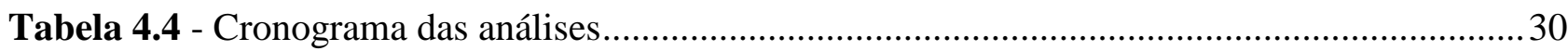

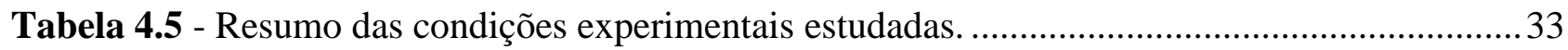

Tabela 5.1 - Valores médios dos parâmetros monitorados - Condição preliminar (DQO 3600 mg.L.'1 $-\mathrm{TC} 4 \mathrm{~h})$

Tabela 5.2- Valores médios dos parâmetros monitorados - Condição I (DQO 3600 mg.L-1 -TC 4h).

Tabela 5.3- Concentração média e composição dos compostos intermediários - Condição I. 53

Tabela 5.4 - Volumes específicos acumulados de gases e proporção de hidrogênio - Condição I...61

Tabela 5.5 - Valores médios dos parâmetros monitorados - Condição II. (DQO 3600 mg.L -1 $^{-1}$ TC 3h) 63

Tabela 5.6 - Concentração média e composição dos compostos intermediários - Condição II. 67

Tabela 5.7 - Volumes específicos acumulados de gases e proporção de hidrogênio - Condição II. 74

Tabela 5.8 - Valores médios dos parâmetros monitorados - Condição III. (DQO 5400 mg.L - $^{-1}$-TC 4h). 76

Tabela 5.9 - Concentração média e composição dos compostos intermediários - Condição III. ...... 80

Tabela 5.10 - Volumes específicos de gases acumulados e proporção de hidrogênio - Condição III. 86

Tabela 5.11 - Valores médios dos parâmetros monitorados - Condição IV. (DQO 5400 mg.L ${ }^{-1}$-TC 3h). 89

Tabela 5.12 - Concentração média e composição dos compostos intermediários - Condição IV ....93 
Tabela 5.13 - Volumes específicos acumulados de gases e proporção de hidrogênio - Condição IV.

Tabela 5.14 - Valores médios dos parâmetros monitorados - Condição V. (DQO 3600 mg.L L $^{-1}$-TC $2 \mathrm{~h})$.

Tabela 5.15 - Concentração média e composição dos compostos intermediários - Condição V....106

Tabela 5.16 - Volumes específicos acumulados de gases e proporção de hidrogênio - Condição V.

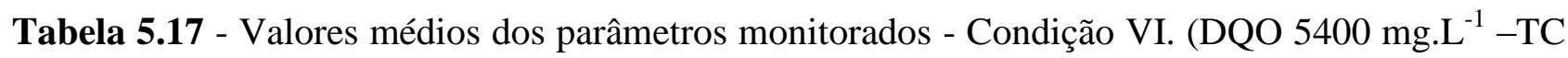
$2 \mathrm{~h})$.

Tabela 5.18 - Concentração média e composição dos compostos intermediários - Condição VI. . 119

Tabela 5.19 - Volumes específicos de gases acumulados e proporção de hidrogênio - Condição VI.

Tabela 5.20 - Eficiências médias de conversão de matéria orgânica (DQO) e de carboidratos (sacarose) em função do aumento da carga orgânica aplicada. 128

Tabela 5.21 - Eficiências médias de conversão de matéria orgânica (DQO) e de carboidratos (sacarose) em função do aumento da concentração afluente.

Tabela 5.22 - Eficiências médias de conversão de matéria orgânica (DQO) e de carboidratos (sacarose) em função da diminuição do tempo de ciclo. 130

Tabela 5.23 - Repartição dos compostos intermediários - Todas condições

Tabela 5.24 - Repartição dos gases produzidos - Todas Condições.

Tabela 5.25 - Indicadores de desempenho por unidade de massa em função do aumento da carga orgânica aplicada. - Todas Condições. 135

Tabela 5.26 - Rendimentos molares por carga aplicada potenciais por vias biológicas. 137

Tabela 5.27 - Desempenho porcentual em função dos potenciais teòricos - Todas Condições. ... 138

Tabela 5.28 - Avaliações da produção de biohidrogênio em função da carga orgânica (Continua). 
Tabela 5.29 - Balanço de massa entre entrada e saída do elemento Carbono.

Tabela 5.30 - Balanço de massa de saída em termos de DQO. 148

Tabela 5.31 - Calor de combustão dos combustiveis 149

Tabela 5.32 - Cotação de preço da gasolina e do açúcar. 151

Tabela 5.33 - Estudo da viabilidade econômica do projeto.

\section{ANEXOS}

Tabela AI-1: Caracteristicas do Afluente em todas condições: concentrações em matéria orgânica DQO e substrato, $\mathrm{pH}$, alcalinidade total, alcalinidade a bicarbonato e ácidos voláteis totais do afluente.

Tabela AII-1: Caracteristicas do efluente e desempenho do reator em todas condições: concentrações em DQO filtrada e total e substrato filtrado e total, eficiênças de remoção filtradas e totais.

Tabela AIII-1: Caracteristicas do efluente em todas condições:, $\mathrm{pH}$, alcalinidade total, alcalinidade a bicarbonato e ácidos voláteis totais do afluente.

Tabela AIV-1: Volume total e específicos do biogás em todas condições.

Tabela AV-1: Valores de Perfis da condição I.

Tabela AV-2: Valores de Perfis da condição II.

Tabela AV-3: Valores de Perfis da condição III.

Tabela AV-4: Valores de Perfis da condição IV.

Tabela AV-5: Valores de Perfis da condição V.

Tabela AV-6: Valores de Perfis da condição VI. 


\section{LISTA DE ABREVIATURAS E SIGLAS}

Acetil-CoA Acetila coenzima A

ADP Adenosina difosfato

AM Agitação mecânica

AnSBBR Reator anaeróbio operado em batelada sequencial com biomassa imobilizada

ASBR Reator anaeróbio operado em batelada sequencial

ATP Adenosina trifosfato

B Biomassa aderida e/ou retida

CNTP Condições Normais de Temperatura e de Pressão

DQO Demanda Química em oxigênio

EEM Escola de Engenharia Mauá

EESC Escola de Engenharia de São Carlos

FID Detector de ionização de chama

HPLC High Performance Liquid Chromatography

IEA International Energy Agency

IMT Instituto Mauá de Tecnologia

LPB Laboratório de Processos Biológicos

$\mathrm{N} \quad$ Elemento nitrogênio

NAD Nicotinamida Adenina Dinucleotideo na forma oxidada

NADH Nicotinamida Adenina Dinucleotideo na forma reduzida

P Elemento fósoforo

RFL Recirculação da fase líquida

rpm Rotações por minuto

SI Suporte inerte

SP São Paulo 
Tempo de ciclo

TCD

Detector de condutividade térmica

$\mathrm{TDH}$

Tempo de detenção hidráulica

UASB Upflow anaerobic sludge Blanket

USP Universidade de São Paulo. 


\section{LISTA DE SÍMBOLOS}

$\mathrm{AB}$

AI

AP

AT

AVT

C

$\mathrm{C}_{\mathrm{CF}, \mathrm{E}}$

$\mathrm{C}_{\mathrm{CT}, \mathrm{A}}$

$\mathrm{C}_{\mathrm{CF}, \mathrm{E}}$

COAE

$\mathrm{COAV}_{\mathrm{CT}}$

$\mathrm{COAV}_{\mathrm{ST}}$

$\mathrm{CORE}_{\mathrm{CF}}$

$\mathrm{CORE}_{\mathrm{SF}} \quad$ Carga orgânica removida volumétrica filtrada na base da DQO [kgDQO.gSVT ${ }^{-1} \cdot \mathrm{d}^{-1}$ ]

$\mathrm{CORV}_{\mathrm{CF}} \quad$ Carga orgânica removida volumétrica na base da sacarose $\left[\mathrm{kgSAC} \cdot \mathrm{m}^{-3} \cdot \mathrm{d}^{-1}\right]$

$\mathrm{CORV}_{\mathrm{SF}} \quad$ Carga orgânica removida volumétrica na base da DQO [kgDQO.m $\left.\mathrm{m}^{-3} \cdot \mathrm{d}^{-1}\right]$

$\mathrm{C}_{\mathrm{SF}, \mathrm{E}} \quad$ Concentração de matéria orgânica na base da DQO no efluente filtrado [mgDQO.L ${ }^{-1}$ ]

$\mathrm{C}_{\mathrm{ST}, \mathrm{A}} \quad$ Concentração de matéria orgânica na base da DQO no afluente não filtrado

$\mathrm{C}_{\mathrm{ST}, \mathrm{E}}$ Concentração de matéria orgânica na base da DQO no efluente não filtrado $\left[\mathrm{mgDQO} . \mathrm{L}^{-1}\right]$ 
$\mathrm{C}_{\mathrm{X}-\mathrm{SVT}} \quad$ Biomassa total presente no reator na forma de sólidos totais voláteis por unidade de volume de fase liquida no reator $\left[\mathrm{gSVT} . \mathrm{L}^{-1}\right]$

$\mathrm{C}_{\mathrm{X} \text {-SvT }}$ Biomassa total presente no reator na forma de sólidos totais voláteis por unidade de massa de material suporte [gSVT.g-suporte $\left.{ }^{-1}\right]$

$\mathrm{E}_{\mathrm{H} 2} \quad$ Potencial energético por combustão do hidrogênio $\left[\mathrm{kJ} . \mathrm{d}^{-1}\right]$

$\varepsilon_{\mathrm{CF}} \quad$ Eficiência de remoção de matéria orgânica na base da sacarose ma forma filtrada [\%]

$\varepsilon_{\mathrm{CT}} \quad$ Eficiência de remoção de matéria orgânica na base da sacarose na forma não filtrada [\%]

$\varepsilon_{\mathrm{SF}} \quad$ Eficiência de remoção de matéria orgânica na base da DQO na forma filtrada [\%]

$\varepsilon_{\text {ST }} \quad$ Eficiência de remoção de matéria orgânica na base da DQO na forma não filtrada [\%]

gDQO massa de DQO [gDQO]

g massa de substrato [gSAC]

HAc Ácido acético

$\mathrm{HBu} \quad$ Ácido butírico

$\mathrm{HCa} \quad$ Ácido capríco

Hisobut Ácido isobutírico

HPr Ácido propionico

HVal Ácido valérico

$\mathrm{M}_{\mathrm{A}-\mathrm{B}} \quad$ Massa amostra biomassa separada na forma de SVT [gSVT]

$\mathrm{M}_{\mathrm{A}-\mathrm{SI}} \quad$ Massa mistura amostra suporte inerte separado [g]

$\mathrm{M}_{\mathrm{A}-\mathrm{SI}+\mathrm{B}} \quad$ Massa mistura amostra suporte inerte + biomassa [g]

$\mathrm{Mg} \quad$ Massa de de gasolina equivalente [g]

$\mathrm{M}_{\mathrm{SVT}} \quad$ Biomassa total presente no reator na forma de sólidos totais voláteis [g]

$\mathrm{M}_{\mathrm{T}-\mathrm{SI}+\mathrm{B}} \quad$ Massa mistura total suporte inerte + biomassa [g]

N Número de ciclos por dia 


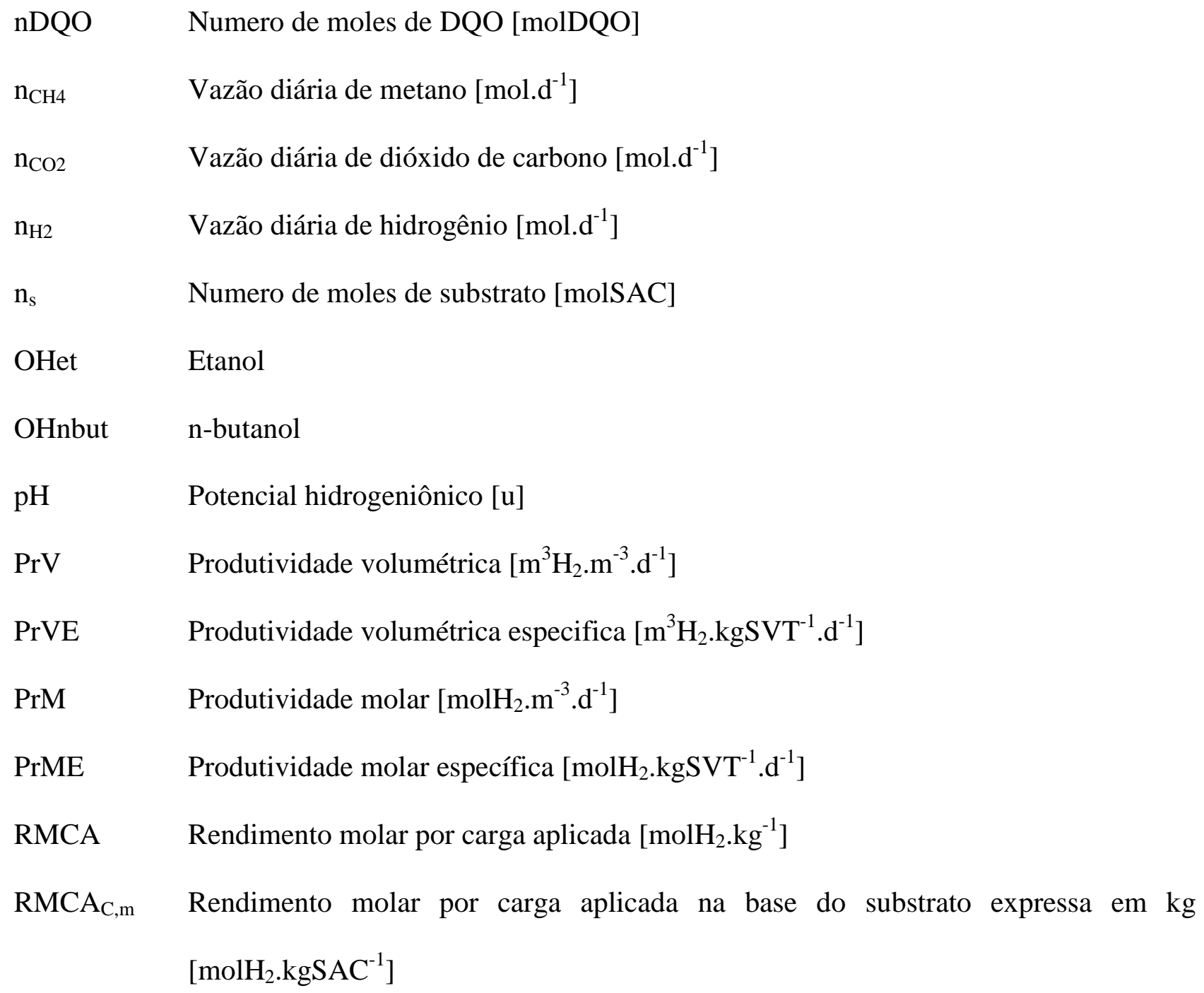

$\mathrm{RMCA}_{\mathrm{C}, \mathrm{n}} \quad$ Rendimento molar por carga aplicada na base do substrato expressa em mol $\left[\mathrm{molH}_{2} \cdot \mathrm{molSAC}^{-1}\right]$

RMCA $_{\mathrm{S}, \mathrm{m}}$ Rendimento molar por carga aplicada na base da DQO expressa em $\mathrm{kg}$ $\left[\mathrm{molH}_{2} \cdot \mathrm{kgDQO}^{-1}\right]$

RMCA $_{\mathrm{S}, \mathrm{n}}$ Rendimento molar por carga aplicada na base da DQO expressa em mol $\left[\mathrm{molH}_{2} \cdot \mathrm{molDQO}^{-1}\right]$

$\mathrm{RMCR}_{\mathrm{C}, \mathrm{m}}$ Rendimento molar por carga removida na base do substrato expressa em $\mathrm{kg}$ $\left[\mathrm{molH}_{2} \cdot \mathrm{kgSAC}^{-1}\right]$

$\mathrm{RMCR}_{\mathrm{C}, \mathrm{n}}$ Rendimento molar por carga removida na base do substrato expressa em mol $\left[\mathrm{molH}_{2} \cdot \mathrm{molSAC}^{-1}\right]$ 
$\mathrm{RMCR}_{\mathrm{S}, \mathrm{m}}$ Rendimento molar por carga removida na base da DQO expressa em $\mathrm{kg}$ $\left[\mathrm{molH}_{2} \cdot \mathrm{kgDQO}^{-1}\right]$

$\mathrm{RMCR}_{\mathrm{S}, \mathrm{n}} \quad$ Rendimento molar por carga removida na base da DQO expressa em mol $\left[\mathrm{molH}_{2} \cdot \mathrm{molDQO}^{-1}\right]$

RVCA Rendimento volumétrico por carga aplicada $\left[\mathrm{m}^{3} \mathrm{H}_{2} \cdot \mathrm{kg}^{-1}\right]$

$\mathrm{RVCA}_{\mathrm{C}, \mathrm{m}} \quad$ Rendimento volumétrico por carga aplicada na base do substrato expressa em $\mathrm{kg}$ $\left[\mathrm{m}^{3} \mathrm{H}_{2} \cdot \mathrm{kgSAC}^{-1}\right]$

RVCA $_{C, n} \quad$ Rendimento volumétrico por carga aplicada na base do substrato expressa em mol $\left[\mathrm{m}^{3} \mathrm{H}_{2} \cdot \mathrm{molSAC}^{-1}\right]$

RVCA $_{S, m} \quad$ Rendimento volumétrico por carga aplicada na base da DQO expressa em kg $\left[\mathrm{m}^{3} \mathrm{H}_{2} \cdot \mathrm{kgDQO}{ }^{-1}\right]$

RVCA $_{\mathrm{S}, \mathrm{n}} \quad$ Rendimento volumétrico por carga aplicada na base da DQO expressa em mol $\left[\mathrm{m}^{3} \mathrm{H}_{2} \cdot \mathrm{molDQO}^{-1}\right]$

RVCR Rendimento volumétrico por carga removida $\left[\mathrm{m}^{3} \mathrm{H}_{2} \cdot \mathrm{kg}^{-1}\right]$

$\mathrm{RVCR}_{\mathrm{C}, \mathrm{m}} \quad$ Rendimento volumétrico por carga removida na base do substrato expressa em $\mathrm{kg}$ $\left[\mathrm{m}^{3} \mathrm{H}_{2} \cdot \mathrm{kgSAC}^{-1}\right]$

$\mathrm{RVCA}_{\mathrm{C}, \mathrm{n}} \quad$ Rendimento volumétrico por carga removida na base do substrato expressa em mol $\left[\mathrm{m}^{3} \mathrm{H}_{2} \cdot \mathrm{molSAC}^{-1}\right]$

RVCA $_{\mathrm{S}, \mathrm{m}}$ Rendimento volumétrico por carga removida na base da DQO expressa em $\mathrm{kg}$ $\left[\mathrm{m}^{3} \mathrm{H}_{2} \cdot \mathrm{kgDQO}^{-1}\right]$

RVCA $_{S, n} \quad$ Rendimento volumétrico por carga removida na base da DQO expressa em mol $\left[\mathrm{m}^{3} \mathrm{H}_{2} \cdot \mathrm{molDQO}^{-1}\right]$

SST Sólidos suspensos totais $\left[\mathrm{mg} . \mathrm{L}^{-1}\right]$

SSV Sólidos suspensos voláteis $\left[\mathrm{mg} . \mathrm{L}^{-1}\right]$

ST Sólidos totais $\left[\mathrm{mg} . \mathrm{L}^{-1}\right]$

SVT Sólidos voláteis totais $\left[\mathrm{mg} . \mathrm{L}^{-1}\right]$ 
$\mathrm{V}_{\mathrm{A}} \quad$ Volume de aguá residuária alimentada no ciclo [L]

$\mathrm{V}_{\mathrm{CH} 4} \quad$ Volume de metano produzido por unidade de tempo [L.d $\mathrm{d}^{-1}$ ou $\left[\mathrm{L} \cdot \mathrm{h}^{-1}\right]$

$\mathrm{V}_{\mathrm{CO} 2} \quad$ Volume de dióxido de carbono produzido por unidade de tempo [L.d ${ }^{-1}$ ] ou [L.h ${ }^{-1}$ ]

$\mathrm{V}_{\mathrm{H} 2} \quad$ Volume de hidrogênio produzido ou por unidade de tempo [L.d ${ }^{-1}$ ] ou $\left[\mathrm{L} \cdot \mathrm{h}^{-1}\right.$ ]

$\mathrm{V}_{\mathrm{R}} \quad$ Volume de meio líquido contido no reator [L]

$\mathrm{V}_{\mathrm{u}} \quad$ Volume de meio líquido útil do reator [L] 


\section{SÚMARIO}

1. INTRODUÇÃO

1

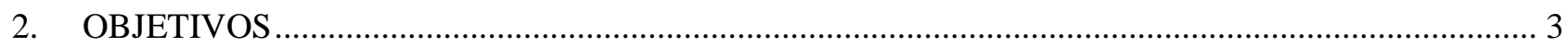

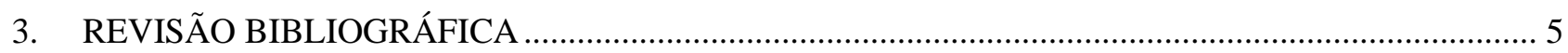

3.1. Reator anaeróbio operado em batelada sequencial ................................................................... 6

3.2. Produção de bio-hidrogênio no processo anaeróbio .................................................................... 8

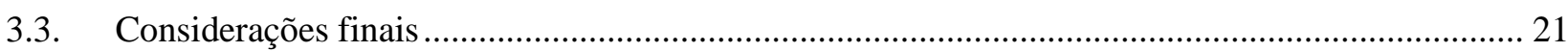

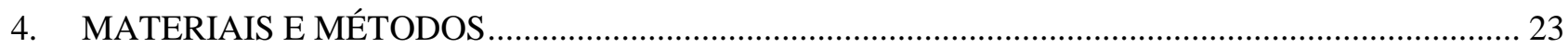

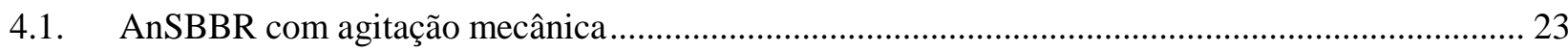

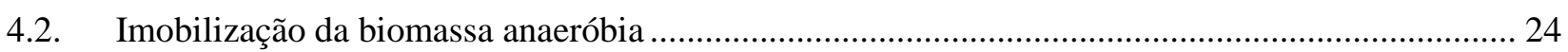

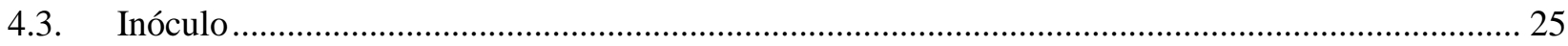

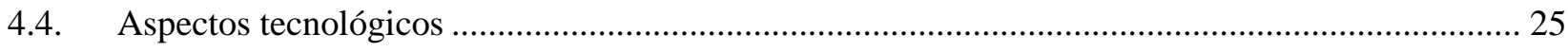

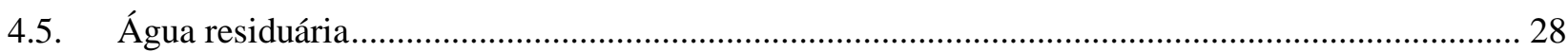

4.6. Análises físico-químicas e exames microbiológicos ..................................................................... 29

4.7. Procedimento experimental da operação do reator...................................................................... 33

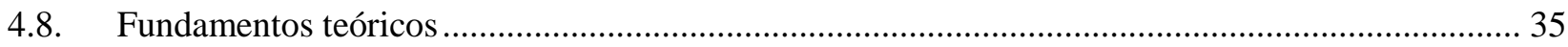




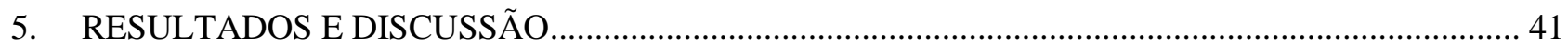

5.1. Condição experimental preliminar (DQO $\left.3600 \mathrm{mg} \cdot \mathrm{L}^{-1}-\mathrm{TC} 4 \mathrm{~h}\right)$.................................................... 41

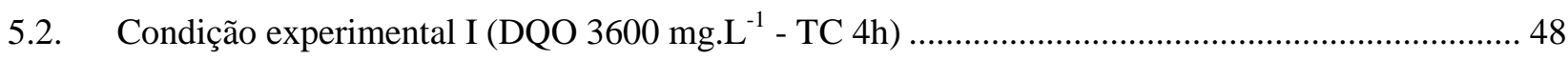

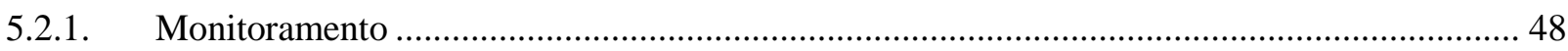

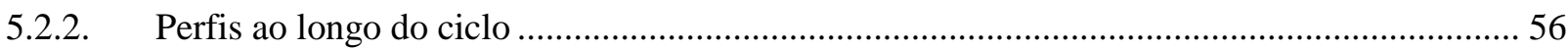

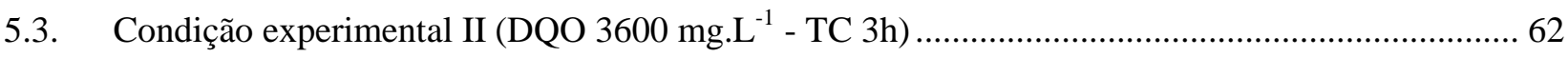

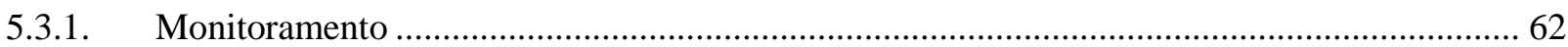

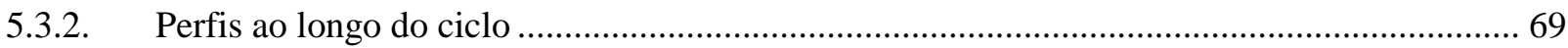

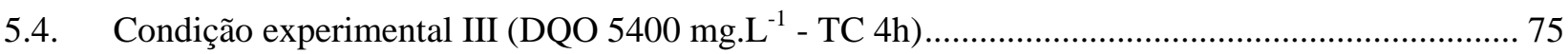

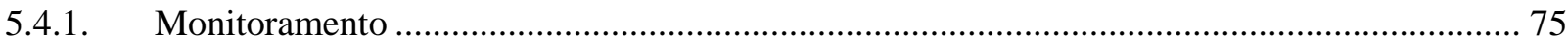

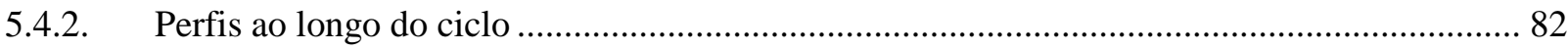

5.5. Condição experimental IV (DQO 5400 mg.L $\mathrm{L}^{-1}$ - TC 3h) ........................................................... 88

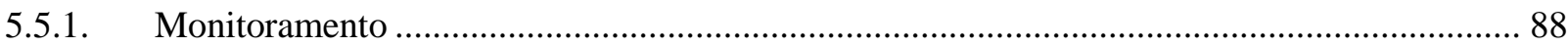

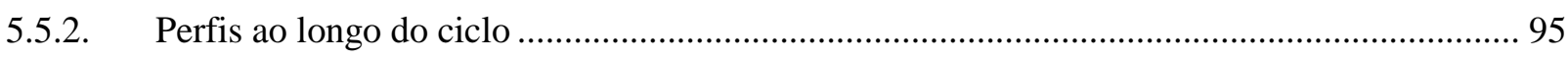

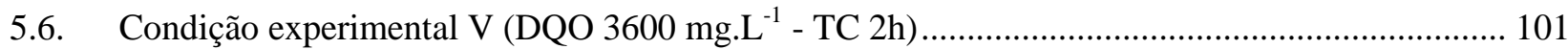

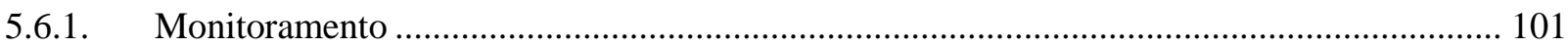

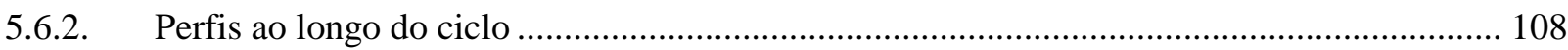

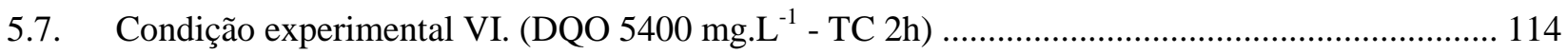

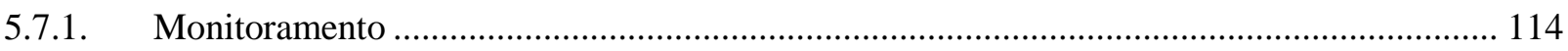

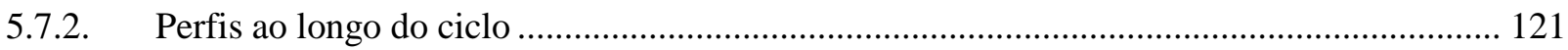

5.8. Análise geral das condições experimentais estudadas ................................................................ 127

5.8.1. Desempenho do reator na conversão de substrato …......................................................... 127

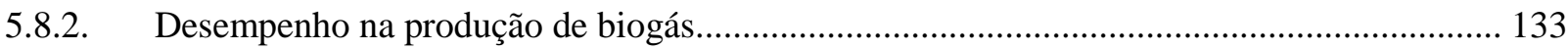

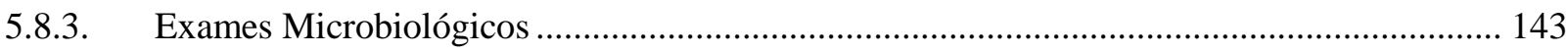




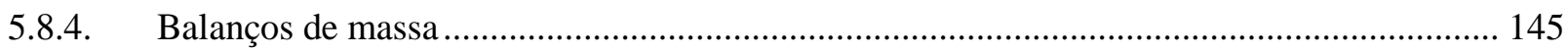

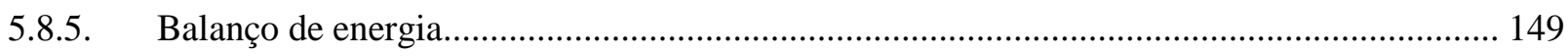

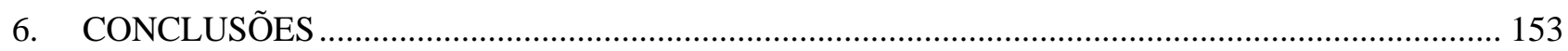

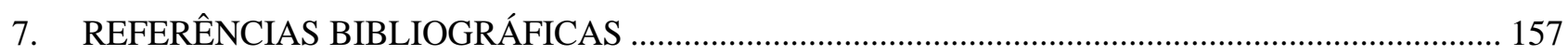

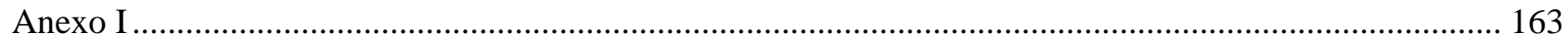

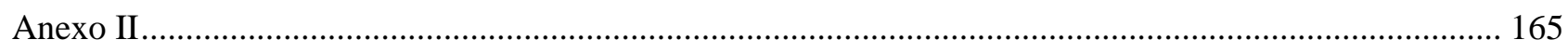

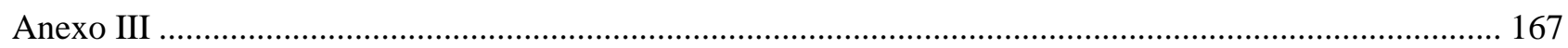

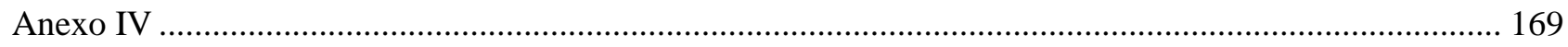

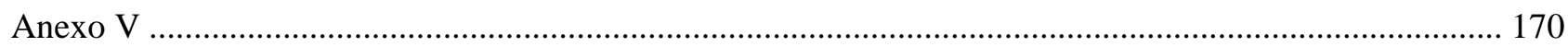




\section{INTRODUÇÃO}

O último relatório publicado pelo IEA (International Energy Agency: Key World Energy Statistics 2011) revela que as energias fósseis representam $80 \%$ das energias primárias consumidas para suprir a demanda mundial trazendo consequências negativas hoje bem identificadas. A revolução desta matriz energética é um dos grandes desafios de nosso século e passa pelo desenvolvimento de soluções tecnológicas sustentáveis. O hidrogênio está sendo explorado como potencial carreador alternativo de energia uma vez que ele apresenta ambas as vantagens de ter um alto potencial energético e de ser neutro por combustão gerando apenas água. Entre as formas de produção deste combustível existem processos físico-químicos, tais como: a reforma de combustíveis fósseis e a eletrólise, ambas necessitando um consumo intensivo de energia; e biológicos, sendo esta de baixo custo por ser operada em condições de temperaturas e de pressão ambientes. Vale destacar a recente importância do processo biológico anaeróbio de fermentação na produção de hidrogênio pela geração do biogás produzido por ser tecnicamente mais simples do que a produção por via da fotossíntese.

Se inscrevendo nesta linha de pesquisa, o núcleo de pesquisa do Laboratório de Processos Biológicos (LPB) da Escola de Engenharia de São Carlos da Universidade de São Paulo (EESC/USP) tem participado a um grande esforço de desenvolvimento e de otimização de configurações de reatores anaeróbicos visando à produção de biohidrogênio por via fermentativa.

Em paralelo, os reatores anaeróbios operados em batelada sequencial vêm sendo estudados por grupos de pesquisa do Laboratório de Engenharia Bioquímica da Escola de Engenharia Mauá do Instituto Mauá de Tecnologia (EEM/IMT) e do Laboratório de Processos Biológicos (LPB) da Escola de Engenharia de São Carlos da Universidade de São Paulo (EESC/USP), nas quais os projetos têm enfoque no estudo da otimização do biorreator convencional e de novas propostas de configurações e aplicação para viabilização do uso do sistema em escala plena. 
Neste contexto, esse projeto objetiva a verificação das características desse tipo de reator operado em batelada sequencial com agitação mecânica e biomassa imobilizada (AnSBBR), aplicado ao tratamento de uma água residuária sintética a base de sacarose para a produção de biohidrogênio. Dessa forma, esta pesquisa avaliou a influência da carga orgânica sobre a eficiência e fator de conversão (entre a matéria orgânica utilizada e o hidrogênio produzido) como também a estabilidade das variáveis monitoradas no intuito de se obter um criterioso conhecimento sobre a viabilidade biotecnológica desse sistema. 


\section{OBJETIVOS}

Esse projeto tem como objetivo principal avaliar a aplicação do reator anaeróbio operado em batelada sequencial com agitação mecânica e biomassa imobilizada (AnSBBR) à produção de biohidrogênio pelo tratamento de efluente sintético a base de sacarose. Os objetivos específicos foram:

- Avaliar o desempenho do reator através do cálculo de indicadores de rendimentos, produtividade e velocidade de produção do bio-hidrogênio para diferentes cargas orgânicas aplicadas, implementadas modificando-se a concentração afluente e o tempo de ciclo do AnSBBR;

- Avaliar o percentual do gás hidrogênio na composição do biogás produzido (relação entre hidrogênio, metano e dióxido de carbono), a distribuição de ácidos voláteis e álcoois produzidos, bem como a remoção de matéria orgânica em cada condição experimental. 


\section{REVISÃO BIBLIOGRÁFICA}

Estudos sobre a influência de variáveis de processo sobre a eficiência e estabilidade do reator do tipo AnSBBR quando aplicado ao tratamento de diferentes efluentes têm sido encontrados em literatura, como os relacionados: (i) ao tipo de mistura, a qual poderá ser implementada por recirculação da fase líquida (CAMARGO et al., 2002; BEZERRA et al., 2007; PINHEIRO et al., 2008) ou por agitação mecânica (RODRIGUES et al., 2003, 2004; DAMASCENO et al., 2008; MICHELAN et al., 2009); (ii) ao tempo de enchimento ou estratégia de alimentação; (BORGES et al., 2004; ORRA et al., 2004; ZIMMER et al., 2008); e (iii) a carga orgânica (SIMAN et al., 2004; CHEBEL et al., 2006; DAMASCENO et al., 2007).

Atualmente verifica-se em literatura um aumento da potencial aplicação desses reatores na geração de bio-hidrogênio num contexto amplo no qual as águas residuárias passam a ser tratadas como matéria-prima e não como resíduos de um processo, com o intuito de viabilizar a obtenção de energia a partir do hidrogênio gerado, sendo mantido o objetivo do controle da poluição ambiental com a adequação de todos os resíduos gerados no processo para a disposição no ambiente. A produção biológica de hidrogênio torna-se uma das mais atrativas, pois é uma tecnologia de baixo custo quando comparada a outras técnicas e requer menos energia para geração, podendo ocorrer por meio de dois processos: fotossíntese e processo fermentativo. A fermentação é tecnicamente mais simples e o hidrogênio pode ser obtido de matéria orgânica presente em águas residuárias. Diversas pesquisas demonstram a viabilidade da utilização do $\mathrm{H}_{2}$, produzido biologicamente, para geração de energia (WU, S. Y. et al., 2003; ALZATE-GAVIRIA et al., 2007; LEITE et al., 2008; BUITRÓN; CARVAJAL, 2010; SREETHAWONG et al., 2010; BADIEI et al., 2011; MOHANAKRISHNA et al., 2011).

A seguinte revisão bibliográfica relaciona o contexto científico referente ao desenvolvimento do reator AnSBBR com os avanços realizados no uso de processos anaeróbios na produção de biohidrogênio. 


\subsection{Reator anaeróbio operado em batelada sequencial}

No início da década de 90, grupos de pesquisa desenvolveram um reator de alto desempenho: o reator anaeróbio operado em bateladas sequenciais (“Anaerobic Sequencing Batch Reactor: ASBR"). Os princípios operacionais são extremamente simples. O tratamento é efetuado em tanque único, obedecendo a um ciclo típico composto por quatro etapas: (i) alimentação; (ii) tratamento propriamente dito, por meio de reações ou biotransformações dos constituintes do esgoto por microrganismos; (iii) sedimentação; e (iv) descarga, com retirada do líquido tratado e clarificado (SUNG; DAGUE, 1995).

A etapa de alimentação envolve a adição de um volume afluente determinado. O tempo de enchimento depende da estratégia de operação aplicada. Na etapa de reação ocorre a realização do processo anaeróbio. Um sistema de mistura permite um contato mais efetivo entre o substrato e a biomassa. O tempo requerido desta fase depende de vários parâmetros, tais como: a qualidade do efluente que se deseja obter, a temperatura do sistema, as características do substrato (composição e concentração) e a concentração da biomassa presente no reator. A etapa de sedimentação garante a separação da biomassa e a clarificação do líquido tratado e pode ser evitada no caso de reatores com biomassa aderida. Finalmente a retirada do efluente clarificado é realizada, sendo o volume removido geralmente igual ao volume alimentado. No final desta fase, o reator está pronto para operação de um novo ciclo.

Os processos anaeróbios operados em bateladas sequenciais se apresentam como uma solução de tratamento apropriada para alguns casos específicos. Eles são adequados para tratamento de efluentes industriais gerados de maneira intermitente, com compostos dificilmente degradáveis ou no caso padrões de lançamento muito restritivos. Implementando diferentes parâmetros de operação do reator (tempo de ciclo principalmente) a remoção desejada pode ser garantida (ZAIAT et al., 2001). Outras vantagens relativas à configuração simples do reator podem ser destacadas, tais como: ausência de curto circuito hidráulico; melhor controle da qualidade do efluente; ausências de 
estabilização do processo sendo descontinuo atingindo uma forma de equilibro, ausências de recirculação da fase sólida nem liquida o processo sendo realizado em tanque único; bom controle do processo; alta velocidade de remoção de matéria orgânica; operação do sistema simples e estável; e ausência de sistema de distribuição do afluente.

Esta configuração ainda está sendo investigada por grupos de pesquisadores. Avanços no entendimento das variáveis do seu desempenho oferecerão novas perspectivas de uso. Dentro dos parâmetros a serem investigados podem ser citados (RODRIGUES et al., 2006): ( $i$ ) efeitos do uso de biomassa na forma granulada ou aderida em suporte inerte; (ii) efeitos da agitação promovida mecanicamente ou por recirculação da fase líquida; (iii) efeitos da intensidade da agitação; (iv) efeitos da estratégia de alimentação; (v) efeitos das operações na estabilidade da biomassa; (vi) aplicações usando diferentes tipos de efluentes; e (vii) aplicações na escala real. Foram destacadas duas áreas de estudo dos reatores ASBR: aquelas utilizando biomassa auto imobilizada e aquelas com biomassa imobilizada, crescendo em suporte inerte (ZAIAT et al., 2001).

A imobilização da biomassa em reatores ASBR foi inicialmente proposta por RATUSZNEI et al., (2000) usando espuma de poliuretano. Os autores estudaram a aplicabilidade desta nova configuração de reator ao tratamento de esgoto sanitário sintético e a denominaram de reator anaeróbio operado em bateladas sequenciais com biofilme aderido ("Anaerobic Sequencing Batch Biofilm Reactor: AnSBBR”). O biofilme pode ser definido como uma população de bactérias aderidas umas às outras ou a uma superfície ou interface. Deste modo, incluem-se na definição agregados ou flocos microbianos, componentes da biomassa auto imobilizada e aderida a meios suportes. A biomassa pode crescer no meio de forma dispersa, sem nenhuma outra estrutura de sustentação ou, ao contrário, aderida a um meio suporte. A matriz do meio suporte pode ser um material sólido natural (pedras, areia) ou artificial (plástico, pneus ralados, polímeros) ou constituído pela própria biomassa no caso do crescimento granulado. A interação entre células é promovida pela presença de moléculas de polímeros na parede celular e pela composição do meio. No biofilme ocorre uma dupla circulação dos compostos do metabolismo celular. Sólidos coloidais 
são hidrolisados pelas ações enzimáticas em moléculas de menores dimensões na superfície e micronutrientes liberados são adsorvidos e transportados através do biofilme. Os produtos resultantes do metabolismo celular circulam no sentido contrário e são evacuados na direção da fase líquida por difusão. Os biofilmes, além de favorecer a cooperação entre os organismos associados reduzindo as distancias entre si, promovem uma forma de proteção contra fatores ambientais adversos. A criação destes micro-ambientes favorece o conjunto, garantindo grande estabilidade às colônias (FLÔRES, 2009).

Estudos mostraram que a mistura promovida dentro dos reatores tem que ser proporcionada no sentido de melhorar os fluxos de transferência de massa, promovendo assim um aumento de velocidade de consumo do substrato e a solubilização da matéria orgânica particulada (RATUSZNEI et al., 2001). A mistura pode ser realizada por agitação mecânica ou por recirculação da fase liquida ou gasosa (para afluentes concentrados gerando quantidades suficientes de biogás). No caso de agitação mecânica, os impelidores têm um papel fundamental no movimento que eles imprimem à fase líquida, podendo provocar um escoamento tangencial, quando o fluido se desloca de maneira circular em torno do eixo, radial, quando o fluido segue de maneira perpendicular ao eixo, ou longitudinal, quando o fluido percorre um caminho paralelo ao eixo. RATUSZNEI et al., (2001); CUBAS, (2004) investigaram a influência da intensidade da agitação implementando em um AnSBBR rotações variando de 0 a 750 rpm. Os autores obtiveram remoções de matéria orgânica de 90 e $92 \%$ para as rotações de 350 e 500 rpm, respectivamente, e concluíram que o aumento da intensidade de agitação melhora o desempenho do reator, entretanto, uma agitação excessiva pode causar a ruptura do biofilme e, assim, o prejudicar.

\subsection{Produção de bio-hidrogênio no processo anaeróbio}

Atualmente a demanda global de energia é em maioria satisfeita pela queima de combustíveis fosseis (em torno de $80 \%$ ). Além de não ser renovável, a utilização deste recurso 
causa danos importantes ao meio ambiente, pela liberação dos produtos de combustão poluentes $\left(\mathrm{CO}_{\mathrm{x}}, \mathrm{NO}_{\mathrm{x}}, \mathrm{SO}_{\mathrm{x}}, \mathrm{C}_{\mathrm{x}} \mathrm{H}_{\mathrm{x}}\right.$, ect) (DAS; VEZIROGLU, 2001). As consequências deste modo de produção de energia são hoje bem identificadas e soluções sustentáveis alternativas devem ser encontradas.

A ideia de usar o hidrogênio como carreador de energia não é nova e se iniciou em 1868 com os trabalhos do cientista E. Viel. As desvantagens do uso de combustíveis fósseis já eram conhecidas naquela época e o hidrogênio apareceu como uma alternativa segura, resultando somente na produção de água (SUZUKI, 1982). Hoje, 90\% do hidrogênio produzido têm origem nas reações de produtos derivados do petróleo. Estes processos, operados em altas temperaturas, necessitam um consumo intensivo de energia e fornecem hidrogênio para aplicações industriais específicas. Assim, esta forma de produção para uso de hidrogênio como fonte de energia não pode ser considerada como economicamente viável. Processos biológicos de produção de hidrogênio são operados em condições de temperatura e de pressão ambiente. O desenvolvimento de tais processos pode oferecer alternativas sustentáveis para responder à crescente demanda de energia. Além do mais, eles podem participar a uma dinâmica de reciclagem quando forem aplicados a valorização de despejos de outro processo. Neste contexto, vários tipos de reatores, operados sob regime contínuo ou em bateladas sequenciais, têm sido estudados, com objetivo de alcançar altas velocidades de produção de bio-hidrogênio (DAVILA-VAZQUEZ et al., 2007). Resultados promissores foram obtidos em parte às contribuições das ciências biológicas no melhor entendimento dos processos anaeróbios.

As diferentes fases nas quais a fermentação acontece foram primeiramente identificadas. A comunidade científica concorda que a fermentação de compostos orgânicos é realizada através de quatro etapas distintas: (i) a primeira etapa é endergônica e envolve a fixação de compostos de fosfato fornecido pela oxidação de ATP a ADP (Adenosina trifosfato/ Adenosina difosfato); (ii) a segunda etapa é a separação do composto de seis carbonos em dois compostos de três carbonos; (iii) na terceira etapa ocorre a fosforização ao nível do substrato onde as bactérias armazenam energia 
pela redução de ADP em ATP, esta etapa termina pela formação do piruvato, composto central do metabolismo; (iv) a quarta etapa depende do tipo de microrganismo presente, sendo que várias reações podem acontecer com o objetivo de regenerar a co-enzima NAD (Nicotinamida Adenina Dinucleotideo, forma oxidada) pela oxidação da NADH (Nicotinamida Adenina Dinucleotideo, forma reduzida) (FORESTI, 1994; TANISHO; ISHIWATA, 1995).

Posteriormente, foram identificadas as rotas específicas de liberação de hidrogênio. No processo de fermentação, podem-se destacar três formas de formação de hidrogênio pelas bactérias: (i) a decomposição do formiato, (ii) a produção a partir da fermentação direta do etanol ou do butanol, (iii) a rota do NADH. A rota de produção de hidrogênio chamada de decomposição do formiato envolve várias reações. O formiato é formado pela decomposição do piruvato em acetilCoA (Acetila coenzima A) e por sua vez a acetil-CoA é levada ao acetato ou etanol. O formiato pela ação das enzimas hidrogenases entra em decomposição e forma hidrogênio e dióxido de carbono, liberando desta forma em torno de $50 \%$ da produção teórica de hidrogênio. Na produção a partir da fermentação do etanol e do butanol, hidrogênio é produzido diretamente sem passar pela forma de formiato. A rota do NADH consiste na regeneração da coenzima NAD a partir da NADH. A NADH é produzida durante a conversão da glicose a piruvato no processo chamado de glicólise (TANISHO, 2001). A rota do NADH pode ser comprometida pelo consumo de NADH por reações concorrentes na formação de ácidos e álcoois. Estes esclarecimentos sobre as origens de geração do hidrogênio indicam que para poder alcançar altas eficiências, existem reações favoráveis que devem ser promovidas e desfavoráveis que devem ser limitadas. A única maneira de influenciar o metabolismo no sentido de favorecer a realização de certas rotas é externa, através da estratégia de operação do reator. Assim, investigações foram conduzidas avaliando indicadores de produção de hidrogênio em função de parâmetros operacionais a fim de determinar as condições ideais, como o efeito da natureza do inóculo usado, do $\mathrm{pH}$, da temperatura, da natureza e concentração do substrato, e do tempo de residência do líquido. 
O uso destes indicadores não foi padronizado internacionalmente e cada grupo de pesquisa costuma apresentar seus resultados em função dos indicadores usados nos seu departamento. Consequentemente existe uma dificuldade em comparar os resultados presentes na literatura, pois conversões sendo uma tarefa complicada e nem sempre possível quando dados são omitidos.

A Figura 3.1 apresenta os diversos indicadores utilizados na literatura e os seus fundamentos teóricos respectivos. Os indicadores relacionam a produção de hidrogênio no numerador com outros parâmetros no denominador, sendo que a produção pode ser expressa em quantidade de matéria de hidrogênio (em base mássica ou molar) ou em volume em condições normais de temperatura e de pressão (CNTP) levando a expressão de indicadores molares ou volumétricos, respectivamente.

Três grupos de indicadores são distintos: a produtividade, o rendimento por carga aplicada e o rendimento por carga removida. Cada um avalia diferentes aspectos da produção de hidrogênio pela variação das variáveis do denominador.

A produtividade relaciona a produção de hidrogênio por unidade de tempo com o volume do reator (produtividade volumétrica) ou a massa de microrganismos presentes (produtividade específica), sendo um parâmetro particularmente interessante no dimensionamento de unidades, permitindo avaliar a capacidade de produção de um reator a partir do volume (ou massa de microrganismos presente) ou, ao contrario, de estimar volume (ou massa de microrganismos) necessário para alcançar uma produção desejada.

Os rendimentos por carga aplicada ou por carga removida podem ser expressos segundo duas bases, considerando as cargas em termos de DQO ou em termos de substrato. As duas bases têm suas utilidades na avaliação do desempenho, a base da DQO sendo útil no caso de efluente de composição desconhecida, e a base do substrato interessante para avaliar as conversões realizadas pelas biotransformações. Em cada uma das duas bases, em termos de DQO ou em termos de substrato, as cargas orgânicas podem ser avaliadas considerando quantidade de matéria em base molar ou mássica. Expressar a carga orgânica considerando a massa permite mais transparência entre diferentes substratos utilizados. O rendimento por carga aplicada, relaciona a produção de 
hidrogênio por unidade alimentada ao reator, sendo interessante a fim de determinar a capacidade de produção em função da quantidade alimentada. O rendimento por carga removida relaciona a produção de hidrogênio por unidade removida pelo reator, sendo interessante a fim de avaliar a forma pela qual o consumo por biotransformação leva à produção de biohidrogênio.

É importante ressaltar o fato de que a avaliação do desempenho de um reator passa por uma utilização de maneira combinada de diferentes indicadores a fim de considerar diferentes aspectos. 


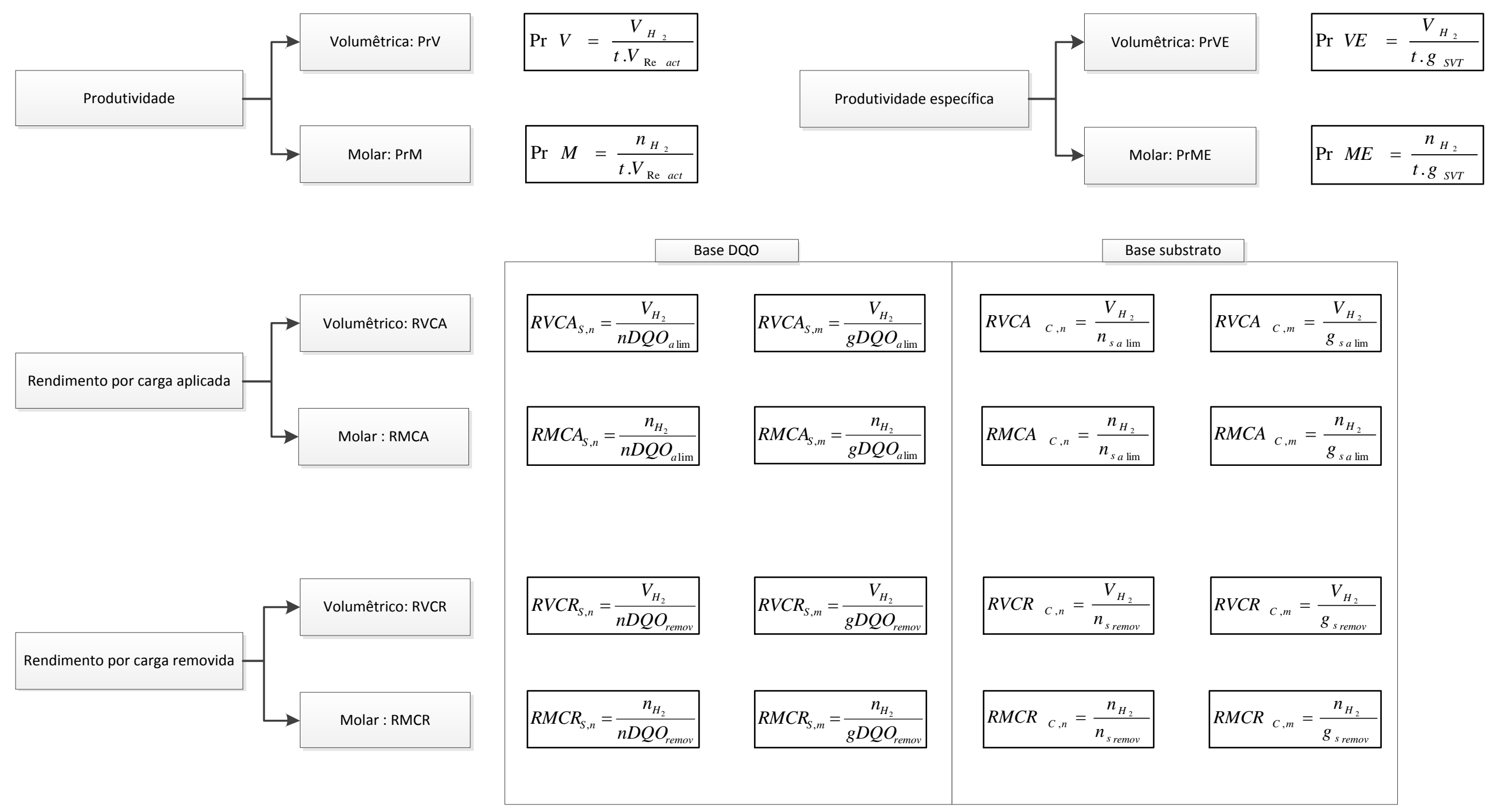

Figura 3.1 - Indicadores de produção de hidrogênio presentes na literatura 


\section{Nomenclatura:}

PrV: Produtividade volumétrica de hidrogênio

PrM: Produtividade molar de hidrogênio

PrVE: Produtividade volumétrica específica de hidrogênio

PrME: Produtividade molar específica de hidrogênio

RVCA $_{S, n}$ : Rendimento volumétrico de hidrogênio por carga aplicada na base da DQO em mol

$\mathrm{RVCA}_{\mathrm{S}, \mathrm{m}}$ : Rendimento volumétrico de hidrogênio por carga aplicada na base da DQO em massa

$\mathrm{RMCA}_{\mathrm{S}, \mathrm{n}}$ : Rendimento molar de hidrogênio por carga aplicada na base da DQO em mol

$\mathrm{RMCA}_{\mathrm{S}, \mathrm{m}}$ : Rendimento molar de hidrogênio por carga aplicada na base da DQO em massa

RVCA $_{\mathrm{C}, \mathrm{n}}$ : Rendimento volumétrico de hidrogênio por carga aplicada na base do substrato (sacarose) em mol

$\mathrm{RVCA}_{\mathrm{C}, \mathrm{m}}$ : Rendimento volumétrico de hidrogênio por carga aplicada na base do substrato (sacarose) em massa

$\mathrm{RMCA}_{\mathrm{C}, \mathrm{n}}$ : Rendimento molar de hidrogênio por carga aplicada na base do substrato (sacarose) em mol

$\mathrm{RMCA}_{\mathrm{C}, \mathrm{m}}$ : Rendimento molar de hidrogênio por carga aplicada na base do substrato (sacarose) em massa

$\mathrm{RVCR}_{\mathrm{S}, \mathrm{n}}$ : Rendimento volumétrico de hidrogênio por carga removida na base da DQO em mol

$\mathrm{RVCR}_{\mathrm{S}, \mathrm{m}}$ : Rendimento volumétrico de hidrogênio por carga removida na base da DQO em massa

$\mathrm{RMCR}_{\mathrm{S}, \mathrm{n}}$ : Rendimento molar de hidrogênio por carga removida na base da DQO em mol

$\mathrm{RMCR}_{\mathrm{S}, \mathrm{m}}$ : Rendimento molar de hidrogênio por carga removida na base da DQO em massa

$\mathrm{RVCR}_{\mathrm{C}, \mathrm{n}}$ : Rendimento volumétrico de hidrogênio por carga removida na base do substrato (sacarose) em mol

$\mathrm{RVCR}_{\mathrm{C}, \mathrm{m}}$ : Rendimento volumétrico de hidrogênio por carga removida na base do substrato (sacarose) em massa

$\mathrm{RMCR}_{\mathrm{C}, \mathrm{n}}$ : Rendimento molar de hidrogênio por carga removida na base do substrato (sacarose) em mol

$\mathrm{RMCR}_{\mathrm{C}, \mathrm{m}}$ : Rendimento molar de hidrogênio por carga removida na base do substrato (sacarose) em massa 
O uso destes indicadores permite avaliar os parâmetros operacionais de produção de hidrogênio quanto à natureza do inóculo usado, ao efeito do $\mathrm{pH}$, ao efeito da temperatura, ao efeito da natureza e concentração do substrato e ao efeito do tempo de residência do líquido.

Quanto à natureza do inóculo, é reconhecido pela comunidade científica que existe uma variedade de microrganismos que podem produzir hidrogênio desde que possuam enzimas hidrogenase ou nitrogenase, podendo-se destacar os gêneros Clostridium; Escherichia Coli; Termonaerobacter e Enterobacter (FERNANDES, 2008). Microrganismos foram investigados tanto na forma de culturas puras (LIU, X. et al., 2006; WU, K. J. et al., 2008; WANG, X. et al., 2009) quanto na forma de culturas mistas (CHEONG; HANSEN, 2006; ZHANG et al., 2006; WANG, Y. et al., 2008) na produção de bio-hidrogênio. O uso de cultura pura é interessante no entendimento de aspectos relativos ao metabolismo, entretanto, de um ponto de vista engenharia, a aplicação de culturas puras na concepção de sistemas de escala maior pode se apresentar como dificilmente viável devido aos problemas de contaminação. Quanto às culturas mistas, elas contêm um consórcio microbiano. O emprego destas culturas requer então certos cuidados, a fim de evitar que microrganismos indesejáveis ao processo se desenvolvem e promovam reações consumidoras de hidrogênio ou produtoras de composto inibidor das rotas desejadas. Algumas técnicas podem ser aplicadas antes ou durante o processo para selecionar a determinada população bacteriana, dentro das quais se destacam: tratamentos por choques térmicos, tratamentos ácidos, tratamentos básicos, e aeração sucessivas ou tratamentos químicos (WANG, J.; WAN, 2009). A maioria dos pesquisadores defende que os inóculos devem ser pré-tratados para eliminar as arqueas metanogênicas e assim otimizar a produção de hidrogênio eliminando espécies consumidoras. Entretanto, ainda é discutido se o tratamento por choque térmico oferece boa eficiência, pois existe o risco de reduzir a diversidade da biomassa como aquelas que formam esporo, sendo que várias bactérias produtoras de hidrogênio não são do tipo formadoras de esporo, podendo-se reduzir a produção de hidrogênio. Os processos de aeração repetida podem garantir uma maior diversidade e assim promover o crescimento de uma biomassa mais complexa e estável (REN et al., 2008). Quanto ao pH, é 
reconhecido ser este um parâmetro que influencia a atividade das bactérias produtoras de hidrogênio, afetando a ação das enzimas hidrogenases e as rotas metabólicas (WANG, J.; WAN, 2009). Assim, tem sido demonstrado que, em uma faixa adequada, o pH pode aumentar a capacidade das bactérias em produzir hidrogênio, porém para valores fora desta faixa ocorre redução significativa da produção. A maioria dos estudos foi realizados em modo batelada sem controle de $\mathrm{pH}$, apenas o efeito do $\mathrm{pH}$ inicial sob a produção foi investigado. Existem desacordos sobre o valor do pH ótimo para produção fermentativa de hidrogênio (WANG, J.; WAN, 2009), sendo verificado que menores $\mathrm{pH}$ iniciais oferecem um maior potencial de produção de hidrogênio, mas uma menor produção. Investigações foram realizadas em estudo em batelada variando o pH inicial e medindo a produção de hidrogênio, sendo obtida a produção máxima para valores de $\mathrm{pH}$ 4,5 tratando efluente sintético a base de sacarose (KHANAL et al, 2003), e de 6,0 tratando soro de queijo (FERCHICHI et al., 2005). Pesquisas similares foram conduzidas usando reatores operados em bateladas sequenciais e um dispositivo de controle de $\mathrm{pH}$ ao longo do ciclo. Valores de $\mathrm{pH}$ ótimos foram de 4,9 tratando efluente sintético a base de sacarose (CHEN, W. et al., 2009) e de 5,0 tratando esterco de suínos (WU, X. et al., 2010). As discordâncias podem ser atribuídas às diferenças entre os estudos em termo de substratos, inóculo e faixas de $\mathrm{pH}$ inicial. Um valor de $\mathrm{pH}$ de operação em torno de 5,0 parece ser o mais indicado na literatura.

A temperatura é outro fator que influencia as atividades dos microrganismos fermentativos produtores de hidrogênio, sendo demonstrado que em uma faixa adequada, aumentos de temperatura podem aumentar a capacidade das bactérias para produzir hidrogênio no processo fermentativo, mas a níveis muito elevados podem reduzir significativamente a atividade das bactérias produtoras de hidrogênio (WANG, J.; WAN, 2009). A maioria dos estudos foi realizada em modo batelada, usando como substrato sacarose ou glicose. Para bactérias mesofílicas, a faixa ideal seria em torno de $37^{\circ} \mathrm{C}$ e para bactérias termofílicas seria em torno de $55^{\circ} \mathrm{C}$ (LI, C.; FANG, 2007). Outros grupos de pesquisadores concordaram com esta proposta, constatando aumentos de 
produção de hidrogênio para temperaturas crescendo de 30 a $39^{\circ} \mathrm{C}$ e decrescendo progressivamente para temperaturas em cima de $41^{\circ} \mathrm{C}$ (MU et al., 2006).

Outro parâmetro importante é o tempo de permanência do líquido no reator. Para processos contínuos esta característica é avaliada pelo tempo de detenção hidráulica (TDH) (FORESTI et al, 1999). O TDH relaciona a vazão ao volume do reator. Por analogia é comum citar TDH para reatores operados em bateladas sequenciais, relacionando o volume alimentado diariamente com volume do reator. Este parâmetro é útil nos cálculos de dimensionamento, permitindo relacionar os volumes de reatores com os volumes de efluentes a tratar, porém ele não representa o tempo de permanência real do líquido dentro do reator. Assim, para investigar o desempenho de processos em bateladas sequenciais é recomendável utilizar como parâmetro os tempos de ciclos (TC). TDH ou TC, em processos contínuos ou sequenciais, têm influência no crescimento da biomassa, pois espécies microbianas com altas velocidades de crescimento conseguem permanecer no reator enquanto espécies com crescimento lento são removidas no efluente líquido. As arqueas metanogênicas (entre as quais, as consumidoras de hidrogênio) têm baixas velocidades de reprodução com tempos de duplicação da ordem de dois a três dias; ao contrário das bactérias acidogênicas (produtoras de hidrogênio) que têm tempos de duplicação da ordem de duas a três horas. Baseado nisso, baixos TDH ou TC podem ser ajustados com objetivo de selecionar as espécies que permanecerão no reator. Grupos de pesquisadores provaram que existe um tempo de permanência do líquido que confere uma maior produção de hidrogênio. Poucas investigações foram realizadas em reatores operados em bateladas sequenciais, sendo que alguns trabalhos mostram que o tratamento de efluente sintético a base de glicose com um ASBR, mantendo-se a carga orgânica igual e variando o volume afluente e o tempo de ciclo, encontra-se uma maior produção para um TC de 4 horas (CHEONG et al., 2007) e que operando um ASBR tratando amido de milho encontra-se uma maior produção para um TC de 6 horas. (AROOJ et al., 2008),

A disponibilidade do substrato para a biomassa deve ser avaliada pela carga orgânica volumétrica aplicada. Este parâmetro integra o tempo de permanência, o volume alimentado e a 
concentração do afluente. Este fator foi o objeto de investigações diretas com foco na influência da carga orgânica na produção de hidrogênio em reatores operados em bateladas sequenciais (VENKATA MOHAN et al., 2007; VIJAYA BHASKAR et al., 2008; SREETHAWONG et al., 2010; MOHANAKRISHNA et al., 2011). Entretanto, outros autores estudaram a produção de hidrogênio em função da variação de parâmetros inerentes à carga orgânica, como o efeito das concentrações iniciais (BUITRÓN; CARVAJAL, 2010), dos volumes afluentes (BADIEI et al., 2011) ou dos tempos de permanência (CHEONG et al., 2007; AROOJ et al., 2008; CHEN, W. et al., 2009). Tais parâmetros foram estudados separadamente ou de maneira combinada, mas não foram relacionados com as cargas orgânicas. A Tabela 3.1 mostra resultados obtidos por diferentes autores, relacionando diferentes indicadores de produção de hidrogênio. 
Tabela 3.1 - Avaliações da produção de biohidrogênio em função da carga orgânica

\begin{tabular}{|c|c|c|c|c|c|c|c|c|c|c|c|c|c|c|}
\hline Substrato & Configuração & $\begin{array}{l}\mathrm{TC} \\
{[\mathrm{h}]}\end{array}$ & $\begin{array}{c}\text { TDH } \\
{[\mathrm{h}]}\end{array}$ & $\begin{array}{l}\mathrm{Vt} \\
{[\mathrm{L}]}\end{array}$ & $\begin{array}{l}\mathrm{Va} \\
{[\mathrm{L}]}\end{array}$ & $\begin{array}{c}\mathrm{COAVc} \\
{\left[\mathrm{kg} \cdot \mathrm{m}^{-3} \cdot \mathrm{d}^{-1}\right]}\end{array}$ & 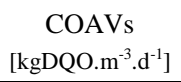 & $\begin{array}{c}\mathrm{n}_{\mathrm{H} 2} \\
{\left[\mathrm{~mol}^{\left.-\mathrm{d}^{-1}\right]}\right.}\end{array}$ & $\begin{array}{c}\text { PrM } \\
{\left[\mathrm{mol} \cdot \mathrm{m}^{-3} \cdot \mathrm{d}^{-1}\right]}\end{array}$ & 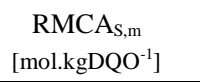 & $\begin{array}{c}\mathrm{RMCA}_{\mathrm{C}, \mathrm{m}} \\
{\left[\mathrm{mol}^{\left.-\mathrm{kg}^{-1}\right]}\right.}\end{array}$ & $\begin{array}{c}\mathrm{RMCR}_{\mathrm{S}, \mathrm{m}} \\
{\left[\mathrm{mol}^{\left.-\mathrm{kgDQO}^{-1}\right]}\right.}\end{array}$ & $\begin{array}{c}\mathrm{RMCR}_{\mathrm{C}, \mathrm{m}} \\
{\left[\mathrm{mol}^{\left.-\mathrm{kg}^{-1}\right]}\right.}\end{array}$ & Referências \\
\hline \multirow{3}{*}{$\begin{array}{l}\text { Efluente de moinho } \\
\text { de óleo de palma }\end{array}$} & \multirow[t]{3}{*}{ ASBR RFL } & 24 & 96 & 3,0 & 0,75 & 1,4 & 5,0 & 0,100 & 33,5 & 6,7 & 24,5 & 14,29 & & \multirow{3}{*}{$\overline{\text { (BADIEI et al., 2011) }}$} \\
\hline & & 24 & 72 & 3,0 & 1,0 & 1,8 & 6,7 & 0,304 & 101,2 & 15,2 & 55,5 & 41,96 & & \\
\hline & & 24 & 36 & 3,0 & 2,0 & 3,6 & 13,3 & 0,036 & 11,9 & 0,9 & 3,3 & 10,71 & & \\
\hline \multirow{6}{*}{$\begin{array}{l}\text { Resíduos sólidos } \\
\text { de mercado de legumes } \\
\text { Diluídos }\end{array}$} & \multirow{6}{*}{ AnSBBR RFL } & 24 & 24 & 1,4 & 1,4 & 1,3 & 4,5 & 0,004 & 2,9 & 0,7 & 2,3 & 1,63 & & \multirow[t]{6}{*}{ (MOHANAKRISHNA et al., 2011) } \\
\hline & & 24 & 24 & 1,4 & 1,4 & 2,5 & 9,0 & 0,007 & 5,2 & 0,6 & 2,1 & 1,69 & & \\
\hline & & 24 & 24 & 1,4 & 1,4 & 4,9 & 17,6 & 0,011 & 8,1 & 0,5 & 1,6 & 2,08 & & \\
\hline & & 24 & 24 & 1,4 & 1,4 & 9,9 & 35,3 & 0,018 & 12,6 & 0,4 & 1,3 & 2,30 & & \\
\hline & & 24 & 24 & 1,4 & 1,4 & 9,9 & 35,3 & 0,019 & 13,5 & 0,4 & 1,4 & 2,26 & & \\
\hline & & 24 & 24 & 1,4 & 1,4 & 12,4 & 44,3 & 0,020 & 14,1 & 0,3 & 1,1 & 2,22 & & \\
\hline \multirow{9}{*}{$\begin{array}{l}\text { Vinhaça de produção } \\
\text { de Tequila }\end{array}$} & \multirow[t]{9}{*}{ ASBR AM } & 12 & 24 & 6,0 & 3,0 & & 0,5 & 0,022 & 3,6 & 14,5 & & & & \multirow[t]{9}{*}{ (BUITRÓN; CARVAJAL, 2010) } \\
\hline & & 12 & 24 & 6,0 & 3,0 & & 1,0 & 0,023 & 3,9 & 7,7 & & & & \\
\hline & & 12 & 24 & 6,0 & 3,0 & & 2,0 & 0,012 & 1,9 & 1,9 & & & & \\
\hline & & 12 & 24 & 6,0 & 3,0 & & 3,0 & 0,008 & 1,3 & 0,9 & & & & \\
\hline & & 12 & 24 & 6,0 & 3,0 & & 1,0 & 0,046 & 7,7 & 15,3 & & & & \\
\hline & & 12 & 24 & 6,0 & 3,0 & & 3,0 & 0,046 & 7,7 & 5,1 & & & & \\
\hline & & 6 & 12 & 6,0 & 3,0 & & 2,0 & 0,079 & 13,2 & 26,5 & & & & \\
\hline & & 6 & 12 & 6,0 & 3,0 & & 6,0 & 0,162 & 27,0 & 18,0 & & & & \\
\hline & & 6 & 12 & 6,0 & 3,0 & & 10,0 & 0,143 & 23,8 & 9,5 & & & & \\
\hline \multirow[t]{10}{*}{ Efluente sintético Glicose } & \multirow[t]{10}{*}{ ASBR AM } & 6 & 24 & 4,0 & 1,0 & 9,4 & 10,0 & 0,071 & 17,9 & 1,8 & 1,9 & 3,43 & 1,2 & \multirow[t]{10}{*}{ (SREETHAWONG et al., 2010) } \\
\hline & & 6 & 24 & 4,0 & 1,0 & 18,8 & 20,0 & 0,393 & 98,2 & 4,9 & 5,2 & 7,22 & 4,6 & \\
\hline & & 6 & 24 & 4,0 & 1,0 & 28,1 & 30,0 & 0,786 & 196,4 & 6,5 & 7,0 & 9,92 & 6,4 & \\
\hline & & 6 & 24 & 4,0 & 1,0 & 37,5 & 40,0 & 0,875 & 218,8 & 5,5 & 5,8 & 11,25 & 5,6 & \\
\hline & & 6 & 24 & 4,0 & 1,0 & 46,9 & 50,0 & 0,714 & 178,6 & 3,6 & 3,8 & 9,40 & 4,0 & \\
\hline & & 6 & 24 & 4,0 & 1,0 & 9,4 & 10,0 & 0,089 & 22,3 & 2,2 & 2,4 & 3,60 & 2,2 & \\
\hline & & 6 & 24 & 4,0 & 1,0 & 18,8 & 20,0 & 0,429 & 107,1 & 5,4 & 5,7 & 7,14 & 5,6 & \\
\hline & & 6 & 24 & 4,0 & 1,0 & 28,1 & 30,0 & 0,804 & 200,9 & 6,7 & 7,1 & 8,81 & 6,7 & \\
\hline & & 6 & 24 & 4,0 & 1,0 & 37,5 & 40,0 & 1,329 & 332,1 & 8,3 & 8,9 & 10,35 & 8,1 & \\
\hline & & 6 & 24 & 4,0 & 1,0 & 46,9 & 50,0 & 0,375 & 93,8 & 1,9 & 2,0 & 4,45 & 2,2 & \\
\hline
\end{tabular}


Tabela 3.1 - Avaliações da produção de biohidrogênio em função da carga orgânica

\begin{tabular}{|c|c|c|c|c|c|c|c|c|c|c|c|c|c|c|}
\hline Substrato & Configuração & $\begin{array}{l}\mathrm{TC} \\
{[\mathrm{h}]}\end{array}$ & $\begin{array}{c}\mathrm{TDH} \\
{[\mathrm{h}]}\end{array}$ & $\begin{array}{l}\mathrm{Vt} \\
{[\mathrm{L}]}\end{array}$ & $\begin{array}{l}\mathrm{Va} \\
{[\mathrm{L}]}\end{array}$ & $\begin{array}{c}\operatorname{COAVc} \\
{\left[\mathrm{kg} \cdot \mathrm{m}^{-3} \cdot \mathrm{d}^{-1}\right]}\end{array}$ & $\begin{array}{c}\text { COAVs } \\
{\left[\mathrm{kgDQO} \cdot \mathrm{m}^{-3} \cdot \mathrm{d}^{-1}\right]}\end{array}$ & $\begin{array}{c}\mathrm{n}_{\mathrm{H} 2} \\
{\left[\mathrm{~mol} \cdot \mathrm{d}^{-1}\right]}\end{array}$ & $\begin{array}{c}\text { PrM } \\
{\left[\mathrm{mol} \cdot \mathrm{m}^{-3} \cdot \mathrm{d}^{-1}\right]}\end{array}$ & $\begin{array}{c}\mathrm{RMCA}_{\mathrm{S}, \mathrm{m}} \\
{\left[\mathrm{mol}^{-k g D Q O}{ }^{-1}\right]}\end{array}$ & $\begin{array}{l}\mathrm{RMCA}_{\mathrm{C}, \mathrm{m}} \\
{\left[\mathrm{mol}^{\left.-\mathrm{kg}^{-1}\right]}\right.}\end{array}$ & $\begin{array}{c}\mathrm{RMCR}_{\mathrm{S}, \mathrm{m}} \\
{\left[\mathrm{mol}^{\left.-\mathrm{kgDQO}^{-1}\right]}\right.}\end{array}$ & $\begin{array}{c}\mathrm{RMCR}_{\mathrm{C}, \mathrm{m}} \\
{\left[\mathrm{mol}^{\left.-\mathrm{kg}^{-1}\right]}\right.}\end{array}$ & Referências \\
\hline \multicolumn{15}{|l|}{ Continuação } \\
\hline Efluente sintético & ASBR AM & 4 & 16 & 3,0 & 0,75 & 20,1 & 22,5 & 0,319 & 106,2 & 4,7 & 5,3 & & 5,4 & (CHEN, W. et al., 2009) \\
\hline Sacarose & & 8 & 16 & 3,0 & 1,5 & 20,1 & 22,5 & 0,188 & 62,8 & 2,8 & 3,1 & & 3,2 & \\
\hline \multirow[t]{5}{*}{ Amido de milho } & ASBR AM & 9 & 18 & 3,0 & 1,5 & 22,5 & 26,7 & 0,117 & 39,3 & 1,5 & 1,7 & & & (AROOJ et al., 2008) \\
\hline & & 8 & 15 & 3,0 & 1,5 & 27,0 & 32,0 & 0,240 & 79,5 & 2,5 & 3,0 & & & \\
\hline & & 6 & 12 & 3,0 & 1,5 & 33,8 & 40,0 & 0,319 & 114,7 & 2,7 & 3,1 & & & \\
\hline & & 3 & 6 & 3,0 & 1,5 & 67,5 & 80,0 & 0,550 & 183,9 & 2,3 & 2,7 & & & \\
\hline & & 2 & 4 & 3,0 & 1,5 & 101,3 & 120,0 & 0,113 & 39,3 & 0,3 & 0,4 & & & \\
\hline \multirow{3}{*}{$\begin{array}{l}\text { Efluente sintético Glicose } \\
\text { com efluente de indústria } \\
\text { química }\end{array}$} & AnSBBR RFL & 24 & 32 & 2,0 & 1,6 & & 6,3 & 0,024 & 11,9 & 1,9 & & & 13,4 & (VIJAYA BHASKAR et al., 2008) \\
\hline & & 24 & 32 & 2,0 & 1,6 & & 7,1 & 0,015 & 7,3 & 1,0 & & & 8,2 & \\
\hline & & 24 & 32 & 2,0 & 1,6 & & 7,9 & 0,010 & 5,2 & 0,7 & & & 6,1 & \\
\hline \multirow[t]{3}{*}{ Efluente sintético Glicose } & ASBR AM & 8 & 16 & 2,6 & 1,3 & 37,5 & 32,0 & 0,250 & 96,3 & 2,6 & 3,0 & & & (CHEONG et al., 2007) \\
\hline & & 6 & 12 & 2,6 & 1,3 & 50,0 & 42,6 & 0,607 & 233,6 & 4,7 & 5,5 & & & \\
\hline & & 4 & 8 & 2,6 & 1,3 & 75,0 & 63,9 & 0,642 & 247,1 & 3,3 & 3,9 & & & \\
\hline
\end{tabular}




\subsection{Considerações finais}

No contexto de procura de energias alternativas, a produção de hidrogênio por processos biológicos anaeróbios tem sido o objeto de interesse da comunidade científica, se manifestando por um número crescente de publicações ligadas a esta linha de pesquisa (foram referenciadas 11 publicações em 2000 e 489 em 2010), sendo que diferentes temas de estudo contribuem para a conquista do conhecimento do processo a partir do entendimento das vias biológicas, da utilização de diversos substratos potenciais e da proposta de novas configurações de biorreatores.

Quanto a novas configurações de biorreatores, o grupo de pesquisa resultante da parceria entre a EESC/USP e EEM/IMT foi precursor no desenvolvimento do AnSBBR, entretanto, esta configuração foi aplicada para a remoção de matéria orgânica e/ou a produção de biogás na forma de metano. Assim, o estudo deste biorreator para a produção de hidrogênio deve seguir uma metodologia de desenvolvimento tecnológico pelo ajuste dos parâmetros de operação. Tais parâmetros devem considerar o efeito da influência da carga orgânica, investigando os efeitos de parâmetros inerentes como tempo de ciclo, volume afluente e concentração do afluente, sendo que os trabalhos encontrados em literatura utilizaram na sua maioria reatores contínuos ou em batelada típica (e não sequencial), ou seja, poucos estudos foram direcionados ao AnSBBR, não tendo sido encontrado estudos com agitação mecânica. Além disso, a grande diversidade de substratos utilizados em literatura dificulta a elucidação dos fenômenos fundamentais e o ajuste das condições ótimas de operação.

Dessa forma, a partir dos estudos encontrados em literatura, justifica-se o objetivo desse trabalho: estudar a aplicação do AnSBBR tratando água residuária sintética a base de sacarose, através de ensaios com diferentes cargas orgânicas obtidas por diferentes tempos de ciclo e concentrações afluente, formatando os resultados obtidos em parâmetros de projeto que procuram interpretar o comportamento do sistema e fornecer informações para uma potencial ampliação de escala e uso de diversos substratos disponíveis. 


\section{MATERIAIS E MÉTODOS}

\subsection{AnSBBR com agitação mecânica}

A Figura 4.2 apresenta o esquema do biorreator com agitação mecânica (modelo BIOFLO III $^{\circledR}$, fabricado pela New Brunswick Scientific Co.), constituído por um frasco de vidro de $20 \mathrm{~cm}$ de diâmetro e $30 \mathrm{~cm}$ de altura, com capacidade total de 7,5 L e capacidade útil de $6,5 \mathrm{~L}$. O material suporte foi confinado em um cesto de aço Inox - 316 perfurado de $18 \mathrm{~cm}$ de altura, $7 \mathrm{~cm}$ e $17,5 \mathrm{~cm}$ de diâmetros interno e externo respectivamente. As partes superior, inferior e lateral do cilindro interno (onde é introduzido o eixo de agitação) foram cobertas por uma tela de aço Inox de malha fina $(1 \mathrm{~mm})$ de modo a reter o biofilme, preso entre o cesto e a própria parede interna do reator.

A Figura 4.3 apresenta umas fotografias do sistema. A agitação fixa de $300 \mathrm{rpm}$ foi implementada por motor acoplado aos impelidores tipo turbina de $6 \mathrm{~cm}$ de diâmetro constituído por seis lâminas planas (padrão Rushton) e instalados a 8 e $16 \mathrm{~cm}$ do fundo do tanque (MICHELAN et al., 2009)

A alimentação e descarga foram realizadas por bombas tipo diafragma marca Prominent modelos $\beta$ e Concept, respectivamente. Um sistema de automação composto por temporizadores foi o responsável pelo acionamento/parada das bombas e do agitador, de modo a implementar as etapas da operação em batelada sequencial: alimentação, reação e descarga. A temperatura foi controlada pela circulação de água, cuja temperatura foi regulada no valor de $30 \pm 1{ }^{\circ} \mathrm{C}$ graça a um banho ultratermostatizado (marca Marconi modelo MA-184), na dupla parede externa do reator. 


\subsection{Imobilização da biomassa anaeróbia}

Foram utilizados grânulos de polietileno de baixa densidade como material suporte da biomassa cujas características foram calculadas relacionando volumes com peso. Elas são descritas pela Tabela 4.1 e a Figura 4.1. A empresa doadora é localizada na região de São Carlos no estado de São Paulo. Este material é um produto intermediário do processo de reciclagem de plásticos de resíduos domésticos. Cabe destacar então o baixo custo, a disponibilidade e a adequação ambiental de tal material.

Tabela 4.1 - Características do material suporte da biomassa

\begin{tabular}{cc}
\hline Propriedades & Valor / Descrição \\
\hline Composição & Polietileno de baixa densidade \\
Diâmetro médio de um grânulo & $3 \mathrm{~mm}$ \\
Comprimento médio de um grânulo & $6 \mathrm{~mm}$ \\
Massa utilizada & $1,2 \mathrm{~kg}$ \\
Massa volumétrica aparente meio suporte & $0,47 \mathrm{~kg} . \mathrm{L}^{-1}$ \\
Densidade do leito & 0,47 \\
Porosidade do leito & 0,43 \\
Comportamento & Flutuante
\end{tabular}

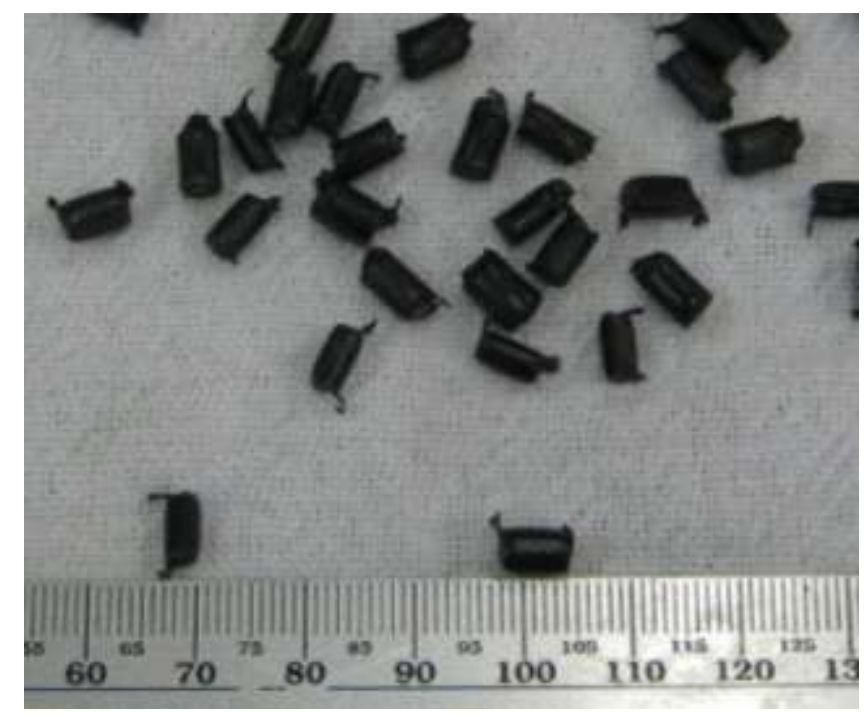

Figura 4.1 - Fotografia dos grânulos do material suporte 


\subsection{Inóculo}

O inóculo utilizado nos experimentos (volume de $2 \mathrm{~L}$ ) foi proveniente de reator anaeróbio de manta de lodo e escoamento ascendente (UASB), tratando água residuária de abatedouro de aves (Avicola Dacar S/A.), sediada em Tietê, SP. Este inóculo apresentou uma concentração de sólidos totais (ST) e de sólidos voláteis totais (SVT) de 62 e 51 g.L $\mathrm{L}^{-1}$, respectivamente. A proposta é iniciar o ensaio com um inóculo formado por lodo anaeróbio "in natura" proveniente de reator tipicamente metanogênico, contendo um diversificado consórcio microbiano com microrganismos de acordo com os resultados do trabalho realizado por KAWAGOSHI et al., (2005). Assim, a partir das condições experimentais impostas, o intuito é favorecer uma adaptação do lodo no sentido do enriquecimento de microrganismos produtores de bio-hidrogênio. A inoculação foi realizada conforme metodologia proposta por ZAIAT et al., (1994). Os grânulos de polietileno foram imersos por duas horas dentro de dois litros de inóculo previamente batido no liquidificador. O excedente de lodo foi retirado e o material suporte foi introduzido no reator dentro do cesto previsto para esse efeito

\subsection{Aspectos tecnológicos}

O contexto desse estudo sendo o desenvolvimento de um bioreator é importante detalhar os aspectos tecnológicos. A Tabela 4.2 e as Figuras 4.2 e 4.3 apresentam as características do sistema.

Tabela 4.2 - Parâmetros operacionais do bioreator

\begin{tabular}{cc}
\hline Parâmetro & Valor \\
\hline Volume total & $7,5 \mathrm{~L}$ \\
Volume útil & $6,5 \mathrm{~L}$ \\
Volume de fase líquida & $3,6 \mathrm{~L}$ \\
Volume de dispositivo de suporte da biomassa & $2,9 \mathrm{~L}$ \\
Volume de trabalho cíclico & $1,5 \mathrm{~L}$ \\
Volume de fase líquida residual entre ciclos & $2,1 \mathrm{~L}$ \\
Tempo total de ciclo & $4 \mathrm{~h}, 3 \mathrm{~h}, 2 \mathrm{~h}$ \\
Tempo de alimentação & $10 \mathrm{~min}$ \\
Tempo de descarga & $10 \mathrm{~min}$ \\
Agitação mecânica & $300 \mathrm{rpm}$ \\
\hline
\end{tabular}




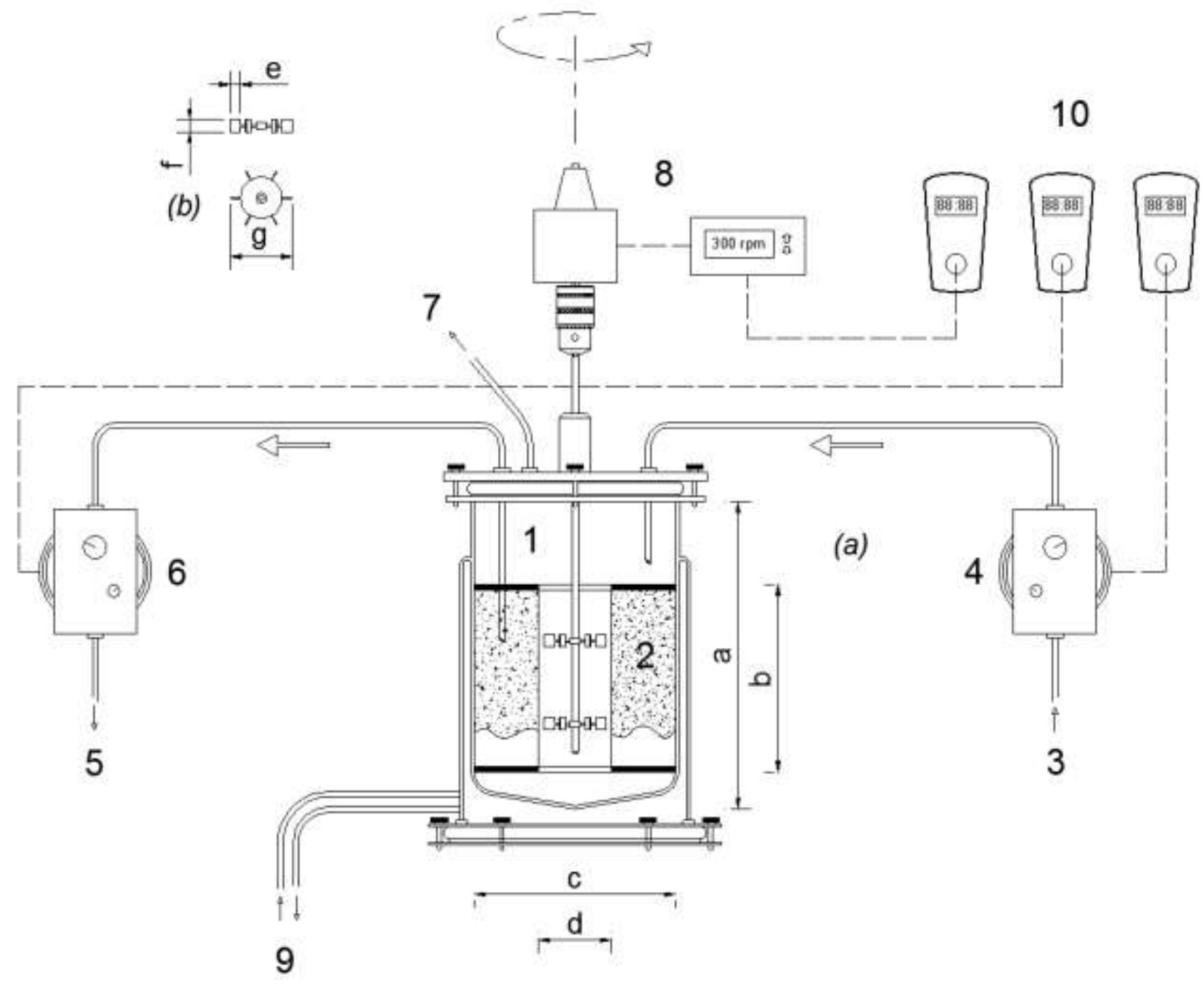

Figura 4.2 - Esquema do reator anaeróbio com agitação operado em bateladas seqüenciais contendo biomassa imobilizada

(a) Reator

1 - Biorreator BIOFLO 110 (New Brunswick Scientific Co.) com capacidade de 7,5 L (a = 29,5 cm; b = 18 $\mathrm{cm} ; \mathrm{c}=18 \mathrm{~cm}) ; 2$ - Cesto de retenção e material suporte da biomassa $(\mathrm{b}=18 \mathrm{~cm} ; \mathrm{d}=7 \mathrm{~cm}) ; 3$ - Afluente; 4 - Bomba de alimentação; 5 - Efluente; 6 - Bomba de descarga; 7 - Saída de biogás; 8 - Sistema de agitação; 9 - Sistema de controle de temperatura (banho termostático); 10 - Sistema de automação.

(b) Detalhes dos impelidores

Dois impelidores tipo turbina com seis pás planas $(\mathrm{e}=2 \mathrm{~cm} ; \mathrm{f}=1.5 \mathrm{~cm} ; \mathrm{g}=6 \mathrm{~cm})$ 

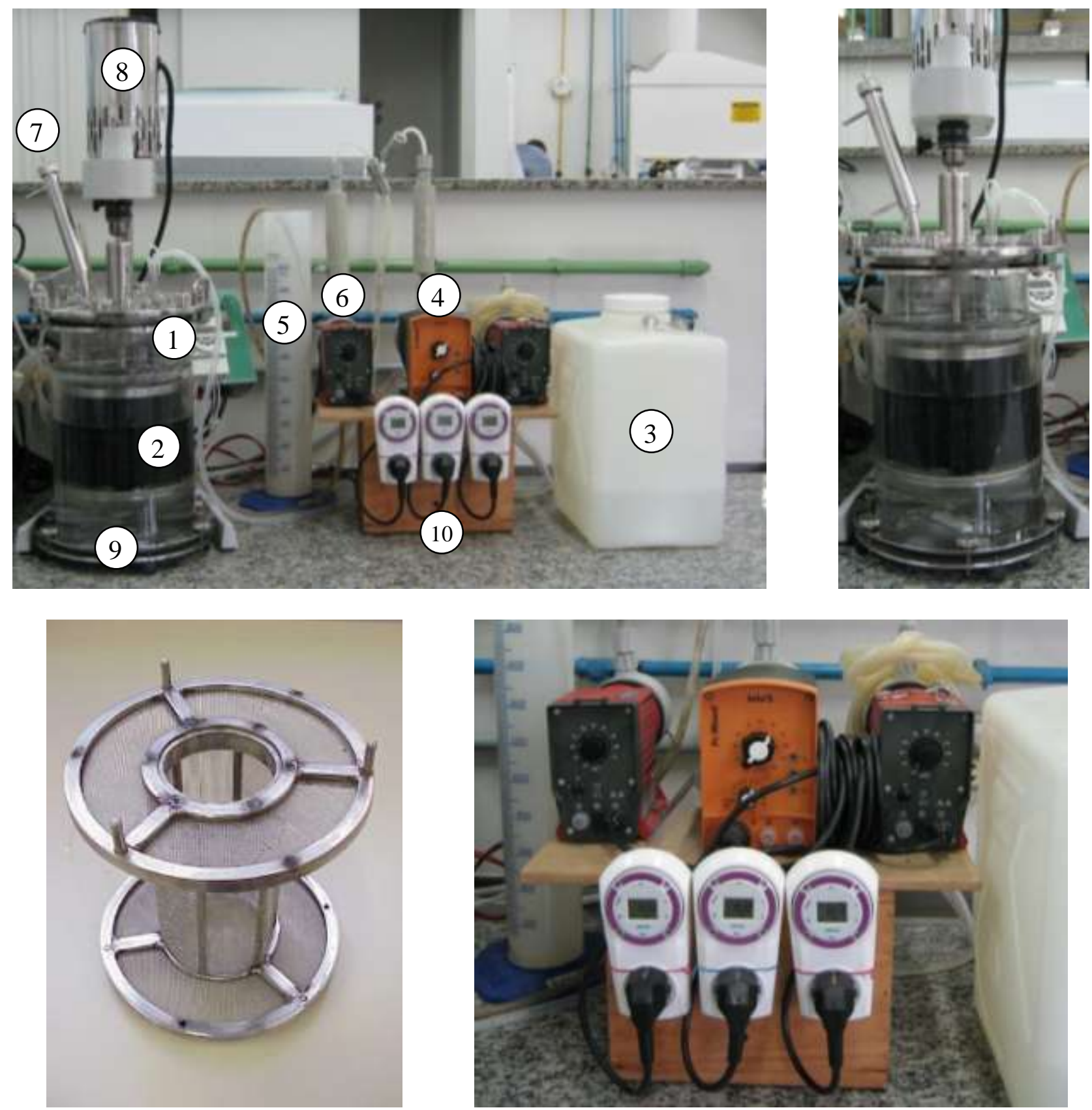

Figura 4.3 - Fotografia do aparato experimental

1 - Biorreator BIOFLO 110 (New Brunswick Scientific Co.) com capacidade de 7,5 L; 2 - Cesto de retenção e material suporte da biomassa 3 - Afluente; 4 - Bomba de alimentação; 5 - Efluente; 6 - Bomba de descarga; 7 - Saída de biogás; 8 - Sistema de agitação; 9 - Sistema de controle de temperatura (banho termostático); 10 - Sistema de automação 


\section{5. Água residuária}

A água residuária utilizada foi formulada a base de sacarose como fonte de carbono e energia, fixando-se a razão entre a fonte de carbono e a fonte de nitrogênio-uréia (C/N) em aproximadamente 140 e razão DQO/P menor que 500 (1000:2). A Tabela 4.2 descreve a composição da água residuária para uma concentração em termos de DQO igual a 1000 mg.L $\mathrm{L}^{-1}$ (DEL NERY, 1987).

A relação $\mathrm{C} / \mathrm{N}\left(\mathrm{g}-\mathrm{C} \cdot \mathrm{g}-\mathrm{N}^{-1}\right)$ foi calculada de acordo com a porcentagem em massa de carbono e nitrogênio dos elementos sacarose (glicose-frutose $-\mathrm{C}_{12} \mathrm{H}_{22} \mathrm{O}_{11}-144 \mathrm{~g}$-C/342g-sacarose) e uréia $\left(\mathrm{CH}_{4} \mathrm{~N}_{2} \mathrm{O}-28 \mathrm{~g}-\mathrm{N} / 60 \mathrm{~g}\right.$-uréia), que constituiram parte do meio. Assim, a relação $\mathrm{C} / \mathrm{N}$ a ser utilizada nesse estudo será:

$$
893 / 5,8=(893 \cdot 144 / 342) /(5,8 \cdot 28 / 60)=376,0 / 2,7=139,3 \mathrm{~g}-\mathrm{C} \cdot \mathrm{g}-\mathrm{N}^{-1}
$$

A relação $\mathrm{C} / \mathrm{P}$ (g-C/g-P) foi calculada de acordo com a porcentagem em massa de carbono e fósforo dos elementos sacarose (glicose-frutose $-\mathrm{C}_{12} \mathrm{H}_{22} \mathrm{O}_{11}-144 \mathrm{~g}$-C/342g-sacarose) e sais de fósforo $\left(\mathrm{KH}_{2} \mathrm{PO}_{4}-31 \mathrm{~g}-\mathrm{P} / 136 \mathrm{~g}-\mathrm{KH}_{2} \mathrm{PO}_{4} ; \mathrm{K}_{2} \mathrm{HPO}_{4}-31 \mathrm{~g}-\mathrm{P} / 174 \mathrm{~g}-\mathrm{K}_{2} \mathrm{HPO}_{4} ; \mathrm{Na}_{2} \mathrm{HPO}_{4}-31 \mathrm{~g}-\mathrm{P} / 142 \mathrm{~g}-\right.$ $\mathrm{Na}_{2} \mathrm{HPO}_{4}$ ), que constituíram parte do meio. Assim, a relação C/P a ser utilizada nesse estudo será:

Em termos de C: $(893 \cdot 144 / 342) /(5,36 \cdot 31 / 136+1,30 \cdot 31 / 174+2,70 \cdot 31 / 142)=376,0 / 2,04=184,3$ g-C.g- $\mathrm{P}^{-1}$ Em termos de DQO: $(1000) /(5,36 \cdot 31 / 136+1,30 \cdot 31 / 174+2,70 \cdot 31 / 142)=1000 / 2,04=490,2$ g-DQO.g-P ${ }^{-1}$ 
Tabela 4.3 - Composição da água residuária sintética a ser utilizada nos ensaios*.

\begin{tabular}{cc}
\hline Composto & Concentração $(\mathrm{mg} / \mathrm{L})$ \\
\hline Sacarose & 893,00 \\
(relação teórica: $1000 \mathrm{mg}$-DQO $=893 \mathrm{mg}$-sacarose) & $(1000 \mathrm{mgDQO} / \mathrm{L})$ \\
Uréia $\left(\mathrm{CH}_{4} \mathrm{~N}_{2} \mathrm{O}\right)$ & 5,80 \\
Sulfato de níquel $\left(\mathrm{NiSO}_{4} \cdot 6 \mathrm{H}_{2} \mathrm{O}\right)$ & 0,50 \\
Sulfato ferroso $\left(\mathrm{FeSO}_{4} \cdot 7 \mathrm{H}_{2} \mathrm{O}\right)$ & 2,50 \\
Cloreto férrico $\left(\mathrm{FeCl}_{3} \cdot 6 \mathrm{H}_{2} \mathrm{O}\right)$ & 0,25 \\
Cloreto de cálcio $\left(\mathrm{CaCl}_{2} \cdot 2 \mathrm{H}_{2} \mathrm{O}\right)$ & 2,06 \\
Cloreto de cobalto $\left(\mathrm{CoCl}_{2} \cdot 6 \mathrm{H}_{2} \mathrm{O}\right)$ & 0,04 \\
Dióxido de selênio $\left(\mathrm{SeO}_{2}\right)$ & 0,04 \\
Fosfato de potássio monobásico $\left(\mathrm{KH}_{2} \mathrm{PO}_{4}\right)$ & 5,36 \\
Fosfato de potássio dibásico $\left(\mathrm{K}_{2} \mathrm{HPO}_{4}\right)$ & 1,30 \\
Fosfato de sódio dibásico $\left(\mathrm{Na}_{2} \mathrm{HPO}_{4}\right)$ & 2,70 \\
Bicarbonato de sódio $\left(\mathrm{NaHCO}_{3}\right)$ & 250,00 \\
\hline
\end{tabular}

*Composição com Base de 1000 mgDQO/L

$\mathrm{pH}_{\text {inicial }}$ ajustado pela adição de ácido clorídrico $12 \mathrm{M}$

Durante a operação, o pH afluente foi ajustado de maneira a manter o valor do pH efluente próximo a 5 .

\subsection{Análises físico-químicas e exames microbiológicos}

O monitoramento do reator foi efetuado medindo-se, em amostras do afluente e do efluente, as concentrações de matéria orgânica nas formas não filtrada $\left(\mathrm{C}_{\mathrm{ST}}\right)$ e filtrada $\left(\mathrm{C}_{\mathrm{SF}}\right)$ (como demanda química de oxigênio - DQO), método de Dubois (1956) para a determinação dos carboidratos totais nas formas não filtrada $\left(\mathrm{C}_{\mathrm{CT}}\right)$ e filtrada $\left(\mathrm{C}_{\mathrm{CF}}\right)$, alcalinidade parcial $(\mathrm{AP})$, alcalinidade intermediária (AI), alcalinidade total (AT), alcalinidade a bicarbonato (AB), ácidos voláteis totais (AVT), sólidos totais (ST), sólidos voláteis totais (SVT), sólidos suspensos totais (SST) e sólidos suspensos voláteis (SSV), além da medida do $\mathrm{pH}$ e do volume de meio alimentado/descarregado. Tais análises foram realizadas de acordo com o (STANDARD METHODS FOR THE EXAMINATION OF 
WATER AND WASTEWATER, 1995), considerando também o método proposto por DILALLO; ALBERTSON, (1961) o qual foi modificado por RIPLEY et al., (1986) na determinação da alcalinidade. Esses parâmetros foram monitorados conforme a Tabela 4.4.

Tabela 4.4 - Cronograma das análises

\begin{tabular}{ccc}
\hline Parâmetros & Locais de coleta & $\begin{array}{c}\text { Frequências } \\
\text { (S:Semanal; C: por condição) }\end{array}$ \\
\hline DQO & Afluente e efluente & $5 \mathrm{~S}$ \\
Carboidratos & Afluente e efluente & $5 \mathrm{~S}$ \\
Sólidos Suspensos & Afluente e efluente & $1 \mathrm{~S}$ \\
Volume de biogás & Saída de gás & $2 \mathrm{~S}$ \\
pH & Afluente e efluente & $5 \mathrm{~S}$ \\
Alcalinidade / AVT & Afluente e efluente & $5 \mathrm{~S}$ \\
Composição do biogás & Saída de gás & $3 \mathrm{C}$ \\
Ácidos voláteis & Efluente & $2 \mathrm{C}$ \\
Álcoois & Efluente & $2 \mathrm{C}$ \\
\hline
\end{tabular}

Os compostos intermediários do metabolismo anaeróbio (acetona, metanol, etanol, nbutanol, ácidos acético, propiônico, butírico, iso-butírico, valérico, iso-valérico e capróico) foram analisados por cromatografia em fase gasosa utilizando-se um cromatógrafo de fase gasosa Agilent Technologies 7890 equipado com detector de ionização de chama (FID), com injetor automático (fase líquida e "head space") GC Sampler 80 e com coluna HP-Innowax com $30 \mathrm{~m} \times 0,25 \mathrm{~mm} \times$ $0,25 \mu \mathrm{m}$ de espessura do filme. O gás de arraste utilizado foi o hidrogênio com vazão de 1,56 $\mathrm{mL} \cdot \mathrm{min}^{-1}$. A temperatura do injetor foi de $250^{\circ} \mathrm{C}$, o volume de injeção de $400 \mu \mathrm{L}$ e a razão de "split" 10 ("head-space"). A temperatura do forno foi programada da seguinte forma: de $35^{\circ} \mathrm{C}$ à $38^{\circ} \mathrm{C}$ em $2^{\circ} \mathrm{C} \cdot \mathrm{min}^{-1}$, de $38^{\circ} \mathrm{C}$ à $75^{\circ} \mathrm{C}$ em $10^{\circ} \mathrm{C} \cdot \mathrm{min}^{-1}$, de $75^{\circ} \mathrm{C}$ à $120^{\circ} \mathrm{C}$ em $35^{\circ} \mathrm{C} \cdot \mathrm{min}^{-1}$, em $120^{\circ} \mathrm{C}$ por 1 min, de $120^{\circ} \mathrm{C}$ à $170^{\circ} \mathrm{C}$ em $10^{\circ} \mathrm{C} \cdot \mathrm{min}^{-1} \mathrm{e}$ em $170^{\circ} \mathrm{C}$ por 2 min ("head-space"). A temperatura do detector foi de $280^{\circ} \mathrm{C}$ ("head-space") com fluxo de hidrogênio (combustível) de $30 \mathrm{~mL} \cdot \mathrm{min}^{-1} \mathrm{de}$ ar sintético (comburente) de 300 mL.min ${ }^{-1}$ e vazão de "make up" de nitrogênio de 30 mL.min ${ }^{-1}$. Foi utilizado nessas análises o métodos por "head-space", utilizando como padrão interno o ácido 
crotônico (na determinação dos ácidos voláteis) e isobutanol (na determinação da acetona e álcoois).

A composição do biogás formado pelo metabolismo anaeróbio foi analisada por cromatografia em fase gasosa utilizando-se um cromatógrafo de fase gasosa Agilent Technologies 7890 equipado com detector de condutividade térmica (TCD) e coluna GS-Carbonplot com $30 \mathrm{~m} \times$ $0,53 \mathrm{~mm} \times 3,0 \mu \mathrm{m}$ de espessura do filme. O gás de arraste utilizado foi o argônio com vazão de 3,67 mL.min ${ }^{-1}$, a temperatura do injetor foi de $185^{\circ} \mathrm{C}$, e o volume de injeção de $200 \mu \mathrm{L}$ e a razão de "split" de 10. A temperatura do forno foi programada da seguinte forma: $40^{\circ} \mathrm{C}$ isotérmico em $5 \mathrm{~min}$. A temperatura do detector foi de $150^{\circ} \mathrm{C}$, com vazão de "make up" de argônio de 8,33 mL.min ${ }^{-1}$.

A produção volumétrica foi analisada por medidor de gás Rittter modelo MilligasCounter.

A quantificação da biomassa presente no biorreator foi feita a cada duas condições experimentais. O procedimento constou, inicialmente, de desmontar o biorreator e retirar todo suporte inerte (SI) presente no reator juntamente com a biomassa aderida e/ou retida (B). O meio líquido contido nessa denominada "mistura total suporte inerte + biomassa" foi drenado naturalmente e a medida da massa total foi realizada $\left(\mathrm{M}_{\mathrm{T}-\mathrm{SI}+\mathrm{B}}\right)$. Após homogeneização da "mistura total suporte inerte + biomassa", foi retirada uma amostra denominada "mistura amostra suporte inerte + biomassa" $\left(\mathrm{M}_{\mathrm{A}-\mathrm{SI}+\mathrm{B}}\right)$, na qual foi medida a massa e feita uma lavagem com água destilada no intuito de separar o suporte inerte da biomassa. $\mathrm{O}$ suporte inerte separado foi levado à estufa $\left(103^{\circ} \mathrm{C}\right)$ por $24 \mathrm{~h}$ para secagem e posterior resfriamento em dessecador para medida da massa $\left(\mathrm{M}_{\mathrm{A}-}\right.$ SI). A biomassa separada foi quantificada $\left(\mathrm{M}_{\mathrm{A}-\mathrm{B}}\right)$, na forma de sólidos voláteis totais da amostra (estufa a $103^{\circ} \mathrm{C}$ por $24 \mathrm{~h}$ e posterior mufla a $550^{\circ} \mathrm{C}$ por $2 \mathrm{~h}$ ).

Dessa forma, foi possível quantificar a biomassa presente no biorreator de três formas:

(i) quantidade total de biomassa presente no biorreator $\left(\mathrm{M}_{\mathrm{SVT}}\right)$, calculada pela relação dos sólidos voláteis totais da amostra $\left(\mathrm{M}_{\mathrm{A}-\mathrm{B}}\right)$ e as massas da "mistura total suporte inerte + biomassa" 
$\left(\mathrm{M}_{\mathrm{T}-\mathrm{SI}+\mathrm{B}}\right)$ e da "mistura amostra suporte inerte + biomassa" $\left(\mathrm{M}_{\mathrm{A}-\mathrm{SI}+\mathrm{B}}\right)$, através da seguinte equação $\mathrm{M}_{\mathrm{SVT}}=\mathrm{M}_{\mathrm{A}-\mathrm{B}} \cdot \mathrm{M}_{\mathrm{T}-\mathrm{SI}+\mathrm{B}} / \mathrm{M}_{\mathrm{A}-\mathrm{SI}+\mathrm{B}}$

(ii) relação entre a quantidade total da biomassa e a quantidade total de suporte inerte presentes no biorreator $\left(\mathrm{C}_{\mathrm{X}-\mathrm{SVT}}^{\prime}\right)$, calculada pela relação entre os sólidos voláteis totais $\left(\mathrm{M}_{\mathrm{A}-\mathrm{B}}\right)$ e a massa de suporte da amostra $\left(\mathrm{M}_{\mathrm{A}-\mathrm{SI}}\right)$, através da seguinte equação $\mathrm{C}_{\mathrm{X}-\mathrm{SVT}}^{\prime}=\mathrm{M}_{\mathrm{A}-\mathrm{B}} / \mathrm{M}_{\mathrm{A}-\mathrm{SI}}$;

(iii) relação entre a quantidade total de biomassa e o volume de meio líquido contido no reator $\left(\mathrm{C}_{\mathrm{X}-\mathrm{SVT}}\right)$, calculada pela relação entre os sólidos voláteis totais $\left(\mathrm{M}_{\mathrm{A}-\mathrm{B}}\right)$ e o volume de meio líquido contido no biorreator $\left(V_{R}\right)$, através da seguinte equação $C_{X-S V T}=M_{A-B} / V_{R}$.

Essas três formas de quantificar a biomassa aderida e/ou retida no biorreator possuem importâncias distintas e complementares. A primeira maneira (item $i$ ) informa sobre a quantidade total de biomassa que ficou aderida e/ou retida no biorreator ao longo da condição experimental, sendo um indicativo da eficiência da configuração do biorreator em reter a biomassa, a qual considera o modo de mistura (agitação ou recirculação da fase líquida), o tipo e concentração da água residuária utilizada (qualidade e quantidade de substrato) e o modo de operação (batelada, batelada alimentada ou contínuo). Portanto, essa variável permite calcular as variáveis de projeto denominadas de "específicas" (cargas orgânicas aplicadas e removidas), ou seja, aquelas que não dependem do volume (denominadas de volumétricas) de meio, mas da biomassa presente no sistema. Entretanto, por ser uma grandeza extensiva, ou seja, depender do "tamanho do sistema", existe a necessidade do cálculo efetuado pelas duas maneiras seguintes. Assim, tem-se a segunda maneira (item $\mathrm{ii}$ ) que relaciona a variável extensiva anterior com a massa de suporte inerte, sendo esta uma grandeza intensiva, ou seja, não depende do "tamanho do sistema". A aplicação desta variável contribui para a estimativa da massa de suporte inerte necessária para um projeto de biorreator em diferente escala. De forma análoga, a terceira maneira (item iii) que relaciona a variável extensiva (item $i$ ) com o volume de meio líquido presente no sistema é também uma 
grandeza intensiva. A aplicação desta variável pode contribuir para a interpretação e/ou comparação de resultados obtidos em diferentes biorreatores, pois está relacionada com a concentração de substrato (relação entre massa de substrato e volume de meio líquido) que é a forma intrinsicamente importante para relacionar as reações do metabolismo celular com o crescimento dos microrganismos (formação daqueles que melhor se adaptaram às condições ambientais impostas), o aproveitamento de nutrientes (substrato alimentado ao biorreator), a formação/consumo de intermediários (ácidos e solventes) e a liberação do produto final (biohidrogênio).

Os exames microbiológicos permitiram avaliar as possíveis mudanças na morfologia microbiana. As amostras foram examinadas em lâminas de vidro por microscopia óptica comum e de contraste de fase por fluorescência, utilizando microscópio Olympus® Microscópio OLYMPUS BX-41-FL-III com câmera digital colorida refrigerada 3.3 MPixel QCOLOR3C e "software" para análise de imagem IMAGE PRO-EXPRESS v. 5.1.

\subsection{Procedimento experimental da operação do reator}

Os ensaios foram realizados utilizando-se cargas orgânicas volumétricas crescentes variando a concentração afluente, 3600 ou 5400 mgDQO.L ${ }^{-1}$, e do tempo de ciclo, 4, 3 e 2 h, ou seja, 6, 8 e 12 ciclos diários, conforme mostrado na Tabela 4.5.

Tabela 4.5 - Resumo das condições experimentais estudadas.

\begin{tabular}{cccc}
\hline Ensaio & $\begin{array}{c}\text { Concentração } \\
\left(\mathrm{mgDQO} . \mathrm{L}^{-1}\right)\end{array}$ & $\begin{array}{c}\text { Tempo de ciclo } \\
(\mathrm{h})\end{array}$ & $\begin{array}{c}\text { Carga orgânica volumétrica } \\
\left(\mathrm{kgDQO} . \mathrm{m}^{-3} \cdot \mathrm{d}\right)\end{array}$ \\
\hline I & 3600 & 4,0 & 9,0 \\
II & 3600 & 3,0 & 12,0 \\
III & 5400 & 4,0 & 13,5 \\
IV & 5400 & 3,0 & 18,0 \\
V & 3600 & 2,0 & 18,0 \\
VI & 5400 & 2,0 & 27,0 \\
\hline
\end{tabular}


A operação do reator foi realizada da seguinte maneira. Inicialmente foi inserido, dentro do volume total do reator de 7,5 L, o dispositivo suporte da biomassa (material suporte, biomassa, volume do cesto) representando um volume de 2,9 L. No primeiro ciclo foram carregados 3,6 L de meio, volume correspondente ao volume de fase líquida em fase de reação, ou seja, o volume útil do reator foi mantido igual a $6,5 \mathrm{~L}(2,9 \mathrm{~L}$ dispositivo suporte $+3,6 \mathrm{~L}$ fase líquida) independentemente da condição estudada. No final do ciclo foram descarregados $1,5 \mathrm{~L}$ de meio em 10 min correspondente ao volume de trabalho cíclico. $5 \mathrm{~L}$ de volume residual foram assim mantido no reator, composto por 2,9 L de dispositivo suporte (material suporte, biomassa, volume do cesto) e 2,1 L de meio residual líquido. Logo após essa descarga, um novo ciclo teve início, no qual, simultaneamente, havia a agitação do meio (300 rpm) e alimentação em, 10 min, com vazão de alimentação constante de um volume de 1,5 L (42\% do volume de meio reacional) de volume de trabalho cíclico a ser tratado. Ao término do ciclo, em seguida, iniciava-se a descarga e, assim, o ciclo foi repetido, caracterizando as bateladas sequenciais conforme a Figura 4.4.

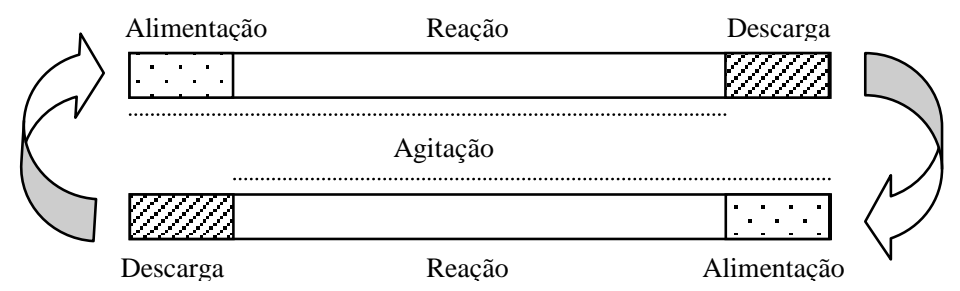

Figura 4.4 - Ciclos típicos de bateladas sequenciais

Uma vez atingida a estabilidade nas condições experimentais, foram obtidos perfis ao longo do ciclo de operação de algumas das variáveis monitoradas. As variáveis de interesse foram: concentrações de matéria orgânica e de carboidratos totais na forma filtrada, de alcalinidade a bicarbonato, de ácidos voláteis totais, de metabólitos intermediários (acetona, ácidos voláteis e álcoois), de biogás (composição e produção), além do pH. Desta forma, foi possível ter uma melhor compreensão das rotas metabólicas ao longo de um ciclo. As amostras retiradas para obtenção do perfil anteriormente citado foram colhidas em intervalos de tempo ao longo do ciclo de 20 a $30 \mathrm{~min}$. 
O volume total retirado nas amostragens foi inferior a $360 \mathrm{~mL}$, ou seja, a $10 \%$ do volume de meio reacional do sistema.

Os resultados experimentais obtidos no monitoramento do sistema e nos perfis ao longo de um ciclo, em cada condição operacional, foram analisados considerando-se a influência das variáveis estudadas sobre a estabilidade e o desempenho do processo assim como os diferentes indicadores de produção de hidrogênio. As análises microbiológicas permitiram de avaliar mudanças na morfologia microbiana.

\subsection{Fundamentos teóricos}

A eficiência de remoção de matéria orgânica na base da DQO nas formas total $\left(\varepsilon_{\mathrm{ST}}\right)$ é calculada pela Equação (4.1), na qual $\mathrm{C}_{\mathrm{ST}, \mathrm{A}}$ é a concentração de matéria orgânica total no afluente e $\mathrm{C}_{\mathrm{ST}, \mathrm{E}}$ é a concentração de matéria orgânica total no efluente.

$$
\varepsilon_{S T}(\%)=\frac{C_{S T, A}-C_{S T, E}}{C_{S T, A}} \cdot 100
$$

A eficiência de remoção de matéria orgânica filtrada na base da DQO $\left(\varepsilon_{\mathrm{SF}}\right)$ é calculada pela Equação (4.2), na qual $\mathrm{C}_{\mathrm{SF}, \mathrm{E}}$ é a concentração de matéria orgânica filtrada no efluente.

$$
\varepsilon_{S F}(\%)=\frac{C_{S T, A}-C_{S F, E}}{C_{S T, A}} \cdot 100
$$

Estes parâmetros serão calculado na base da Sacarose nas formas total $\left(\varepsilon_{\mathrm{CT}}\right)$ é calculada pela Equação (4.3) na qual $\mathrm{C}_{\mathrm{CT}, \mathrm{A}}$ é a concentração de matéria orgânica total no afluente e $\mathrm{C}_{\mathrm{CT}, \mathrm{E}}$ é a concentração de matéria orgânica total no efluente 


$$
\varepsilon_{C T}(\%)=\frac{C_{C T, A}-C_{C T, E}}{C_{C T, A}} \cdot 100
$$

A eficiência de remoção de matéria orgânica filtrada $\left(\varepsilon_{\mathrm{CF}}\right)$ na base da sacarose é calculada pela Equação (4.4), na qual $C_{\mathrm{CF}, \mathrm{E}}$ é a concentração de matéria orgânica filtrada no efluente.

$$
\varepsilon_{C F}(\%)=\frac{C_{C T, A}-C_{C F, E}}{C_{C T, A}} \cdot 100
$$

A carga orgânica aplicada volumétrica (COAV) é definida como sendo a quantidade de matéria orgânica aplicada ao reator por unidade de tempo e por volume de meio do reator. Para reatores operados em batelada pode ser calculada pela Equação (4.4), na qual $\mathrm{V}_{\mathrm{A}}$ é o volume de água residuária alimentada no ciclo, $\mathrm{N}$ é o número de ciclos por dia, $\mathrm{C}_{\mathrm{ST}, \mathrm{A}}$ é a concentração de matéria orgânica no afluente e $V_{R}$ é o volume de água residuária no reator.

$$
C O A V=\frac{\left(V_{A} \cdot N\right) \cdot C_{S A F L}}{V_{R}}
$$

A carga orgânica aplicada específica (COAE) é definida como sendo a quantidade de matéria orgânica aplicada ao reator por unidade de tempo e por massa de sólidos totais voláteis no reator. Para reatores operados em batelada pode ser calculada pela Equação (4.5), na qual $\mathrm{M}_{\mathrm{SvT}}$ é a massa de sólidos voláteis totais no interior do reator.

$$
C O A E=\frac{\left(V_{A} \cdot N\right) \cdot C_{S T, A}}{M_{S V T}}
$$


A carga orgânica removida volumétrica $\left(\mathrm{CORV}_{\mathrm{SF}}\right)$, para amostras filtradas, é definida como sendo a quantidade de matéria orgânica removida pelo reator por unidade de tempo e por volume de meio do reator. Para reatores operados em batelada pode ser calculada pela Equação (4.6).

$$
C O R V_{S F}=\frac{\left(V_{A} \cdot N\right) \cdot\left(C_{S T, A}-C_{S F, E}\right)}{V_{R}}
$$

A carga orgânica removida específica $\left(\mathrm{CORE}_{\mathrm{SF}}\right)$, para amostras filtradas, é definida como sendo a quantidade de matéria orgânica removida pelo reator por unidade de tempo e por massa de sólidos totais voláteis no reator. Para reatores operados em batelada pode ser calculada pela Equação (4.7), na qual $\mathrm{M}_{\mathrm{SvT}}$ é a massa de sólidos voláteis totais no interior do reator.

$$
\operatorname{CORE}_{S F}=\frac{\left(V_{A} \cdot N\right) \cdot\left(C_{S T, A}-C_{S F, E}\right)}{M_{S V T}}
$$

A produtividade molar $(\operatorname{PrM})$ é definida pela relação entre hidrogênio produzido por unidade de tempo e o volume útil do reator $\left(\mathrm{V}_{\mathrm{u}}\right)$. Para reatores operados em batelada sequenciais pode ser calculada pela Equação (4.8) onde $n_{H_{2}}$ representa o numero de moles de hidrogênio produzido por dia.

$$
\operatorname{Pr} M=\frac{n_{H_{2}}}{V_{u}}
$$

A produtividade molar específica (PrME) é definida pela relação entre hidrogênio produzido por unidade de tempo e a massa de sólidos voláteis totais no interior do reator, pode ser calculada pela Equação (4.9), 


$$
\operatorname{Pr} M E=\frac{n_{H_{2}}}{M_{S V T}}
$$

O rendimento molar por carga aplicada $\left(\mathrm{RMCA}_{\mathrm{m}}\right)$ entre o hidrogênio produzido e matéria orgânica aplicada será calculado na base da DQO (RMCA $\left.{ }_{S, m}\right)$ pela Equação (4.10).

$$
R M C A_{S, m}=\frac{n_{H_{2}}}{N \cdot V_{A} \cdot C_{S T, A}}
$$

O rendimento molar por carga aplicada será calculado na base do substrato no caso da Sacarose $\left(\mathrm{RMCA}_{\mathrm{C}, \mathrm{m}}\right)$ pela Equação (4.11)

$$
R M C A_{C, m}=\frac{n_{H_{2}}}{N \cdot V_{A} \cdot C_{C T, A}}
$$

O rendimento molar por carga removida $\left(\mathrm{RMCR}_{\mathbf{m}}\right)$ entre o hidrogênio produzido e matéria orgânica aplicada será calculado na base da DQO $\left(\mathrm{RMCR}_{\mathrm{S}, \mathrm{m}}\right)$ pela Equação (4.12)

$$
R M C R_{S, m}=\frac{n_{H_{2}}}{N \cdot V_{A} \cdot\left(C_{S T, A}-C_{S F, E}\right)}
$$


O rendimento molar por carga removida será calculado na base do substrato no caso da Sacarose $\left(\mathrm{RMCR}_{\mathrm{C}, \mathrm{m}}\right)$ pela Equação (4.13)

$$
R M C R_{C, m}=\frac{n_{H_{2}}}{N \cdot V_{A} \cdot\left(C_{C T, A}-C_{C F, E}\right)}
$$

Estes indicadores serão utilizados para avaliar o desempenho do reator e comentar os resultados, entretanto a conversão para os demais indicadores apresentados na revisão bibliográfica será efetuada a fim de facilitar a transparência dos resultados e o reaproveitamento deste trabalho por outros grupos de pesquisas. 


\section{RESULTADOS E DISCUSSÃO}

O presente capítulo apresenta os dados coletados e os parâmetros calculados durante a operação do reator. Os resultados são apresentados de maneira cronológica conforme foi realizada a fase experimental. Para cada condição são destacados, em parte separadas, variáveis e indicadores de interesse do monitoramento diário e a ao longo de um ciclo.

\subsection{Condição experimental preliminar (DQO 3600 mg. $\mathrm{L}^{-1}-\mathrm{TC}$ 4h)}

Logo depois da montagem do reator se iniciou o monitoramento. A fase preliminar corresponde ao período de ajuste dos métodos e dos procedimentos experimentais. Foram realizadas as curvas de calibração, corrigidos os erros de manipulação e padronizados os procedimentos (diluições e padronização do ritmo semanal). Ao termo destes quinze dias de operação, foram considerados confiáveis os dados coletados.

A Tabela 5.1 apresenta os valores médios dos parâmetros monitorados. Nesta condição não foram considerados aspectos qualitativos dos compostos intermediários e do biogás produzido devido à instalação e calibração do cromatógrafo.

A quantificação da biomassa presente no reator no final da condição também não foi realizada para não desmontar o reator e comprometer a estabilidade ao começo da primeira condição.

O valor das concentrações afluentes reais em sacarose e em DQO, $3270 \mathrm{mgSAC} . \mathrm{L}^{-1}$ e 3643 mgDQO. $\mathrm{L}^{-1}$ respectivamente, mostraram o sucesso em ajustar os parâmetros conforme desejado como os valores nominais $3200 \mathrm{mgSAC} . \mathrm{L}^{-1}$ e $3600 \mathrm{mgDQO} . \mathrm{L}^{-1}$. Assim as cargas orgânicas volumétricas aplicadas reais foram de $8,18 \mathrm{kgSAC} \cdot \mathrm{m}^{-3} \cdot \mathrm{d}^{-1}$ e $9,11 \mathrm{kgDQO} \cdot \mathrm{m}^{-3} \cdot \mathrm{d}^{-1}$ considerando a sacarose ou a DQO, respectivamente. (valores nominais de $8,0 \mathrm{kgSAC} \cdot \mathrm{m}^{-3} \cdot \mathrm{d}^{-1}$ e $9,0 \mathrm{kgDQO} \cdot \mathrm{m}^{-3} \cdot \mathrm{d}^{-1}$ ) 
O reator apresentou uma boa capacidade de retenção da biomassa com valores de sólidos volteis totais e filtrados efluentes da ordem de grandeza dos valores afluentes como pode ser observado na Tabela 5.1.

Tabela 5.1 - Valores médios dos parâmetros monitorados Condição preliminar (DQO 3600 mg. $\mathrm{L}^{-1}$ - TC 4h).

\begin{tabular}{|c|c|c|c|c|c|c|c|c|c|}
\hline \multicolumn{2}{|r|}{ Parametro } & \multicolumn{3}{|c|}{ Afluente } & \multicolumn{5}{|c|}{ Efluente } \\
\hline $\mathrm{C}_{\mathrm{CT}}$ & {$\left[\mathrm{mgSAC} \cdot \mathrm{L}^{-1}\right]$} & 3270 & \pm & 197 & $(7)$ & 291 & \pm & 288 & $(6)$ \\
\hline $\mathrm{C}_{\mathrm{CF}}$ & {$\left[\mathrm{mgSAC} \cdot \mathrm{L}^{-1}\right]$} & - & & - & & 240 & \pm & 279 & $(7)$ \\
\hline$\varepsilon_{\mathrm{CT}}$ & {$[\%]$} & - & & - & & 91 & \pm & 9 & $(6)$ \\
\hline$\varepsilon_{\mathrm{CF}}$ & {$[\%]$} & - & & - & & 93 & \pm & 9 & $(7)$ \\
\hline $\mathrm{C}_{\mathrm{ST}}$ & {$\left[\mathrm{mgDQO} \cdot \mathrm{L}^{-1}\right]$} & 3643 & \pm & 149 & $(9)$ & 2977 & \pm & 192 & $(9)$ \\
\hline $\mathrm{C}_{\mathrm{SF}}$ & {$\left[\mathrm{mgDQO} \cdot \mathrm{L}^{-1}\right]$} & - & & - & & 2994 & \pm & 258 & $(8)$ \\
\hline$\varepsilon_{\mathrm{ST}}$ & {$[\%]$} & - & & - & & 18 & \pm & 5 & $(9)$ \\
\hline$\varepsilon_{\mathrm{SF}}$ & {$[\%]$} & - & & - & & 18 & \pm & 7 & $(8)$ \\
\hline $\mathrm{pH}$ & {$[\mathrm{u}]$} & 6,1 & \pm & 0,1 & ( 11 ) & 4,3 & \pm & 0,2 & $(11)$ \\
\hline AVT & {$\left[\mathrm{mgHAc} . \mathrm{L}^{-1]}\right.$} & 27 & \pm & 10 & ( 11 ) & 715 & \pm & 71 & $(11)$ \\
\hline AT & {$\left[\mathrm{mgCACO}_{3} \cdot \mathrm{L}^{-1}\right]$} & 253 & \pm & 42 & (11) & 29 & \pm & 40 & $(11)$ \\
\hline AP & {$\left[\mathrm{mgCACO}_{3} \cdot \mathrm{L}^{-1}\right]$} & 146 & \pm & 43 & (11) & 0 & \pm & 0 & $(11)$ \\
\hline AI & {$\left[\mathrm{mgCACO}_{3} \cdot \mathrm{L}^{-1}\right]$} & 108 & \pm & 20 & ( 11 ) & 29 & \pm & 40 & $(11)$ \\
\hline $\mathrm{AB}$ & {$\left[\mathrm{mgCACO}_{3} \cdot \mathrm{L}^{-1]}\right.$} & 234 & \pm & 45 & (11) & 0 & \pm & 0 & $(11)$ \\
\hline ST & {$\left[\mathrm{mg} . \mathrm{L}^{-1}\right]$} & 5201 & \pm & 77 & $(3)$ & 3207 & \pm & 287 & $(3)$ \\
\hline SVT & {$\left[\mathrm{mg} . \mathrm{L}^{-1}\right]$} & 3724 & \pm & 91 & $(3)$ & 1837 & \pm & 381 & $(3)$ \\
\hline SST & {$\left[\mathrm{mg} . \mathrm{L}^{-1}\right]$} & 87 & \pm & 3 & $(3)$ & 83 & \pm & 32 & $(3)$ \\
\hline SSV & {$\left[\mathrm{mg} . \mathrm{L}^{-1}\right]$} & 72 & \pm & 24 & $(3)$ & 75 & \pm & 25 & $(3)$ \\
\hline $\mathrm{M}_{\mathrm{SVT}}$ & {$[\mathrm{g}]$} & - & & - & & - & & - & \\
\hline $\mathrm{C}_{\mathrm{X} \text {-SVT }}^{\prime}$ & [g.g-suporte ${ }^{-1}$ ] & - & & - & & - & & - & \\
\hline $\mathrm{C}_{\mathrm{X}-\mathrm{svT}}$ & {$\left[\mathrm{g} \cdot \mathrm{L}^{-1}\right]$} & - & & - & & - & & - & \\
\hline $\mathrm{COAV}_{\mathrm{CT}}$ & {$\left[\mathrm{kgSAC} \cdot \mathrm{m}^{-3} \cdot \mathrm{d}^{-1}\right]$} & 8,18 & & - & & - & & - & \\
\hline $\mathrm{COAV}_{\mathrm{ST}}$ & {$\left[\mathrm{kgDQO} \cdot \mathrm{m}^{-3} \cdot \mathrm{d}^{-1}\right]$} & 9,11 & & - & & - & & - & \\
\hline $\mathrm{COAE}_{\mathrm{CT}}$ & {$\left[\mathrm{kgSAC} \cdot \mathrm{kgSVT}^{-1} \cdot \mathrm{d}^{-1}\right]$} & - & & - & & - & & - & \\
\hline $\mathrm{COAE}_{\mathrm{ST}}$ & {$\left[\mathrm{kgDQO} \cdot \mathrm{kgSVT}^{-1} \cdot \mathrm{d}^{-1}\right]$} & - & & - & & - & & - & \\
\hline $\mathrm{CORV}_{\mathrm{CF}}$ & {$\left[\mathrm{kgSAC} \cdot \mathrm{m}^{-3} \cdot \mathrm{d}^{-1}\right]$} & - & & - & & 7,58 & & - & \\
\hline $\mathrm{CORV}_{\mathrm{SF}}$ & {$\left[\mathrm{kgDQO} \cdot \mathrm{m}^{-3} \cdot \mathrm{d}^{-1}\right]$} & - & & - & & 1,62 & & - & \\
\hline $\mathrm{CORE}_{\mathrm{CF}}$ & {$\left[\mathrm{kgSAC} \cdot \mathrm{kgSVT}^{-1} \cdot \mathrm{d}^{-1}\right]$} & - & & - & & - & & - & \\
\hline $\mathrm{CORE}_{\mathrm{SF}}$ & {$\left[\mathrm{kgDQO} \cdot \mathrm{kgSVT}^{-1} \cdot \mathrm{d}^{-1}\right]$} & - & & - & & - & & - & \\
\hline $\mathrm{n}_{\mathrm{H} 2}$ & {$\left[\mathrm{molH}_{2} \cdot \mathrm{d}^{-1}\right]$} & - & & - & & - & & - & \\
\hline PrM & {$\left[\mathrm{molH}_{2} \cdot \mathrm{m}^{-3} \cdot \mathrm{d}^{-1}\right]$} & - & & - & & - & & - & \\
\hline PrME & {$\left[\mathrm{molH}_{2} \cdot \mathrm{kgSVT}^{-1} \cdot \mathrm{d}^{-1}\right]$} & - & & - & & - & & - & \\
\hline $\mathrm{RMCA}_{\mathrm{C}, \mathrm{n}}$ & {$\left[\mathrm{molH}_{2} \cdot \mathrm{kgSAC}^{-1}\right]$} & - & & - & & - & & - & \\
\hline $\mathrm{RMCA}_{\mathrm{S}, \mathrm{n}}$ & {$\left[\mathrm{molH}_{2} \cdot \mathrm{kgDQO}^{-1}\right]$} & - & & - & & - & & - & \\
\hline $\mathrm{RMCR}_{\mathrm{C}, \mathrm{n}}$ & {$\left[\mathrm{molH}_{2} \cdot \mathrm{kgSAC}^{-1}\right]$} & - & & - & & - & & - & \\
\hline $\mathrm{RMCR}_{\mathrm{S}, \mathrm{n}}$ & {$\left[\mathrm{molH}_{2} \cdot \mathrm{kgDQO}^{-1}\right]$} & - & & - & & - & & - & \\
\hline $\mathrm{V}_{\mathrm{A}}$ & {$[\mathrm{L}]$} & 1,5 & & & & & & & \\
\hline $\mathrm{V}_{\mathrm{R}}$ & {$[\mathrm{L}]$} & 3,6 & & & & & & & \\
\hline
\end{tabular}

(*) Entre parêntese o número de amostras considerado no cálculo da média 
Os dados coletados mostram uma estabilização rápida do reator na conversão da sacarose. As curvas das concentrações residuais em sacarose no efluente filtrado e total (Figura 5.1) e de eficiência de remoção na forma filtrada e total (Figura 5.2) seguiram um regime transiente até o décimo dia tempo a partir de qual se estabilizaram. O reator foi eficiente na conversão da sacarose apresentando concentrações residuais baixas e assim eficiência de remoção média de $91 \%$ e 93\% na forma total e filtrada, respectivamente. $O$ reator apresentou uma baixa eficiência na remoção de DQO, conforme mostram a Figura 5.3 do monitoramento das concentrações afluente e efluentes (totais e filtradas) e a Figura 5.4 do monitoramento das eficiências de remoção na forma total e filtrada. As figuras mostram uma estabilização da remoção em volta de um valor médio de $18 \%$ de remoção na forma filtrada.

A Figura 5.5 mostra um acúmulo estável de ácidos voláteis ao longo da condição. Estes ácidos inicialmente ausentes do afluente foram produzidos pelo metabolismo. A concentração média no efluente filtrado foi de $715 \mathrm{mgHAc} . \mathrm{L}^{-1}$. O acumulo de ácidos no reator levou a uma diminuição do pH da fase líquida conforme pode ser observado na Figura 5.6. O valor médio do $\mathrm{pH}$ efluente foi 4,3. A produção de ácidos provocou um consumo da alcalinidade total presente no afluente. Conforme pode ser observado na Figura 5.7, a alcalinidade total no efluente se estabilizou em valores baixos ou nulos quando toda alcalinidade afluente foi consumida, os valores médios efluentes e afluente foram de $29 \mathrm{mgCaCO}_{3} \cdot \mathrm{L}^{-1}$ e $253 \mathrm{mgCaCO}_{3} \cdot \mathrm{L}^{-1}$, respectivamente. 


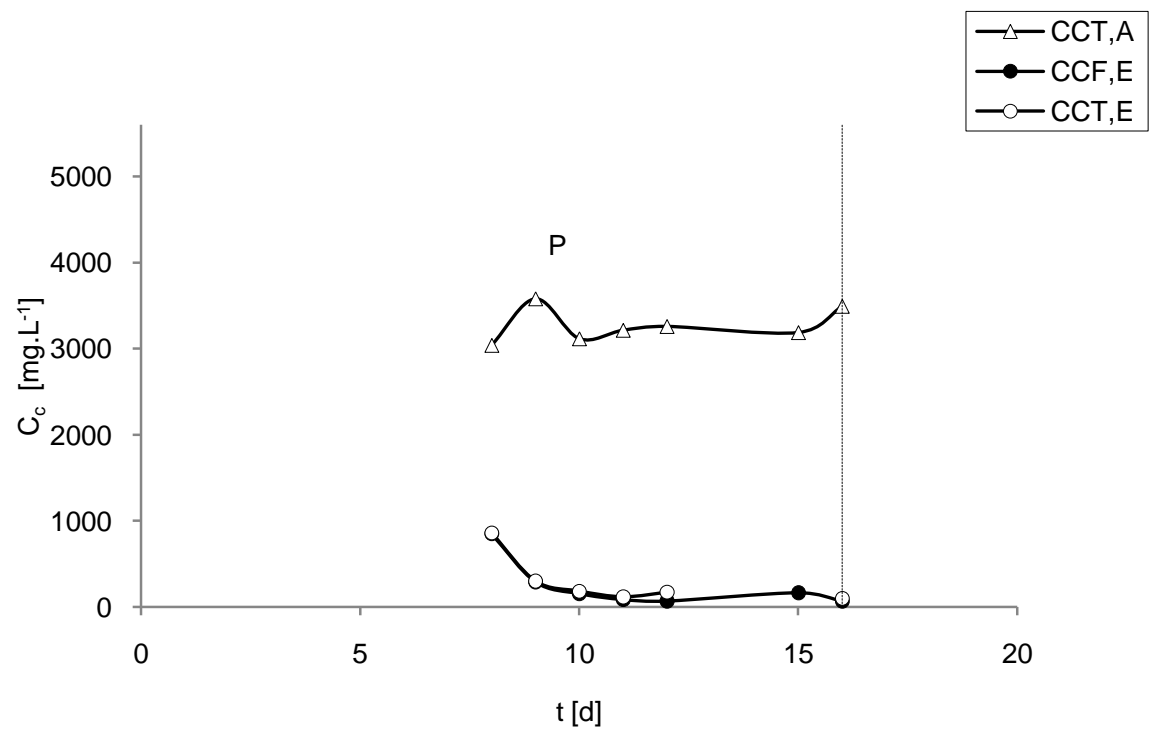

Figura 5.1- Concentrações em carboidratos no afluente e efluente total e filtrado - Condição preliminar.

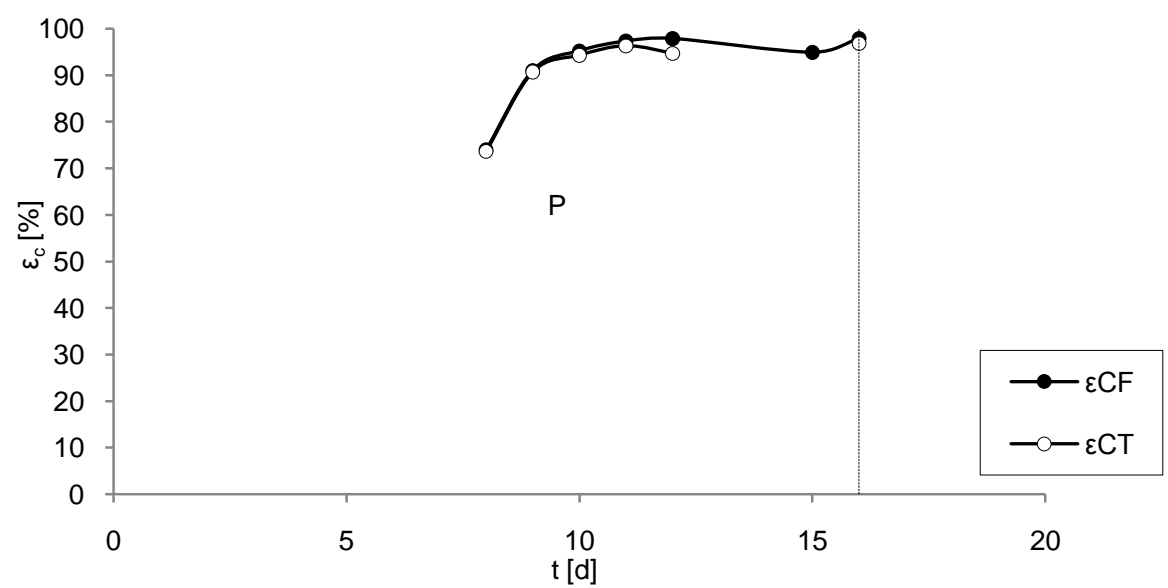

Figura 5.2 - Eficiências de conversão dos carboidratos na forma total e filtrada - Condição preliminar. 


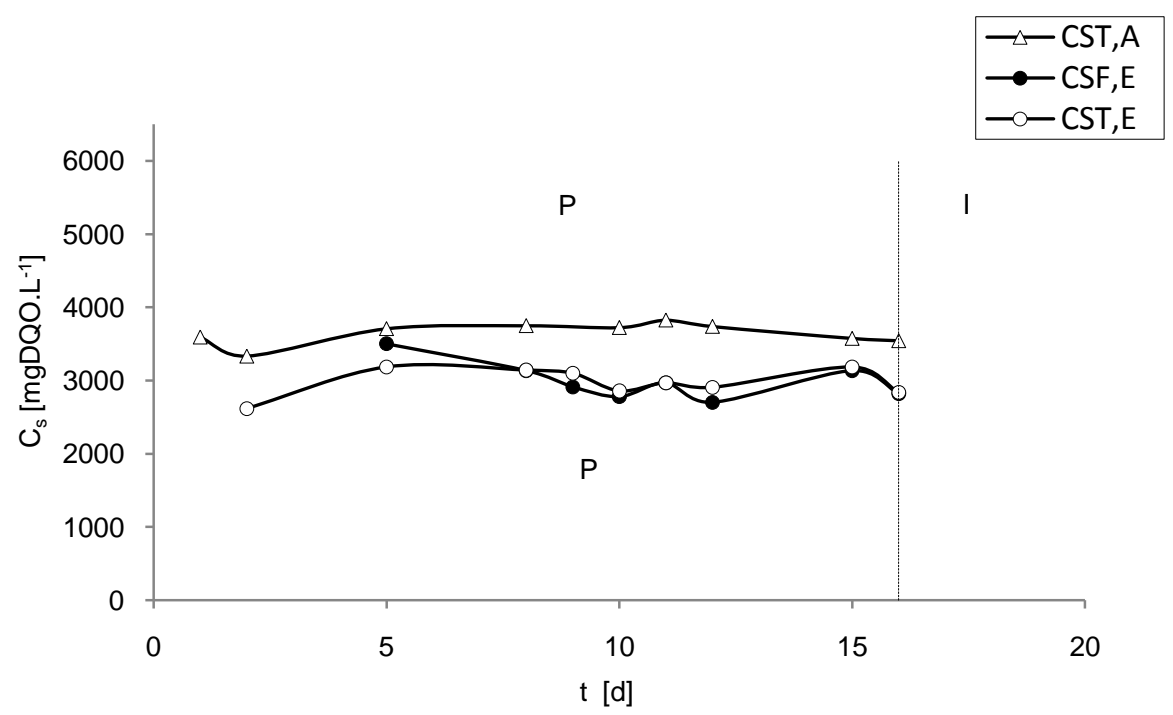

Figura 5.3 - Concentrações em DQO no afluente e efluente total e filtrado- Condição preliminar.

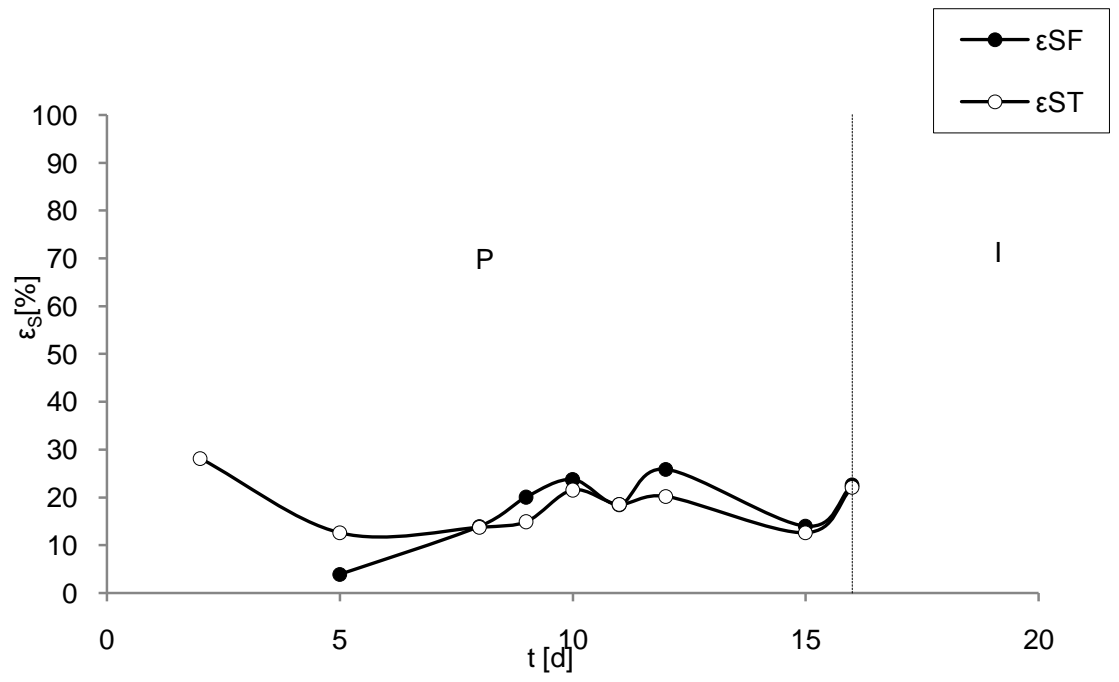

Figura 5.4 - Eficiências de remoção da DQO na forma total e filtrada- Condição preliminar. 


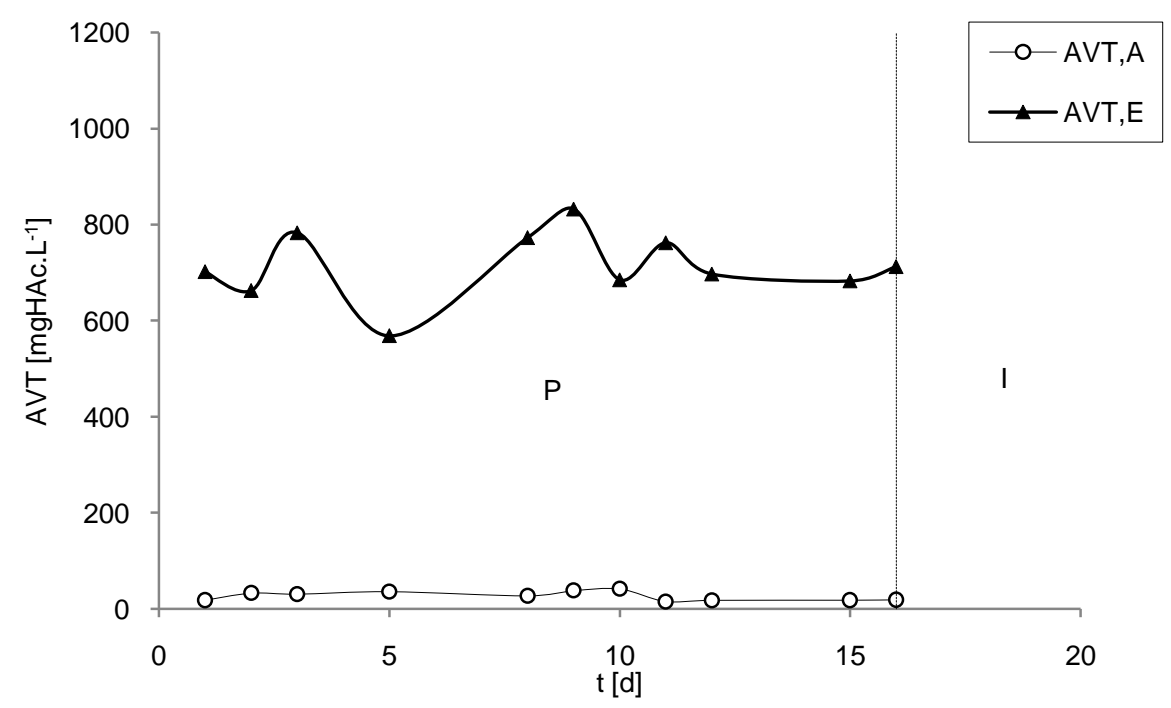

Figura 5.5- Concentrações em ácidos volateís totais por titulação no afluente e efluente - Condição preliminar.

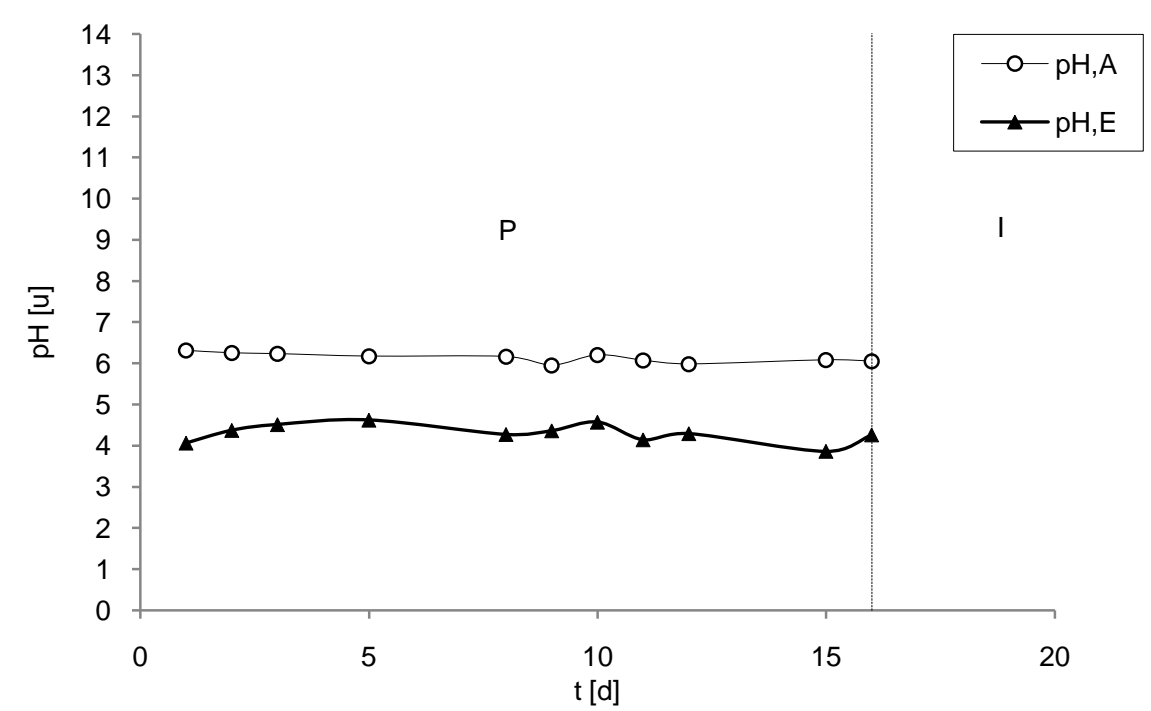

Figura 5.6 - pH afluente e efluente - Condição preliminar. 


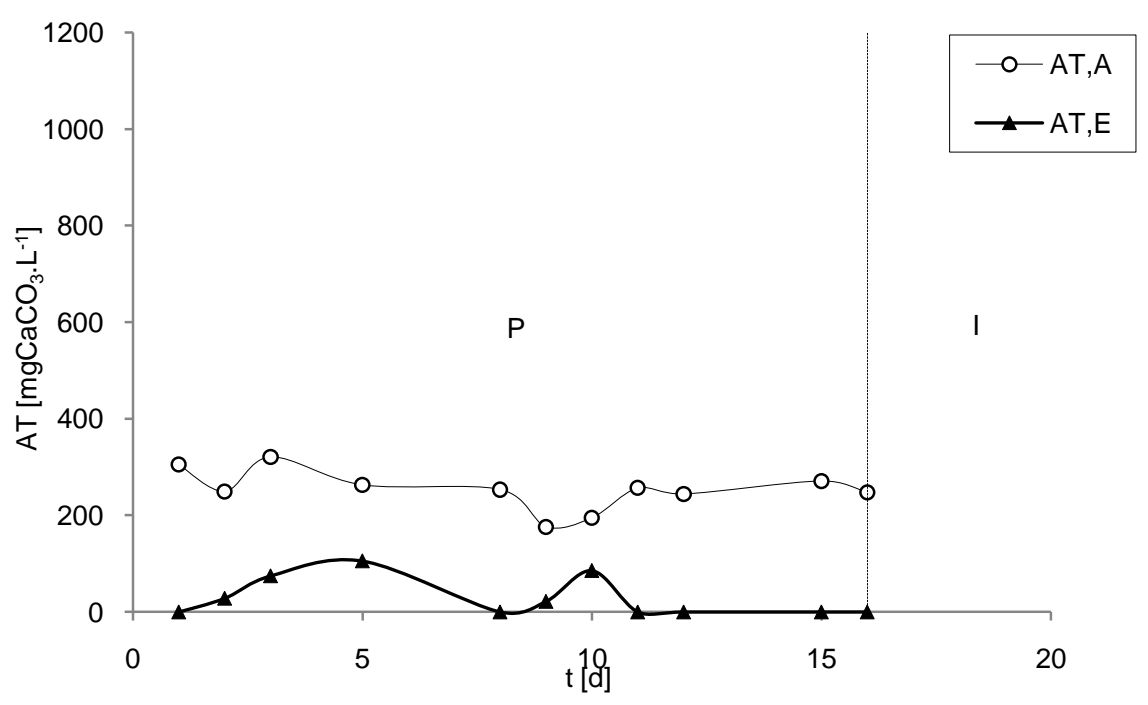

Figura 5.7 - Alcalinidades totais por titulação no afluente e efluente - Condição preliminar.

Esta condição permitiu acompanhar a estabilização do reator e ajustar os procedimentos e métodos experimentais. Ao termino dela, não foram modificados os parâmetros operacionais e foram considerados como confiáveis os dados coletados. 


\subsection{Condição experimental I (DQO 3600 mg.L $\mathrm{L}^{-1}$ - TC 4h)}

\subsubsection{Monitoramento}

A Tabela 5.2 apresenta os valores médios durante os 45 dias de monitoramento da condição I. O reator apresentou uma boa capacidade de retenção da biomassa com valores de sólidos volteis totais e filtrados efluentes da ordem de grandeza dos valores afluentes.

A quantidade de biomassa presente no reator considerada nos cálculos de cargas orgânicas específicas foi admitida igual ao valor determinado no final da Condição II. Esta hipótese foi adotada no intuito de não desmontar o reator depois de cada condição, o que poderia levar a um desequilíbrio da estabilidade do reator. As cargas orgânicas volumétricas aplicadas reais durante a operação foram de $8,13 \mathrm{kgSAC} \cdot \mathrm{m}^{-3} \cdot \mathrm{d}^{-1}$ e $9,28 \mathrm{kgDQO} \cdot \mathrm{m}^{-3} \cdot \mathrm{d}^{-1}$, considerando a sacarose e a DQO respectivamente (valores nominais de $8,0 \mathrm{kgSAC} \cdot \mathrm{m}^{-3} \cdot \mathrm{d}^{-1} \mathrm{e} 9,0 \mathrm{kgDQO} \cdot \mathrm{m}^{-3} \cdot \mathrm{d}^{-1}$ ). 
Tabela 5.2- Valores médios dos parâmetros monitorados Condição I (DQO 3600 mg.L-1 -TC 4h).

\begin{tabular}{|c|c|c|c|c|c|c|c|c|c|c|c|}
\hline \multicolumn{2}{|r|}{ Parâmetro } & \multicolumn{3}{|c|}{ Afluente } & \multicolumn{7}{|c|}{ Efluente } \\
\hline$\overline{\mathrm{C}_{\mathrm{CT}}}$ & {$\left[\mathrm{mgSAC} . \mathrm{L}^{-1}\right]$} & 3250 & \pm & 189 & & $24 \quad$ & 163 & \pm & 82 & & $23 \quad$ \\
\hline $\mathrm{C}_{\mathrm{CF}}$ & {$\left[\operatorname{mgSAC} . \mathrm{L}^{-1}\right]$} & - & & - & & & 95 & \pm & 63 & ( & $24 \quad)$ \\
\hline$\varepsilon_{\mathrm{CT}}$ & [\%] & - & & - & & & 95 & \pm & 3 & ( & $23 \quad)$ \\
\hline$\varepsilon_{\mathrm{CF}}$ & {$[\%]$} & - & & - & & & 97 & \pm & 2 & ( & $24 \quad)$ \\
\hline $\mathrm{C}_{\mathrm{ST}}$ & {$\left[\mathrm{mgDQO} . \mathrm{L}^{-1}\right]$} & 3711 & \pm & 126 & $(2$ & $23 \quad)$ & 3089 & \pm & 178 & ( & $23 \quad$ \\
\hline $\mathrm{C}_{\mathrm{SF}}$ & {$\left[\mathrm{mgDQO} . \mathrm{L}^{-1}\right]$} & - & & - & & & 2951 & \pm & 123 & ( & $23 \quad$ \\
\hline$\varepsilon_{\mathrm{ST}}$ & {$[\%]$} & - & & - & & & 17 & \pm & 5 & ( & $23 \quad$ \\
\hline$\varepsilon_{\mathrm{SF}}$ & {$[\%]$} & - & & - & & & 20 & \pm & 3 & ( & $23)$ \\
\hline $\mathrm{pH}$ & {$[\mathrm{u}]$} & 6,5 & \pm & 0,2 & $(2$ & $23 \quad)$ & 4,5 & \pm & 0,3 & ( & $23 \quad)$ \\
\hline AVT & {$\left[\mathrm{mgHAc} . \mathrm{L}^{-1]}\right.$} & 23 & \pm & 7 & $(2$ & $23 \quad)$ & 735 & \pm & 64 & ( & $23)$ \\
\hline AT & {$\left[\mathrm{mgCACO}_{3} \cdot \mathrm{L}^{-1}\right]$} & 384 & \pm & 131 & $(2$ & $23 \quad)$ & 122 & \pm & 142 & ( & $23 \quad$ \\
\hline $\mathrm{AP}$ & {$\left[\mathrm{mgCACO}_{3} \cdot \mathrm{L}^{-1}\right]$} & 268 & \pm & 103 & $(2$ & $23 \quad$ & 0 & \pm & 0 & ( & $23 \quad)$ \\
\hline AI & {$\left[\mathrm{mgCACO}_{3} \cdot \mathrm{L}^{-1}\right]$} & 116 & \pm & 36 & $(2$ & $23 \quad$ & 122 & \pm & 142 & ( & $23 \quad$ \\
\hline $\mathrm{AB}$ & {$\left[\mathrm{mgCACO}_{3} \cdot \mathrm{L}^{-1]}\right.$} & 368 & \pm & 129 & $(2$ & $23 \quad)$ & 0 & \pm & 0 & ( & $23 \quad)$ \\
\hline ST & {$\left[\mathrm{mg} . \mathrm{L}^{-1}\right]$} & 4653 & \pm & 374 & ( & $7 \quad$ & 2620 & \pm & 245 & ( & 7 ) \\
\hline SVT & {$\left[\mathrm{mg} \cdot \mathrm{L}^{-1}\right]$} & 3648 & \pm & 241 & ( & $7 \quad$ & 1628 & \pm & 220 & ( & $7)$ \\
\hline SST & {$\left[\mathrm{mg} \cdot \mathrm{L}^{-1}\right]$} & 78 & \pm & 17 & ( & $7 \quad$ & 216 & \pm & 111 & ( & $7)$ \\
\hline SSV & {$\left[\mathrm{mg} \cdot \mathrm{L}^{-1}\right]$} & 55 & \pm & 47 & ( & $7 \quad$ & 194 & \pm & 109 & ( & $7)$ \\
\hline $\mathrm{M}_{\mathrm{SVT}}$ & {$[\mathrm{g}]$} & - & & - & & & 24,50 & & - & & \\
\hline $\mathrm{C}_{\mathrm{X}-\mathrm{SVT}}^{\prime}$ & [g.g-suporte ${ }^{-1}$ ] & - & & - & & & 0,02 & & - & & \\
\hline $\mathrm{C}_{\mathrm{X} \text {-svT }}$ & {$\left[\mathrm{g} . \mathrm{L}^{-1}\right]$} & - & & - & & & 6,81 & & - & & \\
\hline $\operatorname{COAV}_{\mathrm{CT}}$ & {$\left[\mathrm{kgSAC} \cdot \mathrm{m}^{-3} \cdot \mathrm{d}^{-1}\right]$} & 8,13 & & - & & & - & & - & & \\
\hline $\operatorname{COAV}_{\mathrm{ST}}$ & {$\left[\mathrm{kgDQO} \cdot \mathrm{m}^{-3} \cdot \mathrm{d}^{-1}\right]$} & 9,28 & & - & & & - & & - & & \\
\hline $\mathrm{COAE}_{\mathrm{CT}}$ & {$\left[\mathrm{kgSAC} \cdot \mathrm{kgSVT}^{-1} \cdot \mathrm{d}^{-1}\right]$} & 1,19 & & - & & & - & & - & & \\
\hline $\mathrm{COAE}_{\mathrm{ST}}$ & {$\left[\mathrm{kgDQO} \cdot \mathrm{kgSVT}^{-1} \cdot \mathrm{d}^{-1}\right]$} & 1,36 & & - & & & - & & - & & \\
\hline $\mathrm{CORV}_{\mathrm{CF}}$ & {$\left[\mathrm{kgSAC} \cdot \mathrm{m}^{-3} \cdot \mathrm{d}^{-1}\right]$} & - & & - & & & 7,89 & & - & & \\
\hline $\mathrm{CORV}_{\mathrm{SF}}$ & {$\left[\mathrm{kgDQO} \cdot \mathrm{m}^{-3} \cdot \mathrm{d}^{-1}\right]$} & - & & - & & & 1,90 & & - & & \\
\hline $\mathrm{CORE}_{\mathrm{CF}}$ & {$\left[\mathrm{kgSAC} \cdot \mathrm{kgSVT}^{-1} \cdot \mathrm{d}^{-1}\right]$} & - & & - & & & 1,16 & & - & & \\
\hline $\mathrm{CORE}_{\mathrm{SF}}$ & {$\left[\mathrm{kgDQO} \cdot \mathrm{kgSVT}^{-1} \cdot \mathrm{d}^{-1}\right]$} & - & & - & & & 0,28 & & - & & \\
\hline $\mathrm{n}_{\mathrm{H} 2}$ & {$\left[\mathrm{molH}_{2} \cdot \mathrm{d}^{-1}\right]$} & - & & - & & & 0,07 & & - & & $2)$ \\
\hline PrM & {$\left[\mathrm{molH}_{2} \cdot \mathrm{m}^{-3} \cdot \mathrm{d}^{-1}\right]$} & 10,04 & & - & & & - & & - & & \\
\hline PrME & {$\left[\mathrm{molH}_{2} \cdot \mathrm{kgSVT}^{-1} \cdot \mathrm{d}^{-1}\right]$} & 2,66 & & - & & & - & & - & & \\
\hline $\mathrm{RMCA}_{\mathrm{C}, \mathrm{n}}$ & {$\left[\mathrm{molH}_{2} \cdot \mathrm{kgSAC}^{-1}\right]$} & 2,23 & & - & & & - & & - & & \\
\hline $\mathrm{RMCA}_{\mathrm{S}, \mathrm{n}}$ & {$\left[\mathrm{molH}_{2} \cdot \mathrm{kgDQO}^{-1}\right]$} & 1,95 & & - & & & - & & - & & \\
\hline $\mathrm{RMCR}_{\mathrm{C}, \mathrm{n}}$ & {$\left[\mathrm{molH}_{2} \cdot \mathrm{kgSAC}^{-1}\right]$} & 2,30 & & - & & & - & & - & & \\
\hline $\mathrm{RMCR}_{\mathrm{S}, \mathrm{n}}$ & {$\left[\mathrm{molH}_{2} \cdot \mathrm{kgDQO}^{-1}\right]$} & 9,54 & & - & & & - & & - & & \\
\hline $\mathrm{V}_{\mathrm{A}}$ & {$[\mathrm{L}]$} & 1,5 & & & & & & & & & \\
\hline $\mathrm{V}_{\mathrm{R}}$ & {$[\mathrm{L}]$} & 3,6 & & & & & & & & & \\
\hline
\end{tabular}

(*) Entre parêntese o número de amostras considerado no cálculo da média

$\mathrm{O}$ reator $\mathrm{f}$ eficiente na conoiversão da sacarose apresentando concentrações residuais baixas e eficiência de remoção média de $95 \%$ e $97 \%$ na forma total e filtrada, respectivamente, como pode 
ser observado na Figura 5.8 que mostra as concentrações residuais em sacarose no afluente e efluente (filtrado e total) e na Figura 5.9 que mostra a eficiência de remoção na forma filtrada e total.

O reator apresentou uma baixa eficiência na remoção de DQO, conforme mostram a Figura 5.10 do monitoramento das concentrações afluente e efluentes (totais e filtradas) e a Figura 5.11do monitoramento das eficiências de remoção na forma total e filtrada. A eficiência de remoção ficou estável com um valor médio de $20 \%$ de remoção na forma filtrada e $17 \%$ na forma não filtrada.

A presença de uma alta concentração em DQO residual leva a pensar que a sacarose degradada foi na maior parte convertida em compostos intermediários como alcoóis e ácidos voláteis. A Figura 5.12 mostra um acúmulo de ácidos voláteis totais ao longo da condição. A concentração média no efluente filtrado foi de $735 \mathrm{mgHAc} . \mathrm{L}^{-1}$.

A análise desses compostos intermediários de forma separada foi realizada em triplicata por cromatografia em fase gasosa, cujos resultados são apresentados na Tabela 5.3. Dentre os ácidos voláteis, o ácido Acético predominou seguido pelo ácido Butírico representando respectivamente $50 \%$ e $8,7 \%$ dos compostos intermediários. O efluente apresentou também uma quantidade importante de etanol representando 31,3\% dos compostos intermediários. 


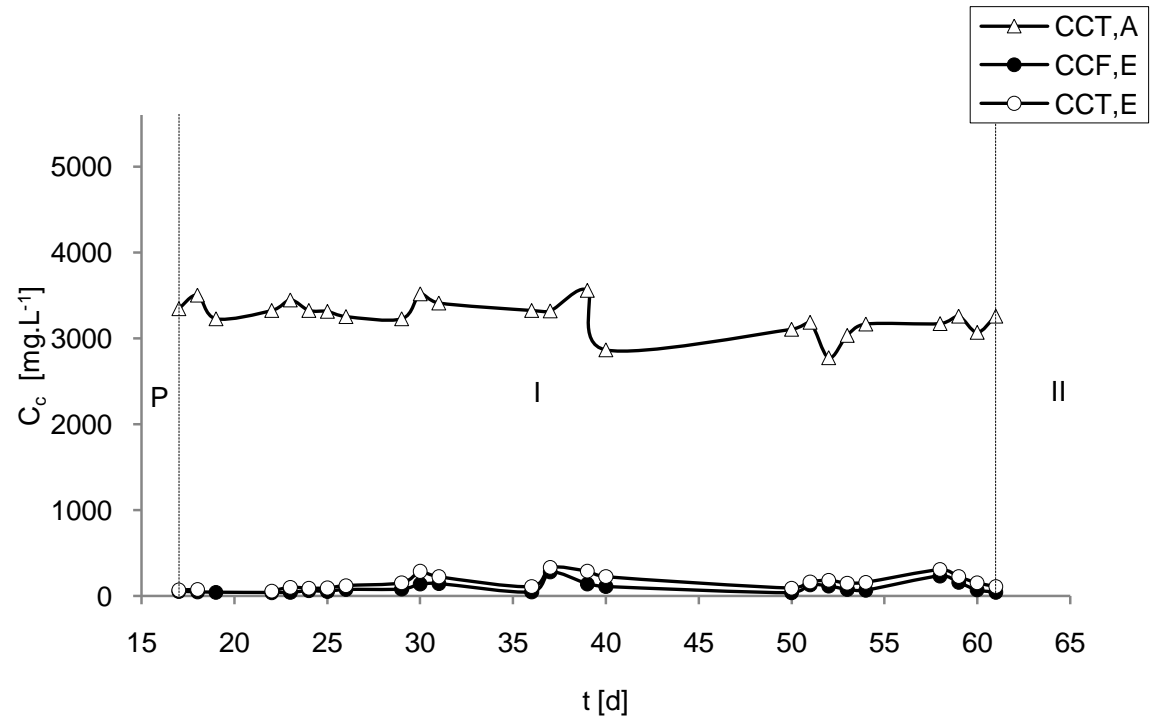

Figura 5.8- Concentrações em carboidratos no afluente e efluente total e filtrado - Condição I.

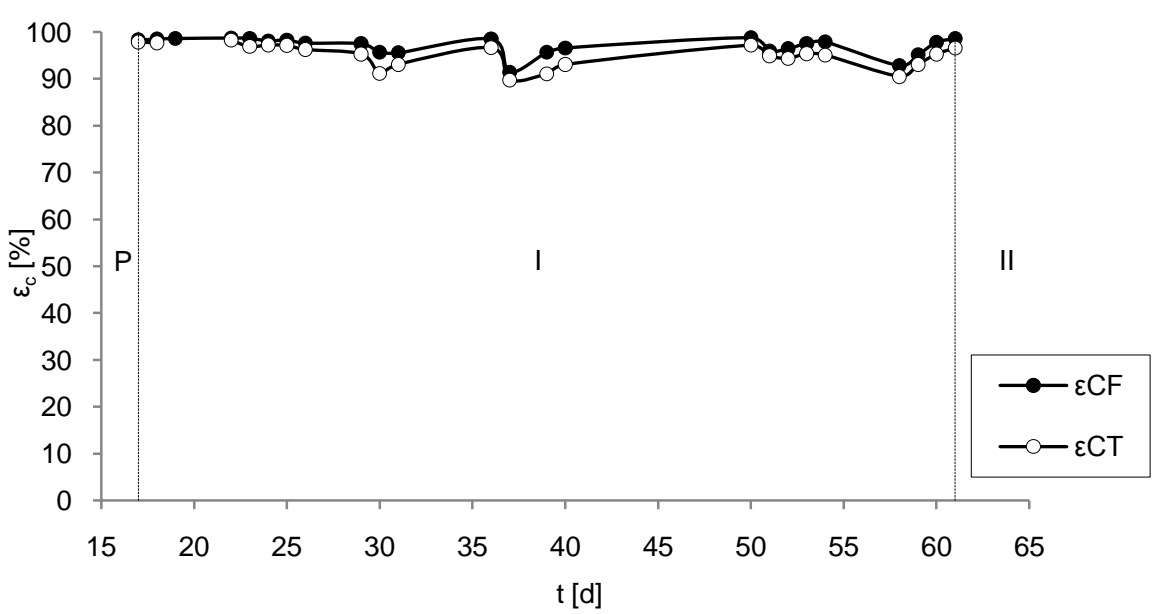

Figura 5.9- Eficiências de conversão dos carboidratos na forma total e filtrada - Condição I. 


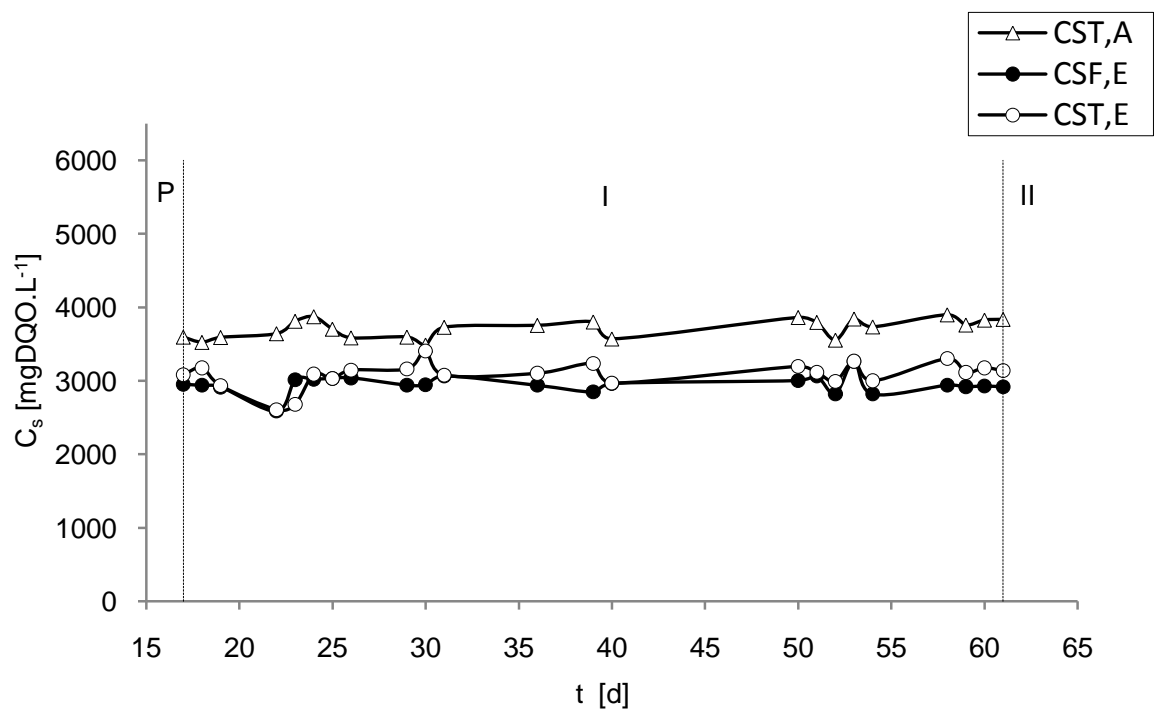

Figura 5.10- Concentrações em DQO no afluente e efluente total e filtrado - Condição I.

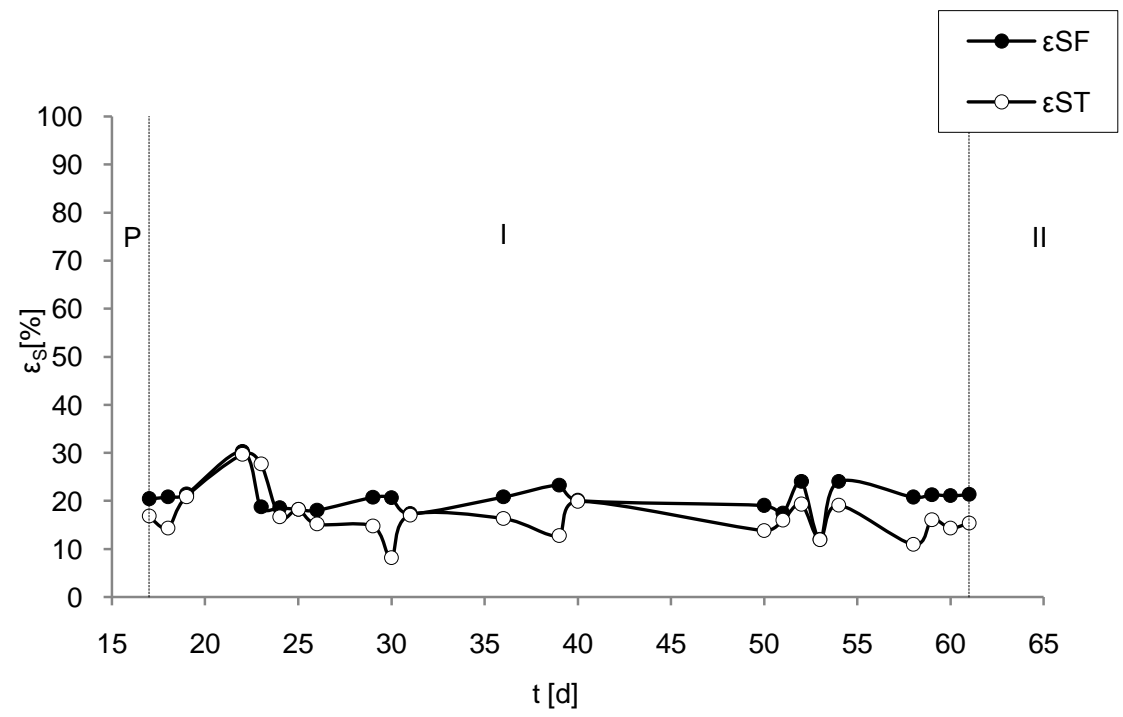

Figura 5.11- Eficiências de remoção da DQO na forma total e filtrada - Condição I 


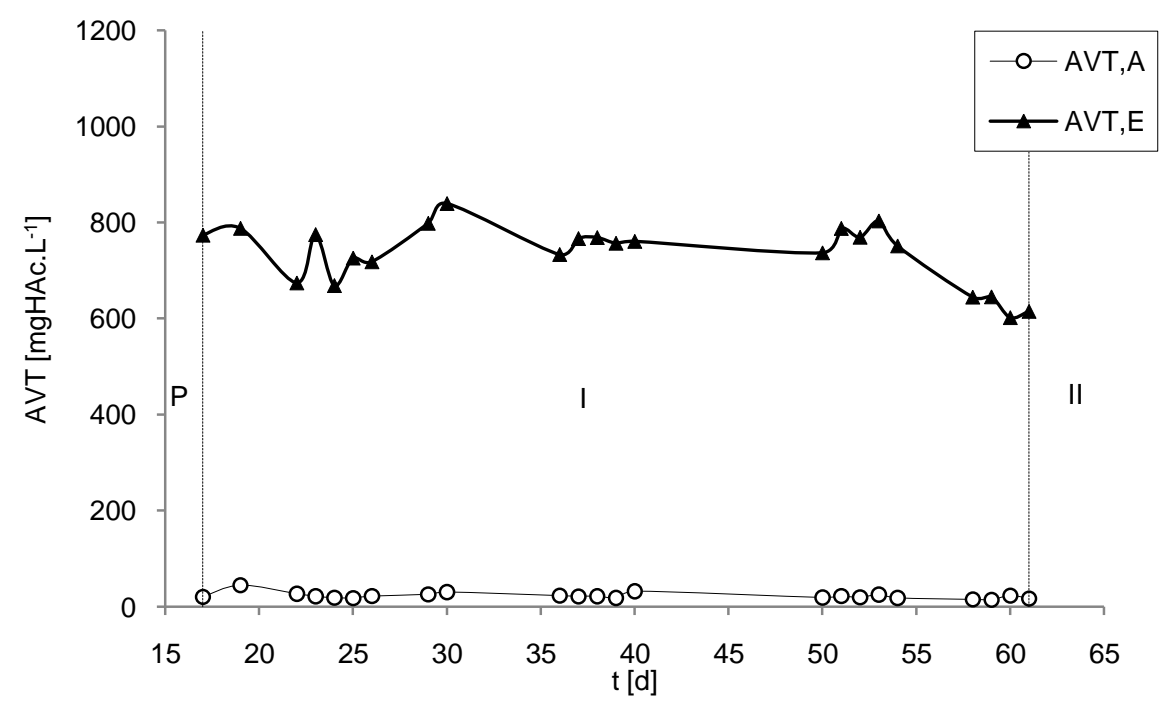

Figura 5.12- Concentrações em ácidos volateís totais por titulação no afluente e efluente - Condição I.

Tabela 5.3- Concentração média e composição dos compostos intermediários - Condição I.

\begin{tabular}{cccccccc}
\hline \multirow{2}{*}{ Espécies } & \multicolumn{3}{c}{ Concentrações média } & \multicolumn{3}{c}{ Repartição } \\
& \multicolumn{3}{c}{$\left[\mathrm{mg} . \mathrm{L}^{-1}\right]$} & \multicolumn{3}{c}{$\left[\begin{array}{c}{\left[\mathrm{mmol} . \mathrm{L}^{-1}\right]} \\
{[\%]}\end{array}\right.$} \\
\hline Acetona & 0,0 & \pm & 0,0 & 0,0 & \pm & 0,0 & 0,0 \\
Metanol & 0,0 & \pm & 0,0 & 0,0 & \pm & 0,0 & 0,0 \\
Etanol & 479,4 & \pm & 54,8 & 10,4 & \pm & 1,2 & 31,3 \\
n-Butanol & 9,9 & \pm & 0,8 & 0,1 & \pm & 0,0 & 0,6 \\
Acético & 765,7 & \pm & 63,9 & 12,8 & \pm & 1,1 & 50,0 \\
Porpiônico & 40,4 & \pm & 4,9 & 0,5 & \pm & 0,1 & 2,6 \\
Isobutírico & 57,6 & \pm & 15,8 & 0,7 & \pm & 0,2 & 3,8 \\
Butírico & 133,8 & \pm & 23,7 & 1,5 & \pm & 0,3 & 8,7 \\
Isovalérico & 7,8 & \pm & 0,7 & 0,1 & \pm & 0,0 & 0,5 \\
Valérico & 12,6 & \pm & 0,3 & 0,1 & \pm & 0,0 & 0,8 \\
Capróico & 24,3 & \pm & 0,1 & 0,2 & \pm & 0,0 & 1,6 \\
\hline
\end{tabular}

$\mathrm{O}$ acúmulo de ácidos no reator levou a uma diminuição do $\mathrm{pH}$ da fase líquida conforme pode ser observado na Figura 5.13. O valor médio do pH efluente foi 4,5. A produção de ácidos também 
resultou em um consumo da alcalinidade total presente no afluente, sendo que os dados coletados podem ser observados na Figura 5.14 do monitoramento da alcalinidade total efluente e afluente.

Depois de 30 dias de operação do sistema (15 dias de operação da Condição I), a composição da água residuária sintética foi modificada. A presença de bicarbonato de sódio no afluente tem como objetivo o tamponamento do sistema, garantindo uma estabilidade e impedindo uma diminuição excessiva do $\mathrm{pH}$ com a produção de metabolitos intermediários ácidos. A correção do pH foi efetuada empiricamente após a preparação do afluente sintético por adição de ácido clorídrico (12 M) no intuito de manter o pH efluente em aproximadamente 5. As concentrações em bicarbonato inicialmente adotadas levavam a um consumo desnecessário de reagente, pois uma quantidade superior de ácido clorídrico era adicionada para consumir o excedente de bicarbonato e assim ajustar o pH. Levando em conta essa consideração, for reformulada a água residuária conforme a Tabela 4.3. A modificação da composição pode ser observada nas curvas de alcalinidade total com a diminuição dos valores a partir do $30^{\circ}$ dia de operação.

A variação da produção de biogás durante um ciclo ao longo da Condição I pode ser observado na Figura 5.15. O volume máximo produzido foi de $1242 \mathrm{~mol} \mathrm{no} 21^{\circ}$ dia de operação do reator $\left(7^{\circ}\right.$ dia de operação da condição), o valor médio de 1146 mL com desvio padrão de $70 \mathrm{~mL}$ indicando uma estabilidade. 


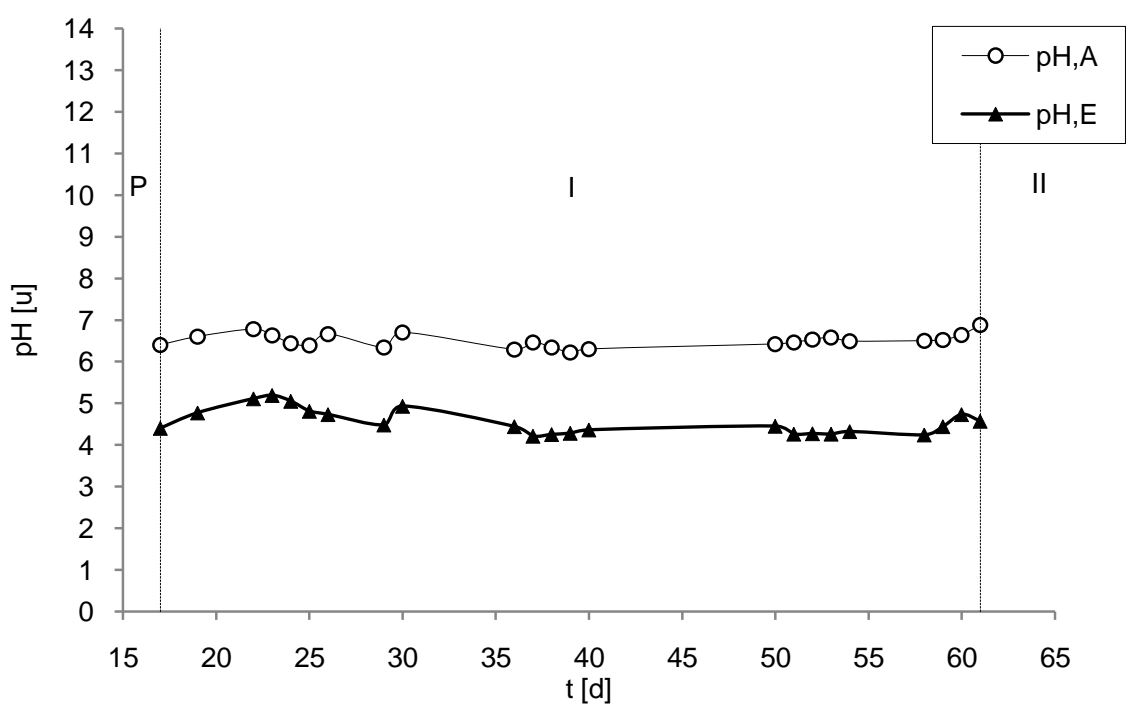

Figura 5.13- pH afluente e efluente - Condição I.

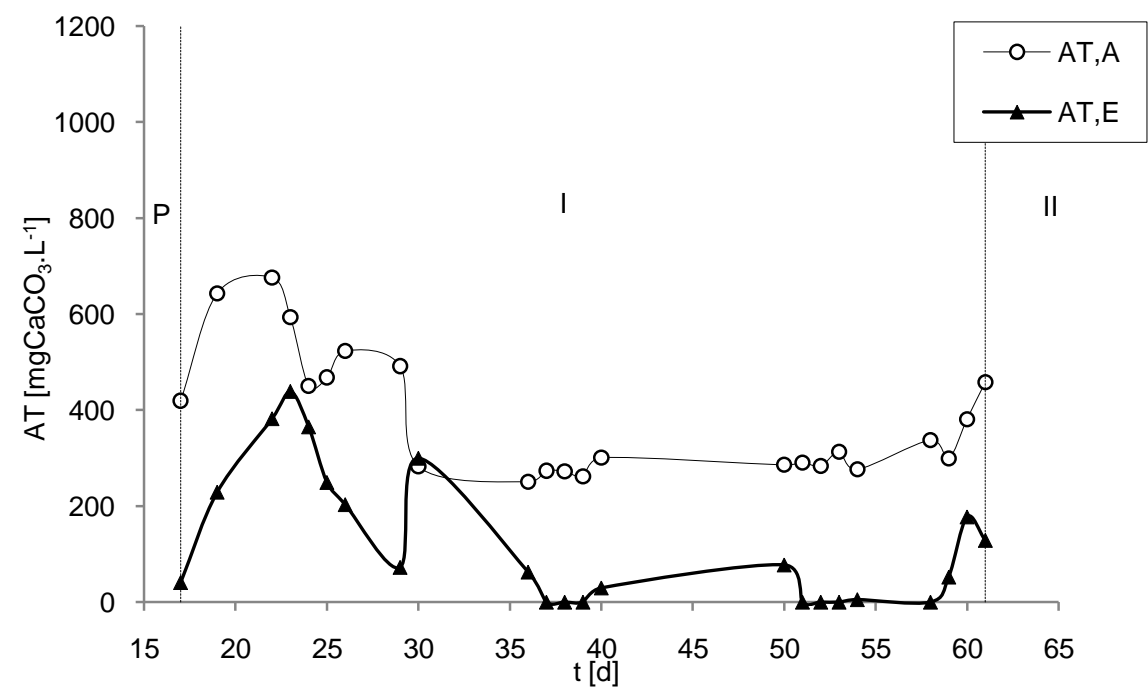

Figura 5.14- Alcalinidades totais por titulação no afluente e efluente - Condição I. 


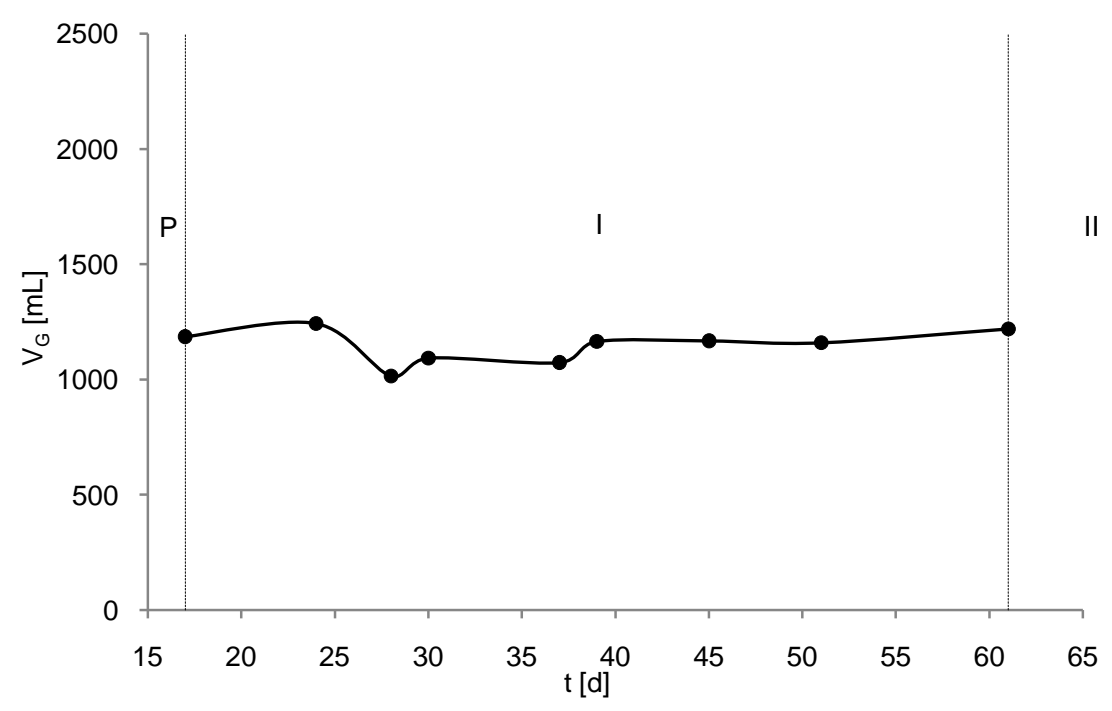

Figura 5.15 - Variação da produção volumétrica de biogás durante um ciclo - Condição I.

\subsubsection{Perfis ao longo do ciclo}

A Figura 5.16 mostra a evolução da concentração em carboidratos totais ao longo do ciclo. Ao iniciou do ciclo (tempo zero) o volume afluente é diluído no volume residual resultando em uma concentração em sacarose da ordem de $1400 \mathrm{mg} \cdot \mathrm{L}^{-1}$. A conversão da sacarose se faz de maneira progressiva ao longo do ciclo. A Figura 5.17 mostra a evolução da concentração em DQO ao longo do ciclo. Pode ser observada uma remoção baixa em DQO, levando a uma alta concentração em DQO no volume residual. Assim, no inicio do ciclo, a diluição do volume carregado pelo volume residual é realizada em proporção bem menor do que no caso dos carboidratos totais, pois as concentrações afluente e residual são muito próximas.

A sacarose degradada é convertida em produtos intermediários do metabolismo anaeróbio. O acúmulo de ácidos voláteis totais ao longo do ciclo pode ser observado na Figura 5.18. A concentração em ácidos voláteis totais aumenta claramente durante a fase de reação para atingir um máximo no final do ciclo. Os resultados dos compostos intermediários por cromatografias em fase gasosas são apresentados na Figura 5.19. Observa se claramente um aumento em ácido acético 
passando de uma concentração inicial de 324,6 mg. $\mathrm{L}^{-1}$ até um máximo de 765,7 mg.L $\mathrm{L}^{-1}$ no final do ciclo.

$\mathrm{O}$ pH diminuiu instantaneamente (em relação ao afluente) com a diluição do afluente com o volume residual no inicio do ciclo (alimentação do reator em 10 minutos) e permaneceu estável ao longo da operação conforme a Figura 5.20. A estabilidade do pH mesmo com a produção de ácidos voláteis é devido ao tamponamento do sistema pelo consumo de alcalinidade ao longo do ciclo. A Figura 5.21 apresenta a evolução da alcalinidade total no reator ao longo do ciclo.

A produção volumétrica acumulada de biogás pode ser observada na Figura 5.22. A maior parte da produção é efetuada no inicio do ciclo e tem uma tendência a se estabilizar no final. A caracterização qualitativa do biogás por cromatografia permite de avaliar os volumes específicos de gases produzidos ao longo do ciclo. A Tabela 5.4 apresenta os resultados obtidos e mostra uma produção acumulada de $244 \mathrm{~mL}$ de hidrogênio (20\%), $974 \mathrm{~mL}$ de dióxido de carbono $(79,8 \%)$ e 3 mL de metano (0,2\%). As curvas relativas à produção de cada gás são apresentadas na Figura 5.23.

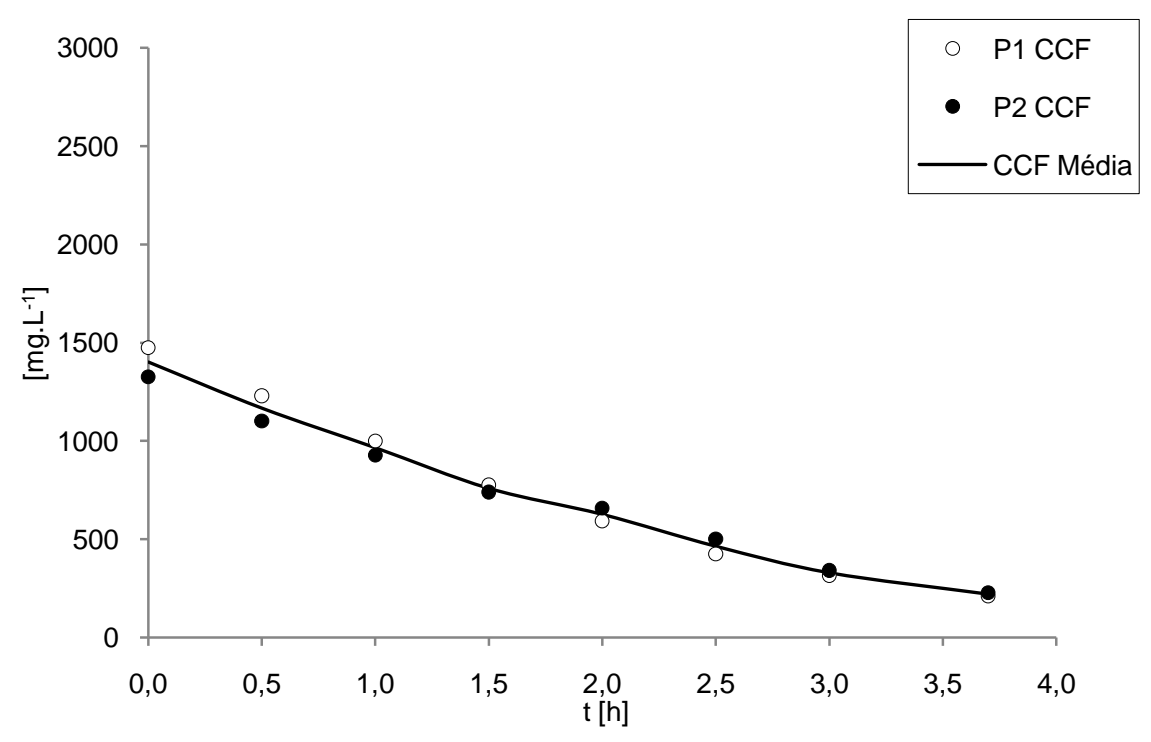

Figura 5.16 - Perfil de evolução da concentração em carboidratos no reator - Condição I. 


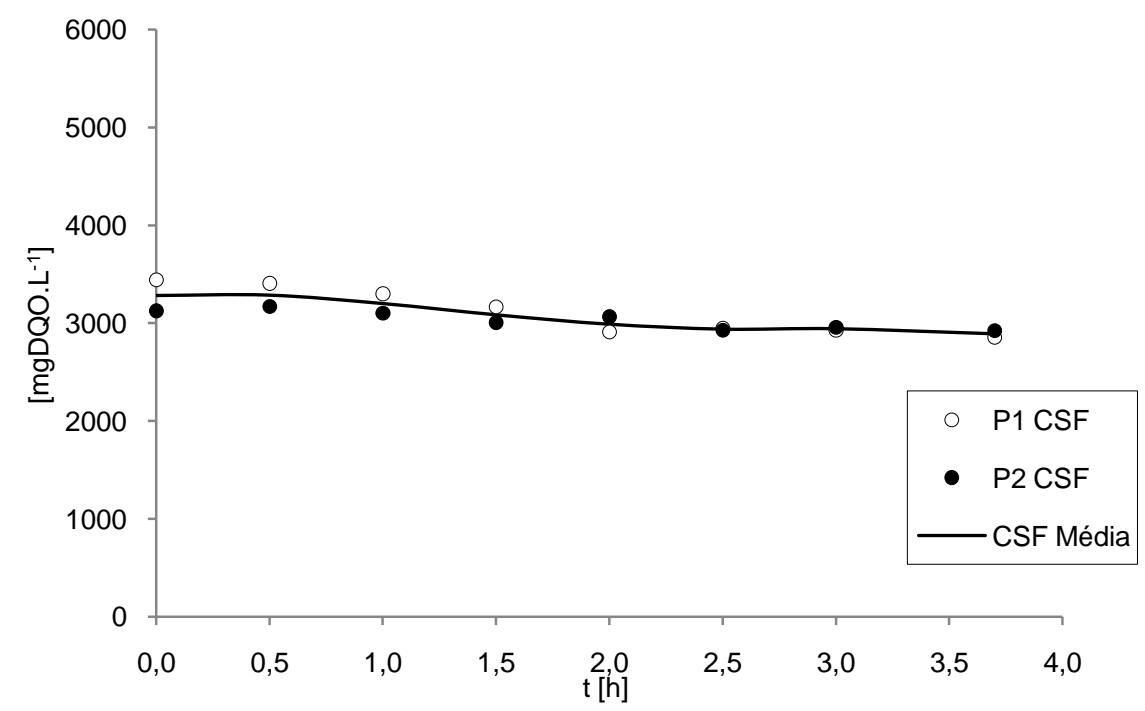

Figura 5.17 - Perfil de evolução da concentração em DQO no reator- Condição I.

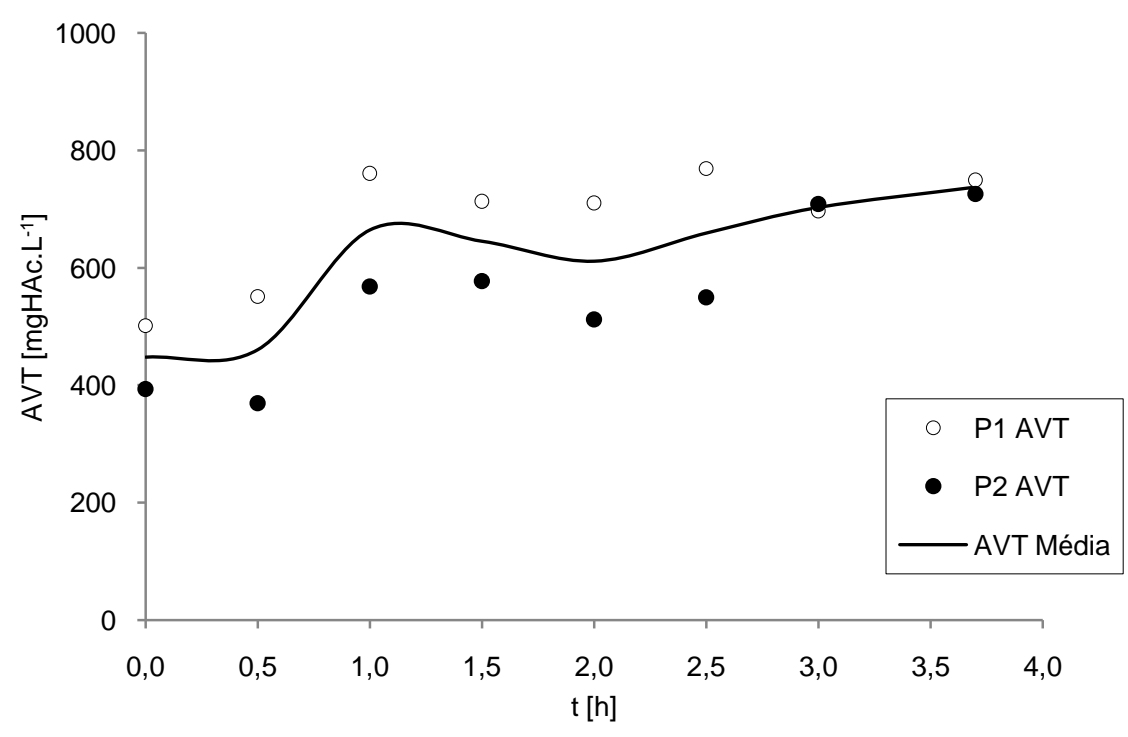

Figura 5.18 - Perfil de evolução da concentração em ácidos volateís totais por titulação no reator - Condição I. 


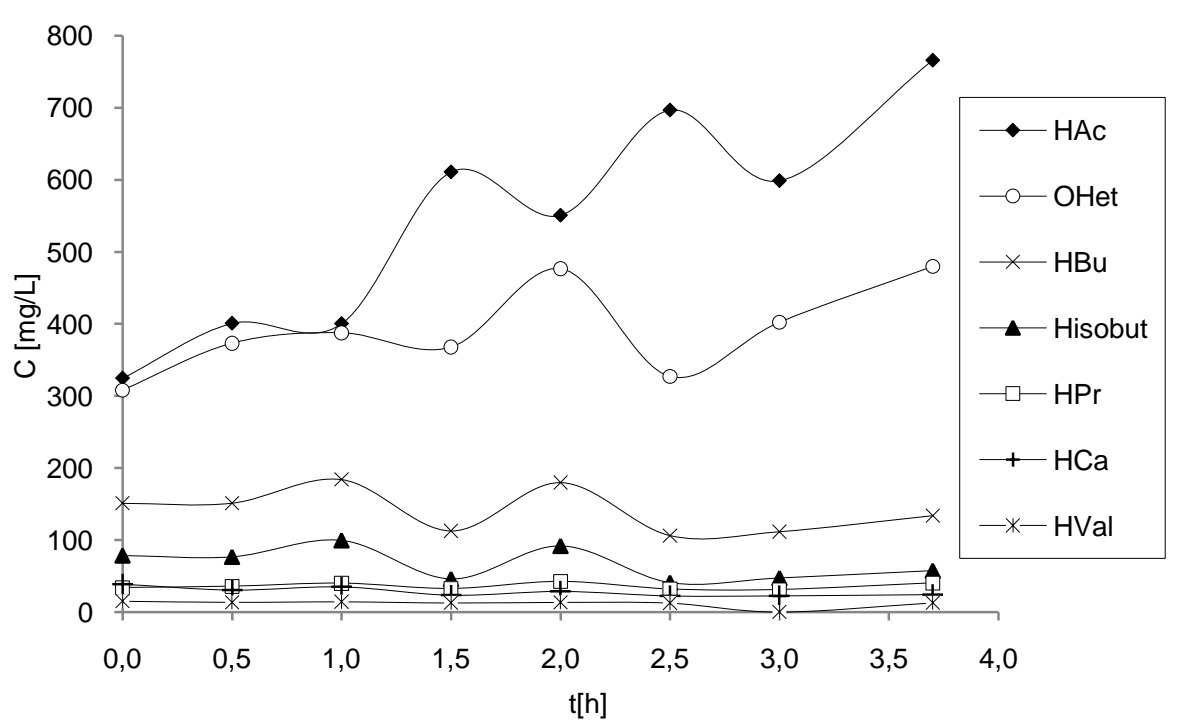

Figura 5.19 - Perfil de evolução das concentrações dos compostos intermediários - Condição I.

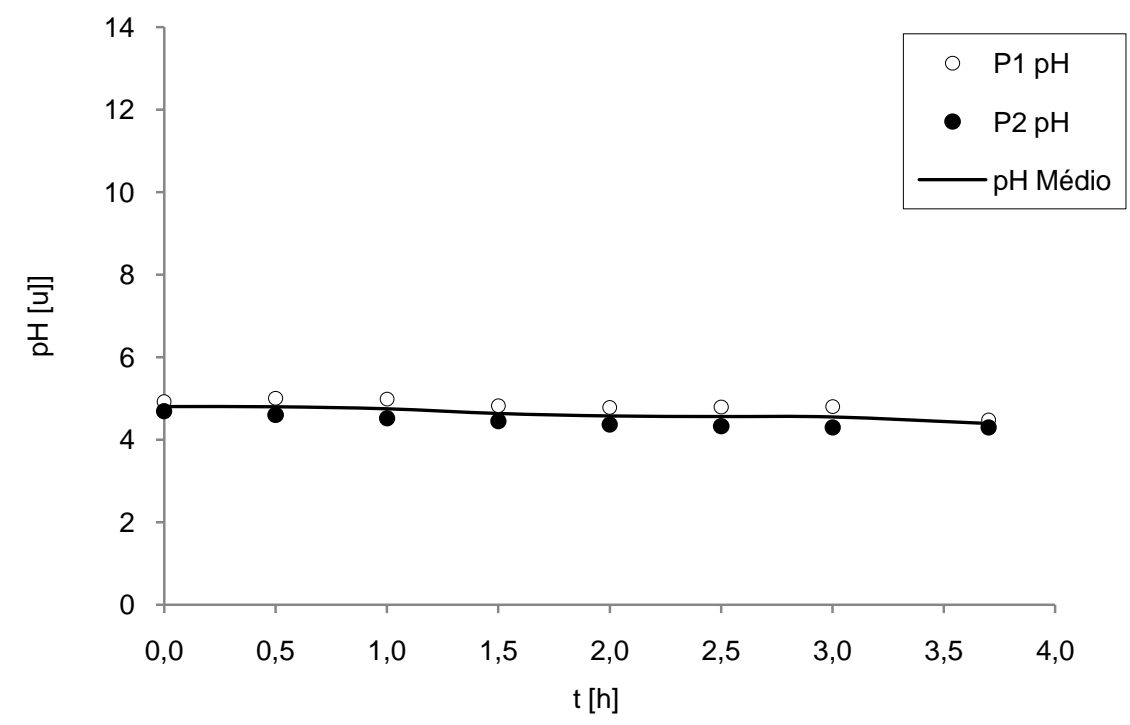

Figura 5.20 - Perfil de evoluçãodo pH no reator- Condição I. 


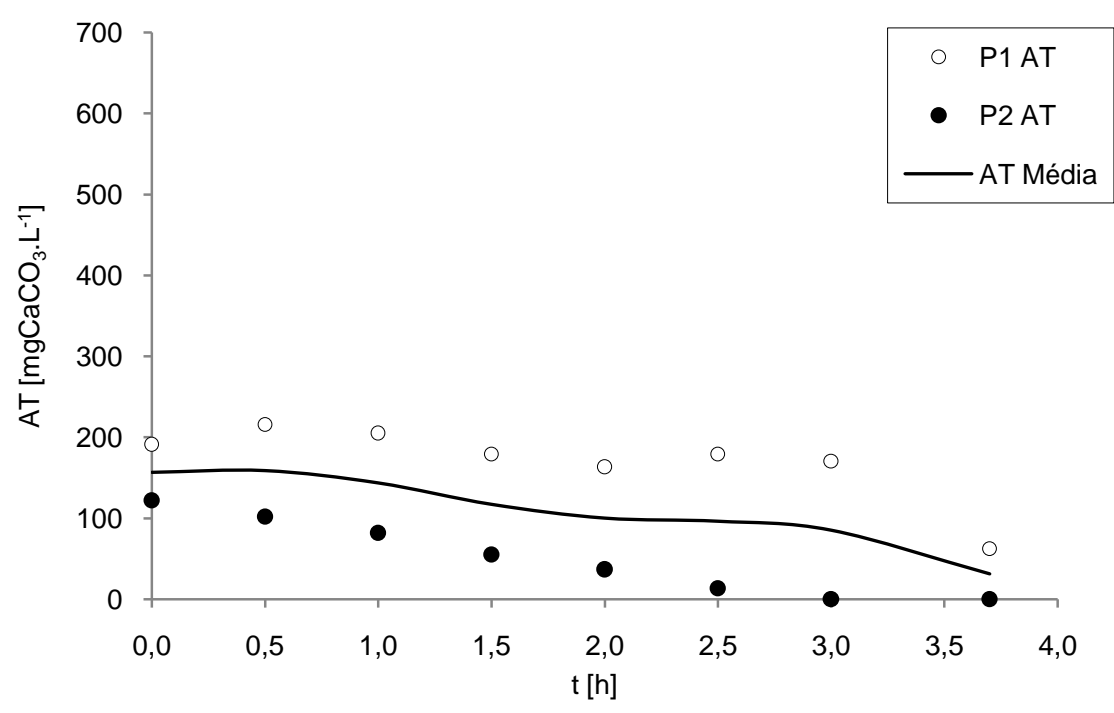

Figura 5.21 - Perfil de evolução da alcalinidade total por titulação no reator - Condição I.

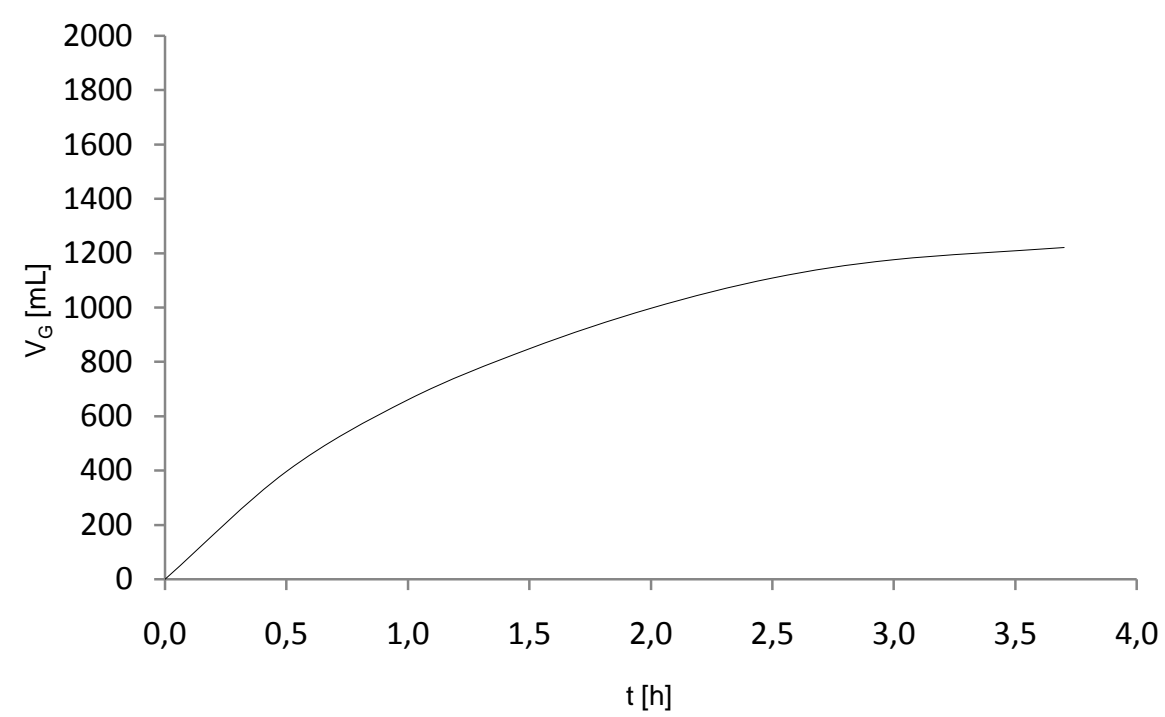

Figura 5.22 - Perfil produção volumétrica acumulada de biogás Condição I. 
Tabela 5.4 - Volumes específicos acumulados de gases e proporção de hidrogênio - Condição I.

\begin{tabular}{ccccc}
\hline Tempo & \multicolumn{3}{c}{ Volumes específicos } & Proporção de hidrogênio \\
& $\mathrm{V}_{\mathrm{H} 2}$ & $\mathrm{~V}_{\mathrm{CO} 2}$ & $\mathrm{~V}_{\mathrm{CH} 4}$ & $\% \mathrm{H}_{2}$ \\
\hline$[\mathrm{h}]$ & {$[\mathrm{mL}]$} & {$[\mathrm{mL}]$} & {$[\mathrm{mL}]$} & {$[\%]$} \\
\hline 0,0 & 0 & 0 & 0 & - \\
0,5 & 40 & 357 & 0 & 10,1 \\
1,0 & 87 & 574 & 0 & 13,1 \\
1,5 & 132 & 716 & 0 & 15,6 \\
2,0 & 173 & 823 & 1 & 17,4 \\
2,5 & 207 & 900 & 2 & 18,7 \\
3,0 & 229 & 945 & 2 & 19,4 \\
3,7 & 244 & 974 & 3 & 20,0 \\
\hline
\end{tabular}

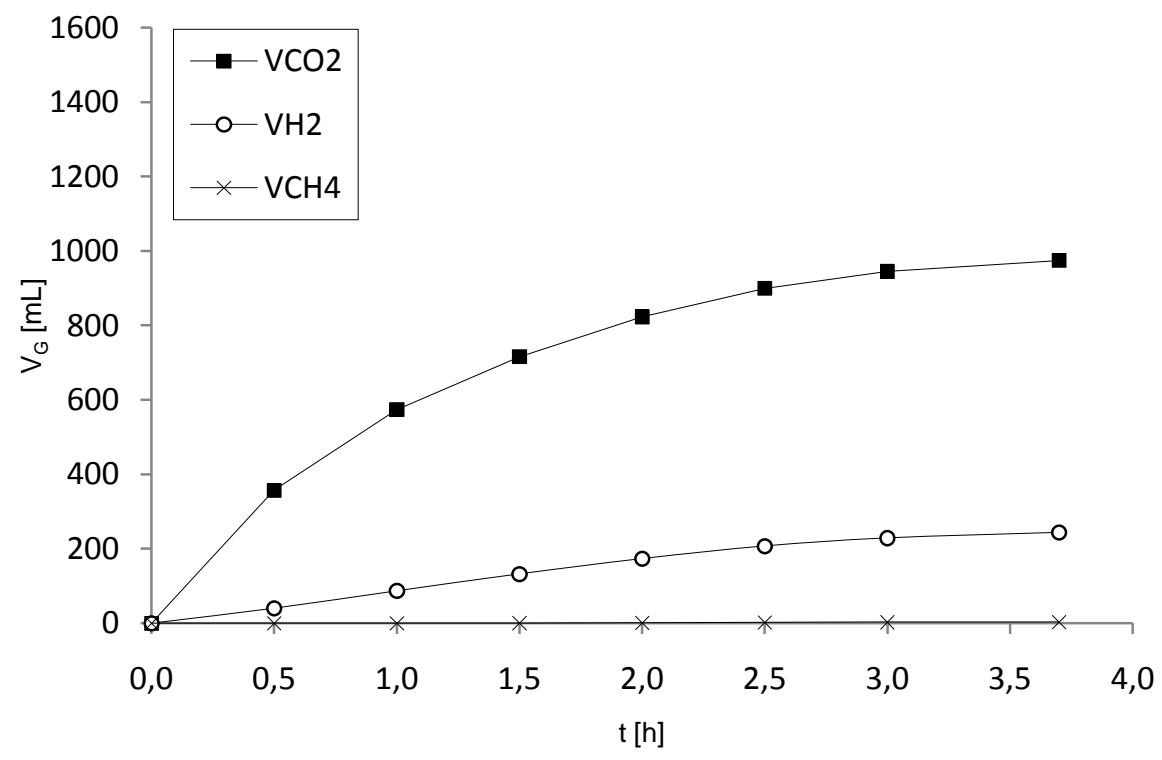

Figura 5.23 - Perfil produção volumétrica espécifica acumulada de gases - Condição I. 


\subsection{Condição experimental II (DQO 3600 mg.L $\mathrm{L}^{-1}$ - TC 3h)}

\subsubsection{Monitoramento}

A Tabela 5.5 apresenta os valores médios durante os 32 dias de monitoramento da Condição II. O reator apresentou uma boa capacidade de retenção da biomassa com valores de sólidos volteis totais e filtrados efluentes da ordem de grandeza dos valores afluentes. A quantidade de biomassa presente no reator considerada nos cálculos de cargas orgânicas específicas foi avaliada no final da condição no valor de 24,51 g de sólidos voláteis totais. As cargas orgânicas volumétricas aplicadas reais durante a operação foram de $10,69 \mathrm{kgSAC} \cdot \mathrm{m}^{-3} \cdot \mathrm{d}^{-1}$ e $12,21 \mathrm{kgDQO} \cdot \mathrm{m}^{-3} \cdot \mathrm{d}^{-1}$ considerando a sacarose e a DQO, respectivamente (valores nominais de $10,66 \mathrm{kgSAC} \cdot \mathrm{m}^{-3} \cdot \mathrm{d}^{-1}$ e $12,00 \mathrm{kgDQO} \cdot \mathrm{m}^{-}$ $\left.{ }^{3} \cdot d^{-1}\right)$. 
Tabela 5.5 - Valores médios dos parâmetros monitorados Condição II. (DQO 3600 mg.L -1 $^{-T C} 3$ h)

\begin{tabular}{|c|c|c|c|c|c|c|c|c|c|c|c|c|c|}
\hline \multicolumn{2}{|r|}{ Parâmetro } & \multicolumn{3}{|c|}{ Afluente } & \multicolumn{9}{|c|}{ Efluente } \\
\hline $\mathrm{C}_{\mathrm{CT}}$ & {$\left[\mathrm{mgSAC} \cdot \mathrm{L}^{-1}\right]$} & 3207 & \pm & 132 & ( & 15 & ) & 180 & \pm & 78 & ( & 15 & ) \\
\hline $\mathrm{C}_{\mathrm{CF}}$ & {$\left[\mathrm{mgSAC} . \mathrm{L}^{-1}\right]$} & - & & - & & & & 105 & \pm & 69 & ( & 15 & ) \\
\hline$\varepsilon_{\mathrm{CT}}$ & {$[\%]$} & - & & - & & & & 94 & \pm & 2 & ( & 15 & ) \\
\hline$\varepsilon_{\mathrm{CF}}$ & {$[\%]$} & - & & - & & & & 97 & \pm & 2 & ( & 15 & ) \\
\hline $\mathrm{C}_{\mathrm{ST}}$ & {$\left[\mathrm{mgDQO} \cdot \mathrm{L}^{-1}\right]$} & 3664 & \pm & 143 & ( & 15 & ) & 3207 & \pm & 172 & ( & 15 & ) \\
\hline $\mathrm{C}_{\mathrm{SF}}$ & {$\left[\mathrm{mgDQO} \cdot \mathrm{L}^{-1}\right]$} & - & & - & & & & 3030 & \pm & 129 & ( & 15 & ) \\
\hline$\varepsilon_{\mathrm{ST}}$ & {$[\%]$} & - & & - & & & & 12 & \pm & 5 & ( & 15 & ) \\
\hline$\varepsilon_{\mathrm{SF}}$ & {$[\%]$} & - & & - & & & & 17 & \pm & 4 & ( & 15 & ) \\
\hline $\mathrm{pH}$ & {$[\mathrm{u}]$} & 7,4 & \pm & 0,1 & ( & 15 & ) & 5,0 & \pm & 0,1 & ( & 17 & ) \\
\hline AVT & {$\left[\mathrm{mgHAc} . \mathrm{L}^{-1]}\right.$} & 24 & \pm & 8 & ( & 15 & ) & 623 & \pm & 105 & ( & 17 & ) \\
\hline AT & {$\left[\mathrm{mgCACO}{ }_{3} \cdot \mathrm{L}^{-1}\right]$} & 579 & \pm & 43 & ( & 15 & ) & 303 & \pm & 48 & ( & 17 & ) \\
\hline AP & {$\left[\mathrm{mgCACO} \mathrm{Al}_{3} \cdot \mathrm{L}^{-1}\right]$} & 471 & \pm & 34 & ( & 15 & ) & 0 & \pm & 0 & ( & 17 & ) \\
\hline AI & {$\left[\mathrm{mgCACO}_{3} \cdot \mathrm{L}^{-1}\right]$} & 109 & \pm & 19 & ( & 15 & ) & 303 & \pm & 48 & ( & 17 & ) \\
\hline $\mathrm{AB}$ & {$\left[\mathrm{mgCACO}{ }_{3} \cdot \mathrm{L}^{-1]}\right.$} & 562 & \pm & 41 & ( & 15 & ) & 1 & \pm & 3 & ( & 17 & ) \\
\hline ST & {$\left[\mathrm{mg} . \mathrm{L}^{-1}\right]$} & 3806 & \pm & 1121 & ( & 4 & ) & 2667 & \pm & 1178 & ( & 4 & ) \\
\hline SVT & {$\left[\mathrm{mg} . \mathrm{L}^{-1}\right]$} & 3020 & \pm & 1165 & ( & 4 & ) & 1964 & \pm & 1086 & ( & 4 & ) \\
\hline SST & {$\left[\mathrm{mg} . \mathrm{L}^{-1}\right]$} & 77 & \pm & 52 & ( & 4 & ) & 207 & \pm & 73 & ( & 4 & ) \\
\hline SSV & {$\left[\mathrm{mg} . \mathrm{L}^{-1}\right]$} & 29 & \pm & 33 & ( & 4 & ) & 164 & \pm & 52 & ( & 4 & ) \\
\hline $\mathrm{M}_{\mathrm{SVT}}$ & [g] & - & & - & & & & 24,51 & & - & & & \\
\hline $\mathrm{C}_{\mathrm{X}-\mathrm{SVT}}^{\prime}$ & [g.g-suporte ${ }^{-1}$ ] & - & & - & & & & 0,02 & & - & & & \\
\hline $\mathrm{C}_{\mathrm{X}-\mathrm{SVT}}$ & {$\left[\mathrm{g} . \mathrm{L}^{-1}\right]$} & - & & - & & & & 6,81 & & - & & & \\
\hline $\mathrm{COAV}_{\mathrm{CT}}$ & {$\left[\mathrm{kgSAC} \cdot \mathrm{m}^{-3} \cdot \mathrm{d}^{-1}\right]$} & 10,69 & & - & & & & - & & - & & & \\
\hline $\mathrm{COAV}_{\mathrm{ST}}$ & {$\left[\mathrm{kgDQO} \cdot \mathrm{m}^{-3} \cdot \mathrm{d}^{-1}\right]$} & 12,21 & & - & & & & - & & - & & & \\
\hline $\mathrm{COAE}_{\mathrm{CT}}$ & {$\left[\mathrm{kgSAC} \cdot \mathrm{kgSVT}^{-1} \cdot \mathrm{d}^{-1}\right]$} & 1,57 & & - & & & & - & & - & & & \\
\hline $\mathrm{COAE}_{\mathrm{ST}}$ & {$\left[\mathrm{kgDQO} \cdot \mathrm{kgSVT}^{-1} \cdot \mathrm{d}^{-1}\right]$} & 1,79 & & - & & & & - & & - & & & \\
\hline $\mathrm{CORV}_{\mathrm{CF}}$ & {$\left[\mathrm{kgSAC} \cdot \mathrm{m}^{-3} \cdot \mathrm{d}^{-1}\right]$} & - & & - & & & & 10,34 & & - & & & \\
\hline $\mathrm{CORV}_{\mathrm{SF}}$ & {$\left[\mathrm{kgDQO} \cdot \mathrm{m}^{-3} \cdot \mathrm{d}^{-1}\right]$} & - & & - & & & & 2,11 & & - & & & \\
\hline $\mathrm{CORE}_{\mathrm{CF}}$ & {$\left[\mathrm{kgSAC} \cdot \mathrm{kgSVT}^{-1} \cdot \mathrm{d}^{-1}\right]$} & - & & - & & & & 1,52 & & - & & & \\
\hline $\mathrm{CORE}_{\mathrm{SF}}$ & {$\left[\mathrm{kgDQO} \cdot \mathrm{kgSVT}^{-1} \cdot \mathrm{d}^{-1}\right]$} & - & & - & & & & 0,31 & & - & & & \\
\hline $\mathrm{n}_{\mathrm{H} 2}$ & {$\left[\mathrm{molH}_{2} \cdot \mathrm{d}^{-1}\right]$} & - & & - & & & & 0,10 & & - & ( & 2 & ) \\
\hline $\operatorname{PrM}$ & {$\left[\mathrm{molH}_{2} \cdot \mathrm{m}^{-3} \cdot \mathrm{d}^{-1}\right]$} & 15,57 & & - & & & & - & & - & & & \\
\hline PrME & {$\left[\mathrm{molH}_{2} \cdot \mathrm{kgSVT}^{-1} \cdot \mathrm{d}^{-1}\right]$} & 4,13 & & - & & & & - & & - & & & \\
\hline $\mathrm{RMCA}_{\mathrm{C}, \mathrm{n}}$ & {$\left[\mathrm{molH}_{2} \cdot \mathrm{kgSAC}^{-1}\right]$} & 3,51 & & - & & & & - & & - & & & \\
\hline $\mathrm{RMCA}_{\mathrm{S}, \mathrm{n}}$ & {$\left[\mathrm{molH}_{2} \cdot \mathrm{kgDQO}^{-1}\right]$} & 3,07 & & - & & & & - & & - & & & \\
\hline $\mathrm{RMCR}_{\mathrm{C}, \mathrm{n}}$ & {$\left[\mathrm{molH}_{2} \cdot \mathrm{kgSAC}^{-1}\right]$} & 3,63 & & - & & & & - & & - & & & \\
\hline $\mathrm{RMCR}_{\mathrm{S}, \mathrm{n}}$ & {$\left[\mathrm{molH}_{2} \cdot \mathrm{kgDQO}^{-1}\right]$} & 17,73 & & - & & & & - & & - & & & \\
\hline $\mathrm{V}_{\mathrm{A}}$ & {$[\mathrm{L}]$} & 1,5 & & & & & & & & & & & \\
\hline $\mathrm{V}_{\mathrm{R}}$ & {$[\mathrm{L}]$} & 3,6 & & & & & & & & & & & \\
\hline
\end{tabular}

(*) Entre parêntese o número de amostras considerado no cálculo da média

O reator apresentou uma boa capacidade de conversão da sacarose como mostra a Figura 5.24 contendo a evolução das concentrações afluente e efluente (total e filtrada). A Figura 5.25 apresenta 
a evolução das eficiências de conversão ao longo da condição. Os valores ficaram elevados e estáveis perto de um valor de $94 \%$ na forma total e $97 \%$ na forma filtrada. O reator continuou apresentando baixa eficiência de remoção de DQO como pode ser observado na Figura 5.26 com a evolução das concentrações em DQO afluente e efluente (total e filtrada). A Figura 5.27 apresenta a evolução das eficiências de remoção da DQO quem ficaram estáveis perto de um valor de $12 \%$ na forma total e $17 \%$ na forma filtrada. A Figura 5.28 mostra o acúmulo dos ácidos voláteis totais, cuja concentração média no efluente filtrado foi de $623 \mathrm{mgHAc}^{-1} \mathrm{~L}^{-1}$.

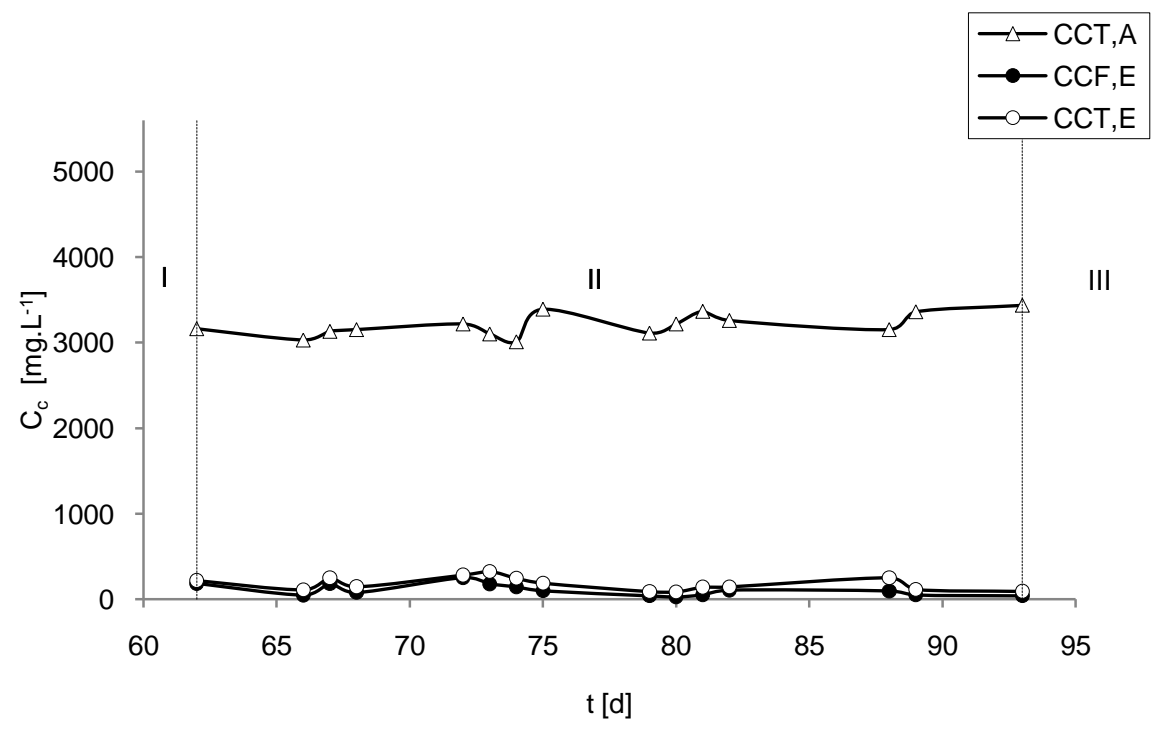

Figura 5.24 - Concentrações em carboidratos no afluente e efluente total e filtrado - Condição II. 


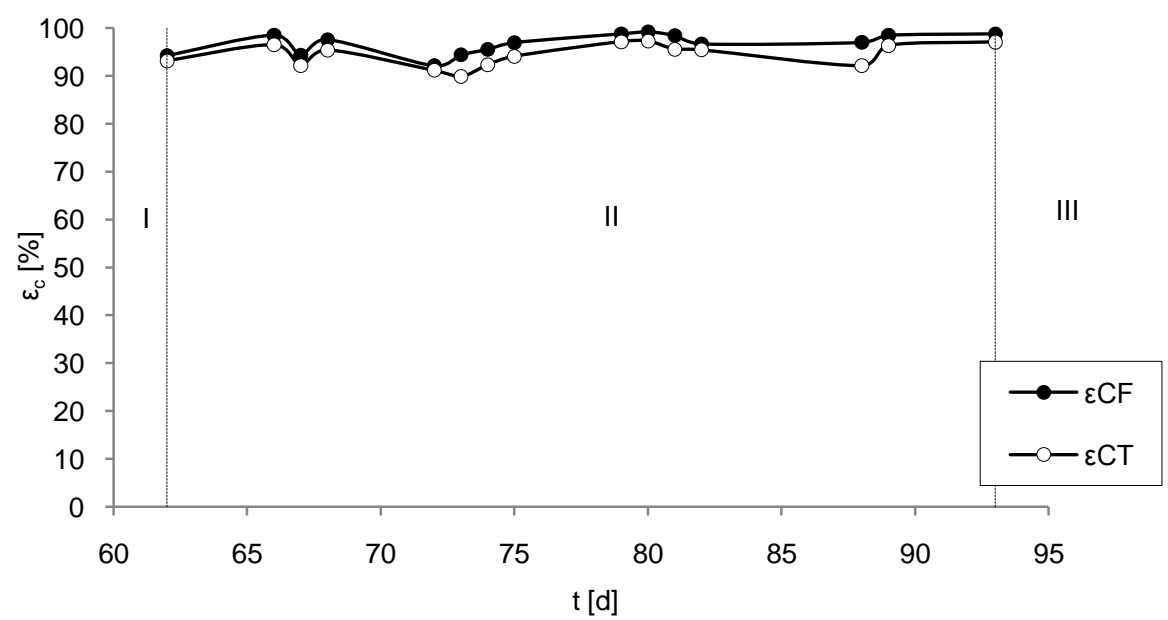

Figura 5.25 - Eficiências de conversão dos carboidratos na forma total e filtrada - Condição II.

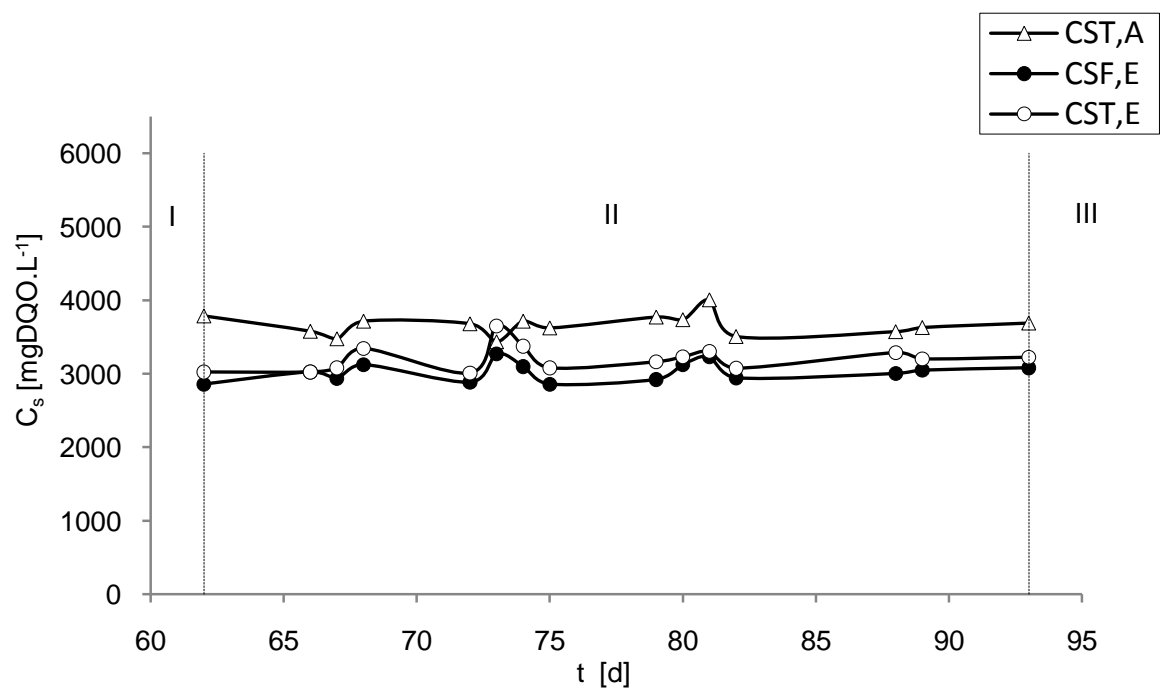

Figura 5.26- Concentrações em DQO no afluente e efluente total e filtrado - Condição II. 


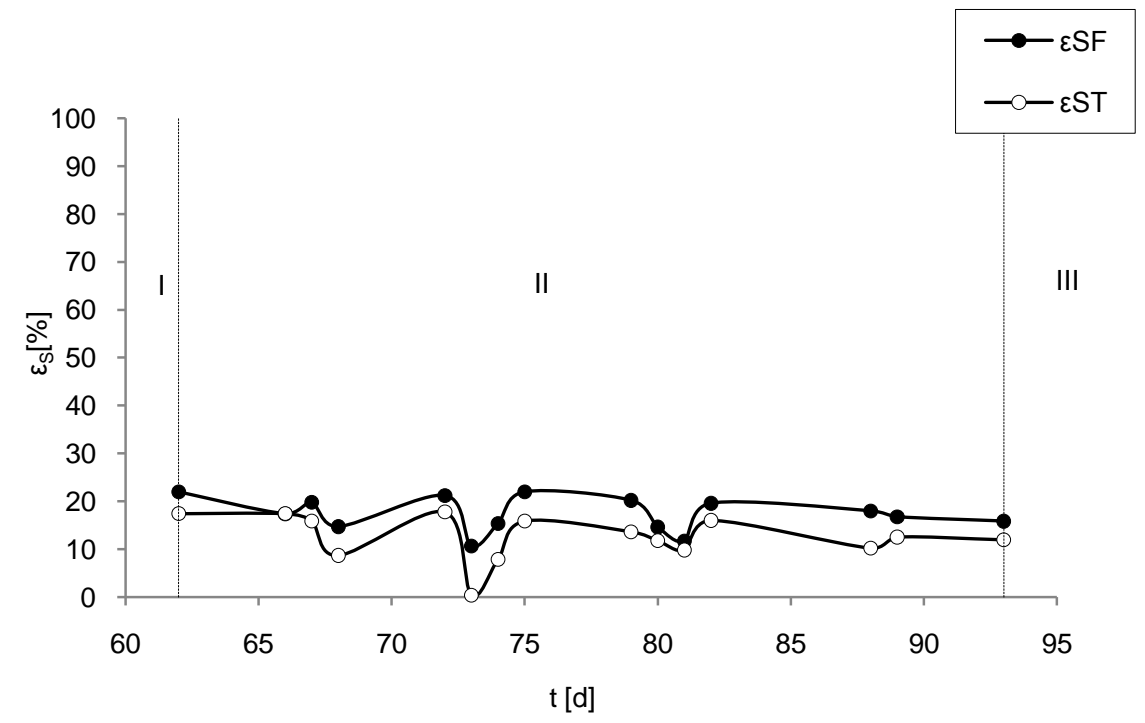

Figura 5.27- Eficiências de remoção da DQO na forma total e filtrada - Condição II.

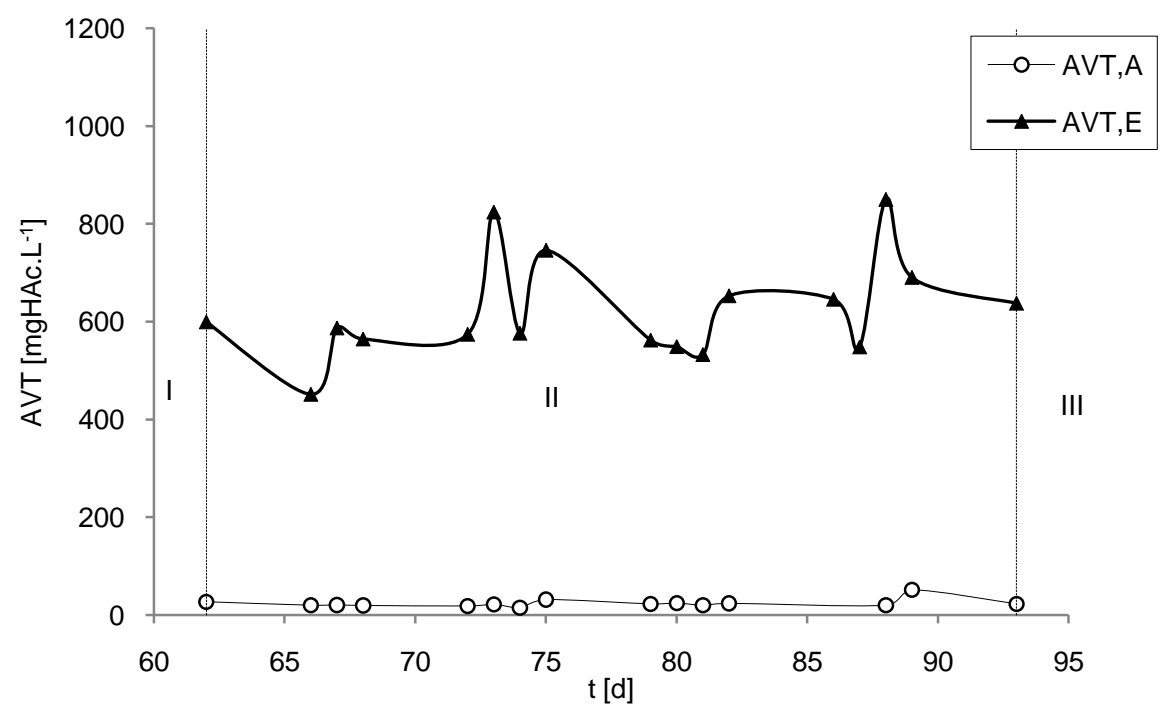

Figura 5.28- Concentrações em ácidos volateís totais por titulação no afluente e efluente - Condição II.

A Tabela 5.6 apresenta os resultados da quantificação dos compostos intermediários realizada por cromatografia gasosa. Dentre dos ácidos voláteis, o ácido Acético predominou seguido pelo ácido Butírico representado, respectivamente, 41,7\% e 14,6\% dos compostos intermediários. $\mathrm{O}$ efluente apresentou também uma quantidade importante de etanol representando 
24,8 \% dos compostos intermediários. O acumulo de ácidos no reator levou a uma diminuição do pH da fase líquida conforme pode ser observado na Figura 5.29, o que resultou em um consumo da alcalinidade total conforme apresentado pela Figura 5.30. O valor médio do $\mathrm{pH}$ foi de 7,38 para o afluente contra 5,05 para o efluente. A alcalinidade média foi de $579 \mathrm{mgCaCO}_{3} \cdot \mathrm{L}^{-1}$ para o efluente contra $303 \mathrm{mgCaCO} \cdot \mathrm{L}^{-1}$ no efluente.

A variação da produção de biogás durante um ciclo ao longo da Condição II pode ser observado na Figura 5.31. O volume máximo produzido foi de $1313 \mathrm{~mL}$ no $76^{\circ}$ dia de operação do reator $\left(15^{\circ}\right.$ dia de operação da condição), sendo o valor médio de $965 \mathrm{~mL}$ com desvio padrão de 200 $\mathrm{mL}$ indicando variações durante a condição.

Tabela 5.6 - Concentração média e composição dos compostos intermediários - Condição II.

\begin{tabular}{cccccccc}
\hline Espécies & \multicolumn{4}{c}{ Concentrações média } & & Repartição \\
& \multicolumn{3}{c}{$\left[\mathrm{mg.L}^{-1}\right]$} & \multicolumn{3}{c}{$\left[\begin{array}{c}{\left[\mathrm{mmol} . \mathrm{L}^{-1}\right]} \\
{[\%]}\end{array}\right.$} \\
\hline Acetona & 0,0 & \pm & - & 0,0 & \pm & 0,0 & 0,0 \\
Metanol & 0,0 & \pm & - & 0,0 & \pm & 0,0 & 0,0 \\
Etanol & 332,6 & \pm & 55,1 & 7,2 & \pm & 1,2 & 24,8 \\
n-Butanol & 7,8 & \pm & 0,6 & 0,1 & \pm & 0,0 & 0,6 \\
Acético & 559,0 & \pm & 18,5 & 9,3 & \pm & 0,3 & 41,7 \\
Porpiônico & 43,8 & \pm & 10,2 & 0,6 & \pm & 0,1 & 3,3 \\
Isobutírico & 75,7 & \pm & 26,5 & 0,9 & \pm & 0,3 & 5,6 \\
Butírico & 195,0 & \pm & 49,8 & 2,2 & \pm & 0,6 & 14,6 \\
Isovalérico & 8,7 & \pm & 1,1 & 0,1 & \pm & 0,0 & 0,6 \\
Valérico & 22,6 & \pm & 3,9 & 0,2 & \pm & 0,0 & 1,7 \\
Capróico & 94,6 & \pm & 31,6 & 0,8 & \pm & 0,3 & 7,1 \\
\hline
\end{tabular}




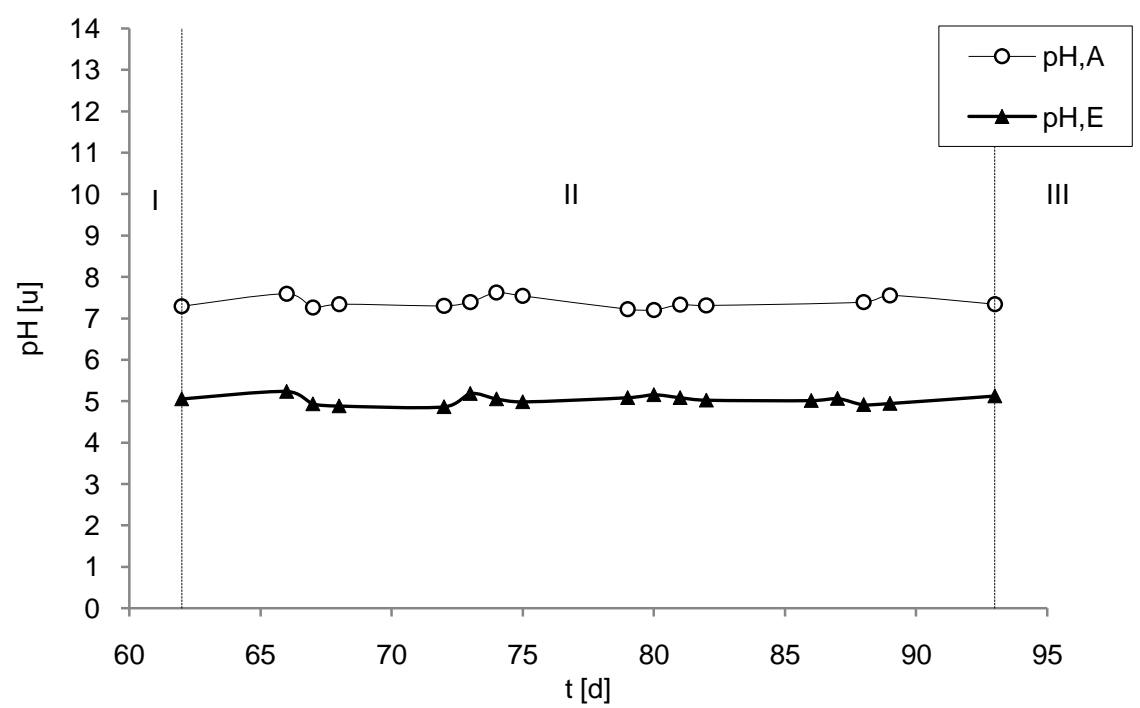

Figura 5.29- pH afluente e efluente - Condição II.

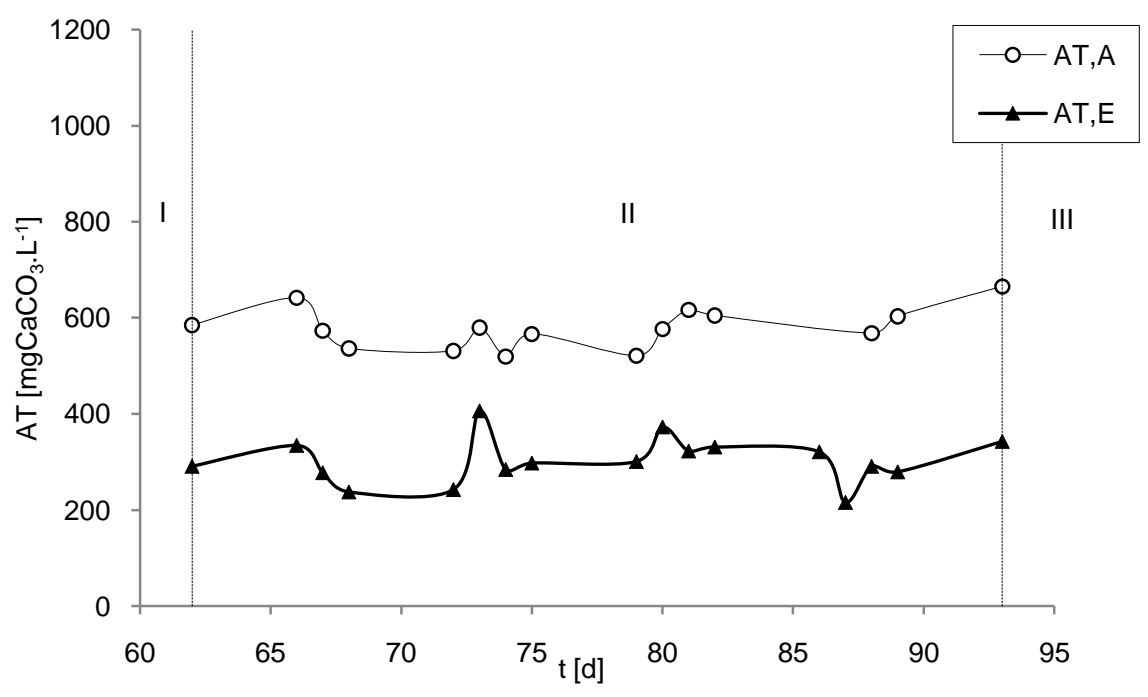

Figura 5.30- Alcalinidades totais por titulação no afluente e efluente - Condição II. 


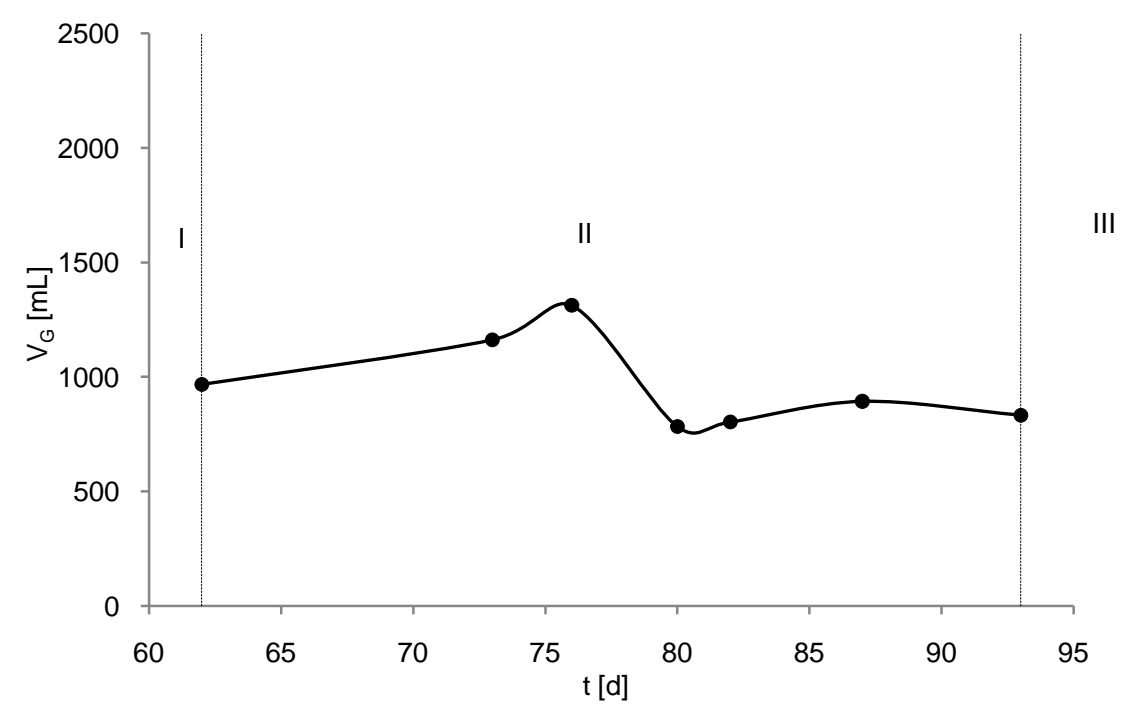

Figura 5.31- Variação da produção volumétrica de biogás durante um ciclo - Condição II.

\subsubsection{Perfis ao longo do ciclo}

A Figura 5.32 mostra a evolução da concentração em carboidratos totais ao longo do ciclo. Ao iniciou do ciclo (tempo zero) o volume afluente é diluído no volume residual resultando em uma concentração em sacarose da ordem de $1500 \mathrm{mg} \cdot \mathrm{L}^{-1}$. A conversão da sacarose se faz de maneira progressiva ao longo do ciclo. A Figura 5.33 mostra a evolução da concentração em DQO ao longo do ciclo. Pode ser observada uma remoção baixa em DQO ao longo do ciclo levando a uma alta concentração em DQO no volume residual.

A sacarose convertida em produtos intermediários do metabolismo anaeróbio leva a um acúmulo de ácidos voláteis totais ao longo do ciclo conforme pode ser observado na Figura 5.34. A concentração em ácidos voláteis totais aumenta claramente durante a fase de reação para atingir um máximo no final do ciclo. Os resultados da análise dos compostos intermediários ao longo do ciclo por cromatografia em fase gasosa são apresentados na Figura 5.35. Observa-se um aumento em ácido acético passando de uma concentração inicial de 275,2 mg. $\mathrm{L}^{-1}$ até um máximo de 559,0 mg.L${ }^{1}$ no final do ciclo. 
$\mathrm{O}$ pH do afluente diminuiu instantaneamente com a diluição ao inicio do ciclo devido à mistura entre o volume alimentado com o volume residual, permanecendo estável ao longo da operação. Entretanto uma leva diminuição pode ser observada, provavelmente devido ao acúmulo de ácidos voláteis conforme representado na Figura 5.36. A estabilidade do pH mesmo com a produção de ácidos voláteis é devido ao tamponamento do sistema pelo consumo de alcalinidade ao longo do ciclo. A Figura 5.37 apresenta a evolução da alcalinidade total no reator ao longo do ciclo.

A produção volumétrica acumulada de biogás pode ser observada na Figura 5.38. A curva de produção tem comportamento crescente no inicio do ciclo e tende a se estabilizar no final. A caracterização qualitativa do biogás por cromatografia permitiu avaliar os volumes específicos de gases produzidos ao longo do ciclo. A Tabela 5.7 apresentando os resultados obtidos mostra uma produção acumulada de $283 \mathrm{~mL}$ de hidrogênio $(24,7 \%), 859 \mathrm{~mL}$ de dióxido de carbono (75,0\%) e $3 m L$ de metano $(0,3 \%)$. As curvas relativas à produção de cada gás são apresentadas na Figura 5.39.

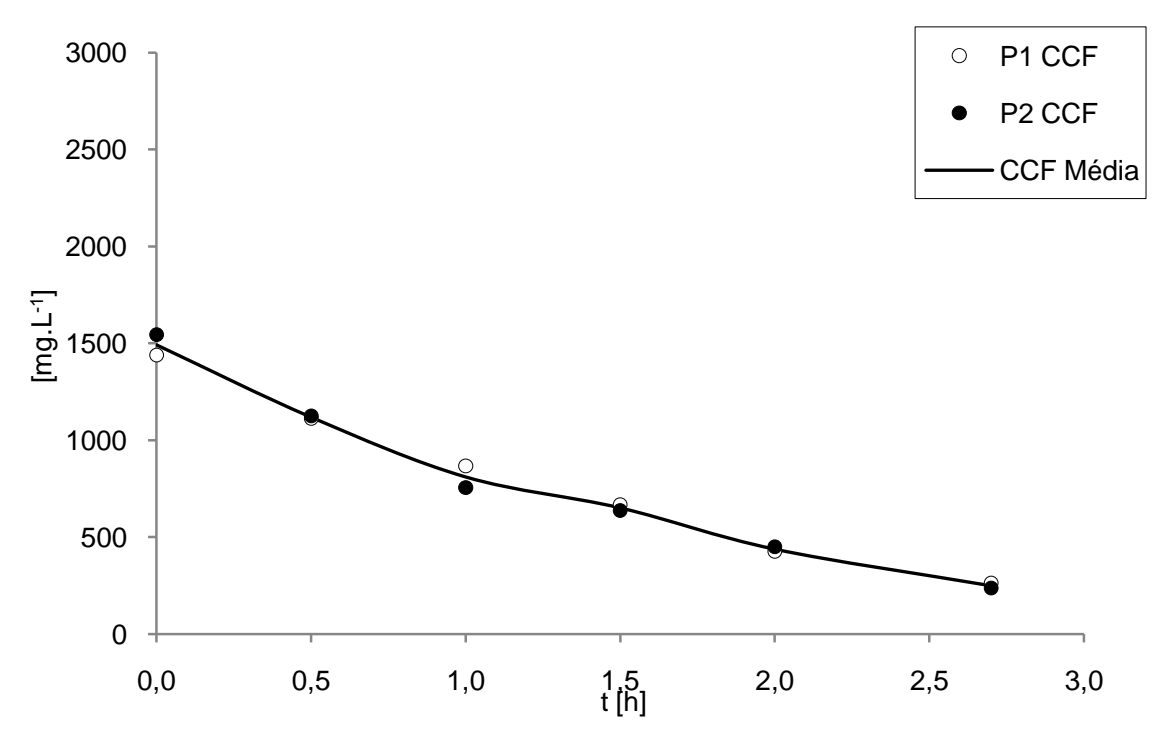

Figura 5.32- Perfil de evolução da concentração em carboidratos no reator - Condição II. 


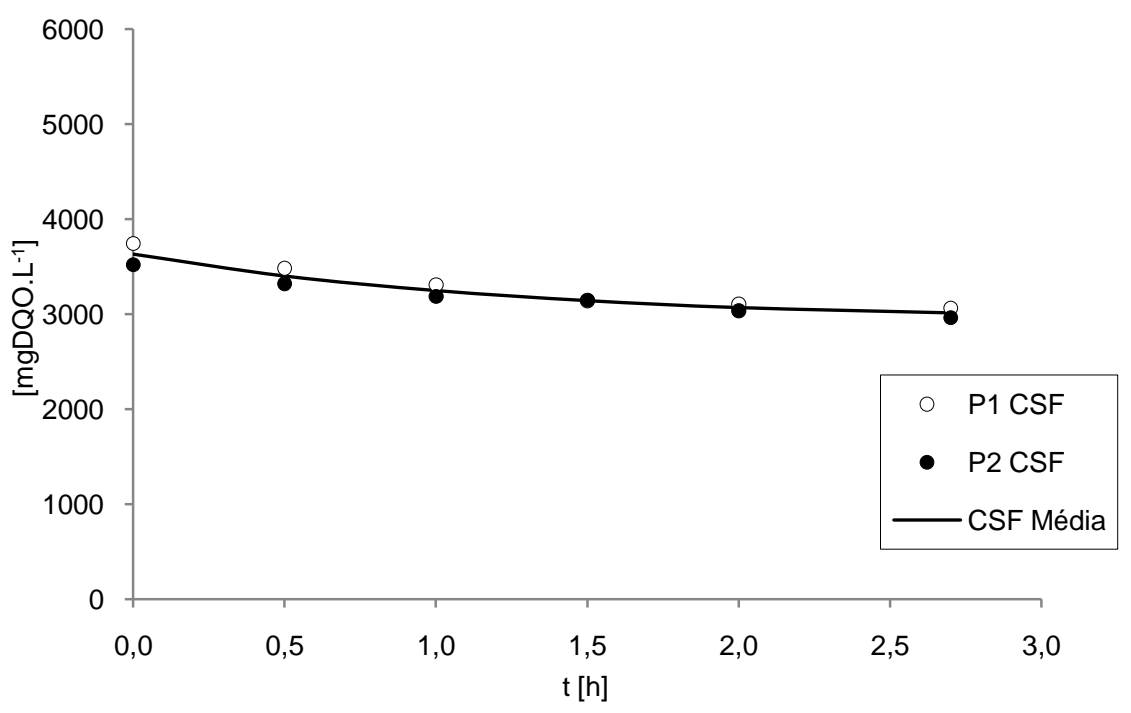

Figura 5.33- Perfil de evolução da concentração em DQO no reator- Condição II.

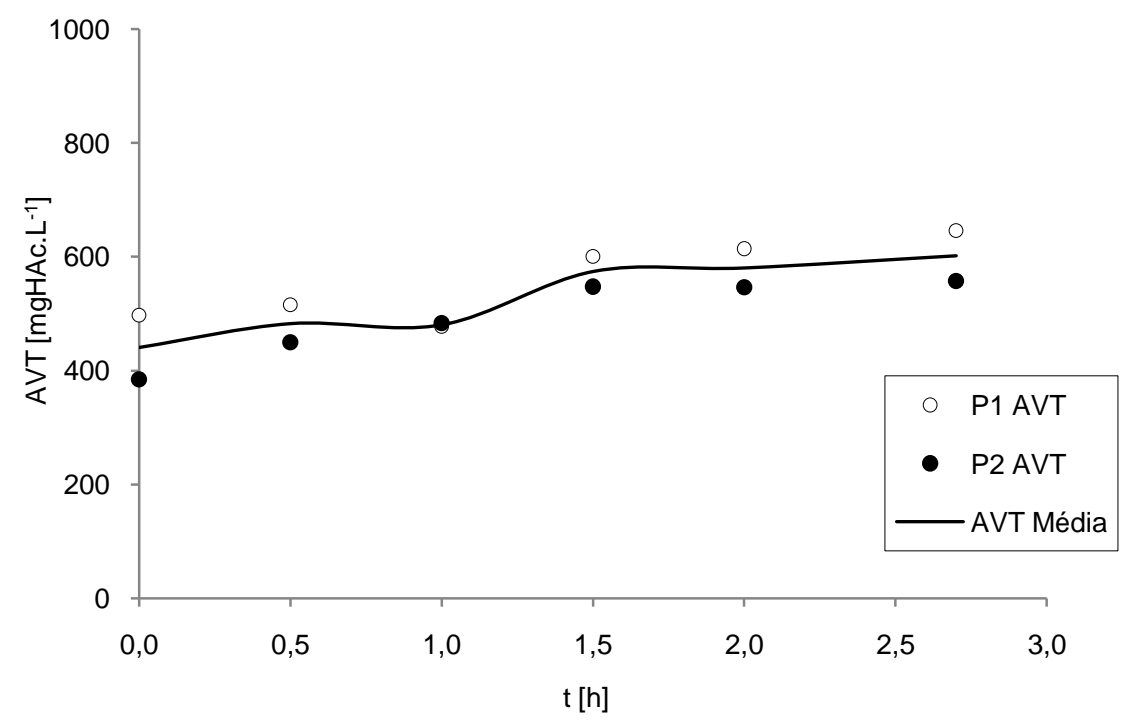

Figura 5.34- Perfil de evolução da concentração em ácidos volateís totais por titulação no reator - Condição II. 


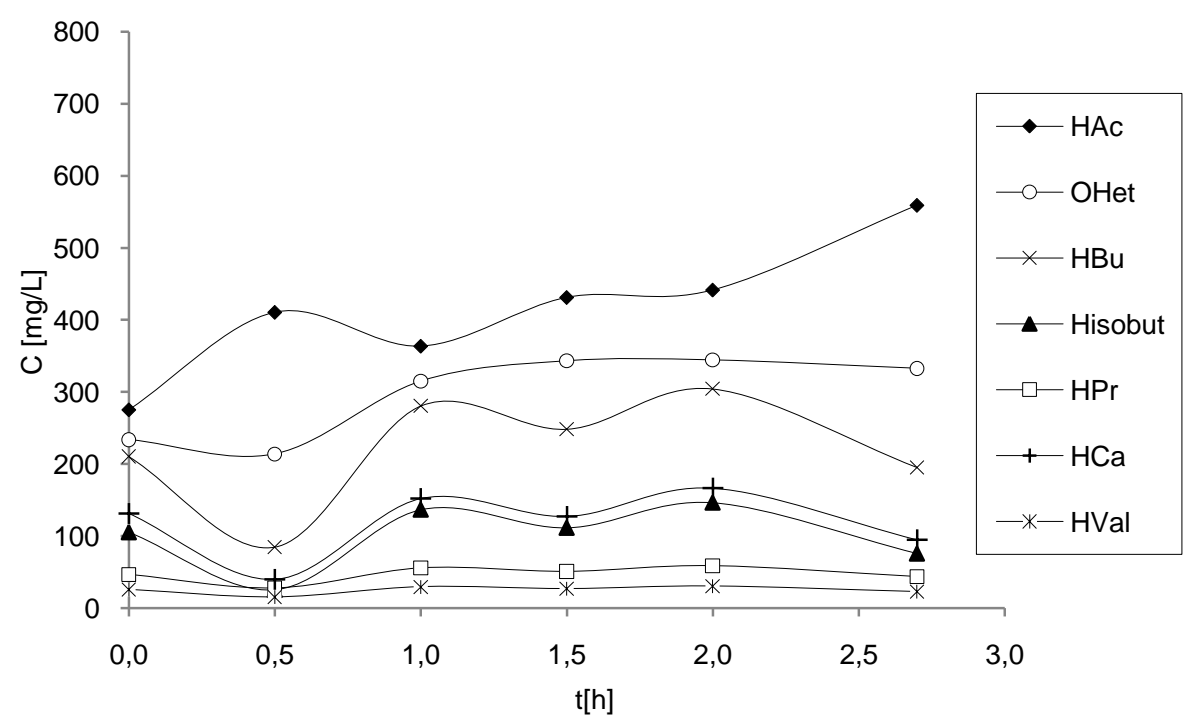

Figura 5.35 - Perfil de evolução das concentrações dos compostos intermediários - Condição II.

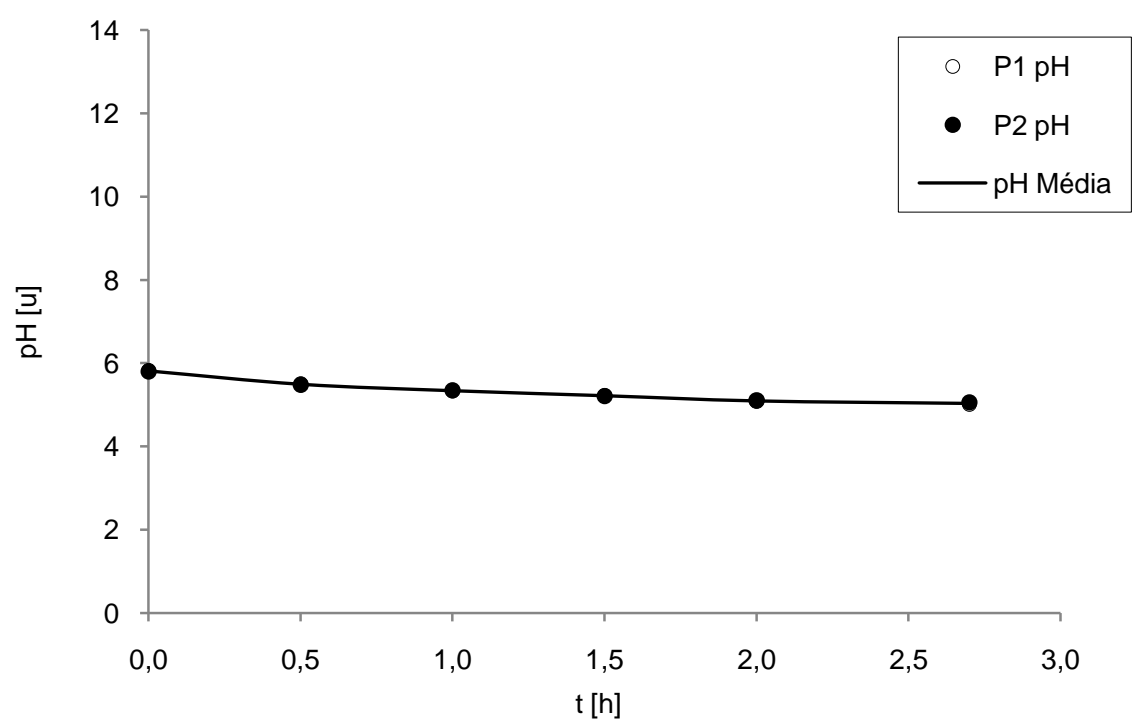

Figura 5.36- Perfil de evolução do pH no reator- Condição II. 


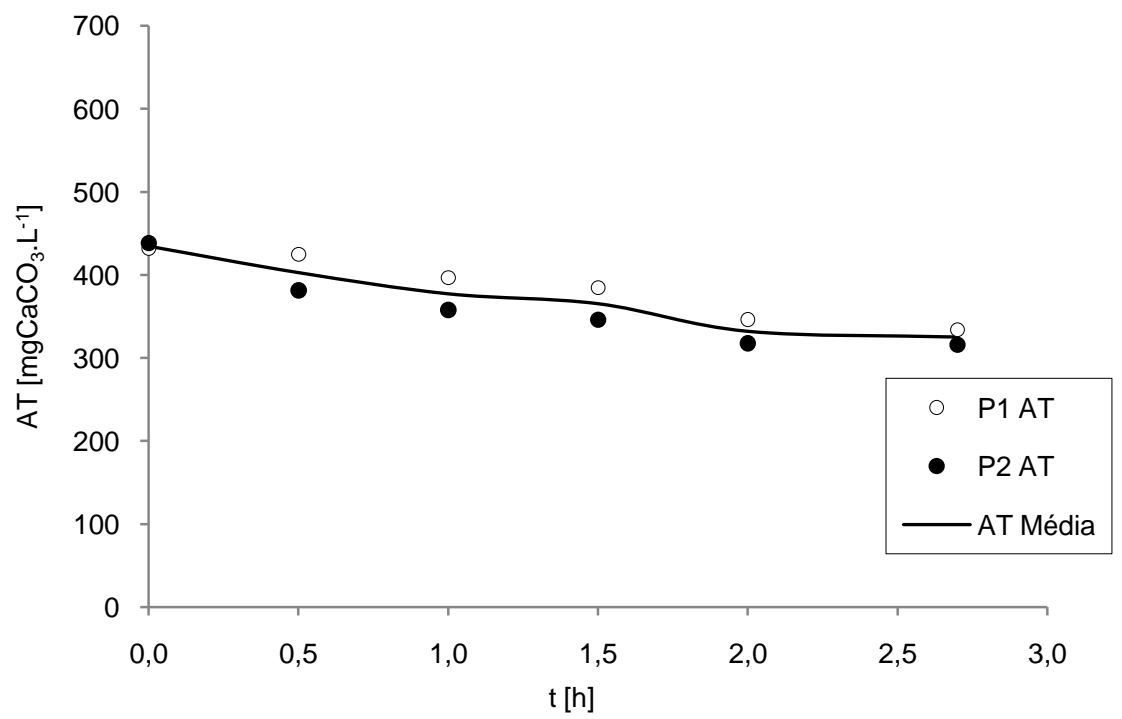

Figura 5.37- Perfil de evolução da alcalinidade total por titulação no reator - Condição II.

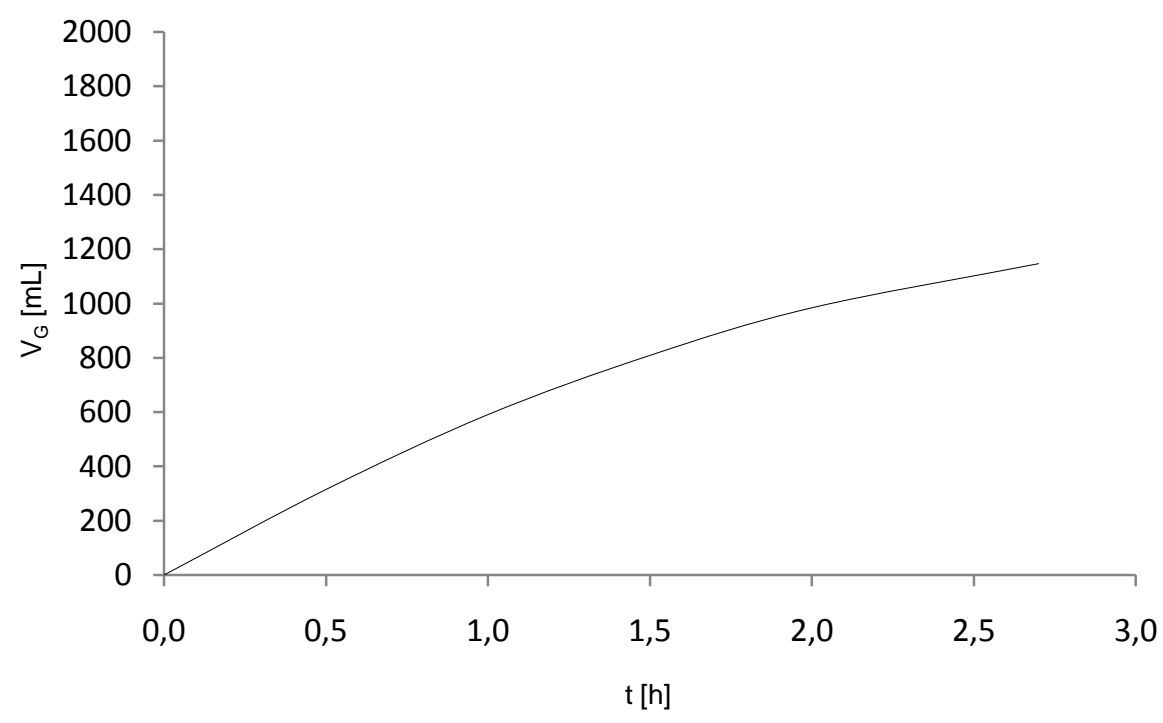

Figura 5.38 - Perfil produção volumétrica acumulada de biogás Condição II. 
Tabela 5.7 - Volumes específicos acumulados de gases e proporção de hidrogênio - Condição II.

\begin{tabular}{ccccc}
\hline & \multicolumn{3}{c}{ Volumes específicos } & Proporção de hidrogênio \\
Tempo & \multicolumn{3}{c}{ acumulados } & \\
& $\mathrm{V}_{\mathrm{H} 2}$ & $\mathrm{~V}_{\mathrm{CO} 2}$ & $\mathrm{~V}_{\mathrm{CH} 4}$ & $\% \mathrm{H}_{2}$ \\
\hline$[\mathrm{h}]$ & {$[\mathrm{mL}]$} & {$[\mathrm{mL}]$} & {$[\mathrm{mL}]$} & {$[\%]$} \\
\hline 0,0 & 0 & 0 & 0 & - \\
0,5 & 50 & 265 & 0 & 15,9 \\
1,0 & 116 & 474 & 0 & 19,7 \\
1,5 & 177 & 631 & 0 & 21,9 \\
2,0 & 231 & 752 & 1 & 23,5 \\
2,7 & 283 & 859 & 3 & 24,7 \\
\hline
\end{tabular}

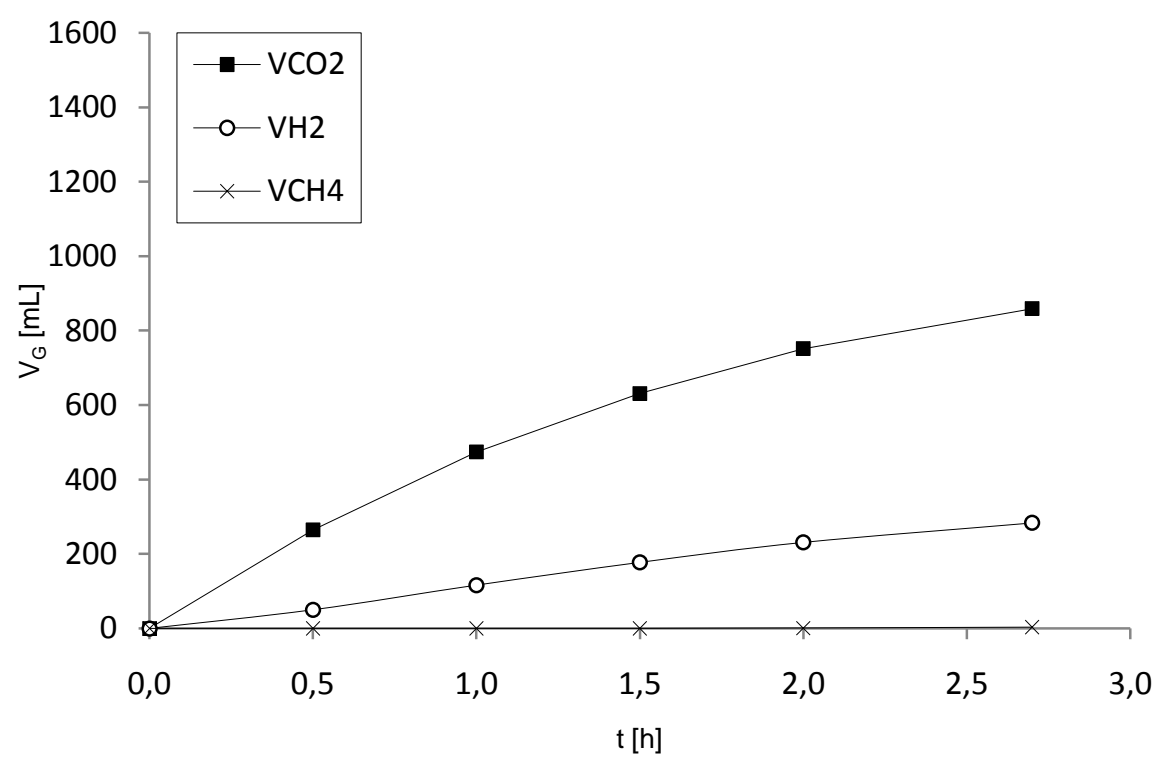

Figura 5.39 - Perfil produção volumétrica espécifica acumulada de gases - Condição II. 


\subsection{Condição experimental III (DQO 5400 mg.L ${ }^{-1}$ - TC 4h)}

\subsubsection{Monitoramento}

A Tabela 5.8 apresenta os valores médios durante os 43 dias de monitoramento da condição III. O reator continuou apresentando uma boa capacidade de retenção da biomassa com valores de sólidos volteis totais e filtrados efluentes da ordem de grandeza dos valores afluentes. A quantidade de biomassa presente no reator considerada nos cálculos de cargas orgânicas específicas foi determinado no final da condição IV. As cargas orgânicas volumétricas aplicadas reais durante a operação foram de 11,93 $\mathrm{kgSAC} \cdot \mathrm{m}^{-3} \cdot \mathrm{d}^{-1} \mathrm{e} 13,45 \mathrm{kgDQO} \cdot \mathrm{m}^{-3} \cdot \mathrm{d}^{-1}$ considerando a sacarose e a DQO, respectivamente (valores nominais de $12,00 \mathrm{kgSAC} \cdot \mathrm{m}^{-3} \cdot \mathrm{d}^{-1} \mathrm{e} 13,50 \mathrm{kgDQO} \cdot \mathrm{m}^{-3} \cdot \mathrm{d}^{-1}$ ). 
Tabela 5.8 - Valores médios dos parâmetros monitorados Condição III. (DQO 5400 mg.L -1 $^{-T C}$ 4h)

\begin{tabular}{|c|c|c|c|c|c|c|c|c|c|c|c|c|c|}
\hline \multicolumn{2}{|r|}{ Parâmetro } & \multicolumn{3}{|c|}{ Afluente } & \multicolumn{9}{|c|}{ Efluente } \\
\hline$\overline{\mathrm{C}_{\mathrm{CT}}}$ & {$\left[\mathrm{mgSAC} . \mathrm{L}^{-1}\right]$} & 4773 & \pm & 477 & ( & 20 & ) & 412 & \pm & 253 & ( & 20 & 7 \\
\hline $\mathrm{C}_{\mathrm{CF}}$ & {$\left[\mathrm{mgSAC} \cdot \mathrm{L}^{-1}\right]$} & - & & - & & & & 341 & \pm & 267 & ( & 20 & ) \\
\hline$\varepsilon_{\mathrm{CT}}$ & {$[\%]$} & - & & - & & & & 91 & \pm & 5 & ( & 20 & ) \\
\hline$\varepsilon_{\mathrm{CF}}$ & {$[\%]$} & - & & - & & & & 93 & \pm & 6 & ( & 20 & ) \\
\hline $\mathrm{C}_{\mathrm{ST}}$ & {$\left[\mathrm{mgDQO} . \mathrm{L}^{-1}\right]$} & 5378 & \pm & 637 & ( & 19 & ) & 4587 & \pm & 428 & ( & 19 & ) \\
\hline $\mathrm{C}_{\mathrm{SF}}$ & {$\left[\mathrm{mgDQO} . \mathrm{L}^{-1}\right]$} & - & & - & & & & 4420 & \pm & 411 & ( & 19 & ) \\
\hline$\varepsilon_{\mathrm{ST}}$ & {$[\%]$} & - & & - & & & & 15 & \pm & 8 & ( & 19 & ) \\
\hline$\varepsilon_{\mathrm{SF}}$ & {$[\%]$} & - & & - & & & & 18 & \pm & 8 & ( & 19 & ) \\
\hline $\mathrm{pH}$ & {$[\mathrm{u}]$} & 7,4 & \pm & 0,1 & ( & 16 & ) & 4,9 & \pm & 0,1 & ( & 16 & ) \\
\hline AVT & {$\left[\mathrm{mgHAc} . \mathrm{L}^{-1]}\right.$} & 28 & \pm & 5 & ( & 16 & ) & 874 & \pm & 139 & ( & 16 & ) \\
\hline AT & {$\left[\mathrm{mgCACO}{ }_{3} \cdot \mathrm{L}^{-1}\right]$} & 772 & \pm & 82 & ( & 16 & ) & 377 & \pm & 45 & ( & 16 & ) \\
\hline AP & {$\left[\mathrm{mgCACO}{ }_{3} \cdot \mathrm{L}^{-1}\right]$} & 629 & \pm & 70 & ( & 16 & ) & 0 & \pm & 0 & ( & 16 & ) \\
\hline AI & {$\left[\mathrm{mgCACO}_{3} \cdot \mathrm{L}^{-1}\right]$} & 143 & \pm & 23 & ( & 16 & ) & 377 & \pm & 45 & ( & 16 & ) \\
\hline $\mathrm{AB}$ & {$\left[\mathrm{mgCACO}_{3} \cdot \mathrm{L}^{-1]}\right.$} & 753 & \pm & 81 & ( & 16 & ) & 0 & \pm & 0 & ( & 16 & ) \\
\hline $\mathrm{ST}$ & {$\left[\mathrm{mg} . \mathrm{L}^{-1}\right]$} & 6123 & \pm & 182 & ( & 4 & ) & 2533 & \pm & 926 & ( & 4 & ) \\
\hline SVT & {$\left[\mathrm{mg} . \mathrm{L}^{-1}\right]$} & 5061 & \pm & 242 & ( & 4 & ) & 1501 & \pm & 739 & ( & 4 & ) \\
\hline SST & {$\left[\mathrm{mg} \cdot \mathrm{L}^{-1}\right]$} & 139 & \pm & 43 & ( & 4 & ) & 223 & \pm & 71 & ( & 4 & ) \\
\hline SSV & {$\left[\mathrm{mg} \cdot \mathrm{L}^{-1}\right]$} & 107 & \pm & 21 & ( & 4 & ) & 172 & \pm & 41 & ( & 4 & ) \\
\hline $\mathrm{M}_{\mathrm{SVT}}$ & {$[\mathrm{g}]$} & - & & - & & & & 23,96 & & - & & & \\
\hline $\mathrm{C}_{\mathrm{X}-\mathrm{SVT}}^{\prime}$ & [g.g-suporte ${ }^{-1}$ ] & - & & - & & & & 0,02 & & - & & & \\
\hline $\mathrm{C}_{\mathrm{X}-\mathrm{SVT}}$ & {$\left[\right.$ g. $\left.\mathrm{L}^{-1}\right]$} & - & & - & & & & 6,66 & & - & & & \\
\hline $\mathrm{COAV}_{\mathrm{CT}}$ & {$\left[\mathrm{kgSAC} \cdot \mathrm{m}^{-3} \cdot \mathrm{d}^{-1}\right]$} & 11,93 & & - & & & & - & & - & & & \\
\hline $\mathrm{COAV}_{\mathrm{ST}}$ & {$\left[\mathrm{kgDQO} \cdot \mathrm{m}^{-3} \cdot \mathrm{d}^{-1}\right]$} & 13,45 & & - & & & & - & & - & & & \\
\hline $\mathrm{COAE}_{\mathrm{CT}}$ & {$\left[\mathrm{kgSAC} \cdot \mathrm{kgSVT}^{-1} \cdot \mathrm{d}^{-1}\right]$} & 1,79 & & - & & & & - & & - & & & \\
\hline $\mathrm{COAE}_{\mathrm{ST}}$ & {$\left[\mathrm{kgDQO} \cdot \mathrm{kgSVT}^{-1} \cdot \mathrm{d}^{-1}\right]$} & 2,02 & & - & & & & - & & - & & & \\
\hline $\mathrm{CORV}_{\mathrm{CF}}$ & {$\left[\mathrm{kgSAC} \cdot \mathrm{m}^{-3} \cdot \mathrm{d}^{-1}\right]$} & - & & - & & & & 11,08 & & - & & & \\
\hline $\mathrm{CORV}_{\mathrm{SF}}$ & {$\left[\mathrm{kgDQO} \cdot \mathrm{m}^{-3} \cdot \mathrm{d}^{-1}\right]$} & - & & - & & & & 2,39 & & - & & & \\
\hline $\mathrm{CORE}_{\mathrm{CF}}$ & {$\left[\mathrm{kgSAC} \cdot \mathrm{kgSVT}^{-1} \cdot \mathrm{d}^{-1}\right]$} & - & & - & & & & 1,66 & & - & & & \\
\hline $\mathrm{CORE}_{\mathrm{SF}}$ & {$\left[\mathrm{kgDQO} \cdot \mathrm{kgSVT}^{-1} \cdot \mathrm{d}^{-1}\right]$} & - & & - & & & & 0,36 & & - & & & \\
\hline $\mathrm{n}_{\mathrm{H} 2}$ & {$\left[\mathrm{molH}_{2} \cdot \mathrm{d}^{-1}\right]$} & - & & - & & & & 0,12 & & - & & 2 & ( \\
\hline PrM & {$\left[\mathrm{molH}_{2} \cdot \mathrm{m}^{-3} \cdot \mathrm{d}^{-1}\right]$} & 18,69 & & - & & & & - & & - & & & \\
\hline PrME & {$\left[\mathrm{molH}_{2} \cdot \mathrm{kgSVT}^{-1} \cdot \mathrm{d}^{-1}\right]$} & 5,07 & & - & & & & - & & - & & & \\
\hline $\mathrm{RMCA}_{\mathrm{C}, \mathrm{n}}$ & {$\left[\mathrm{molH}_{2} \cdot \mathrm{kgSAC}^{-1}\right]$} & 2,83 & & - & & & & - & & - & & & \\
\hline $\mathrm{RMCA}_{\mathrm{S}, \mathrm{n}}$ & {$\left[\mathrm{molH}_{2} \cdot \mathrm{kgDQO}^{-1}\right]$} & 2,51 & & - & & & & - & & - & & & \\
\hline $\mathrm{RMCR}_{\mathrm{C}, \mathrm{n}}$ & {$\left[\mathrm{molH}_{2} \cdot \mathrm{kgSAC}^{-1}\right]$} & 3,04 & & - & & & & - & & - & & & \\
\hline $\mathrm{RMCR}_{\mathrm{S}, \mathrm{n}}$ & {$\left[\mathrm{molH}_{2} \cdot \mathrm{kgDQO}^{-1}\right]$} & 14,09 & & - & & & & - & & - & & & \\
\hline
\end{tabular}

(*) Entre parêntese o número de amostras considerado no cálculo da média

O reator foi eficiente na remoção de sacarose como pode ser observado na Figura 5.40 com a evolução das concentrações afluente e efluente (total e filtrada). A Figura 5.41 apresenta a evolução das eficiências de conversão que ficaram estáveis perto de um valor de $91 \%$ na forma total 
e $93 \%$ na forma filtrada. O reator continuou apresentando baixa eficiência de remoção de DQO como pode ser observado na Figura 5.42 com a evolução das concentrações em DQO afluente e efluente (total e filtrada). A Figura 5.43 apresenta a evolução das eficiências de remoção da DQO quem ficaram estáveis perto de um valor de $15 \%$ na forma total e $18 \%$ na forma filtrada.

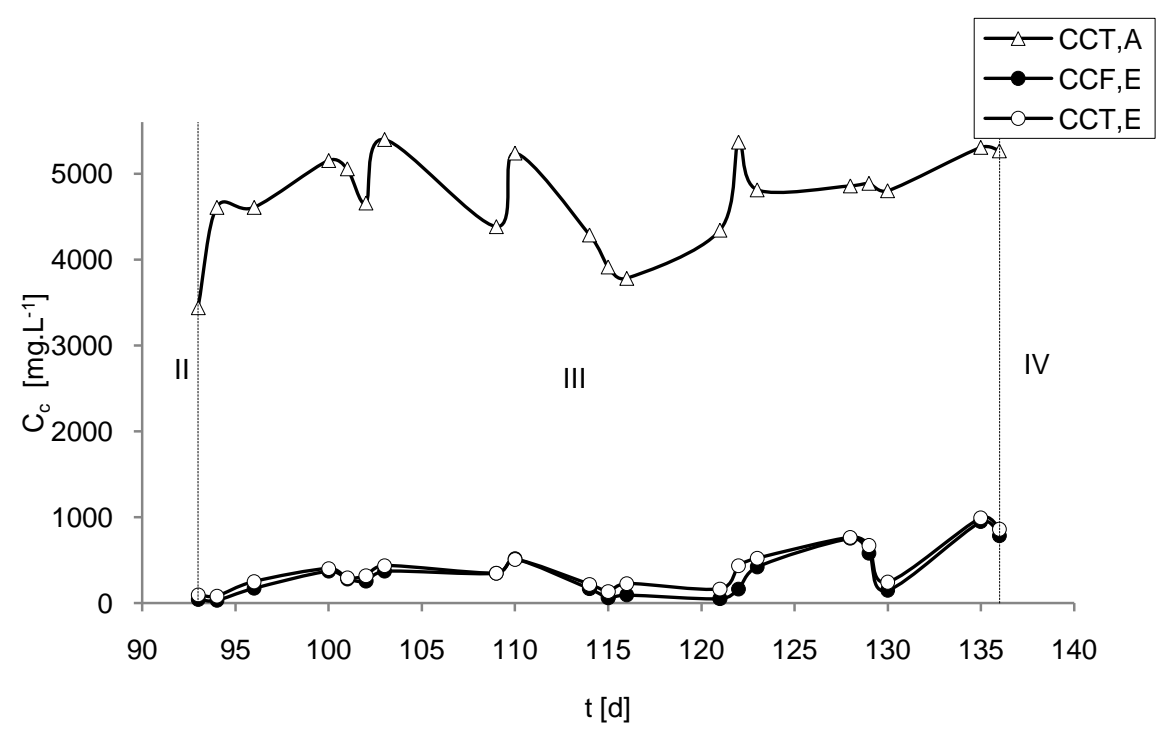

Figura 5.40 - Concentrações em carboidratos no afluente e efluente total e filtrado - Condição III.

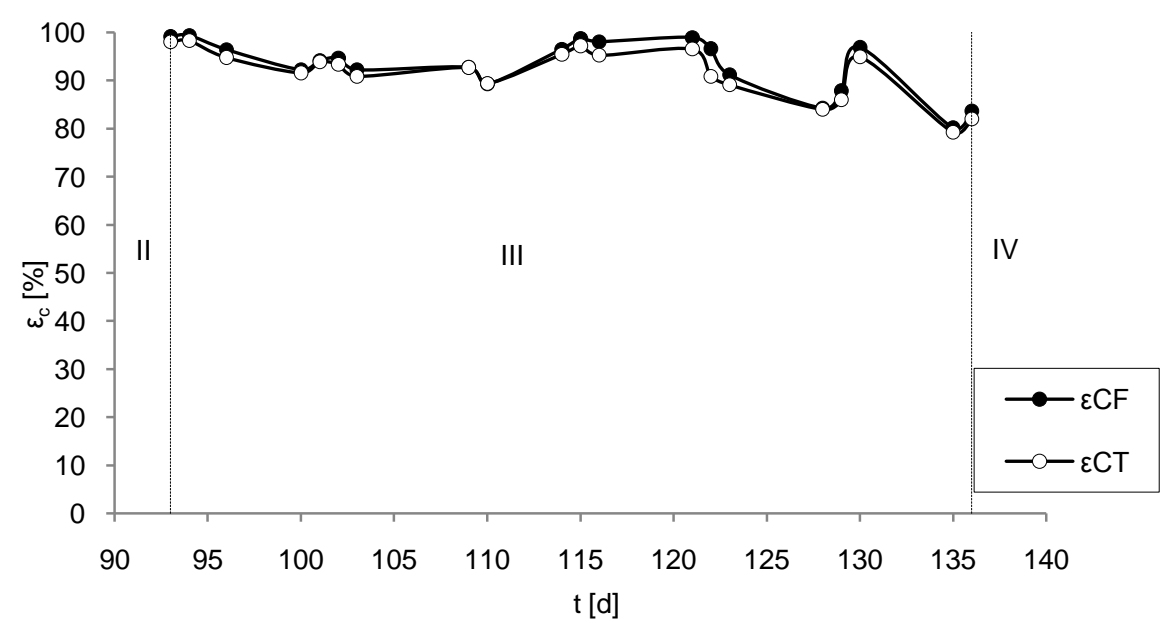

Figura 5.41 - Eficiências de conversão dos carboidratos na forma total e filtrada - Condição III. 


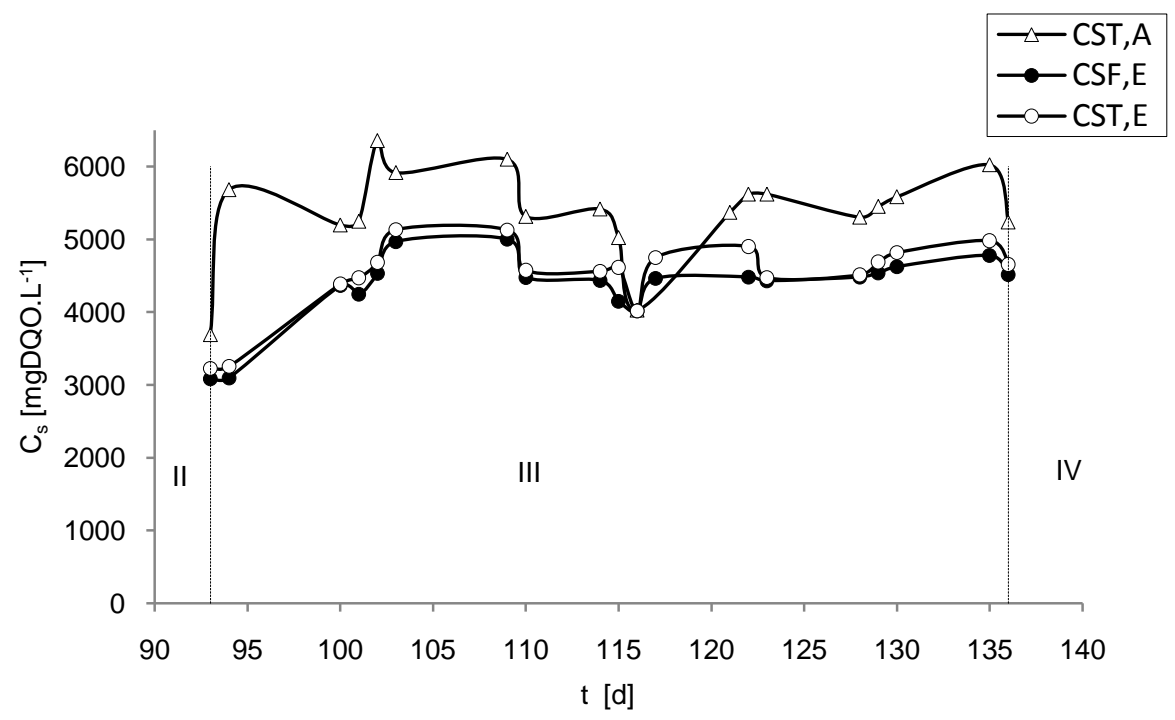

Figura 5.42- Concentrações em DQO no afluente e efluente total e filtrado - Condição III.

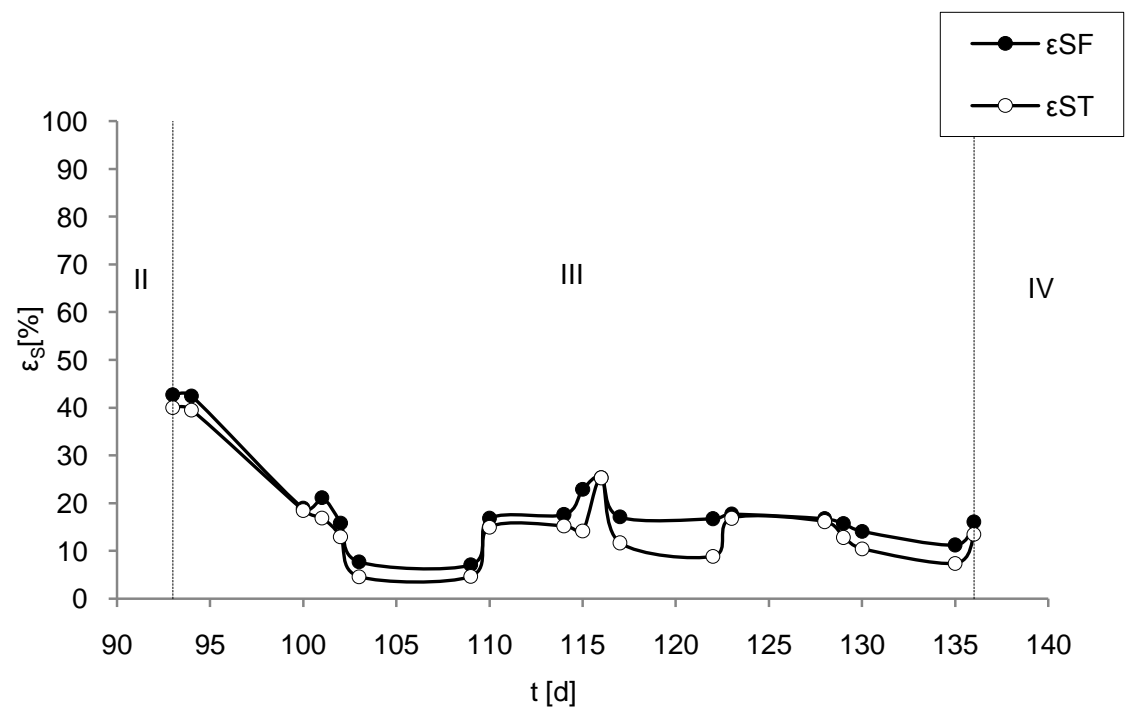

Figura 5.43- Eficiências de remoção da DQO na forma total e filtrada - Condição III.

A Figura 5.44 da quantificação dos ácidos totais voláteis totais mostra um acúmulo, sendo que a concentração média no efluente filtrado foi de 874 mgHAc.L ${ }^{-1}$. A Tabela 5.9 apresenta os resultados da quantificação dos compostos intermediários realizada por cromatografia gasosa. 
Dentre dos ácidos voláteis, o ácido Acético predominou seguido pelo ácido Butírico representado, respectivamente, $43,8 \%$ e 12,3\% dos compostos intermediários. O efluente apresentou também uma quantidade importante de etanol representando $27,6 \%$ dos compostos intermediários. O acúmulo de ácidos no reator levou a uma diminuição do $\mathrm{pH}$ da fase líquida conforme pode ser observado na Figura 5.45, resultante de um consumo da alcalinidade total conforme apresentado pela Figura 5.46. O valor médio do $\mathrm{pH}$ foi de 7,4 para o afluente contra 4,9 para o efluente. A alcalinidade média foi de $772 \mathrm{mgCaCO}_{3} \cdot \mathrm{L}^{-1}$ para o efluente contra $377 \mathrm{mgCaCO}_{3} \cdot \mathrm{L}^{-1}$ no efluente.

A variação da produção de biogás durante um ciclo ao longo da Condição III pode ser observado na Figura 5.47. O volume máximo produzido foi de $2168 \mathrm{~mL}$ o $136^{\circ}$ dia de operação do reator ( $43^{\circ}$ dia de operação da condição), com valor médio de $1645 \mathrm{~mL}$ e desvio padrão de $275 \mathrm{~mL}$, indicando variações durante a condição.

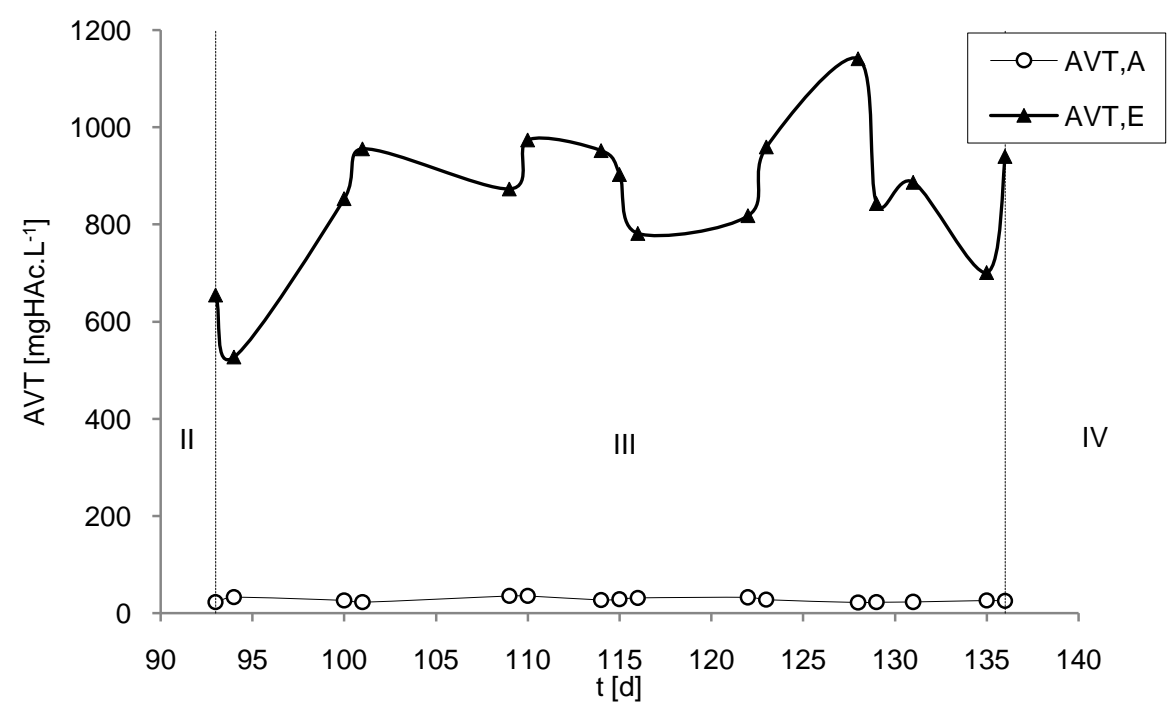

Figura 5.44- Concentrações em ácidos volateís totais por titulação no afluente e efluente - Condição III. 
Tabela 5.9 - Concentração média e composição dos compostos intermediários - Condição III.

\begin{tabular}{cccccccc}
\hline \multirow{2}{*}{ Espécies } & \multicolumn{3}{c}{ Concentrações média } & \multicolumn{3}{c}{ Repartição } \\
& \multicolumn{3}{c}{$\left[\mathrm{mg} . \mathrm{L}^{-1}\right]$} & \multicolumn{3}{c}{$\left[\begin{array}{c}{\left[\mathrm{mmol} . \mathrm{L}^{-1}\right]} \\
{[\%]}\end{array}\right.$} \\
\hline Acetona & 0,0 & \pm & 0,0 & 0,0 & \pm & 0,0 & 0,0 \\
Metanol & 0,0 & \pm & 0,0 & 0,0 & \pm & 0,0 & 0,0 \\
Etanol & 458,6 & \pm & 71,4 & 10,0 & \pm & 1,5 & 27,6 \\
n-Butanol & 8,5 & \pm & 1,2 & 0,1 & \pm & 0,0 & 0,5 \\
Acético & 729,1 & \pm & 90,6 & 12,1 & \pm & 1,5 & 43,8 \\
Porpiônico & 70,0 & \pm & 13,8 & 0,9 & \pm & 0,2 & 4,2 \\
Isobutírico & 59,1 & \pm & 17,6 & 0,7 & \pm & 0,2 & 3,5 \\
Butírico & 205,0 & \pm & 48,7 & 2,3 & \pm & 0,6 & 12,3 \\
Isovalérico & 33,3 & \pm & 40,4 & 0,3 & \pm & 0,4 & 2,0 \\
Valérico & 22,9 & \pm & 3,4 & 0,2 & \pm & 0,0 & 1,4 \\
Capróico & 78,0 & \pm & 21,4 & 0,7 & \pm & 0,2 & 4,7 \\
\hline
\end{tabular}

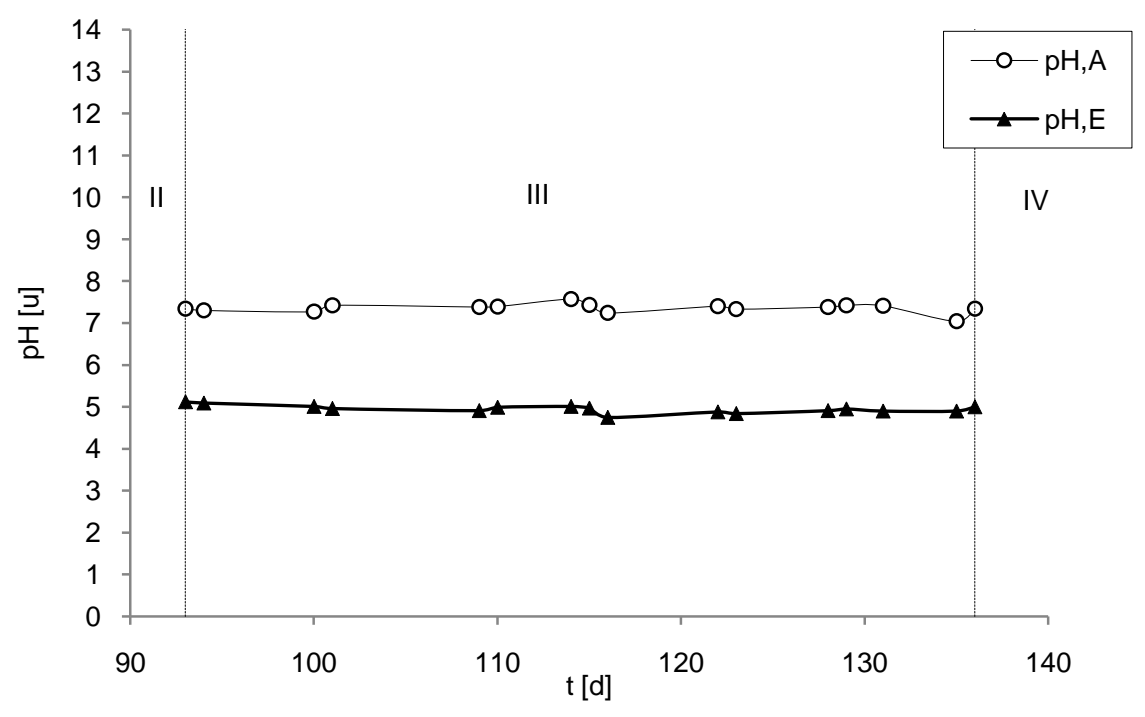

Figura 5.45- pH afluente e efluente - Condição III. 


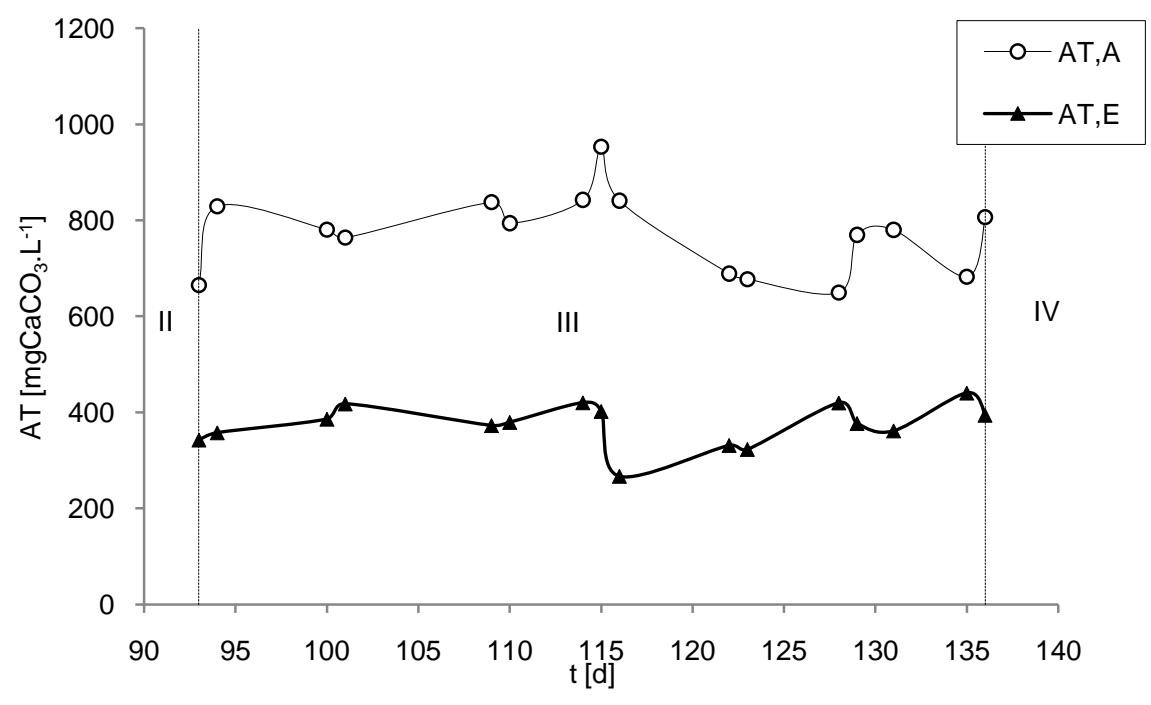

Figura 5.46- Alcalinidades totais por titulação no afluente e efluente - Condição III.

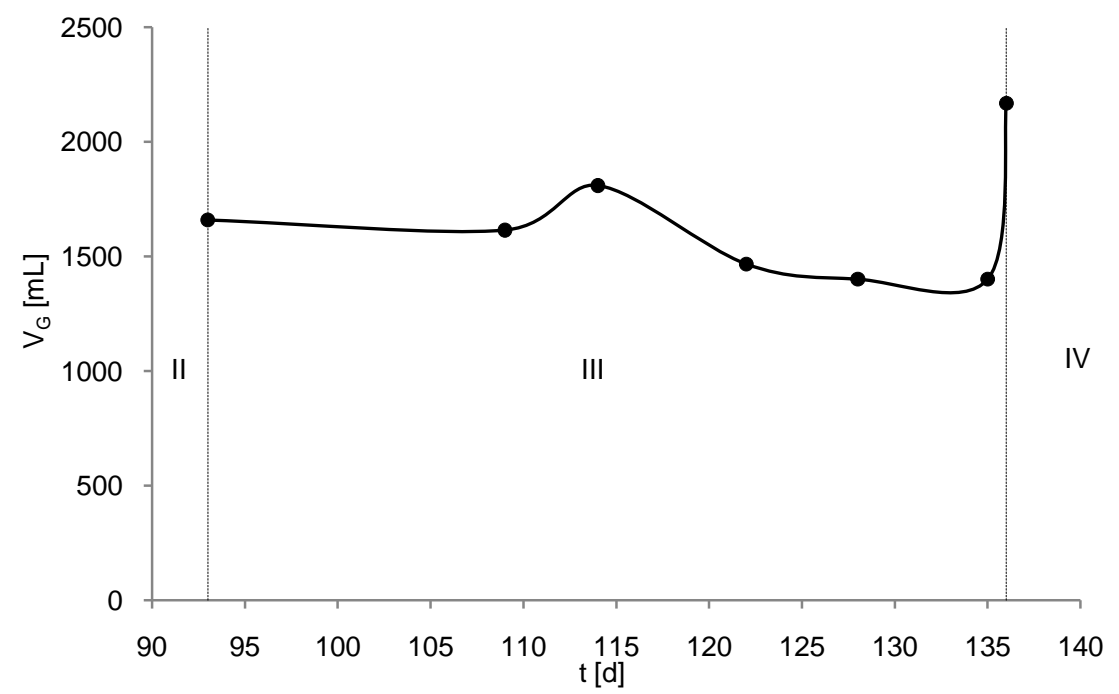

Figura 5.47- Variação da produção volumétrica de biogás durante um ciclo - Condição III. 


\subsubsection{Perfis ao longo do ciclo}

A Figura 5.48 mostra a evolução da concentração em carboidratos totais ao longo do ciclo. Ao iniciou do ciclo (tempo zero) o volume afluente foi diluído ao volume residual resultando em uma concentração em sacarose da ordem de $2500 \mathrm{mg} \cdot \mathrm{L}^{-1}$. A conversão da sacarose se faz de maneira progressiva ao longo do ciclo. A Figura 5.49 mostra a evolução da concentração em DQO ao longo do ciclo. Pode ser observada uma remoção baixa em DQO levando a uma alta concentração em DQO no volume residual.

A sacarose convertida em produtos intermediários do metabolismo anaeróbio leva a um acúmulo de ácidos voláteis conforme pode ser observado na Figura 5.50. A concentração em ácidos voláteis totais aumenta claramente durante a fase de reação para atingir um máximo no final do ciclo. Os resultados dos compostos intermediários por cromatografia em fase gasosa são apresentados na Figura 5.51. Observa se claramente uma predominância do ácido acético passando de uma concentração inicial de 405,1 mg.L $\mathrm{L}^{-1}$ até um máximo de 729,1 mg.L. $\mathrm{L}^{-1}$ no final do ciclo.

$\mathrm{O}$ pH diminua instantaneamente com a diluição do afluente ao inicio do ciclo e permanece estável ao longo da operação. Entretanto uma ligeira diminuição pode ser observada, provavelmente devido ao acúmulo de ácidos voláteis conforme representado na Figura 5.52. A estabilidade do pH mesmo com a produção de ácidos voláteis é devido ao tamponamento do sistema pelo consumo de alcalinidade ao longo do ciclo. A Figura 5.53 apresenta a evolução da alcalinidade total no reator ao longo do ciclo.

A produção volumétrica acumulada de biogás pode ser observada na Figura 5.54. A curva de produção tem comportamento crescente no inicio do ciclo e tende a se estabilizar no final. A caracterização qualitativa do biogás por cromatografia permitiu avaliar os volumes específicos de gases produzidos ao longo do ciclo. A Tabela 5.10 apresentando os resultados obtidos mostra uma produção acumulada de $453 \mathrm{~mL}$ de hidrogênio $(24,2 \%), 1412 \mathrm{~mL}$ de dióxido de carbono $(75,2 \%)$ e 
$11 \mathrm{~mL}$ de metano $(0,6 \%)$. As curvas relativas à produção de cada gás são apresentadas na Figura 5.55 .

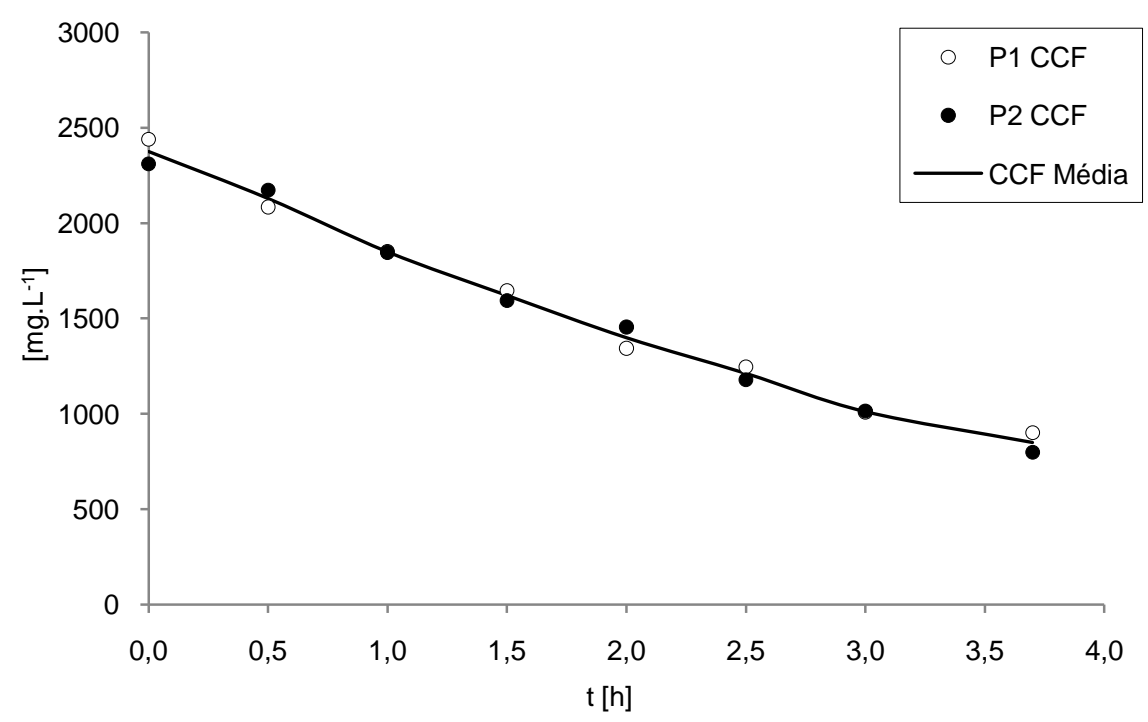

Figura 5.48- Perfil de evolução da concentração em carboidratos no reator - Condição III.

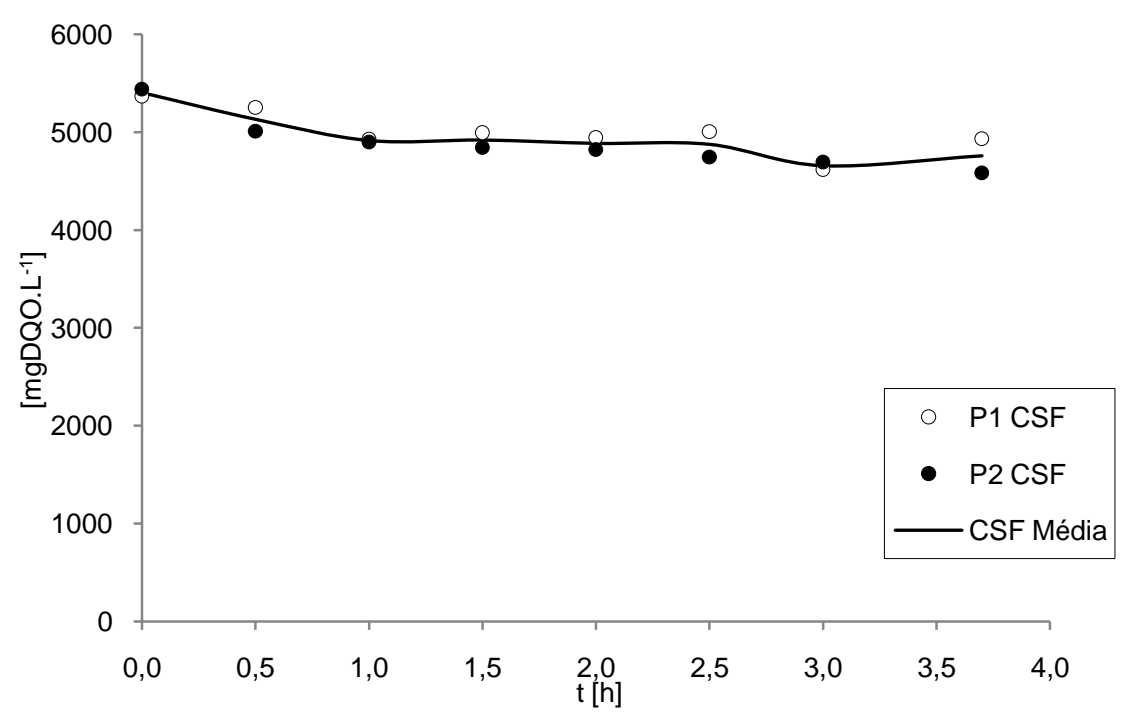

Figura 5.49- Perfil de evolução da concentração em DQO no reator- Condição III. 


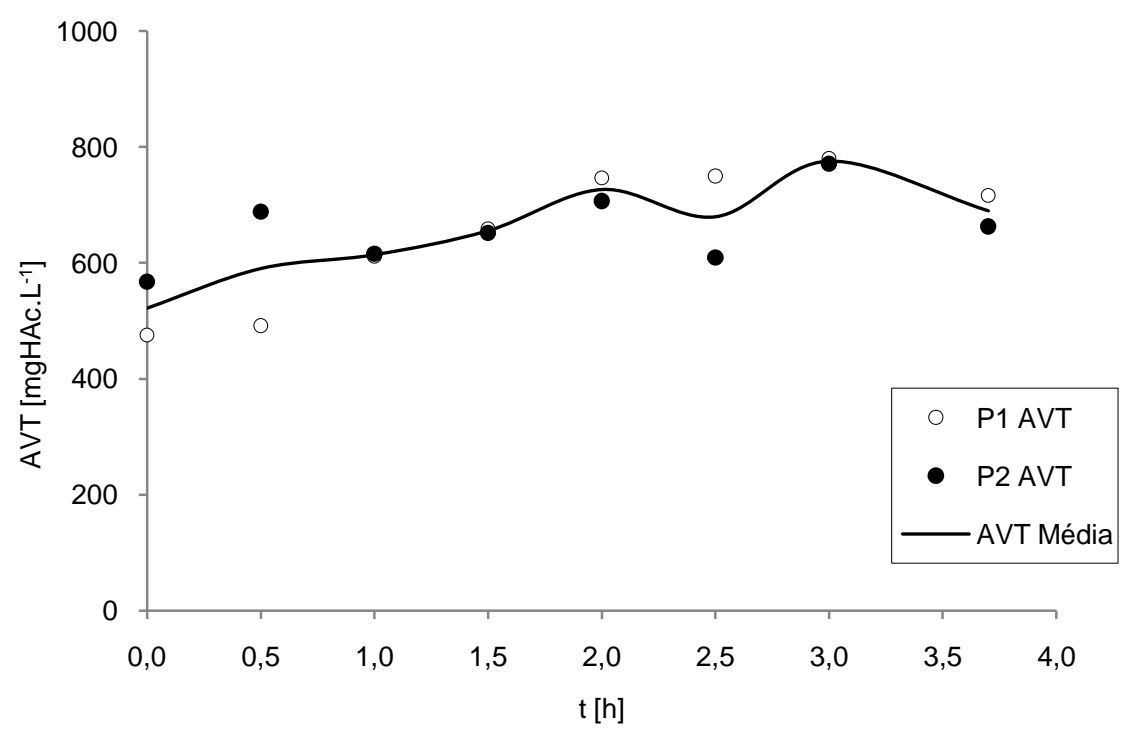

Figura 5.50- Perfil de evolução da concentração em ácidos volateís totais por titulação no reator- Condição III.

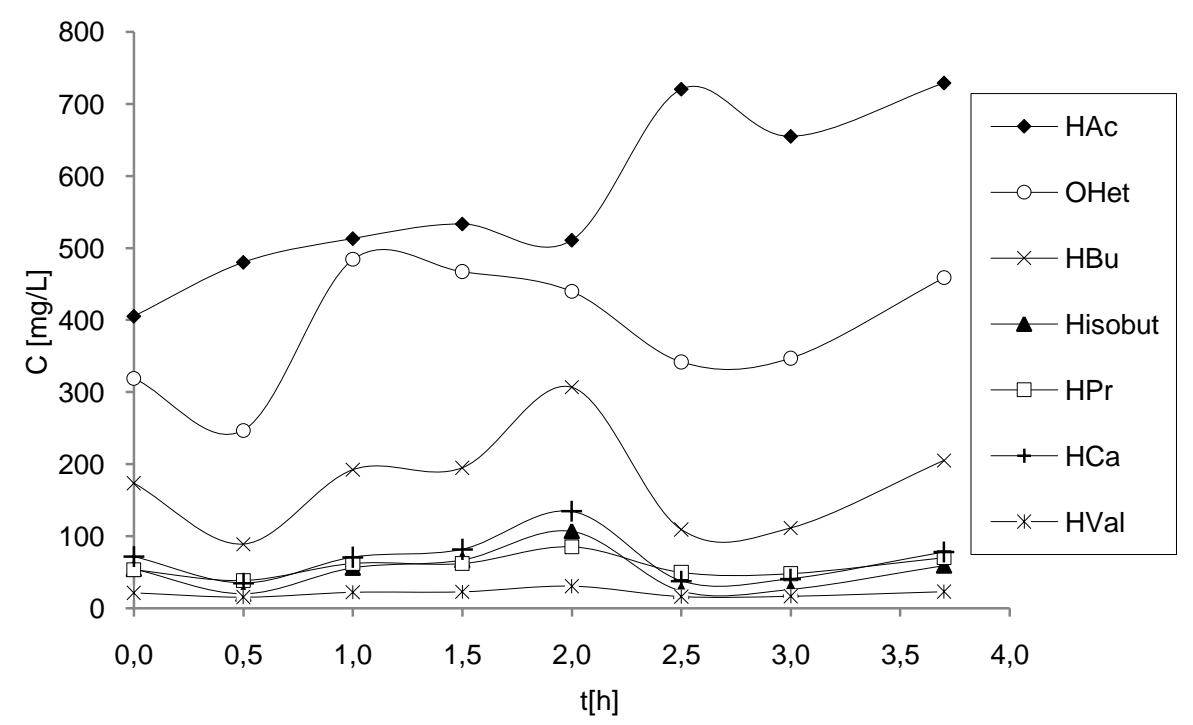

Figura 5.51 - Perfil de evolução das concentrações dos compostos intermediários - Condição III. 


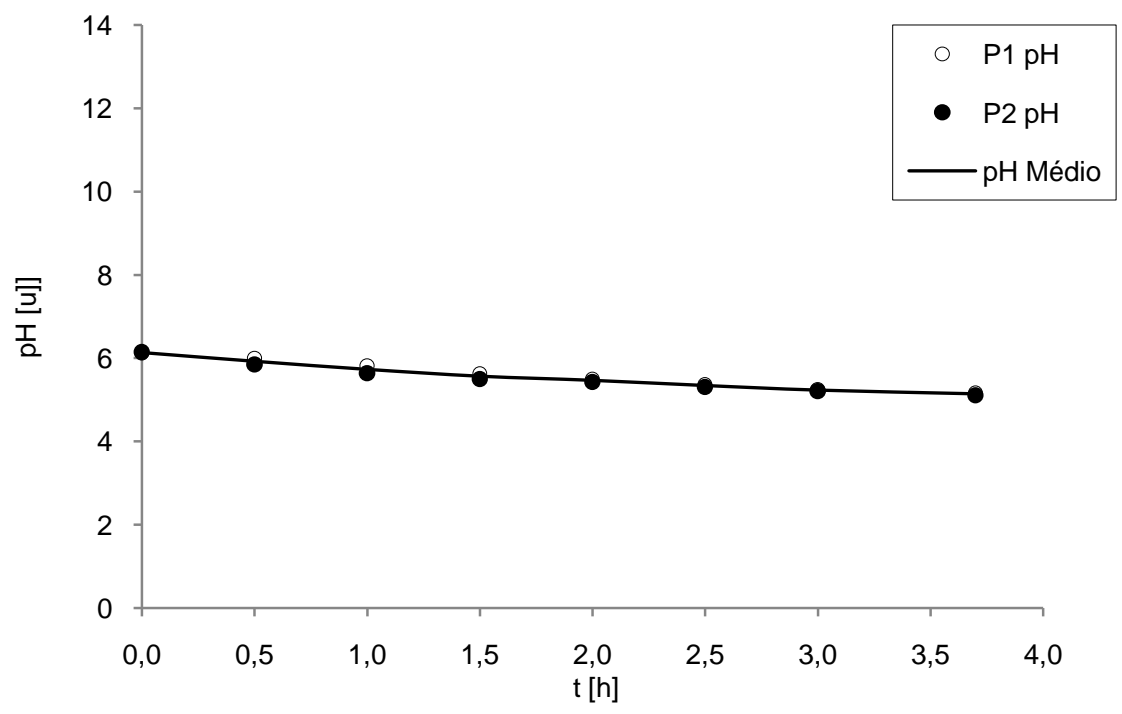

Figura 5.52- Perfil de evolução do pH no reator- Condição III.

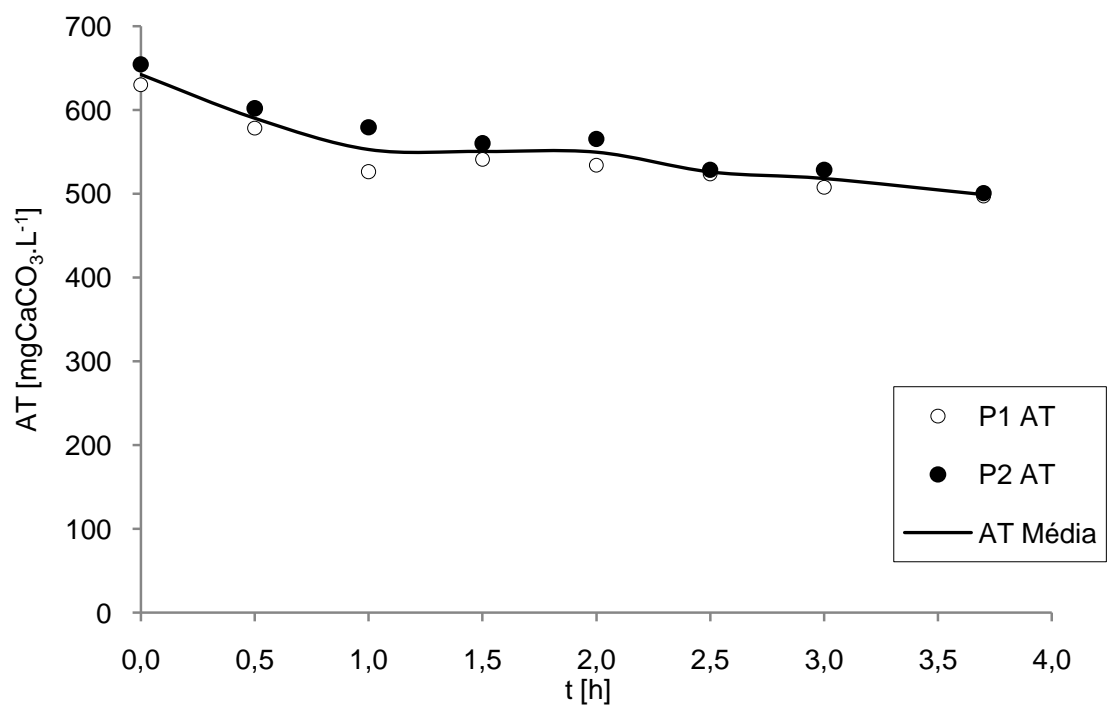

Figura 5.53- Perfil de evolução da alcalinidade total por titulação no reator - Condição III. 


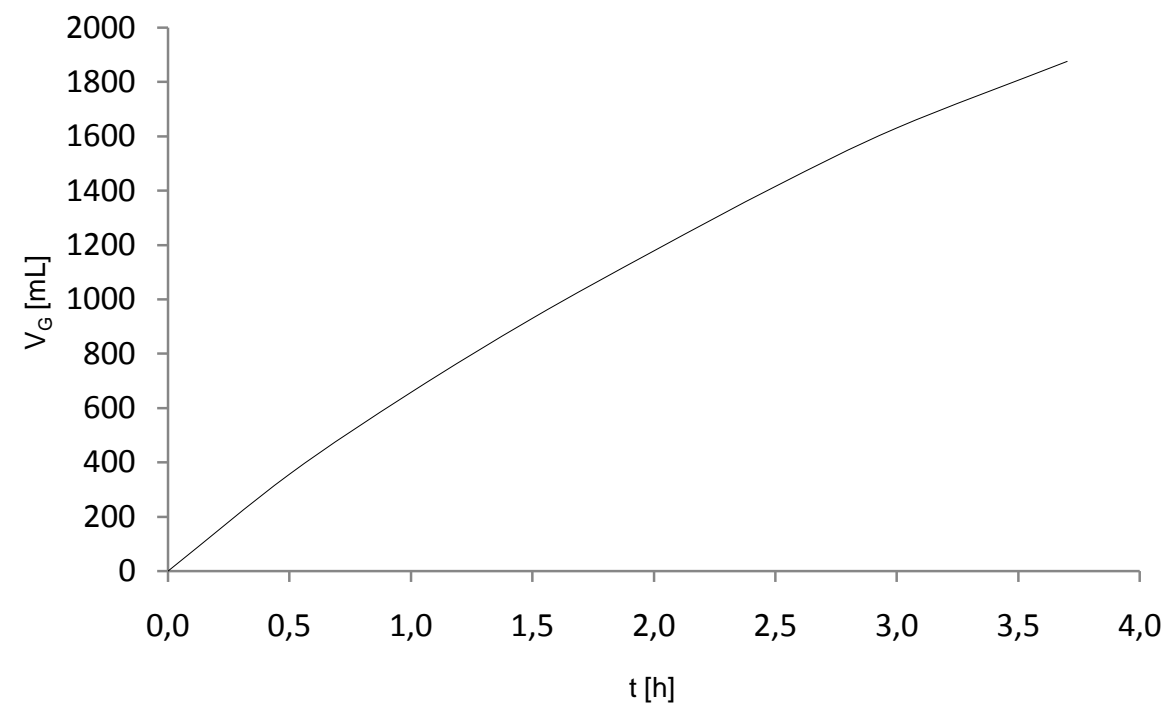

Figura 5.54- Perfil produção volumétrica acumulada de biogás Condição III.

Tabela 5.10 - Volumes específicos de gases acumulados e proporção de hidrogênio - Condição III.

\begin{tabular}{ccccc}
\hline Tempo & \multicolumn{3}{c}{ Volumes específicos } & Proporção de hidrogênio \\
& $\mathrm{V}_{\mathrm{H} 2}$ & $\mathrm{~V}_{\mathrm{CO} 2}$ & $\mathrm{~V}_{\mathrm{CH} 4}$ & $\% \mathrm{H}_{2}$ \\
\hline$[\mathrm{h}]$ & {$[\mathrm{mL}]$} & {$[\mathrm{mL}]$} & {$[\mathrm{mL}]$} & {$[\%]$} \\
\hline 0,0 & 0 & 0 & 0 & - \\
0,5 & 41 & 316 & 0 & 11,5 \\
1,0 & 100 & 558 & 0 & 15,2 \\
1,5 & 168 & 762 & 2 & 18,0 \\
2,0 & 235 & 940 & 4 & 19,9 \\
2,5 & 306 & 1104 & 6 & 21,6 \\
3,0 & 373 & 1250 & 8 & 22,9 \\
3,7 & 453 & 1412 & 11 & 24,2 \\
\hline
\end{tabular}




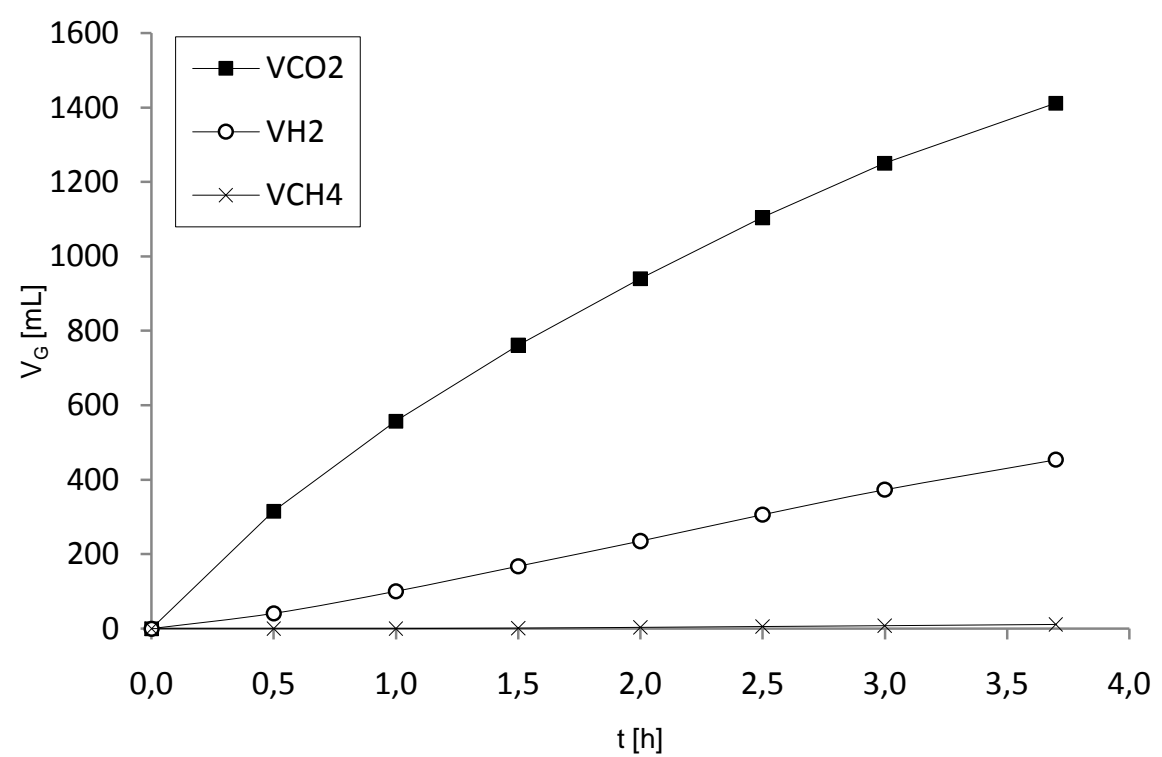

Figura 5.55 - Perfil produção volumétrica espécifica acumulada de gases - Condição III. 


\subsection{Condição experimental IV (DQO 5400 mg.L $\mathrm{L}^{-1}$ - TC 3h)}

\subsubsection{Monitoramento}

A Tabela 5.11 apresenta os valores médios obtidos durante os 27 dias de monitoramento da Condição IV. O reator continuou apresentando uma boa capacidade de retenção da biomassa com valores de sólidos volteis totais e filtrados efluentes da ordem de grandeza dos valores afluentes. A quantidade de biomassa presente no reator considerada nos cálculos de cargas orgânicas específicas foi determinado no final da condição. As cargas orgânicas volumétricas aplicadas reais durante a operação foram de $15,35 \mathrm{kgSAC} \cdot \mathrm{m}^{-3} \cdot \mathrm{d}^{-1} \mathrm{e} 16,81 \mathrm{kgDQO} \cdot \mathrm{m}^{-3} \cdot \mathrm{d}^{-1}$, considerando a sacarose e a DQO, respectivamente (valores nominais de $16,00 \mathrm{kgSAC} \cdot \mathrm{m}^{-3} \cdot \mathrm{d}^{-1} \mathrm{e} 18,00 \mathrm{kgDQO} \cdot \mathrm{m}^{-3} \cdot \mathrm{d}^{-1}$ ). 
Tabela 5.11 - Valores médios dos parâmetros monitorados Condição IV. (DQO 5400 mg.L.- ${ }^{-1}$-TC 3h)

\begin{tabular}{|c|c|c|c|c|c|c|c|c|c|c|c|}
\hline \multicolumn{2}{|r|}{ Parâmetro } & \multicolumn{3}{|c|}{ Afluente } & \multicolumn{7}{|c|}{ Efluente } \\
\hline$\overline{\mathrm{C}_{\mathrm{CT}}}$ & {$\left[\operatorname{mgSAC} . \mathrm{L}^{-1}\right]$} & 4605 & \pm & 274 & ( & $\begin{array}{ll}14 \quad) \\
\end{array}$ & 625 & \pm & 290 & & $14 \quad$ \\
\hline $\mathrm{C}_{\mathrm{CF}}$ & {$\left[\mathrm{mgSAC} \cdot \mathrm{L}^{-1}\right]$} & - & & - & & & 533 & \pm & 240 & ( & $14)$ \\
\hline$\varepsilon_{\mathrm{CT}}$ & {$[\%]$} & - & & - & & & 86 & \pm & 6 & & $14)$ \\
\hline$\varepsilon_{\mathrm{CF}}$ & {$[\%]$} & - & & - & & & 88 & \pm & 5 & & $14)$ \\
\hline $\mathrm{C}_{\mathrm{ST}}$ & {$\left[\mathrm{mgDQO} . \mathrm{L}^{-1}\right]$} & 5042 & \pm & 444 & ( & $14 \quad)$ & 4263 & \pm & 367 & & $14)$ \\
\hline $\mathrm{C}_{\mathrm{SF}}$ & {$\left[\mathrm{mgDQO} . \mathrm{L}^{-1}\right]$} & - & & - & & & 4003 & \pm & 281 & ( & $14)$ \\
\hline$\varepsilon_{\mathrm{ST}}$ & [\%] & - & & - & & & 15 & \pm & 7 & & $14)$ \\
\hline$\varepsilon_{\mathrm{SF}}$ & {$[\%]$} & - & & - & & & 21 & \pm & 6 & & $14)$ \\
\hline $\mathrm{pH}$ & {$[\mathrm{u}]$} & 7,4 & \pm & 0,2 & ( & $14 \quad)$ & 5,0 & \pm & 0,1 & ( & $14)$ \\
\hline AVT & {$\left[\mathrm{mgHAc} . \mathrm{L}^{-1]}\right.$} & 46 & \pm & 27 & ( & $14 \quad)$ & 890 & \pm & 81 & ( & $14)$ \\
\hline AT & {$\left[\mathrm{mgCACO}_{3} \cdot \mathrm{L}^{-1}\right]$} & 822 & \pm & 99 & ( & $14 \quad)$ & 382 & \pm & 76 & ( & $14)$ \\
\hline AP & {$\left[\mathrm{mgCACO}_{3} \cdot \mathrm{L}^{-1}\right]$} & 683 & \pm & 108 & ( & $14 \quad)$ & 0 & \pm & 0 & ( & $14)$ \\
\hline AI & {$\left[\mathrm{mgCACO}_{3} \cdot \mathrm{L}^{-1}\right]$} & 138 & \pm & 23 & ( & $14)$ & 382 & \pm & 76 & ( & $14)$ \\
\hline $\mathrm{AB}$ & {$\left[\mathrm{mgCACO}_{3} \cdot \mathrm{L}^{-1]}\right.$} & 789 & \pm & 99 & ( & $14 \quad)$ & 0 & \pm & 0 & ( & $14)$ \\
\hline ST & {$\left[\mathrm{mg} . \mathrm{L}^{-1}\right]$} & 6116 & \pm & 367 & ( & $4 \quad)$ & 3387 & \pm & 322 & ( & $4 \quad)$ \\
\hline SVT & {$\left[\mathrm{mg} . \mathrm{L}^{-1}\right]$} & 5026 & \pm & 379 & ( & $4 \quad)$ & 2325 & \pm & 353 & & $4 \quad)$ \\
\hline SST & {$\left[\mathrm{mg} . \mathrm{L}^{-1}\right]$} & 158 & \pm & 42 & ( & $4 \quad)$ & 214 & \pm & 53 & & $4 \quad)$ \\
\hline SSV & {$\left[\mathrm{mg} . \mathrm{L}^{-1}\right]$} & 92 & \pm & 38 & ( & $4 \quad)$ & 176 & \pm & 31 & & $4 \quad)$ \\
\hline $\mathrm{M}_{\mathrm{SVT}}$ & {$[\mathrm{g}]$} & - & & - & & & 23,96 & & - & & \\
\hline $\mathrm{C}_{\mathrm{X}-\mathrm{SVT}}$ & [g.g-suporte ${ }^{-1}$ ] & - & & - & & & 0,02 & & - & & \\
\hline $\mathrm{C}_{\mathrm{X} \text {-svT }}$ & {$\left[\mathrm{g} . \mathrm{L}^{-1}\right]$} & - & & - & & & 6,66 & & - & & \\
\hline $\operatorname{COAV}_{\mathrm{CT}}$ & {$\left[\mathrm{kgSAC} \cdot \mathrm{m}^{-3} \cdot \mathrm{d}^{-1}\right]$} & 15,35 & & - & & & - & & - & & \\
\hline $\mathrm{COAV}_{\mathrm{ST}}$ & {$\left[\mathrm{kgDQO} \cdot \mathrm{m}^{-3} \cdot \mathrm{d}^{-1}\right]$} & 16,81 & & - & & & - & & - & & \\
\hline $\operatorname{COAE}_{\mathrm{CT}}$ & {$\left[\mathrm{kgSAC} \cdot \mathrm{kgSVT}^{-1} \cdot \mathrm{d}^{-1}\right]$} & 2,31 & & - & & & - & & - & & \\
\hline $\mathrm{COAE}_{\mathrm{ST}}$ & {$\left[\mathrm{kgDQO} \cdot \mathrm{kgSVT}^{-1} \cdot \mathrm{d}^{-1}\right]$} & 2,53 & & - & & & - & & - & & \\
\hline $\mathrm{CORV}_{\mathrm{CF}}$ & {$\left[\operatorname{kgSAC} \cdot \mathrm{m}^{-3} \cdot \mathrm{d}^{-1}\right]$} & - & & - & & & 13,57 & & - & & \\
\hline $\mathrm{CORV}_{\mathrm{SF}}$ & {$\left[\mathrm{kgDQO} \cdot \mathrm{m}^{-3} \cdot \mathrm{d}^{-1}\right]$} & - & & - & & & 3,46 & & - & & \\
\hline $\mathrm{CORE}_{\mathrm{CF}}$ & {$\left[\mathrm{kgSAC} \cdot \mathrm{kgSVT}^{-1} \cdot \mathrm{d}^{-1}\right]$} & - & & - & & & 2,04 & & - & & \\
\hline $\mathrm{CORE}_{\mathrm{SF}}$ & {$\left[\mathrm{kgDQO} \cdot \mathrm{kgSVT}^{-1} \cdot \mathrm{d}^{-1}\right]$} & - & & - & & & 0,52 & & - & & \\
\hline $\mathrm{n}_{\mathrm{H} 2}$ & {$\left[\mathrm{molH}_{2} \cdot \mathrm{d}^{-1}\right]$} & - & & - & & & 0,12 & & - & & $3)$ \\
\hline PrM & {$\left[\mathrm{molH}_{2} \cdot \mathrm{m}^{-3} \cdot \mathrm{d}^{-1}\right]$} & 18,58 & & - & & & - & & - & & \\
\hline PrME & {$\left[\mathrm{molH}_{2} \cdot \mathrm{kgSVT}^{-1} \cdot \mathrm{d}^{-1}\right]$} & 5,04 & & - & & & - & & - & & \\
\hline $\mathrm{RMCA}_{\mathrm{C}, \mathrm{n}}$ & {$\left[\mathrm{molH}_{2} \cdot \mathrm{kgSAC}^{-1}\right]$} & 2,19 & & - & & & - & & - & & \\
\hline $\mathrm{RMCA}_{\mathrm{S}, \mathrm{n}}$ & {$\left[\mathrm{molH}_{2} \cdot \mathrm{kgDQO}^{-1}\right]$} & 2,00 & & - & & & - & & - & & \\
\hline $\mathrm{RMCR}_{\mathrm{C}, \mathrm{n}}$ & {$\left[\mathrm{molH}_{2} \cdot \mathrm{kgSAC}^{-1}\right]$} & 2,47 & & - & & & - & & - & & \\
\hline $\mathrm{RMCR}_{\mathrm{S}, \mathrm{n}}$ & {$\left[\mathrm{molH}_{2} \cdot \mathrm{kgDQO}^{-1}\right]$} & 9,68 & & - & & & - & & - & & \\
\hline $\mathrm{V}_{\mathrm{A}}$ & {$[\mathrm{L}]$} & 1,5 & & & & & & & & & \\
\hline$V_{R}$ & {$[\mathrm{~L}]$} & 3,6 & & & & & & & & & \\
\hline
\end{tabular}

(*) Entre parêntese o número de amostras considerado no cálculo da média

A eficiência de remoção da sacarose diminuiu um pouco, mas continuou alta como pode ser observado na Figura 5.56 com a evolução das concentrações afluente e efluente total e filtrada. A 
Figura 5.57 apresenta a evolução das eficiências de conversão que ficaram estáveis perto de um valor de $86 \%$ na forma total e $88 \%$ na forma filtrada. O reator continuou apresentando baixa eficiência de remoção de DQO como pode ser observado na Figura 5.58 com a evolução das concentrações em DQO afluente e efluente (total e filtrada). A Figura 5.59 apresenta a evolução das eficiências de remoção da DQO quem ficaram estáveis perto de um valor de $15 \%$ na forma total e $21 \%$ na forma filtrada.

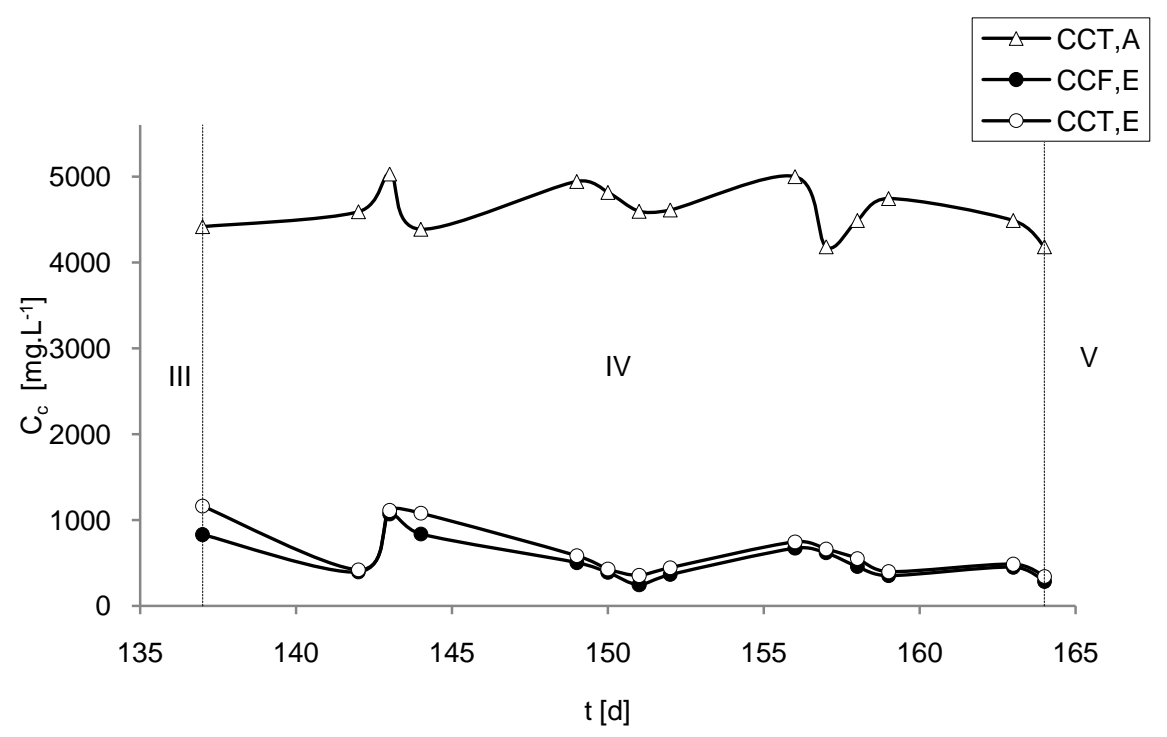

Figura 5.56 - Concentrações em carboidratos totais no afluente e efluente total e filtrado - Condição IV. 


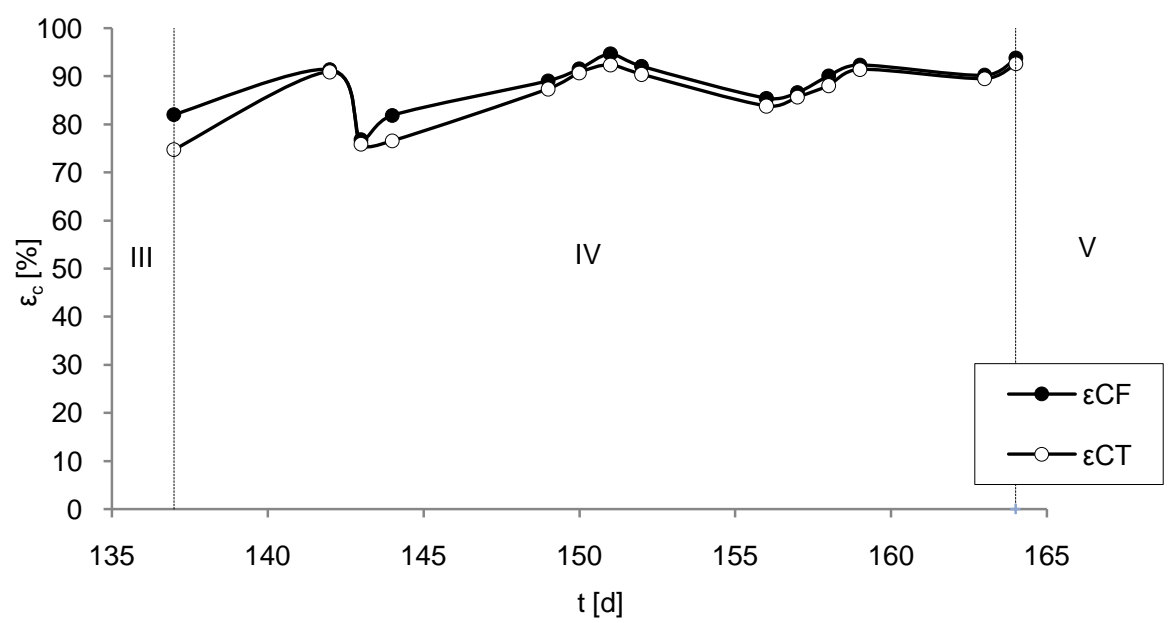

Figura 5.57 - Eficiências de conversão dos carboidratos totais na forma total e filtrada - Condição IV.

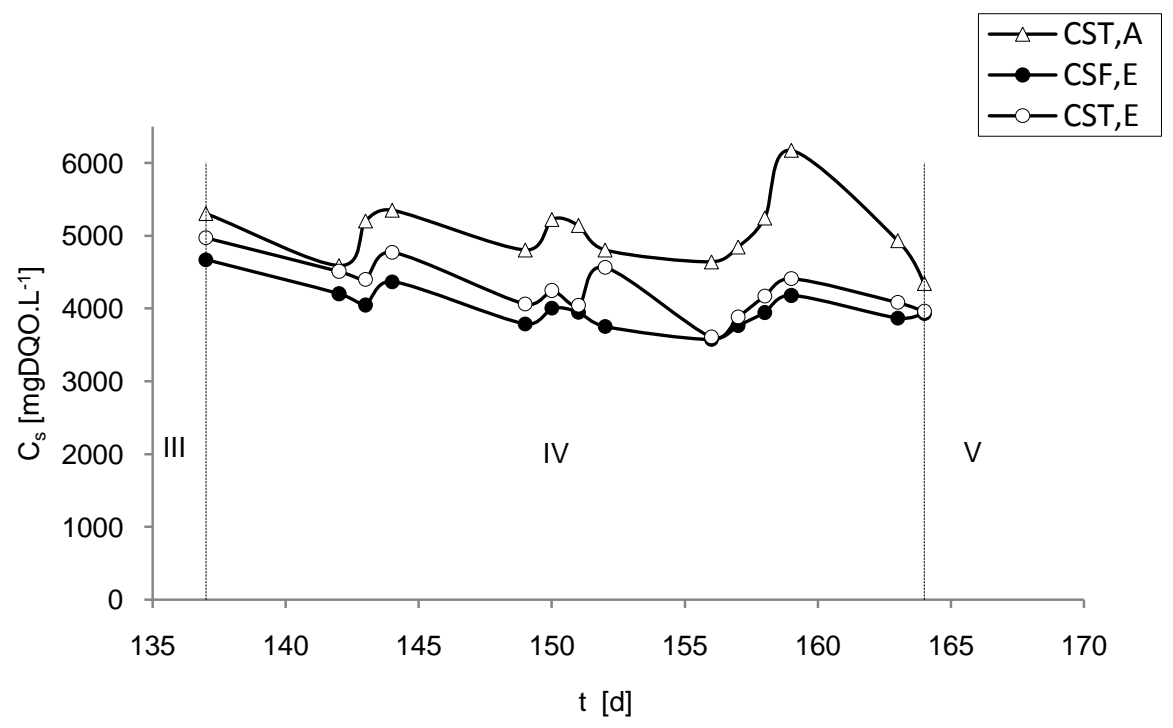

Figura 5.58- Concentrações em DQO no afluente e efluente total e filtrado - Condição IV. 


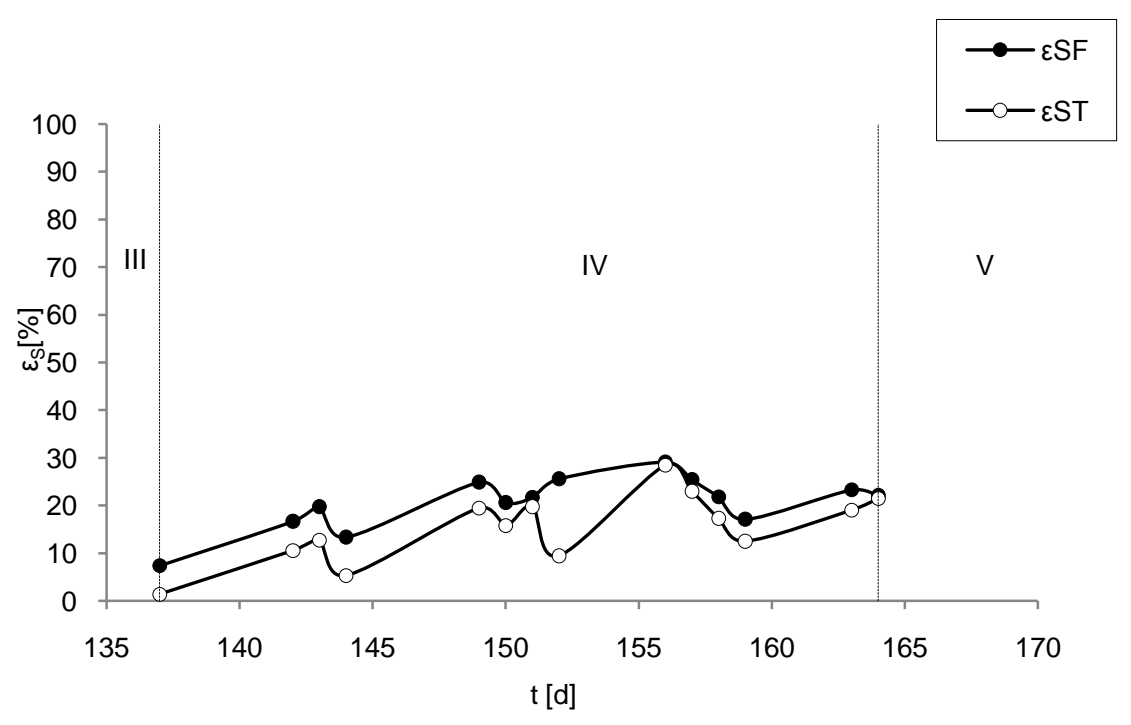

Figura 5.59- Eficiências de remoção da DQO na forma total e filtrada - Condição IV.

A Figura 5.60 mostra a quantificação dos ácidos voláteis totais, cuja concentração média no efluente filtrado foi de $890 \mathrm{mgHAc} . \mathrm{L}^{-1}$. A Tabela 5.12 apresenta os resultados da quantificação dos compostos intermediários realizada por cromatografia em fase gasosa. Dentre os ácidos voláteis, o ácido Acético predominou seguido pelo ácido Butírico representado respectivamente 38,2\% e $11,5 \%$ dos compostos intermediários. O efluente apresentou também uma quantidade importante de etanol representando 33,5\% dos compostos intermediários.

$\mathrm{O}$ acúmulo de ácidos no reator levou a uma diminuição do $\mathrm{pH}$ da fase líquida conforme pode ser observado na Figura 5.61, resultando em um consumo da alcalinidade total conforme apresentado pela Figura 5.62 do monitoramento das alcalinidades totais efluente e afluente. O valor médio do $\mathrm{pH}$ foi de 7,4 para o afluente contra 5,0 para o efluente. A alcalinidade média foi de 822 $\mathrm{mgCaCO}_{3} \cdot \mathrm{L}^{-1}$ para o efluente contra $382 \mathrm{mgCaCO}_{3} \cdot \mathrm{L}^{-1}$ no efluente.

A variação da produção de biogás durante um ciclo ao longo da Condição IV pode ser observado na Figura 5.63. O volume máximo produzido foi de $1715 \mathrm{~mL}$ no $144^{\circ}$ dia de operação do reator ( $7^{\circ}$ dia de operação da condição), com o valor médio de $1281 \mathrm{~mL}$ e desvio padrão de $357 \mathrm{~mL}$ indicando variações durante a condição. 


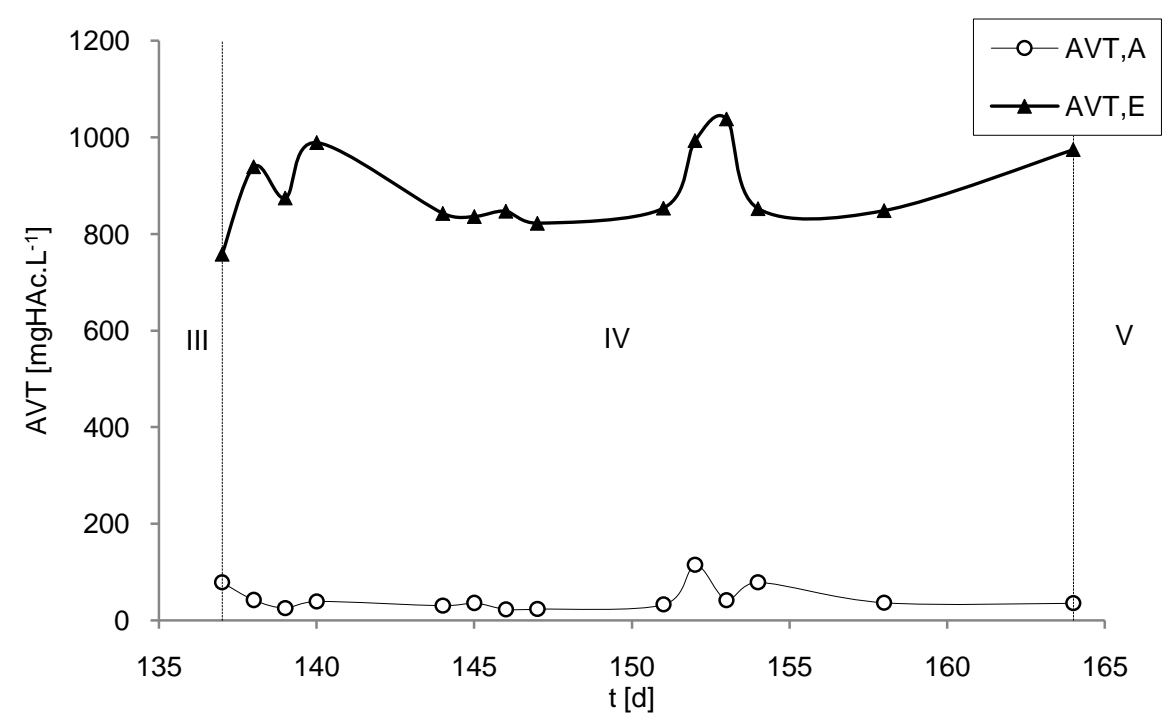

Figura 5.60- Concentrações em ácidos volateís totais por titulação no afluente e efluente - Condição IV.

Tabela 5.12 - Concentração média e composição dos compostos intermediários - Condição IV.

\begin{tabular}{cccccccc}
\hline Espécies & \multicolumn{9}{c}{ Concentração média } & \multicolumn{3}{c}{ Repartição } \\
& \multicolumn{3}{c}{$\left[\mathrm{mg.L}^{-1}\right]$} & \multicolumn{1}{c}{$\left[\begin{array}{c}\left.\mathrm{mmol}^{-1}\right] \\
{[\%]}\end{array}\right.$} \\
\hline Acetona & 0,0 & \pm & 0,0 & 0,0 & \pm & 0,0 & 0,0 \\
Metanol & 0,0 & \pm & 0,0 & 0,0 & \pm & 0,0 & 0,0 \\
Etanol & 542,6 & \pm & 150,8 & 11,8 & \pm & 3,3 & 33,5 \\
n-Butanol & 4,6 & \pm & 4,0 & 0,1 & \pm & 0,1 & 0,3 \\
Acético & 618,9 & \pm & 68,0 & 10,3 & \pm & 1,1 & 38,2 \\
Porpiônico & 114,6 & \pm & 33,4 & 1,5 & \pm & 0,5 & 7,1 \\
Isobutírico & 49,6 & \pm & 28,5 & 0,6 & \pm & 0,3 & 3,1 \\
Butírico & 187,2 & \pm & 84,6 & 2,1 & \pm & 1,0 & 11,5 \\
Isovalérico & 9,0 & \pm & 1,9 & 0,1 & \pm & 0,0 & 0,6 \\
Valérico & 29,4 & \pm & 8,9 & 0,3 & \pm & 0,1 & 1,8 \\
Capróico & 66,2 & \pm & 31,2 & 0,6 & \pm & 0,3 & 4,1 \\
\hline
\end{tabular}




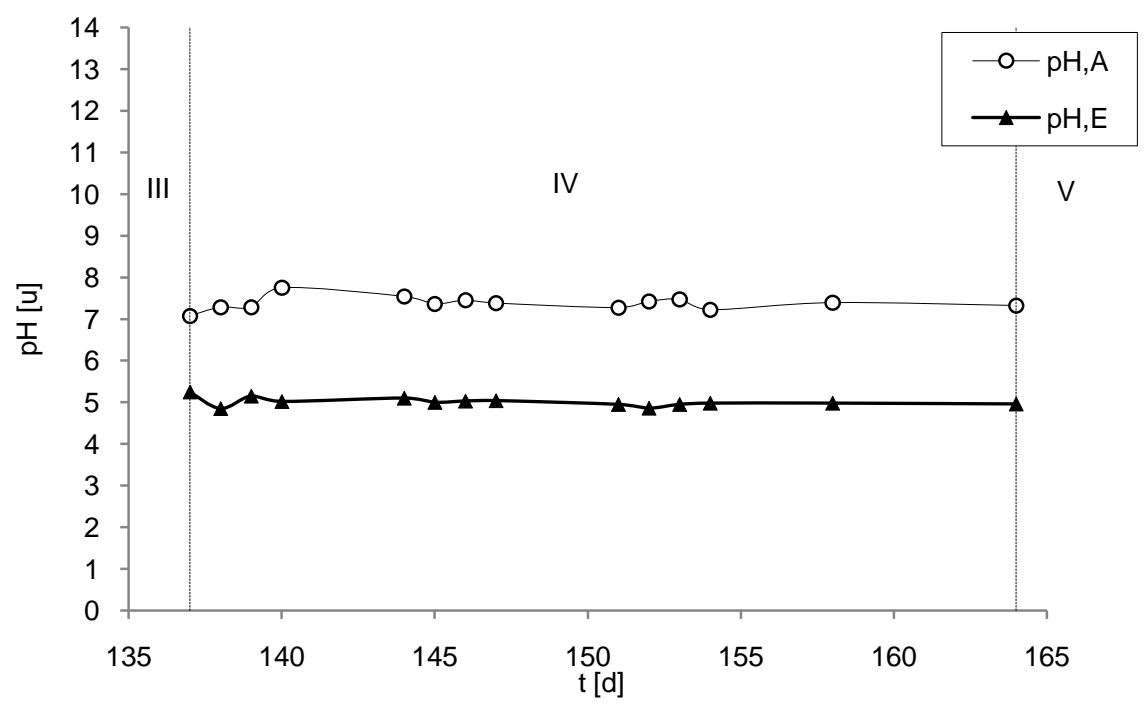

Figura 5.61- pH afluente e efluente - Condição IV.

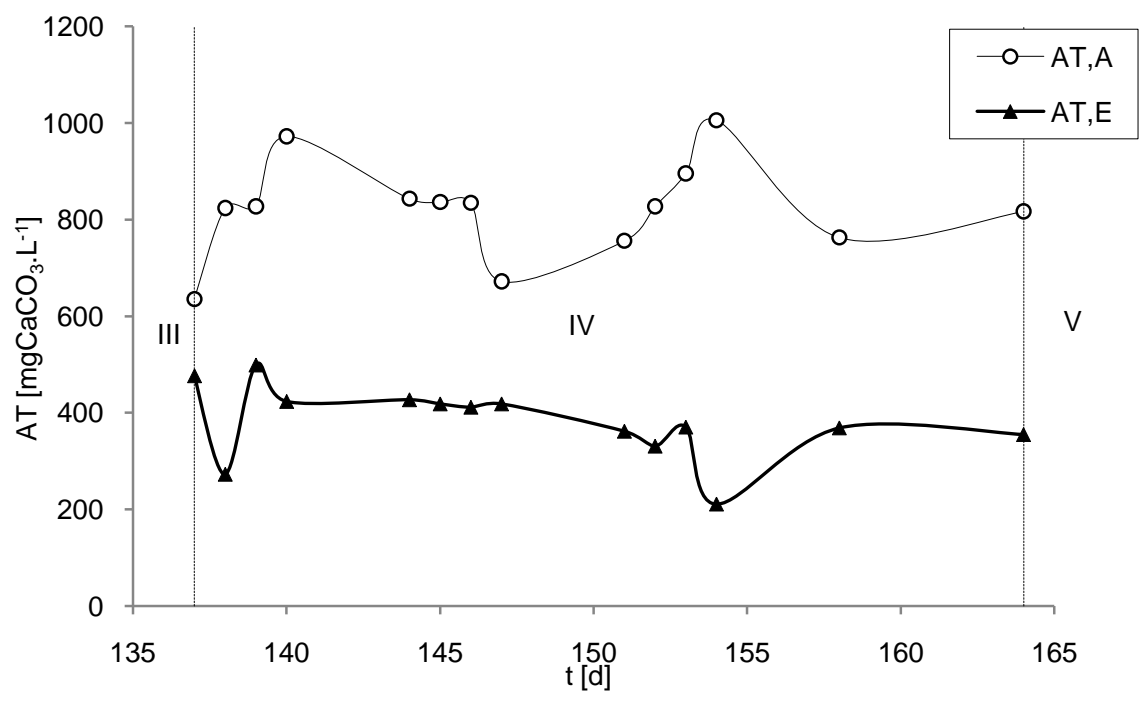

Figura 5.62- Alcalinidades totais por titulação no afluente e efluente - Condição IV. 


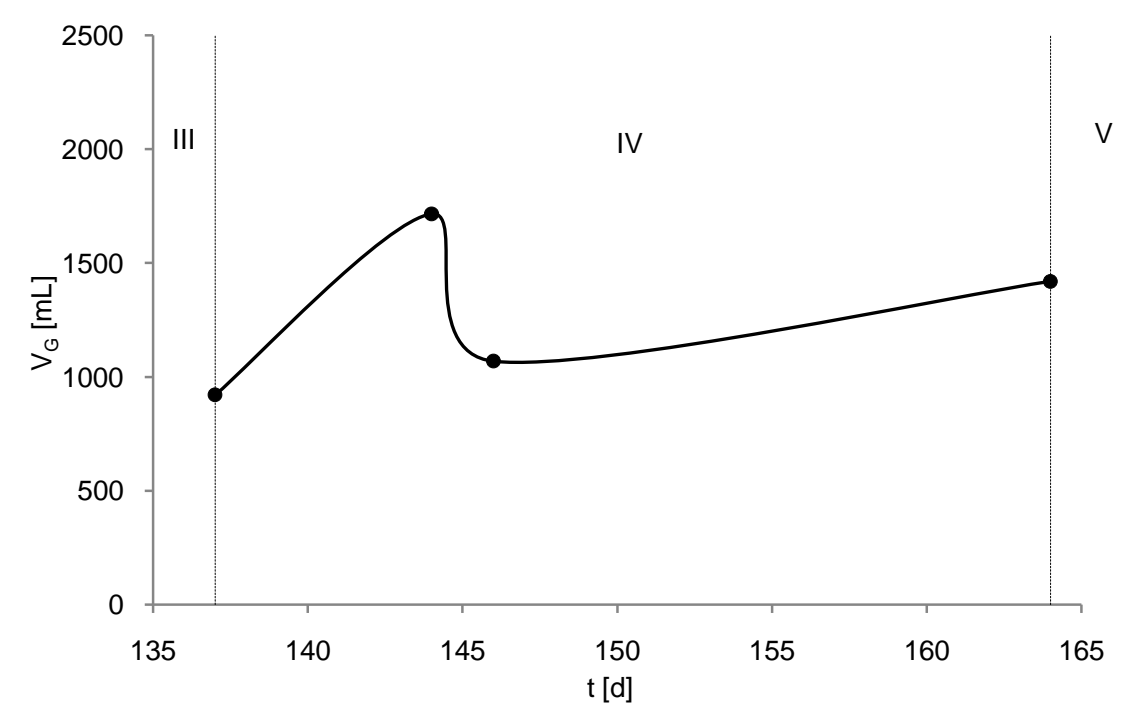

Figura 5.63- Variação da produção volumétrica de biogás durante um ciclo - Condição IV.

\subsubsection{Perfis ao longo do ciclo}

A Figura 5.63 mostra a evolução da concentração em carboidratos totais ao longo do ciclo. Ao iniciou do ciclo (tempo zero) o volume afluente foi diluído ao volume residual resultando em uma concentração em sacarose da ordem de $2000 \mathrm{mg} \cdot \mathrm{L}^{-1}$. A conversão da sacarose se faz de maneira progressiva ao longo do ciclo. A Figura 5.65 mostra a evolução da concentração em DQO ao longo do ciclo. Pode ser observada uma remoção baixa em DQO ao longo do ciclo levando a uma alta concentração em DQO no volume residual.

A sacarose convertida em produtos intermediários do metabolismo anaeróbio leva a um acúmulo de ácidos voláteis conforme pode ser observado na Figura 5.66. A concentração em ácidos voláteis totais aumenta claramente durante a fase de reação para atingir um máximo no final do ciclo. Os resultados dos compostos intermediários obtidos por cromatografia em fase gasosa são 
apresentados na Figura 5.67. Observa se claramente um aumento em ácido acético passando de uma concentração inicial de 359,1 mg.L $\mathrm{L}^{-1}$ até um máximo de 542,6 mg.L $\mathrm{L}^{-1}$ no final do ciclo.

$\mathrm{O}$ pH diminuiu instantaneamente com a diluição do afluente ao inicio do ciclo e permaneceu estável ao longo da operação com uma ligeira diminuição, provavelmente devido ao acúmulo de ácidos voláteis conforme representado na Figura 5.68. A estabilidade do $\mathrm{pH}$ mesmo com a produção de ácidos voláteis é devido ao tamponamento do sistema pelo consumo de alcalinidade ao longo do ciclo. A Figura 5.69 apresenta a evolução da alcalinidade total no reator ao longo do ciclo.

A produção volumétrica acumulada de biogás pode ser observada na Figura 5.70. A curva de produção tem comportamento crescente no inicio do ciclo e tende a se estabilizar no final. A Tabela 5.13 apresentando os resultados obtidos mostra uma produção acumulada de $338 \mathrm{~mL}$ de hidrogênio $(24,2 \%), 1061 \mathrm{~mL}$ de dióxido de carbono $(75,8 \%)$ e $1 \mathrm{~mL}$ de metano $(>0,1 \%)$. As curvas relativas à produção de cada gás são apresentadas na Figura 5.71.

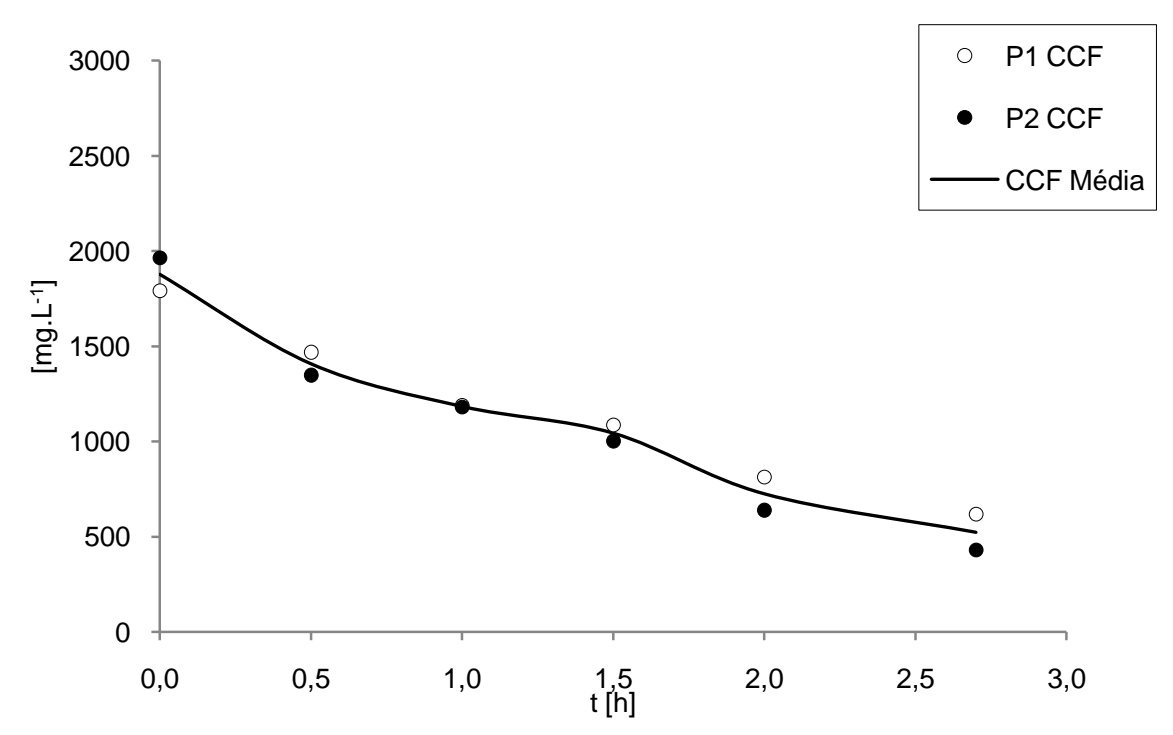

Figura 5.64- Perfil de evolução da concentração em carboidratos totais no reator - Condição IV. 


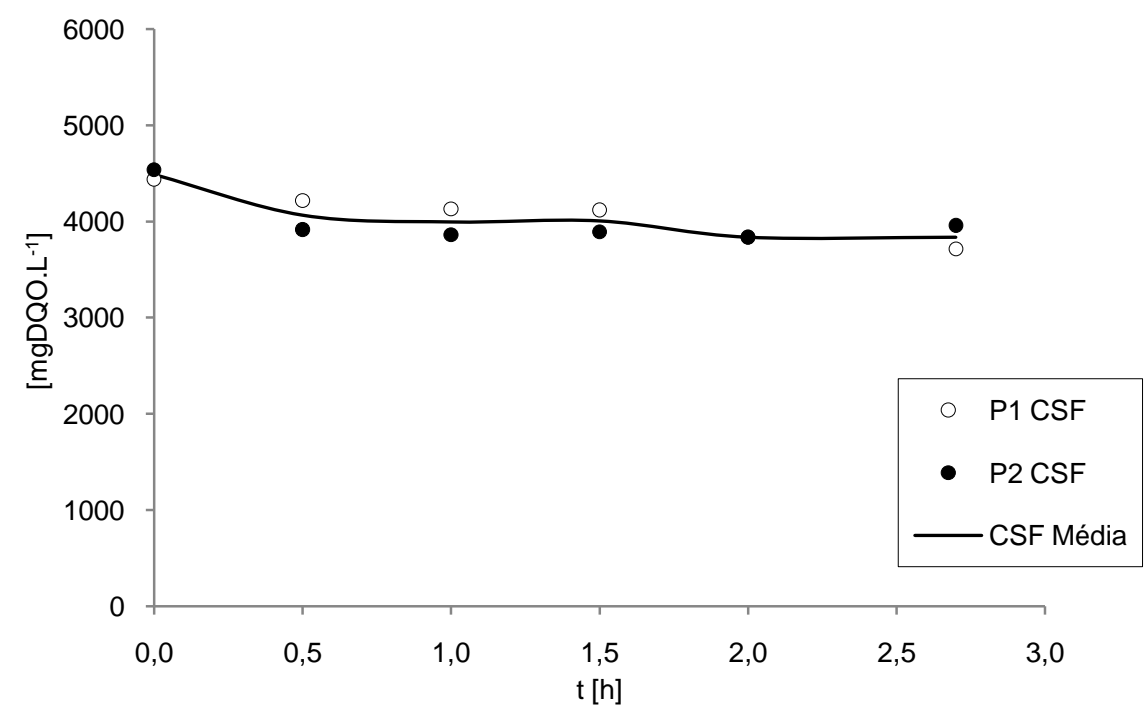

Figura 5.65- Perfil de evolução da concentração em DQO no reator- Condição IV.

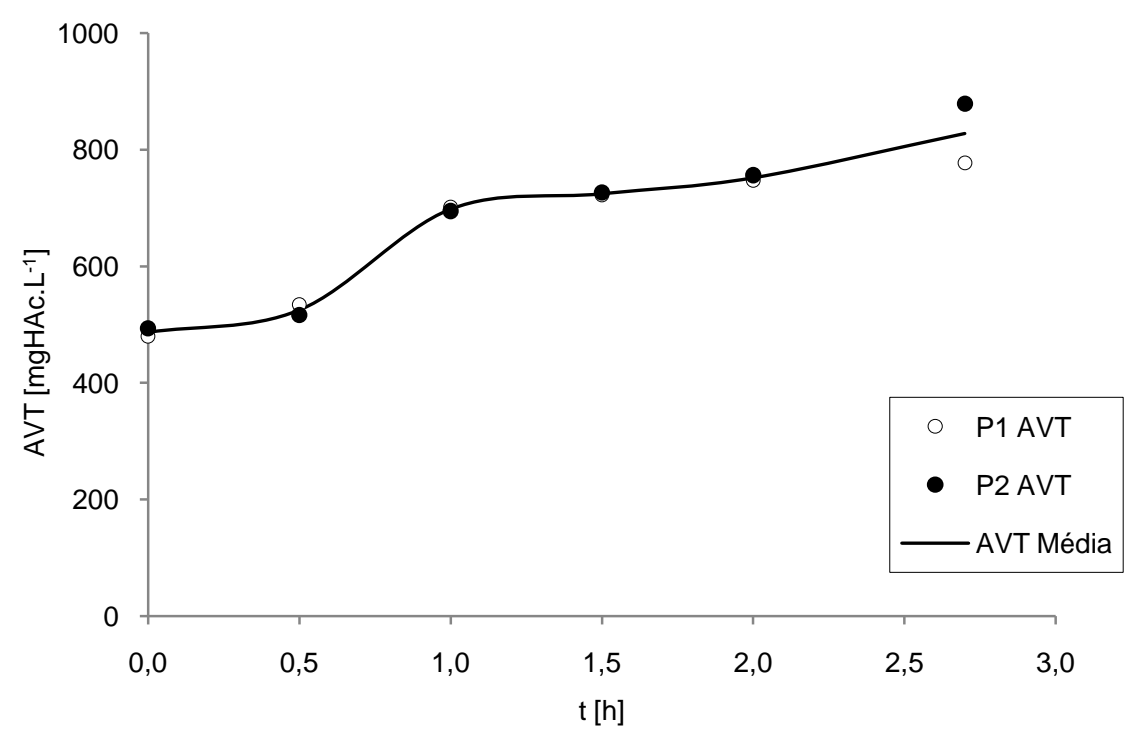

Figura 5.66- Perfil de evolução da concentração em ácidos volateís totais por titulação no reator- Condição IV. 


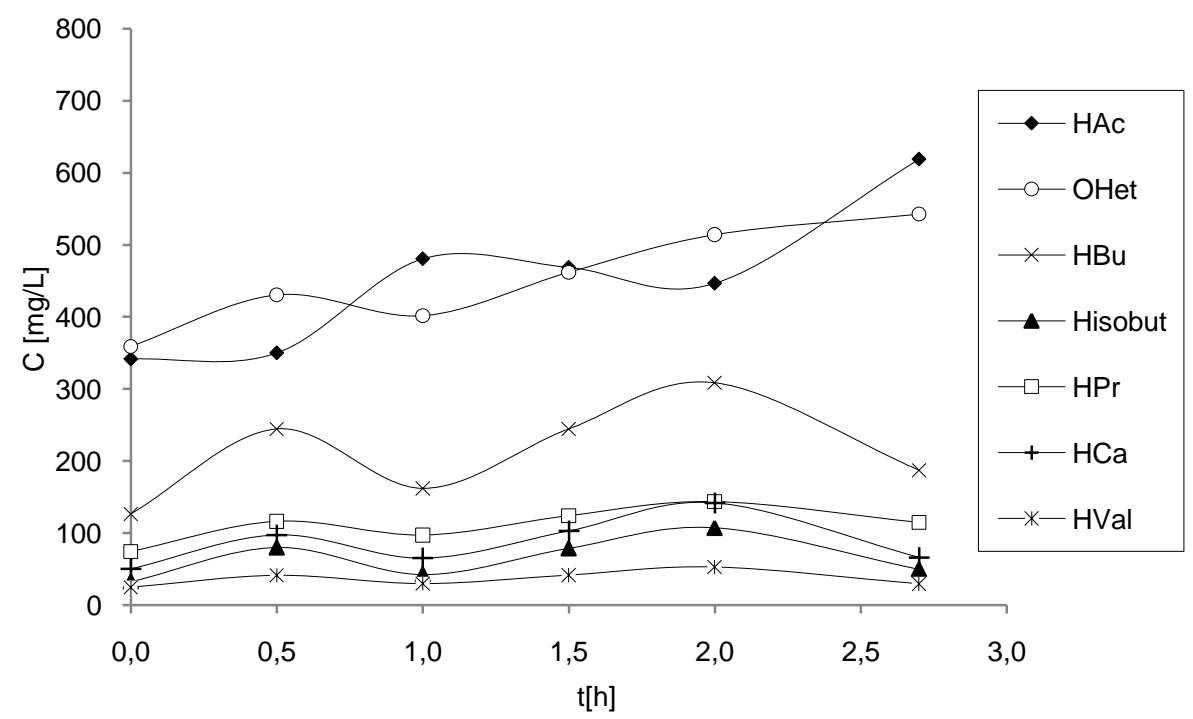

Figura 5.67 - Perfil de evolução das concentrações dos compostos intermediários - Condição IV.

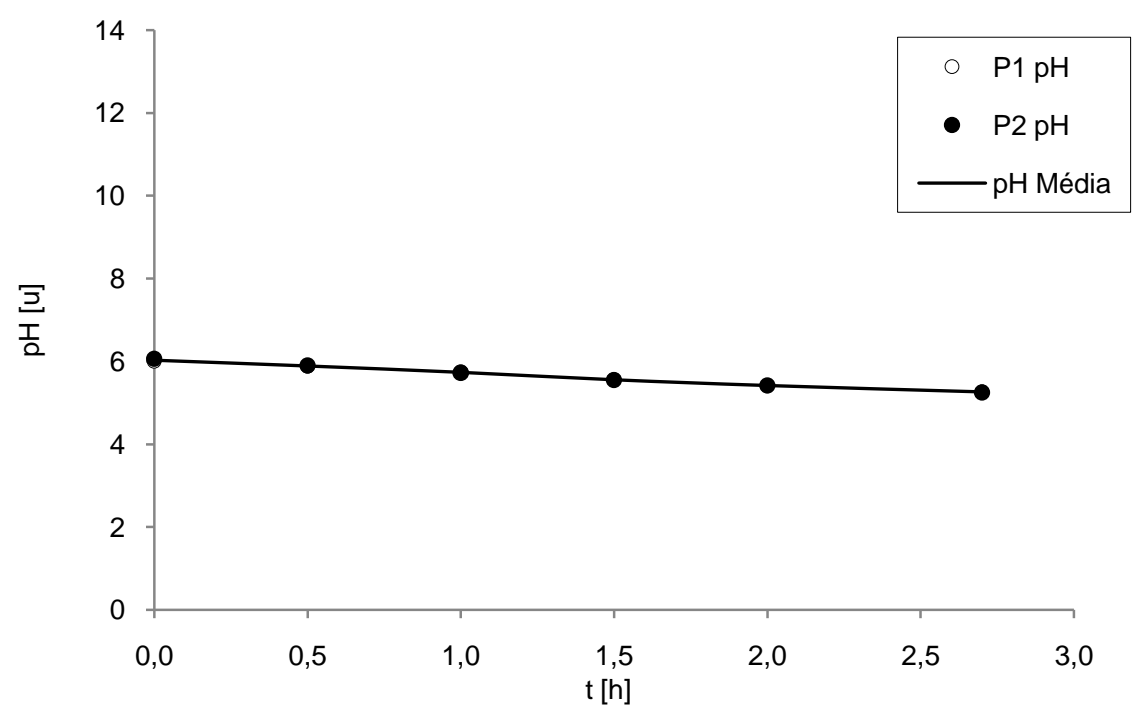

Figura 5.68- Perfil de evolução do pH no reator- Condição IV. 


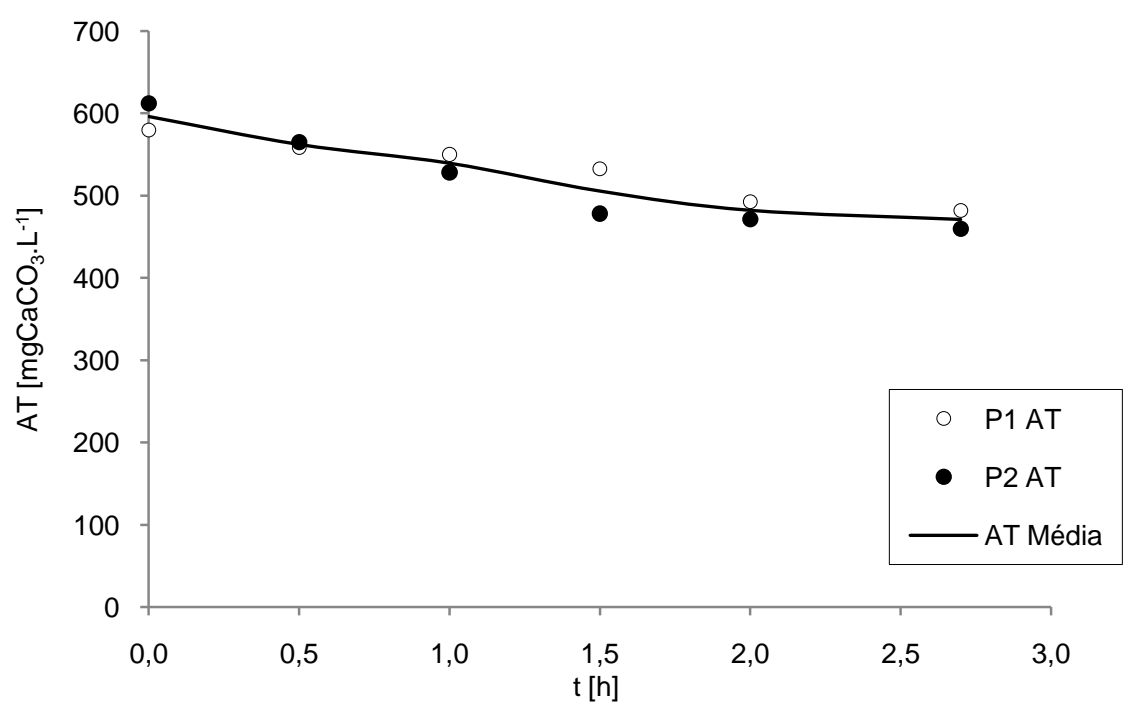

Figura 5.69- Perfil de evolução da alcalinidade total por titulação no reator - Condição IV.

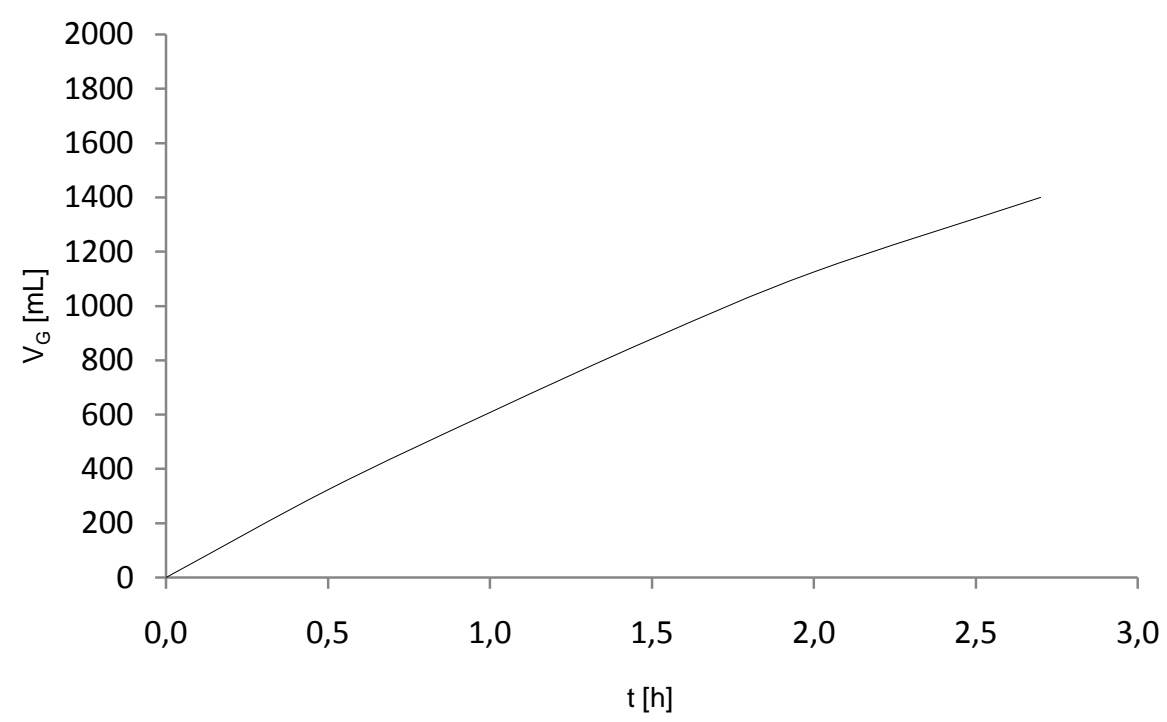

Figura 5.70- Perfil produção volumétrica acumulada de biogás Condição IV. 
Tabela 5.13 - Volumes específicos acumulados de gases e proporção de hidrogênio - Condição IV.

\begin{tabular}{|c|c|c|c|c|}
\hline \multirow{2}{*}{ Tempo } & \multicolumn{3}{|c|}{$\begin{array}{c}\text { Volumes específicos } \\
\text { acumulados }\end{array}$} & \multirow{2}{*}{$\begin{array}{c}\text { Proporção de hidrogênio } \\
\qquad \% \mathrm{H}_{2}\end{array}$} \\
\hline & $\mathrm{V}_{\mathrm{H} 2}$ & $\mathrm{~V}_{\mathrm{CO} 2}$ & $\mathrm{~V}_{\mathrm{CH} 4}$ & \\
\hline$[\mathrm{h}]$ & {$[\mathrm{mL}]$} & {$[\mathrm{mL}]$} & {$[\mathrm{mL}]$} & [\%] \\
\hline 0,0 & 0 & 0 & 0 & - \\
\hline 0,5 & 46 & 277 & 0 & 14,2 \\
\hline 1,0 & 108 & 500 & 0 & 17,8 \\
\hline 1,5 & 179 & 699 & 0 & 20,4 \\
\hline 2,0 & 251 & 874 & 0 & 22,3 \\
\hline 2,7 & 338 & 1061 & 1 & 24,2 \\
\hline
\end{tabular}

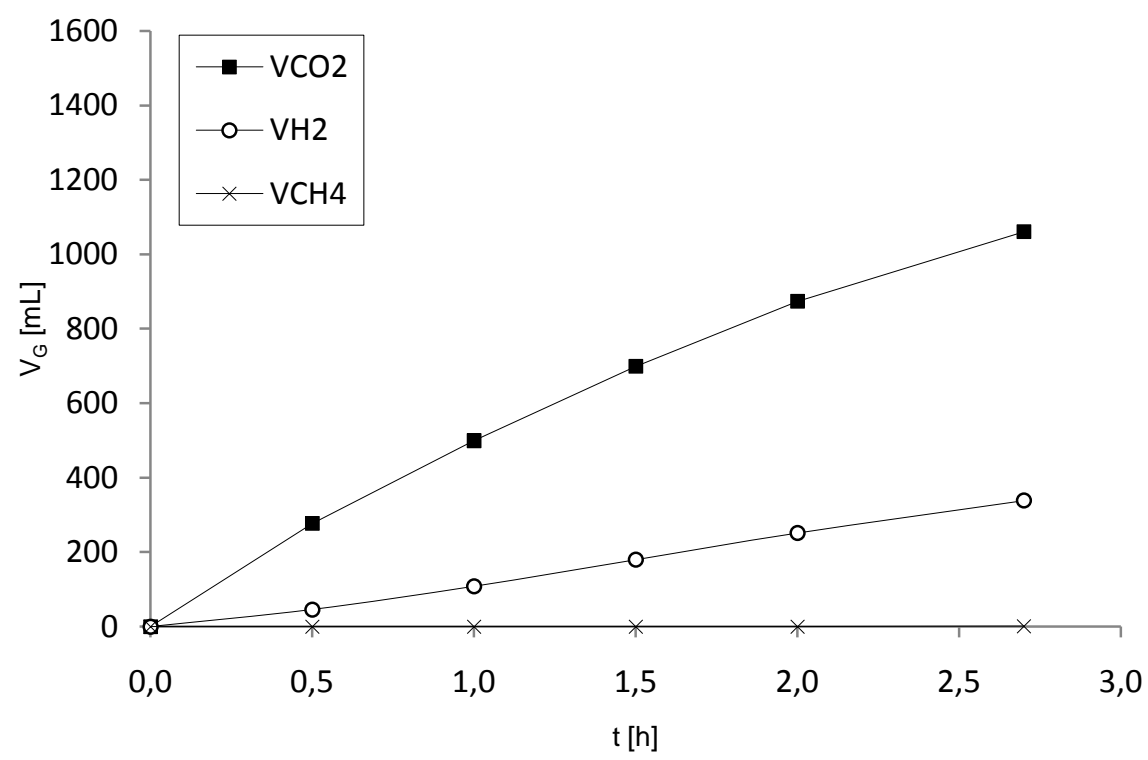

Figura 5.71 - Perfil produção volumétrica espécifica cumulada de gases - Condição IV. 


\subsection{Condição experimental V (DQO 3600 mg.L $\mathrm{L}^{-1}$ - TC 2h)}

\subsubsection{Monitoramento}

A Tabela 5.14 apresenta os valores médios durante os 28 dias de monitoramento da condição V. O reator continuou apresentando uma boa capacidade de retenção da biomassa com valores de sólidos voláteis totais e filtrados efluentes da ordem de grandeza dos valores afluentes. A quantidade de biomassa presente no reator considerada nos cálculos de cargas orgânicas específicas foi determinado no final da condição VI. As cargas orgânicas volumétricas aplicadas reais durante a operação foram de $17,14 \mathrm{kgSAC} \cdot \mathrm{m}^{-3} \cdot \mathrm{d}^{-1}$ e $18,10 \mathrm{kgDQO} \cdot \mathrm{m}^{-3} \cdot \mathrm{d}^{-1}$ considerando a sacarose e a DQO, respectivamente (valores nominais de $16,00 \mathrm{kgSAC} \cdot \mathrm{m}^{-3} \cdot \mathrm{d}^{-1} \mathrm{e} 18,00 \mathrm{kgDQO} \cdot \mathrm{m}^{-3} \cdot \mathrm{d}^{-1}$ ). 
Tabela 5.14 - Valores médios dos parâmetros monitorados -

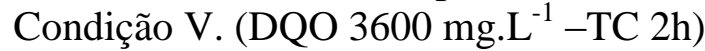

\begin{tabular}{|c|c|c|c|c|c|c|c|c|c|c|c|c|c|}
\hline \multicolumn{2}{|r|}{ Parâmetro } & \multicolumn{3}{|c|}{ Afluente } & \multicolumn{9}{|c|}{ Efluente } \\
\hline $\mathrm{C}_{\mathrm{CT}}$ & {$\left[\mathrm{mgSAC} \cdot \mathrm{L}^{-1}\right]$} & 3429 & \pm & 310 & ( & 12 & ) & 410 & \pm & 286 & ( & 12 & ) \\
\hline $\mathrm{C}_{\mathrm{CF}}$ & {$\left[\mathrm{mgSAC} \cdot \mathrm{L}^{-1}\right]$} & - & & - & & & & 380 & \pm & 291 & ( & 12 & ) \\
\hline$\varepsilon_{\mathrm{CT}}$ & {$[\%]$} & - & & - & & & & 88 & \pm & 8 & ( & 12 & ) \\
\hline$\varepsilon_{\mathrm{CF}}$ & {$[\%]$} & - & & - & & & & 89 & \pm & 8 & ( & 12 & ) \\
\hline $\mathrm{C}_{\mathrm{ST}}$ & {$\left[\mathrm{mgDQO} \cdot \mathrm{L}^{-1}\right]$} & 3620 & \pm & 237 & ( & 10 & ) & 3048 & \pm & 278 & ( & 12 & ) \\
\hline $\mathrm{C}_{\mathrm{SF}}$ & {$\left[\mathrm{mgDQO} . \mathrm{L}^{-1}\right]$} & - & & - & & & & 2996 & \pm & 261 & ( & 12 & ) \\
\hline$\varepsilon_{\mathrm{ST}}$ & {$[\%]$} & - & & - & & & & 16 & \pm & 8 & ( & 12 & ) \\
\hline$\varepsilon_{\mathrm{SF}}$ & {$[\%]$} & - & & - & & & & 17 & \pm & 7 & ( & 12 & ) \\
\hline $\mathrm{pH}$ & {$[\mathrm{u}]$} & 7,3 & \pm & 0,1 & ( & 10 & ) & 5,2 & \pm & 0,1 & ( & 10 & ) \\
\hline AVT & {$\left[\mathrm{mgHAc} . \mathrm{L}^{-1]}\right.$} & 42 & \pm & 21 & ( & 10 & ) & 545 & \pm & 78 & ( & 10 & ) \\
\hline $\mathrm{AT}$ & {$\left[\mathrm{mgCACO}_{3} \cdot \mathrm{L}^{-1}\right]$} & 578 & \pm & 38 & ( & 10 & ) & 286 & \pm & 50 & ( & 10 & ) \\
\hline $\mathrm{AP}$ & {$\left[\mathrm{mgCACO}{ }_{3} \cdot \mathrm{L}^{-1}\right]$} & 481 & \pm & 42 & ( & 10 & ) & 0 & \pm & 0 & ( & 10 & ) \\
\hline $\mathrm{AI}$ & {$\left[\mathrm{mgCACO}{ }_{3} \cdot \mathrm{L}^{-1}\right]$} & 97 & \pm & 23 & ( & 10 & ) & 286 & \pm & 50 & ( & 10 & ) \\
\hline $\mathrm{AB}$ & {$\left[\mathrm{mgCACO}_{3} \cdot \mathrm{L}^{-1]}\right.$} & 549 & \pm & 41 & ( & 10 & ) & 0 & \pm & 0 & ( & 10 & ) \\
\hline ST & {$\left[\mathrm{mg} . \mathrm{L}^{-1}\right]$} & 4758 & \pm & 1099 & ( & 3 & ) & 2576 & \pm & 299 & ( & 3 & ) \\
\hline SVT & {$\left[\mathrm{mg} . \mathrm{L}^{-1}\right]$} & 3981 & \pm & 1323 & ( & 3 & ) & 1899 & \pm & 333 & ( & 3 & ) \\
\hline SST & {$\left[\mathrm{mg} . \mathrm{L}^{-1}\right]$} & 73 & \pm & 26 & ( & 3 & ) & 121 & \pm & 23 & ( & 3 & ) \\
\hline SSV & {$\left[\mathrm{mg} . \mathrm{L}^{-1}\right]$} & 56 & \pm & 9 & ( & 3 & ) & 101 & \pm & 21 & ( & 3 & ) \\
\hline $\mathrm{M}_{\mathrm{SVT}}$ & {$[\mathrm{g}]$} & - & & - & & & & 25,27 & & - & & & \\
\hline $\mathrm{C}_{\mathrm{X}-\mathrm{SVT}}^{\prime}$ & [g.g-suporte $\left.{ }^{-1}\right]$ & - & & - & & & & 0,02 & & - & & & \\
\hline $\mathrm{C}_{\mathrm{X}-\mathrm{SVT}}$ & {$\left[\right.$ g. $\left.\mathrm{L}^{-1}\right]$} & - & & - & & & & 7,02 & & - & & & \\
\hline $\mathrm{COAV}_{\mathrm{CT}}$ & {$\left[\mathrm{kgSAC} \cdot \mathrm{m}^{-3} \cdot \mathrm{d}^{-1}\right]$} & 17,14 & & - & & & & - & & - & & & \\
\hline $\mathrm{COAV}_{\mathrm{ST}}$ & {$\left[\mathrm{kgDQO} \cdot \mathrm{m}^{-3} \cdot \mathrm{d}^{-1}\right]$} & 18,10 & & - & & & & - & & - & & & \\
\hline $\mathrm{COAE}_{\mathrm{CT}}$ & {$\left[\mathrm{kgSAC} \cdot \mathrm{kgSVT}^{-1} \cdot \mathrm{d}^{-1}\right]$} & 2,44 & & - & & & & - & & - & & & \\
\hline $\mathrm{COAE}_{\mathrm{ST}}$ & {$\left[\mathrm{kgDQO} \cdot \mathrm{kgSVT}^{-1} \cdot \mathrm{d}^{-1}\right]$} & 2,58 & & - & & & & - & & - & & & \\
\hline $\mathrm{CORV}_{\mathrm{CF}}$ & {$\left[\mathrm{kgSAC} \cdot \mathrm{m}^{-3} \cdot \mathrm{d}^{-1}\right]$} & - & & - & & & & 15,24 & & - & & & \\
\hline $\mathrm{CORV}_{\mathrm{SF}}$ & {$\left[\mathrm{kgDQO} \cdot \mathrm{m}^{-3} \cdot \mathrm{d}^{-1}\right]$} & - & & - & & & & 3,12 & & - & & & \\
\hline $\mathrm{CORE}_{\mathrm{CF}}$ & {$\left[\mathrm{kgSAC} \cdot \mathrm{kgSVT}^{-1} \cdot \mathrm{d}^{-1}\right]$} & - & & - & & & & 2,17 & & - & & & \\
\hline $\mathrm{CORE}_{\mathrm{SF}}$ & {$\left[\mathrm{kgDQO} \cdot \mathrm{kgSVT}^{-1} \cdot \mathrm{d}^{-1}\right]$} & - & & - & & & & 0,44 & & - & & & \\
\hline $\mathrm{n}_{\mathrm{H} 2}$ & {$\left[\mathrm{molH}_{2} \cdot \mathrm{d}^{-1}\right]$} & - & & - & & & & 0,14 & & - & & 2 & \\
\hline PrM & {$\left[\mathrm{molH}_{2} \cdot \mathrm{m}^{-3} \cdot \mathrm{d}^{-1}\right]$} & 21,38 & & - & & & & - & & - & & & \\
\hline PrME & {$\left[\mathrm{molH}_{2} \cdot \mathrm{kgSVT}^{-1} \cdot \mathrm{d}^{-1}\right]$} & 5,50 & & - & & & & - & & - & & & \\
\hline $\mathrm{RMCA}_{\mathrm{C}, \mathrm{n}}$ & {$\left[\mathrm{molH}_{2} \cdot \mathrm{kgSAC}^{-1}\right]$} & 2,25 & & - & & & & - & & - & & & \\
\hline $\mathrm{RMCA}_{\mathrm{S}, \mathrm{n}}$ & {$\left[\mathrm{molH}_{2} \cdot \mathrm{kgDQO}^{-1}\right]$} & 2,13 & & - & & & & - & & - & & & \\
\hline $\mathrm{RMCR}_{\mathrm{C}, \mathrm{n}}$ & {$\left[\mathrm{molH}_{2} \cdot \mathrm{kgSAC}^{-1}\right]$} & 2,53 & & - & & & & - & & - & & & \\
\hline $\mathrm{RMCR}_{\mathrm{S}, \mathrm{n}}$ & {$\left[\mathrm{molH}_{2} \cdot \mathrm{kgDQO}^{-1}\right]$} & 12,38 & & - & & & & - & & - & & & \\
\hline $\mathrm{V}_{\mathrm{A}}$ & {$[\mathrm{L}]$} & 1,5 & & & & & & & & & & & \\
\hline $\mathrm{V}_{\mathrm{R}}$ & {$[\mathrm{L}]$} & 3,6 & & & & & & & & & & & \\
\hline
\end{tabular}

(*) Entre parêntese o número de amostras considerado no cálculo da média

O reator foi eficiente na remoção de sacarose como pode ser observado na Figura 5.72 da evolução das concentrações afluente e efluente total e filtrada. A Figura 5.73 apresenta a evolução 
das eficiências de conversão que ficaram estáveis perto de um valor de $88 \%$ na forma total e $89 \%$ na forma filtrada. O reator continuou apresentando baixa eficiência de remoção de DQO como pode ser observado na Figura 5.74 que contém as concentrações em DQO afluente e efluente total e filtrada. A Figura 5.75 apresenta a evolução das eficiências de remoção da DQO quem ficaram estáveis perto de um valor de $16 \%$ na forma total e $17 \%$ na forma filtrada.

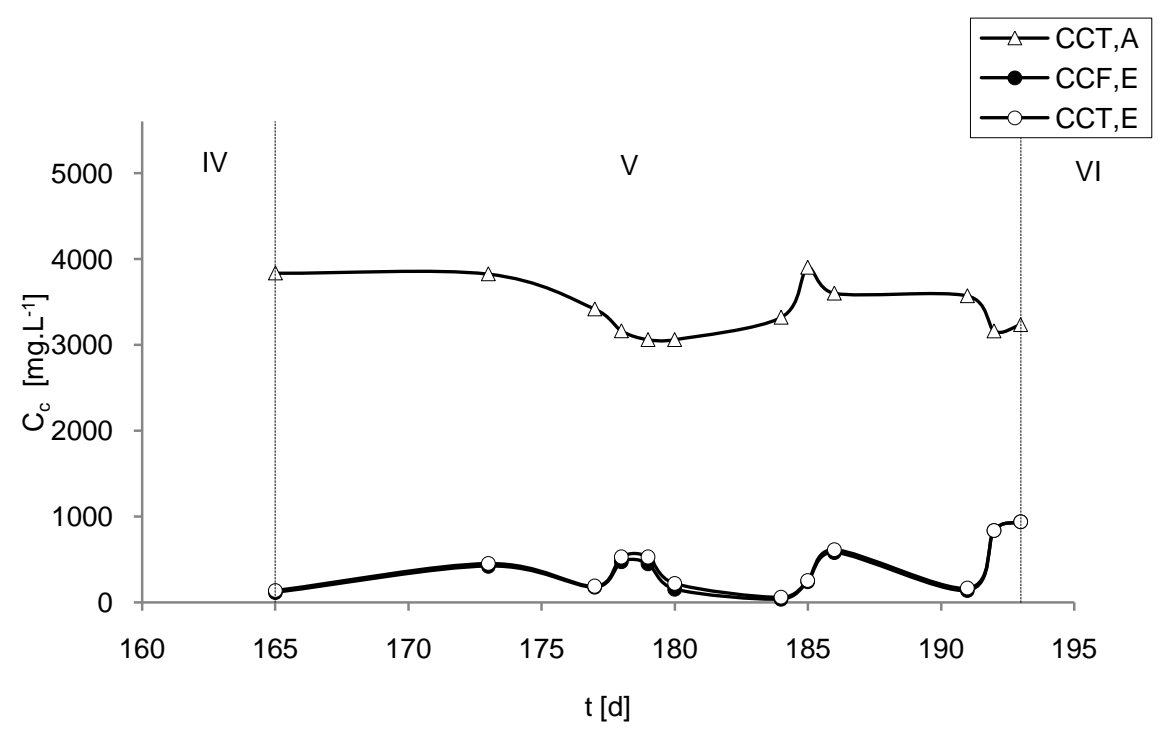

Figura 5.72 - Concentrações em carboidratos no afluente e efluente total e filtrado - Condição V. 


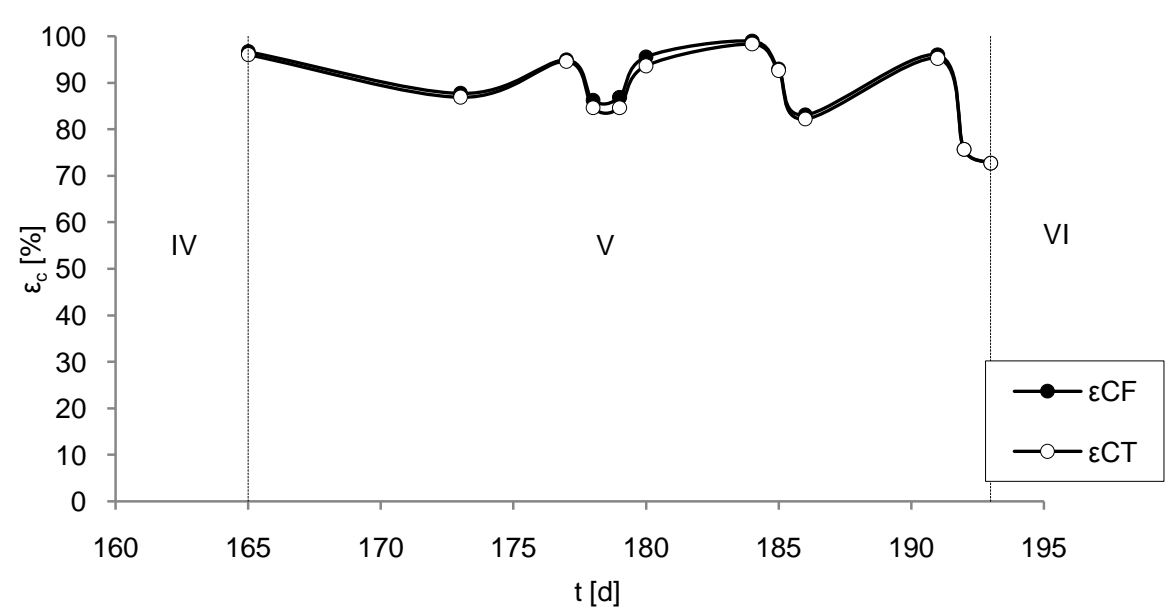

Figura 5.73 - Eficiências de conversão dos carboidratos na forma total e filtrada - Condição V.

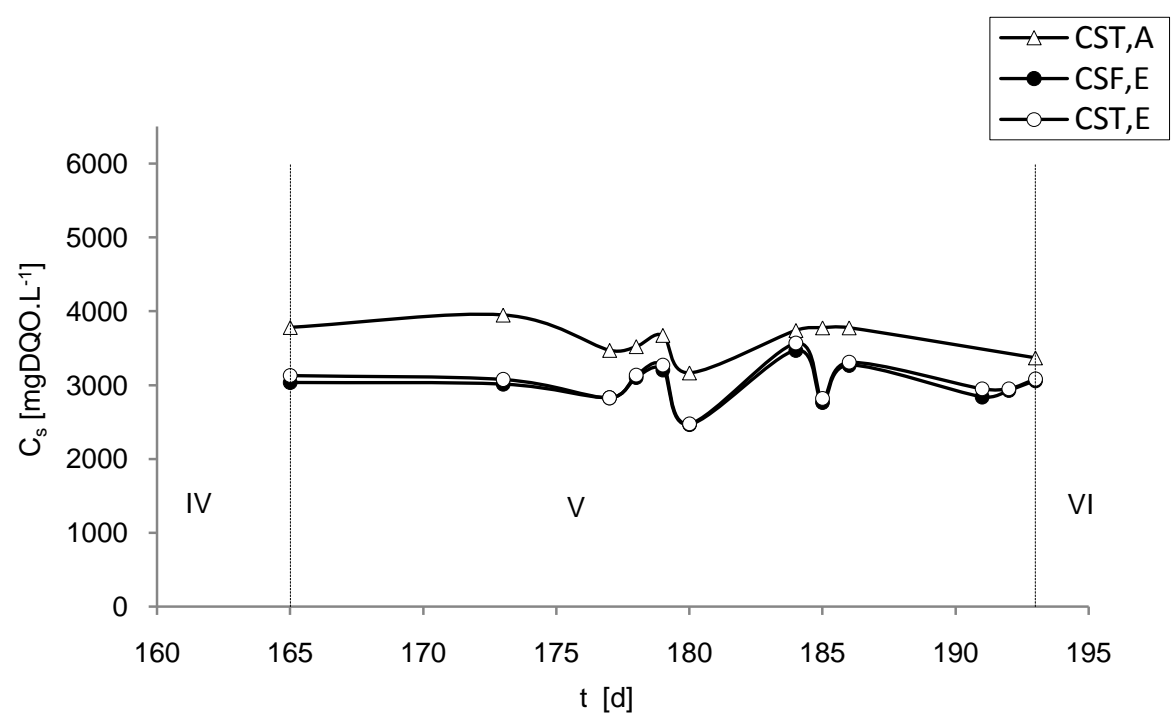

Figura 5.74- Concentrações em DQO no afluente e efluente total e filtrado - Condição V. 


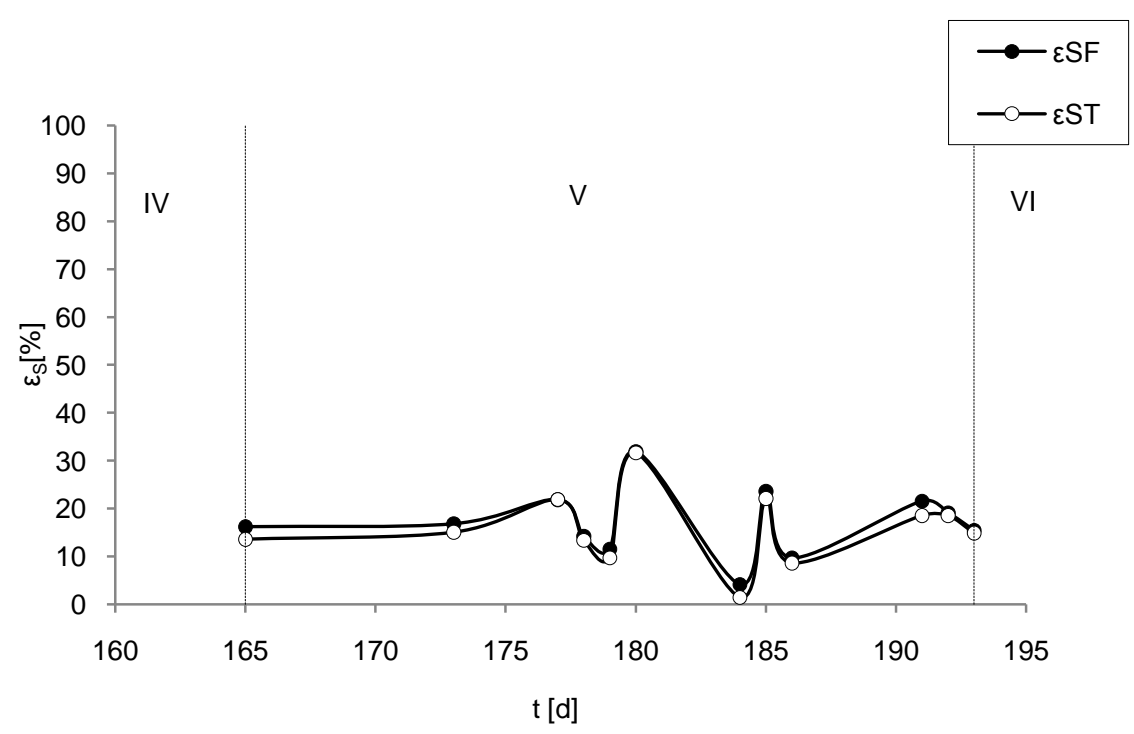

Figura 5.75- Eficiências de remoção da DQO na forma total e filtrada - Condição V.

A Figura 5.76 mostra a quantificação dos ácidos totais voláteis, cuja concentração média no efluente filtrado foi de $545 \mathrm{mgHAc} . \mathrm{L}^{-1}$. A Tabela 5.15 apresenta os resultados da quantificação dos compostos intermediários realizada por cromatografia gasosa. Dentro dos ácidos voláteis, o ácido Acético predominou seguido pelo ácido Butírico representado respectivamente $33,6 \%$ e 13,9\% dos compostos intermediários. O efluente apresentou também uma quantidade importante de etanol representando $29,5 \%$ dos compostos intermediários.

$\mathrm{O}$ acúmulo de ácidos no reator levou a uma diminuição do $\mathrm{pH}$ da fase líquida conforme pode ser observado na Figura 5.77 resultando em um consumo da alcalinidade total conforme apresentado pela Figura 5.78. O valor médio do $\mathrm{pH}$ foi 7,3 para o afluente contra 5,2 para o efluente. A alcalinidade média foi de $578 \mathrm{mgCaCO}_{3} \cdot \mathrm{L}^{-1}$ para o efluente contra $286 \mathrm{mgCaCO}_{3} \cdot \mathrm{L}^{-1}$ no efluente.

A variação da produção de biogás durante um ciclo ao longo da Condição V. pode ser observado na Figura 5.79. O volume máximo produzido foi de $1357 \mathrm{~mL}$ o $193^{\circ}$ dia de operação do reator ( $28^{\circ}$ dia de operação da condição), o valor médio de $1080 \mathrm{~mL}$ com desvio padrão de $211 \mathrm{~mL}$ indicando variações durante a condição. 


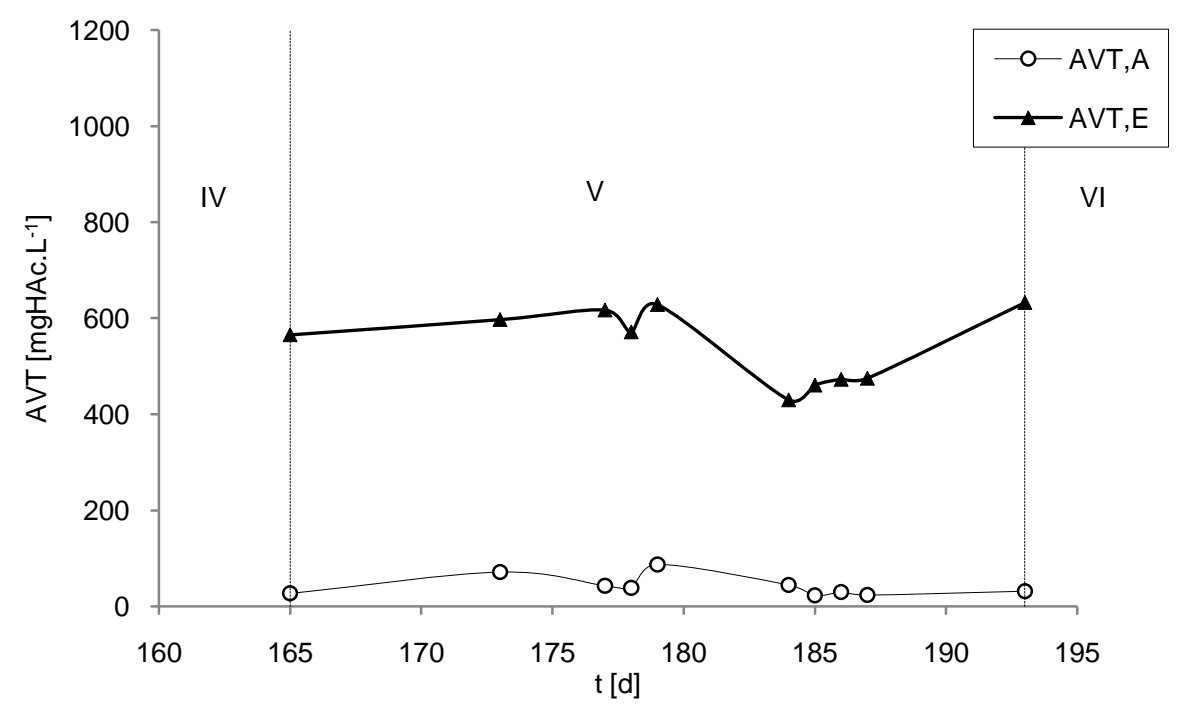

Figura 5.76- Concentrações em ácidos volateís totais por titulação no afluente e efluente - Condição V.

Tabela 5.15 - Concentração média e composição dos compostos intermediários - Condição V.

\begin{tabular}{|c|c|c|c|c|c|c|c|}
\hline \multirow{3}{*}{$\begin{array}{l}\text { Espécies } \\
\text { Acetona }\end{array}$} & \multicolumn{6}{|c|}{ Concentração média } & \multirow{3}{*}{$\begin{array}{c}\text { Repartição } \\
{[\%]}\end{array}$} \\
\hline & \multicolumn{3}{|c|}{$\left[\mathrm{mg} . \mathrm{L}^{-1}\right]$} & \multicolumn{3}{|c|}{$\left[\mathrm{mmol} . \mathrm{L}^{-1}\right]$} & \\
\hline & 0,0 & \pm & - & 0,0 & \pm & 0,0 & \\
\hline Metanol & 0,0 & \pm & - & 0,0 & \pm & 0,0 & 0,0 \\
\hline Etanol & 389,2 & \pm & 26,0 & 8,4 & \pm & 0,6 & 29,5 \\
\hline n-Butanol & 4,8 & \pm & 0,2 & 0,1 & \pm & 0,0 & 0,4 \\
\hline Acético & 442,7 & \pm & 44,0 & 7,4 & \pm & 0,7 & 33,6 \\
\hline Porpiônico & 95,0 & \pm & 9,5 & 1,3 & \pm & 0,1 & 7,2 \\
\hline Isobutírico & 37,6 & \pm & 8,6 & 0,4 & \pm & 0,1 & 2,8 \\
\hline Butírico & 183,5 & \pm & 31,0 & 2,1 & \pm & 0,4 & 13,9 \\
\hline Isovalérico & 11,6 & \pm & 1,6 & 0,1 & \pm & 0,0 & 0,9 \\
\hline Valérico & 38,3 & \pm & 5,1 & 0,4 & \pm & 0,0 & 2,9 \\
\hline Capróico & 116,2 & \pm & 30,3 & 1,0 & \pm & 0,3 & 8,8 \\
\hline
\end{tabular}




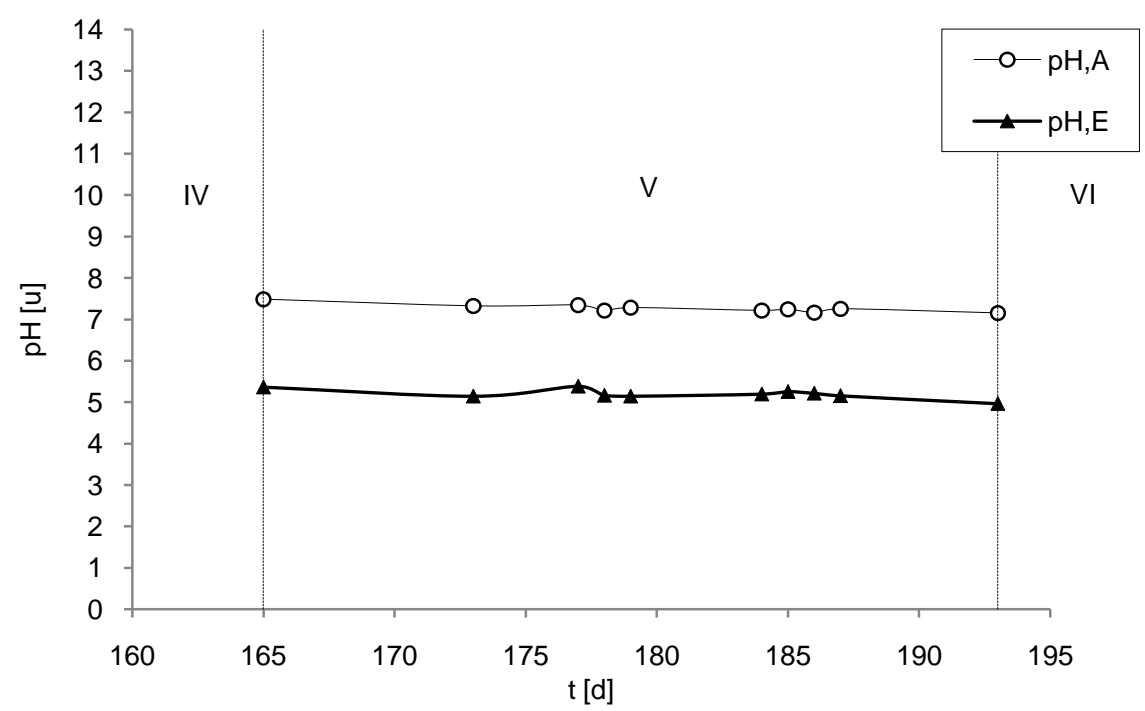

Figura 5.77- pH afluente e efluente - Condição V.

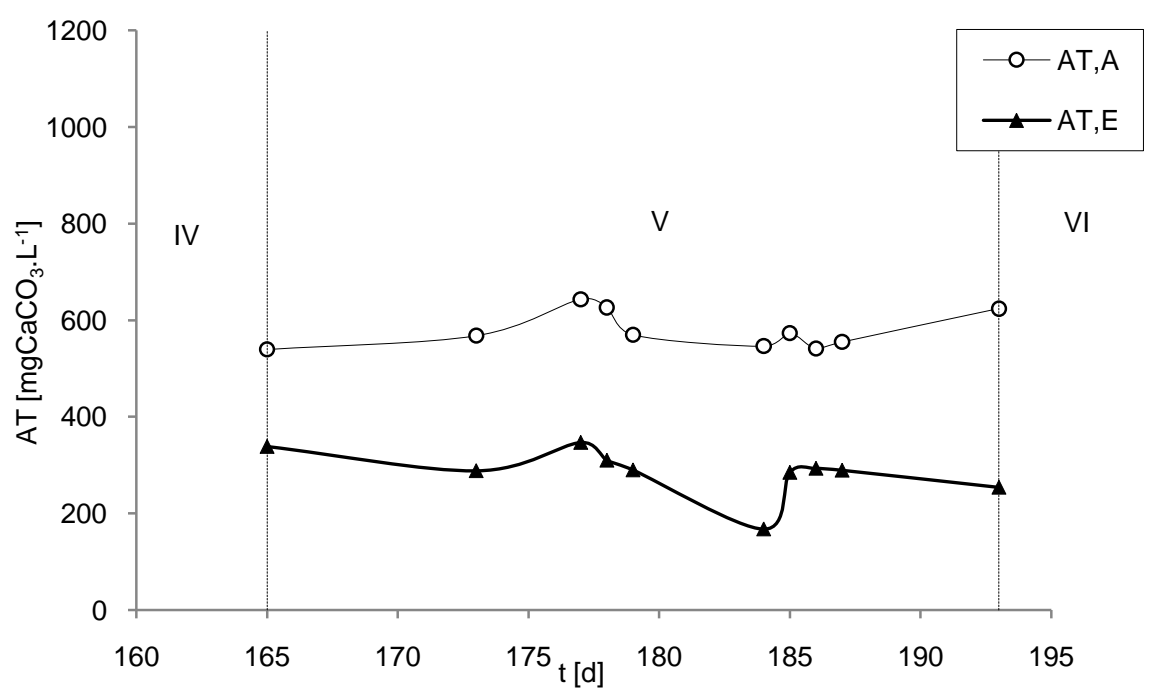

Figura 5.78- Alcalinidades totais por titulação no afluente e efluente - Condição V. 


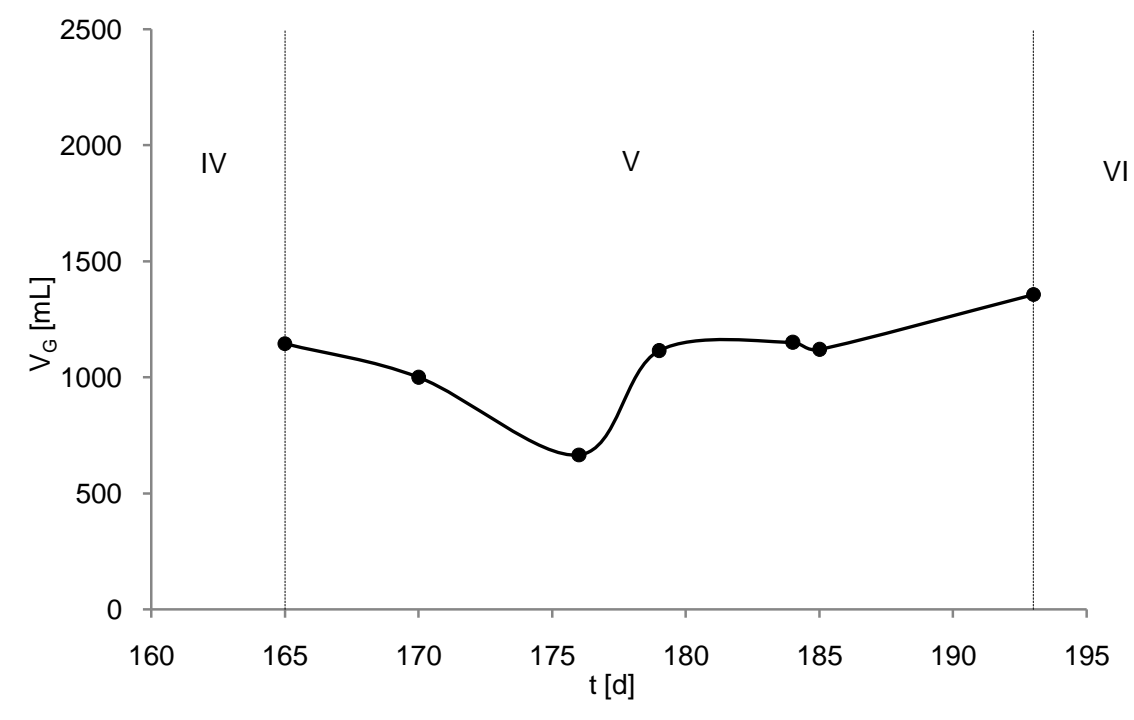

Figura 5.79- Variação da produção volumétrica de biogás durante um ciclo - Condição V.

\subsubsection{Perfis ao longo do ciclo}

A Figura 5.80 mostra a evolução da concentração em carboidratos totais ao longo do ciclo. Ao iniciou do ciclo (tempo zero) o volume afluente foi diluído ao volume residual resultando em uma concentração em sacarose da ordem de 2000 mg.L $\mathrm{L}^{-1}$. A conversão da sacarose se faz de maneira progressiva ao longo do ciclo. A Figura 5.81 mostra a evolução da concentração em DQO ao longo do ciclo, pela qual pode ser observada uma remoção baixa em DQO ao longo do ciclo levando a uma alta concentração em DQO no volume residual.

A sacarose convertida em produtos intermediários do metabolismo anaeróbio leva a um acúmulo de ácidos voláteis conforme pode ser observado na Figura 5.82. A concentração em ácidos voláteis totais aumenta claramente durante a fase de reação para atingir um máximo no final do ciclo. Os resultados da análise de compostos intermediários por cromatografia em fase gasosa são 
apresentados na Figura 5.83, pela qual se observa uma predominância de ácido acético passando de uma concentração inicial de $269,0 \mathrm{mg} . \mathrm{L}^{-1}$ até um máximo de 475,6 mg. $\mathrm{L}^{-1} \mathrm{em}$ uma hora e se estabilizando em volta deste valor até o final do ciclo.

$\mathrm{O}$ pH diminuiu instantaneamente com a diluição do afluente ao inicio do ciclo e permanece estável com ligeira diminuição ao longo da operação conforme representado na Figura 5.84. A estabilidade do $\mathrm{pH}$ mesmo com a produção de ácidos voláteis é devido ao tamponamento do sistema pelo consumo de alcalinidade ao longo do ciclo, mostrada na Figura 5.85.

A produção volumétrica acumulada de biogás pode ser observada na Figura 5.38. A curva de produção tem comportamento crescente no inicio do ciclo e tende a se estabilizar no final. A Tabela 5.16 apresenta a composição do biogás com uma produção acumulada de $259 \mathrm{~mL}$ de hidrogênio (22,9\%), $873 \mathrm{~mL}$ de dióxido de carbono $(76,9 \%)$ e $2 \mathrm{~mL}$ de metano $(0,2 \%)$. As curvas relativas à produção de cada gás são apresentadas na Figura 5.87.

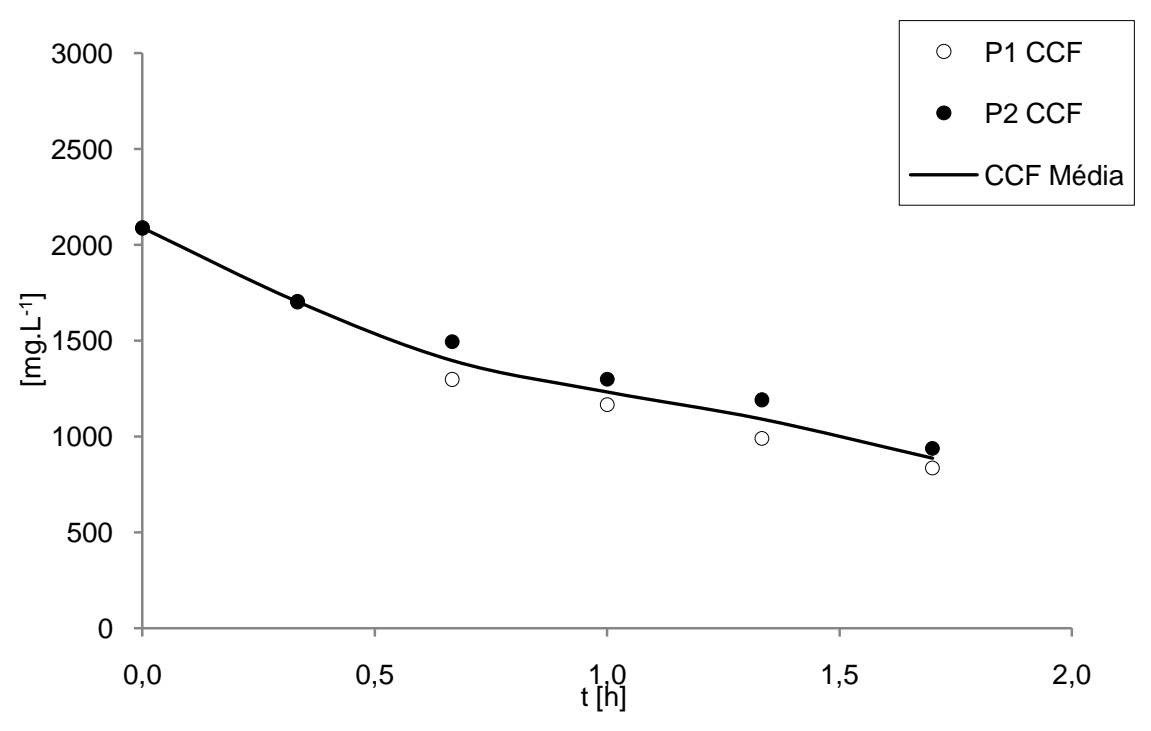

Figura 5.80- Perfil de evolução da concentração em carboidratos no reator - Condição V. 


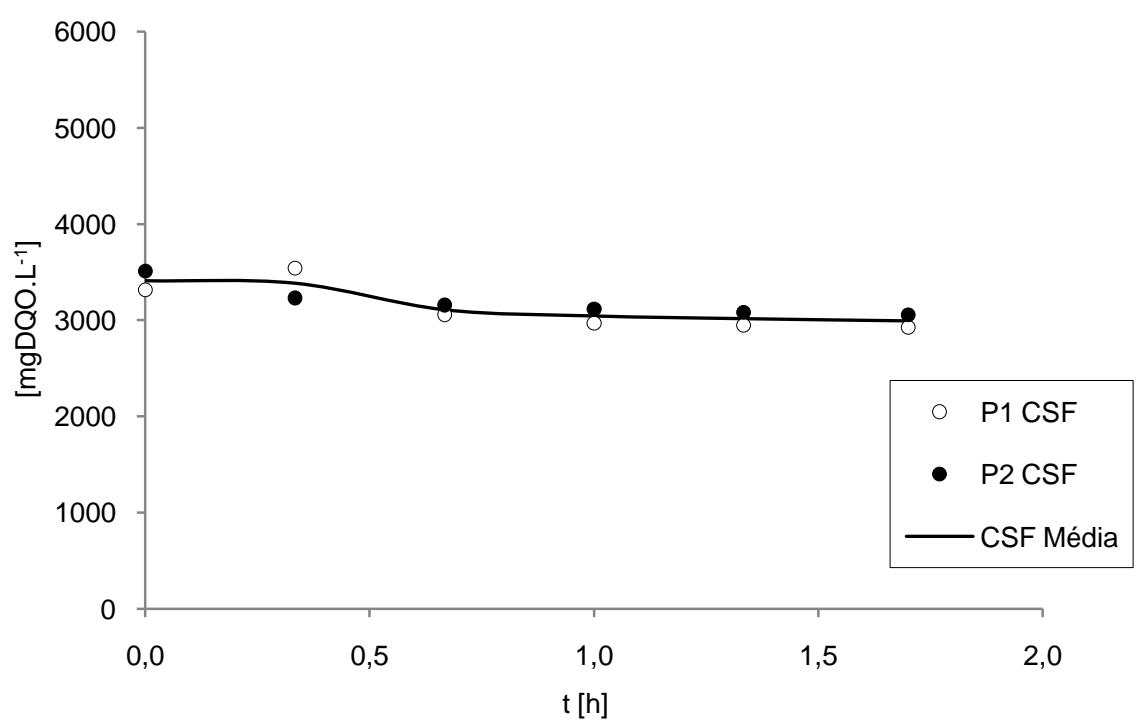

Figura 5.81- Perfil de evolução da concentração em DQO no reator- Condição V.

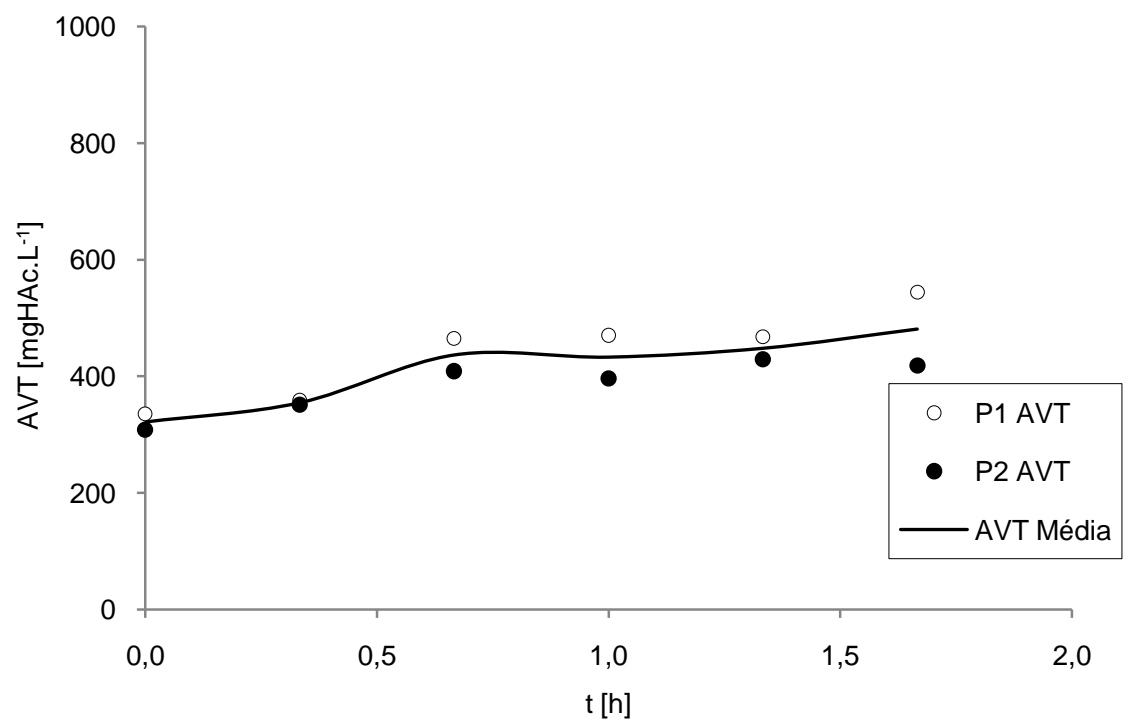

Figura 5.82- Perfil de evolução da concentração em ácidos volateís totais por titulação no reator- Condição V. 


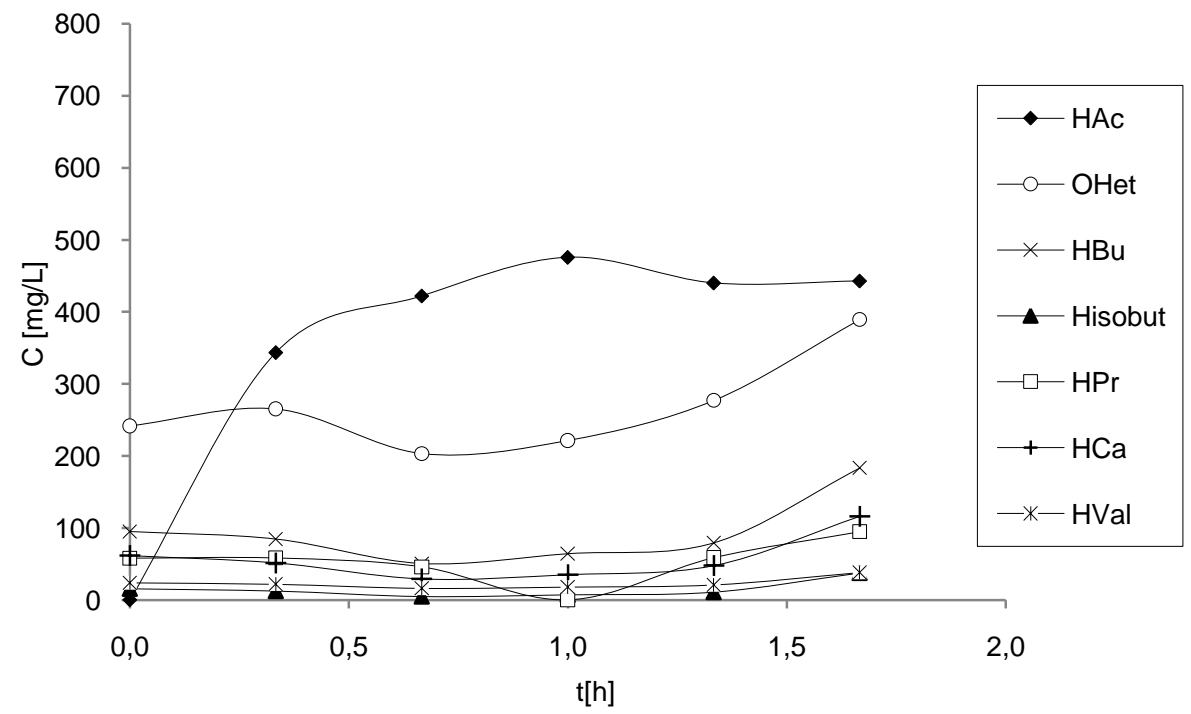

Figura 5.83 - Perfil de evolução das concentrações dos compostos intermediários - Condição V.

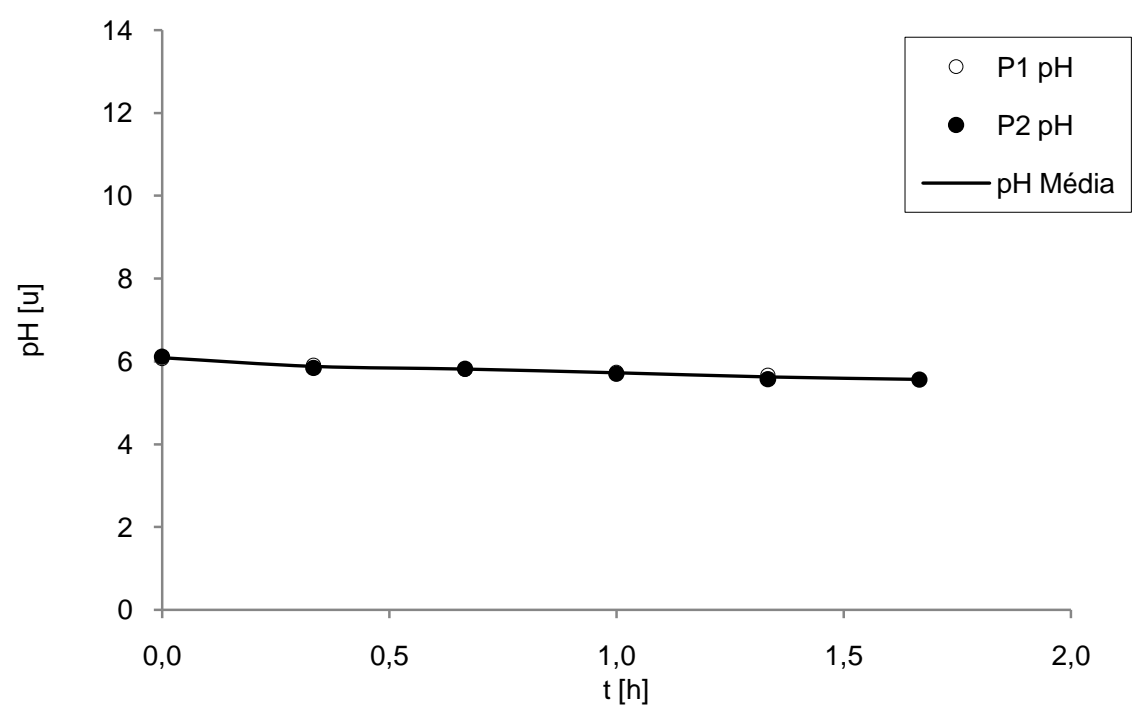

Figura 5.84- Perfil de evolução do pH no reator- Condição V. 


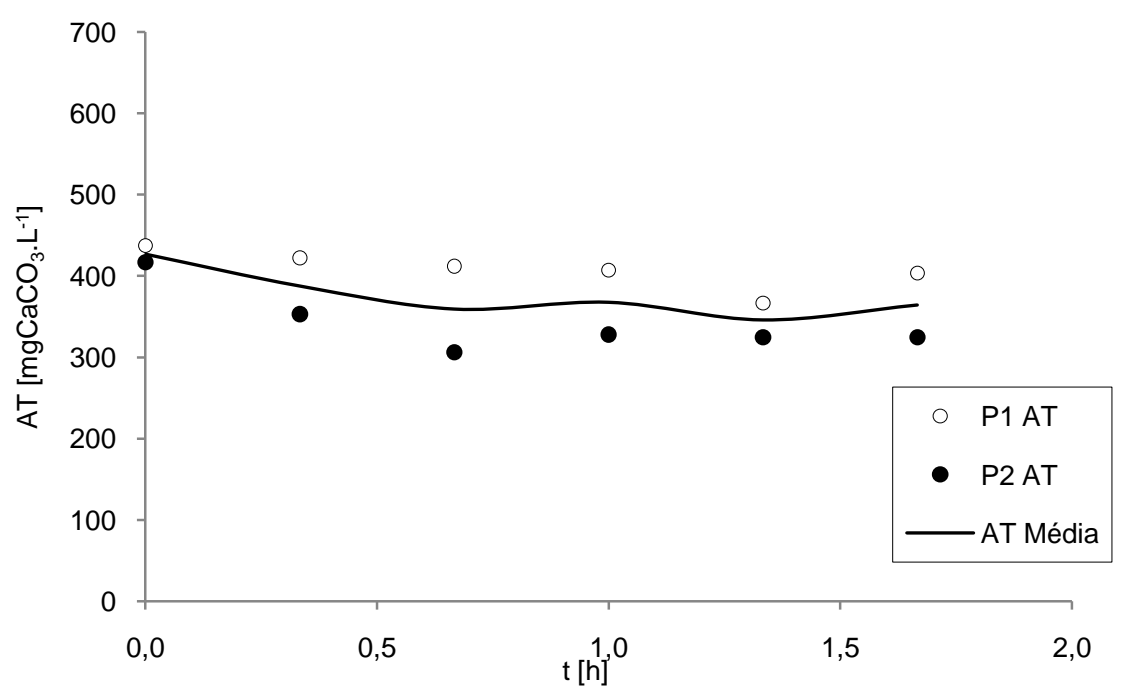

Figura 5.85- Perfil de evolução da alcalinidade total por titulação no reator - Condição V.

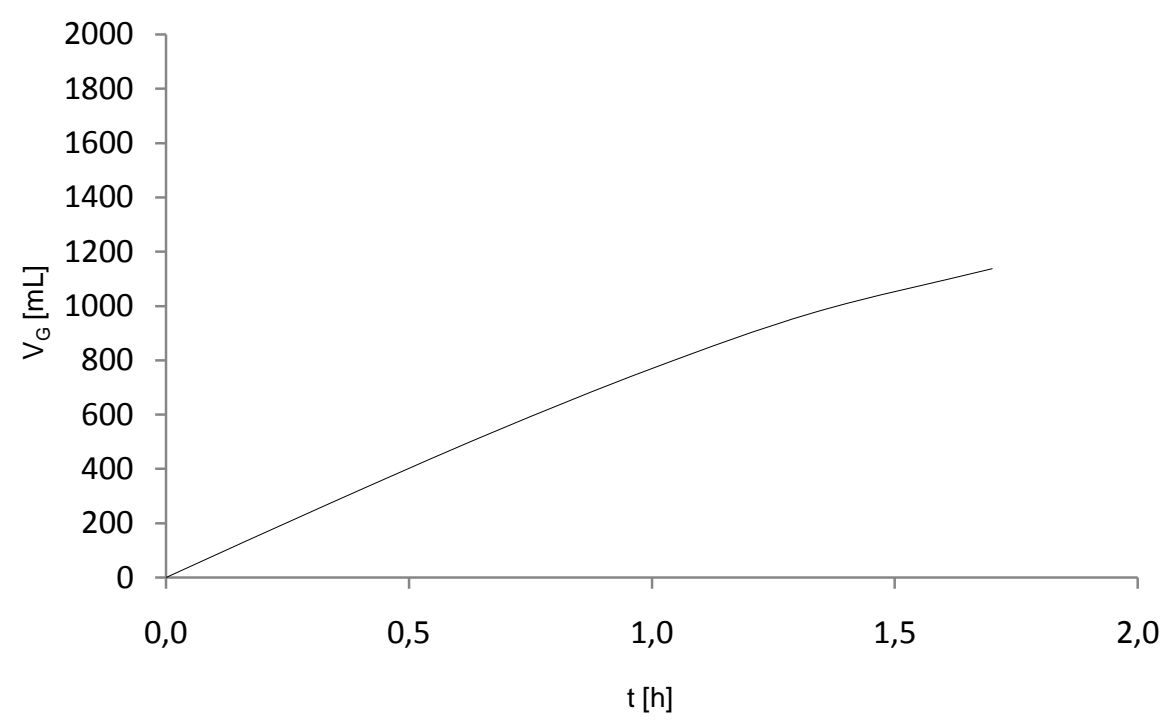

Figura 5.86- Perfil produção volumétrica acumulada de biogás Condição V. 
Tabela 5.16 - Volumes específicos acumulados de gases e proporção de hidrogênio - Condição V.

\begin{tabular}{ccccc}
\hline & \multicolumn{3}{c}{$\begin{array}{c}\text { Volumes específicos } \\
\text { acumulados }\end{array}$} & Proporção de hidrogênio \\
Tempo & $\mathrm{V}_{\mathrm{H} 2}$ & $\mathrm{~V}_{\mathrm{CO} 2}$ & $\mathrm{~V}_{\mathrm{CH} 4}$ & $\% \mathrm{H}_{2}$ \\
\hline$[\mathrm{h}]$ & {$[\mathrm{mL}]$} & {$[\mathrm{mL}]$} & {$[\mathrm{mL}]$} & {$[\%]$} \\
\hline 0,0 & 0 & 0 & 0 & - \\
0,3 & 38 & 233 & 0 & 13,9 \\
0,7 & 90 & 441 & 0 & 16,9 \\
1,0 & 154 & 615 & 1 & 20,0 \\
1,3 & 210 & 763 & 2 & 21,5 \\
1,7 & 259 & 873 & 2 & 22,9 \\
\hline
\end{tabular}

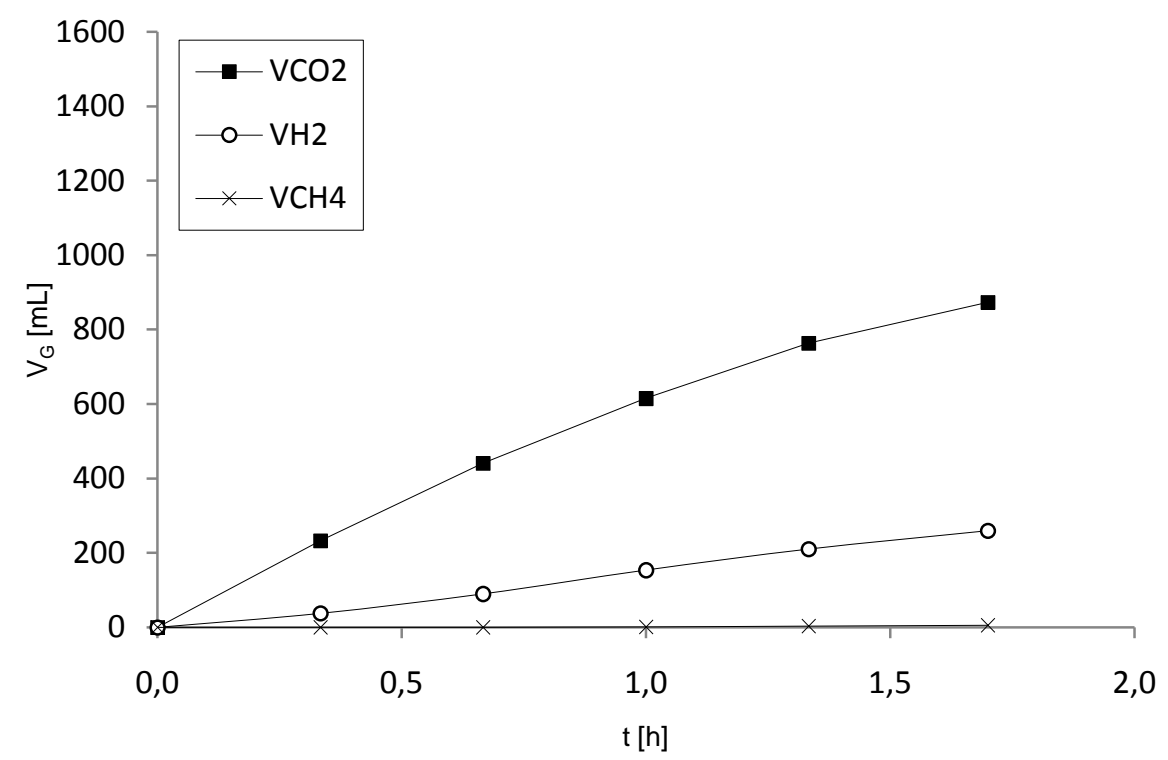

Figura 5.87 - Perfil produção volumétrica espécifica cumulada de gases - Condição V. 


\subsection{Condição experimental VI. (DQO $5400 \mathrm{mg.L}^{-1}$ - TC 2h)}

\subsubsection{Monitoramento}

A Tabela 5.17 apresenta os valores médios durante os 28 dias de monitoramento da Condição VI. O reator continuou apresentando uma boa capacidade de retenção da biomassa com valores de sólidos voláteis totais e filtrados efluentes da ordem de grandeza dos valores afluentes. A quantidade de biomassa presente no reator considerada nos cálculos de cargas orgânicas específicas foi determinada no final da condição. As cargas orgânicas volumétricas aplicadas reais durante a operação foram de $25,75 \mathrm{kgSAC} \cdot \mathrm{m}^{-3} \cdot \mathrm{d}^{-1}$ e $26,25 \mathrm{kgDQO} \cdot \mathrm{m}^{-3} \cdot \mathrm{d}^{-1}$ considerando a sacarose e a DQO, respectivamente (valores nominais de 24,0 kgSAC.m $\mathrm{m}^{-3} \cdot \mathrm{d}^{-1}$ e $27,0 \mathrm{kgDQO} \cdot \mathrm{m}^{-3} \cdot \mathrm{d}^{-1}$ ). 
Tabela 5.17 - Valores médios dos parâmetros monitorados Condição VI. (DQO 5400 mg.L.'-1 -TC 2h)

\begin{tabular}{|c|c|c|c|c|c|c|c|c|c|c|c|}
\hline \multicolumn{2}{|r|}{ Parâmetro } & \multicolumn{3}{|c|}{ Afluente } & \multicolumn{7}{|c|}{ Efluente } \\
\hline $\mathrm{C}_{\mathrm{CT}}$ & {$\left[\operatorname{mgSAC} . \mathrm{L}^{-1}\right]$} & 5150 & \pm & 85 & & 112 & 920 & \pm & 332 & ( & 115 \\
\hline $\mathrm{C}_{\mathrm{CF}}$ & {$\left[\mathrm{mgSAC} \cdot \mathrm{L}^{-1}\right]$} & - & & - & & & 861 & \pm & 325 & ( & $11)$ \\
\hline$\varepsilon_{\mathrm{CT}}$ & [\%] & - & & - & & & 82 & \pm & 6 & ( & $11)$ \\
\hline$\varepsilon_{\mathrm{CF}}$ & {$[\%]$} & - & & - & & & 83 & \pm & 6 & ( & $11)$ \\
\hline $\mathrm{C}_{\mathrm{ST}}$ & {$\left[\mathrm{mgDQO} . \mathrm{L}^{-1}\right]$} & 5251 & \pm & 285 & $(1$ & $11)$ & 4697 & \pm & 148 & ( & $11)$ \\
\hline $\mathrm{C}_{\mathrm{SF}}$ & {$\left[\mathrm{mgDQO} . \mathrm{L}^{-1}\right]$} & - & & - & & & 4537 & \pm & 153 & ( & $11)$ \\
\hline$\varepsilon_{S T}$ & {$[\%]$} & - & & - & & & 14 & \pm & 5 & ( & $11)$ \\
\hline$\varepsilon_{\mathrm{SF}}$ & {$[\%]$} & - & & - & & & 14 & \pm & 3 & ( & $11)$ \\
\hline $\mathrm{pH}$ & {$[\mathrm{u}]$} & 7,2 & \pm & 0,2 & ( & $9 \quad)$ & 5,2 & \pm & 0,2 & & $9 \quad)$ \\
\hline AVT & {$\left[\mathrm{mgHAc} . \mathrm{L}^{-1]}\right.$} & 32 & \pm & 3 & ( & 9 ) & 649 & \pm & 99 & ( & $9 \quad)$ \\
\hline AT & {$\left[\mathrm{mgCACO}_{3} \cdot \mathrm{L}^{-1}\right]$} & 698 & \pm & 62 & ( & $9 \quad)$ & 377 & \pm & 31 & & $9 \quad)$ \\
\hline $\mathrm{AP}$ & {$\left[\mathrm{mgCACO}_{3} \cdot \mathrm{L}^{-1}\right]$} & 571 & \pm & 64 & ( & $9 \quad)$ & 0 & \pm & 0 & ( & $9 \quad)$ \\
\hline AI & {$\left[\mathrm{mgCACO}_{3} \cdot \mathrm{L}^{-1}\right]$} & 126 & \pm & 26 & ( & $9 \quad)$ & 377 & \pm & 31 & ( & $9 \quad$ \\
\hline $\mathrm{AB}$ & {$\left[\mathrm{mgCACO}_{3} \cdot \mathrm{L}^{-1]}\right.$} & 675 & \pm & 61 & ( & $9 \quad)$ & 1 & \pm & 4 & ( & $9 \quad)$ \\
\hline ST & {$\left[\mathrm{mg} . \mathrm{L}^{-1}\right]$} & 6314 & \pm & 222 & ( & $4 \quad)$ & 3552 & \pm & 344 & ( & $4 \quad)$ \\
\hline SVT & {$\left[\mathrm{mg} \cdot \mathrm{L}^{-1}\right]$} & 5487 & \pm & 217 & ( & $4 \quad)$ & 2587 & \pm & 383 & ( & $4 \quad)$ \\
\hline SST & {$\left[\mathrm{mg} \cdot \mathrm{L}^{-1}\right]$} & 93 & \pm & 31 & ( & $4 \quad)$ & 208 & \pm & 5 & ( & $4 \quad)$ \\
\hline SSV & {$\left[\mathrm{mg} \cdot \mathrm{L}^{-1}\right]$} & 58 & \pm & 32 & ( & $4 \quad)$ & 169 & \pm & 10 & ( & $4 \quad)$ \\
\hline $\mathrm{M}_{\mathrm{SVT}}$ & [g] & - & & - & & & 25,27 & & - & & \\
\hline $\mathrm{C}_{\mathrm{X} \text {-SVT }}^{\prime}$ & [g.g-suporte ${ }^{-1}$ ] & - & & - & & & 0,02 & & - & & \\
\hline $\mathrm{C}_{\mathrm{X} \text {-SVT }}$ & {$\left[\mathrm{g} . \mathrm{L}^{-1}\right]$} & - & & - & & & 7,02 & & - & & \\
\hline $\mathrm{COAV}_{\mathrm{CT}}$ & {$\left[\mathrm{kgSAC} \cdot \mathrm{m}^{-3} \cdot \mathrm{d}^{-1}\right]$} & 25,75 & & - & & & - & & - & & \\
\hline $\mathrm{COAV}_{\mathrm{ST}}$ & {$\left[\mathrm{kgDQO} \cdot \mathrm{m}^{-3} \cdot \mathrm{d}^{-1}\right]$} & 26,25 & & - & & & - & & - & & \\
\hline $\mathrm{COAE}_{\mathrm{CT}}$ & {$\left[\mathrm{kgSAC} \cdot \mathrm{kgSVT}^{-1} \cdot \mathrm{d}^{-1}\right]$} & 3,67 & & - & & & - & & - & & \\
\hline $\mathrm{COAE}_{\mathrm{ST}}$ & {$\left[\mathrm{kgDQO} \mathrm{kgSVT}^{-1} \cdot \mathrm{d}^{-1}\right]$} & 3,74 & & - & & & - & & - & & \\
\hline $\mathrm{CORV}_{\mathrm{CF}}$ & {$\left[\mathrm{kgSAC} \cdot \mathrm{m}^{-3} \cdot \mathrm{d}^{-1}\right]$} & - & & - & & & 21,44 & & - & & \\
\hline $\mathrm{CORV}_{\mathrm{SF}}$ & {$\left[\mathrm{kgDQO} \cdot \mathrm{m}^{-3} \cdot \mathrm{d}^{-1}\right]$} & - & & - & & & 3,57 & & - & & \\
\hline $\mathrm{CORE}_{\mathrm{CF}}$ & {$\left[\mathrm{kgSAC} \cdot \mathrm{kgSVT}^{-1} \cdot \mathrm{d}^{-1}\right]$} & - & & - & & & 3,06 & & - & & \\
\hline $\mathrm{CORE}_{\mathrm{SF}}$ & {$\left[\mathrm{kgDQO} \cdot \mathrm{kgSVT}^{-1} \cdot \mathrm{d}^{-1}\right]$} & - & & - & & & 0,51 & & - & & \\
\hline $\mathrm{n}_{\mathrm{H} 2}$ & {$\left[\mathrm{molH}_{2} \cdot \mathrm{d}^{-1}\right]$} & - & & - & & & 0,11 & & - & & $2)$ \\
\hline PrM & {$\left[\mathrm{molH}_{2} \cdot \mathrm{m}^{-3} \cdot \mathrm{d}^{-1}\right]$} & 17,01 & & - & & & - & & - & & \\
\hline PrME & {$\left[\mathrm{molH}_{2} \cdot \mathrm{kgSVT}^{-1} \cdot \mathrm{d}^{-1}\right]$} & 4,38 & & - & & & - & & - & & \\
\hline $\mathrm{RMCA}_{\mathrm{C}, \mathrm{n}}$ & {$\left[\mathrm{molH}_{2} \cdot \mathrm{kgSAC}^{-1}\right]$} & 1,19 & & - & & & - & & - & & \\
\hline $\mathrm{RMCA}_{\mathrm{S}, \mathrm{n}}$ & {$\left[\mathrm{molH}_{2} \cdot \mathrm{kgDQO}^{-1}\right]$} & 1,17 & & - & & & - & & - & & \\
\hline $\mathrm{RMCR}_{\mathrm{C}, \mathrm{n}}$ & {$\left[\mathrm{molH}_{2} \cdot \mathrm{kgSAC}^{-1}\right]$} & 1,43 & & - & & & - & & - & & \\
\hline $\mathrm{RMCR}_{\mathrm{S}, \mathrm{n}}$ & {$\left[\mathrm{molH}_{2} \cdot \mathrm{kgDQO}^{-1}\right]$} & 8,61 & & - & & & - & & - & & \\
\hline $\mathrm{V}_{\mathrm{A}}$ & {$[\mathrm{L}]$} & 1,5 & & & & & & & & & \\
\hline $\mathrm{V}_{\mathrm{R}}$ & {$[\mathrm{L}]$} & 3,6 & & & & & & & & & \\
\hline
\end{tabular}

(*) Entre parêntese o número de amostras considerado no cálculo da média

O reator foi eficiente na remoção de sacarose como pode ser observado na Figura 5.88 da evolução das concentrações afluente e efluente total e filtrada. A Figura 5.89 apresenta a evolução 
das eficiências de conversão que ficaram estáveis perto de um valor de $82 \%$ na forma total e $83 \%$ na forma filtrada. O reator continuou apresentando baixa eficiência de remoção de DQO como pode ser observado na Figura 5.90 que contém as concentrações em DQO afluente e efluente (total e filtrada). A Figura 5.91 apresenta a evolução das eficiências de remoção da DQO quem ficaram estáveis perto de um valor de $14 \%$ na forma total e filtrada.

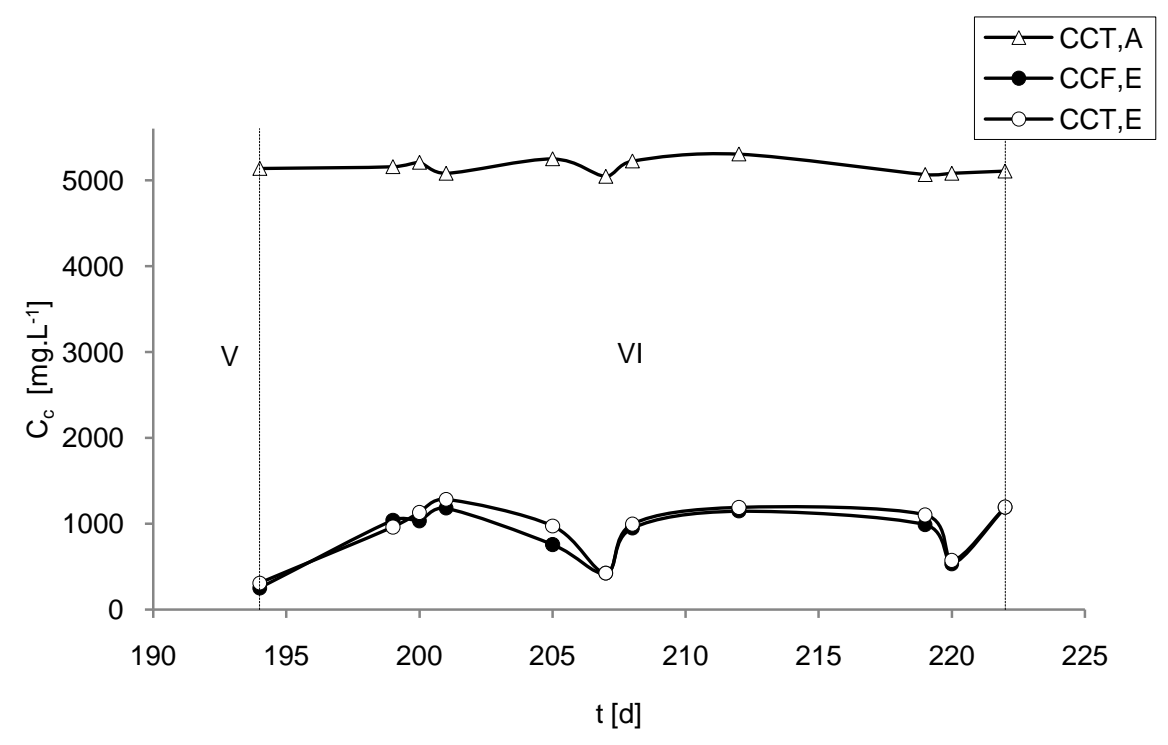

Figura 5.88 - Concentrações em carboidratos no afluente e efluente total e filtrado - Condição VI. 


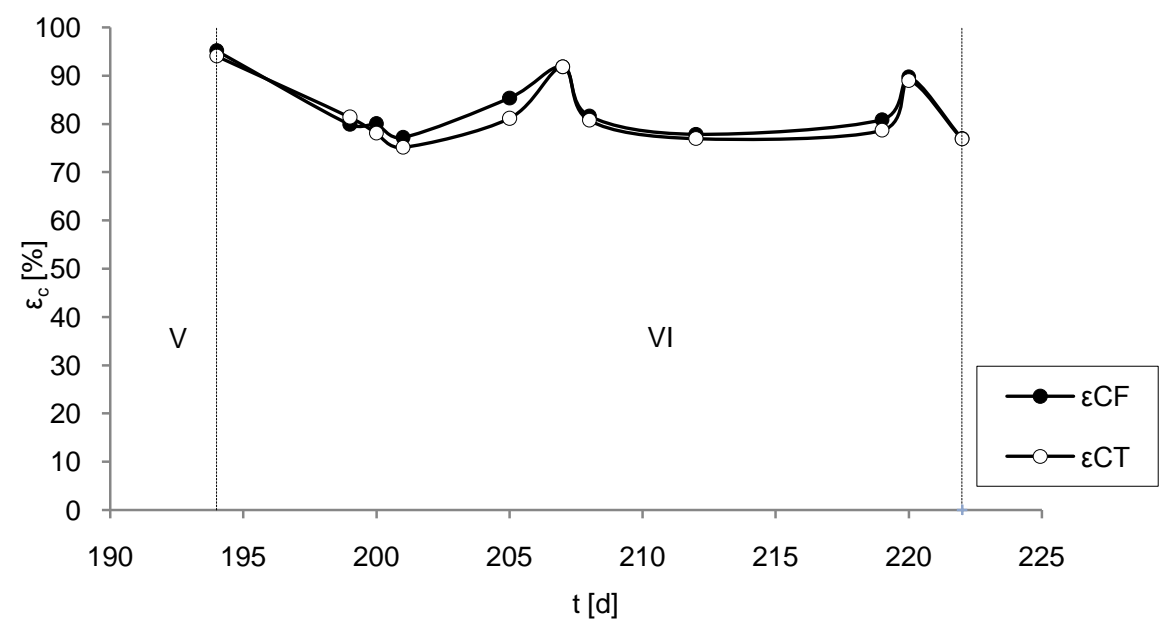

Figura 5.89 - Eficiências de conversão dos carboidratos na forma total e filtrada - Condição VI.

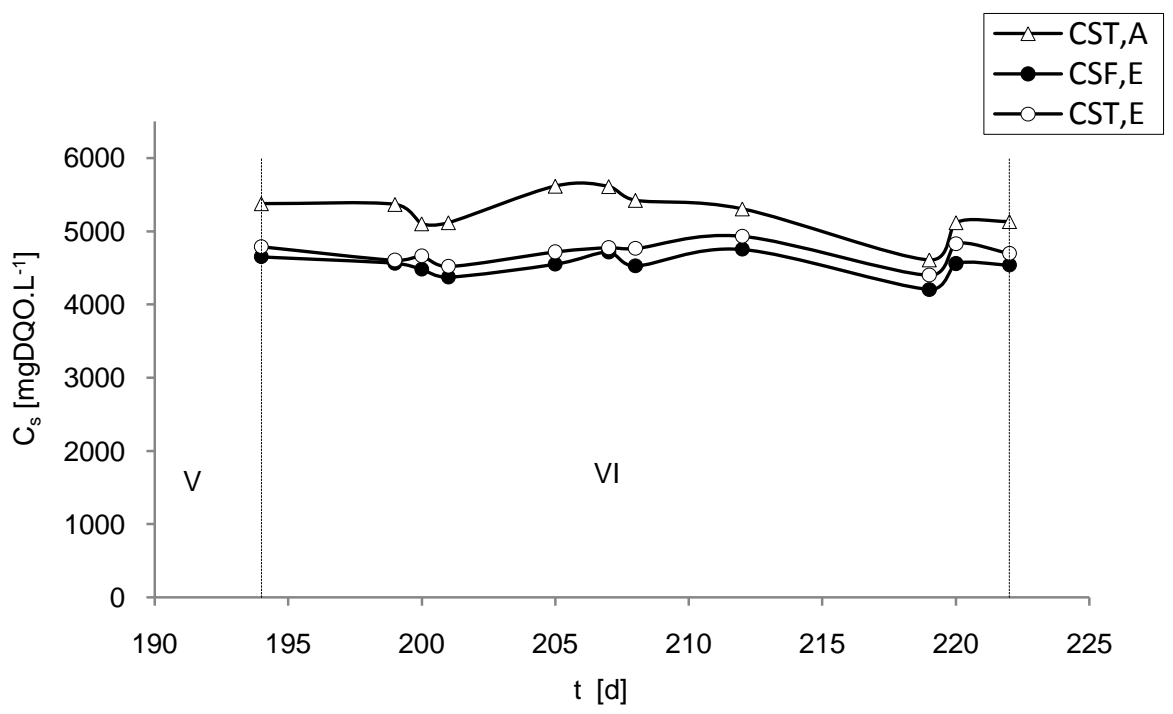

Figura 5.90- Concentrações em DQO no afluente e efluente total e filtrado - Condição VI. 


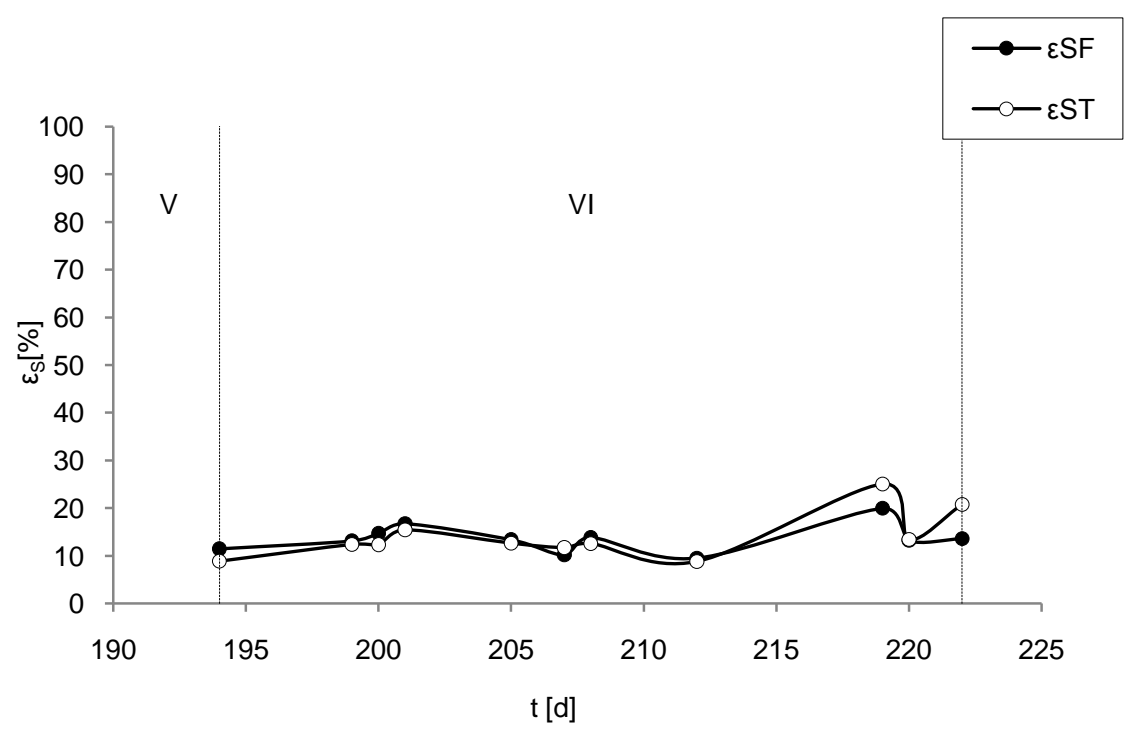

Figura 5.91- Eficiências de remoção da DQO na forma total e filtrada - Condição VI.

A Figura 5.92 mostra a quantificação dos ácidos voláteis totais, cuja concentração média no efluente filtrado foi de $649 \mathrm{mgHAc} . \mathrm{L}^{-1}$. A Tabela 5.18 apresenta os resultados da quantificação dos compostos intermediários realizada por cromatografia gasosa. O ácido Acético predominou seguido pelo ácido Butírico representando, respectivamente, 42,3\% e 13,0\% dos compostos intermediários. O efluente apresentou também uma quantidade importante de etanol representando 30,1\% dos compostos intermediários.

$\mathrm{O}$ acumulo de ácidos no reator levou a uma diminuição do $\mathrm{pH}$ da fase líquida conforme pode ser observado na Figura 5.93 resultando em um consumo da alcalinidade total conforme apresentado pela Figura 5.94. O valor médio do $\mathrm{pH}$ foi 7,2 para o afluente contra 5,2 para o efluente. A alcalinidade média foi de $698 \mathrm{mgCaCO}_{3} \cdot \mathrm{L}^{-1}$ para o efluente contra $377 \mathrm{mgCaCO}_{3} \cdot \mathrm{L}^{-1}$ no efluente.

A variação da produção de biogás durante um pode ser observado na Figura 5.95. O volume máximo produzido foi de $1384 \mathrm{~mL}$ o $194^{\circ}$ dia de operação do reator $\left(1^{\circ}\right.$ dia de operação da condição), o valor médio de $1181 \mathrm{~mL}$ com desvio padrão de $156 \mathrm{~mL}$ indicando reduzidas variações. 


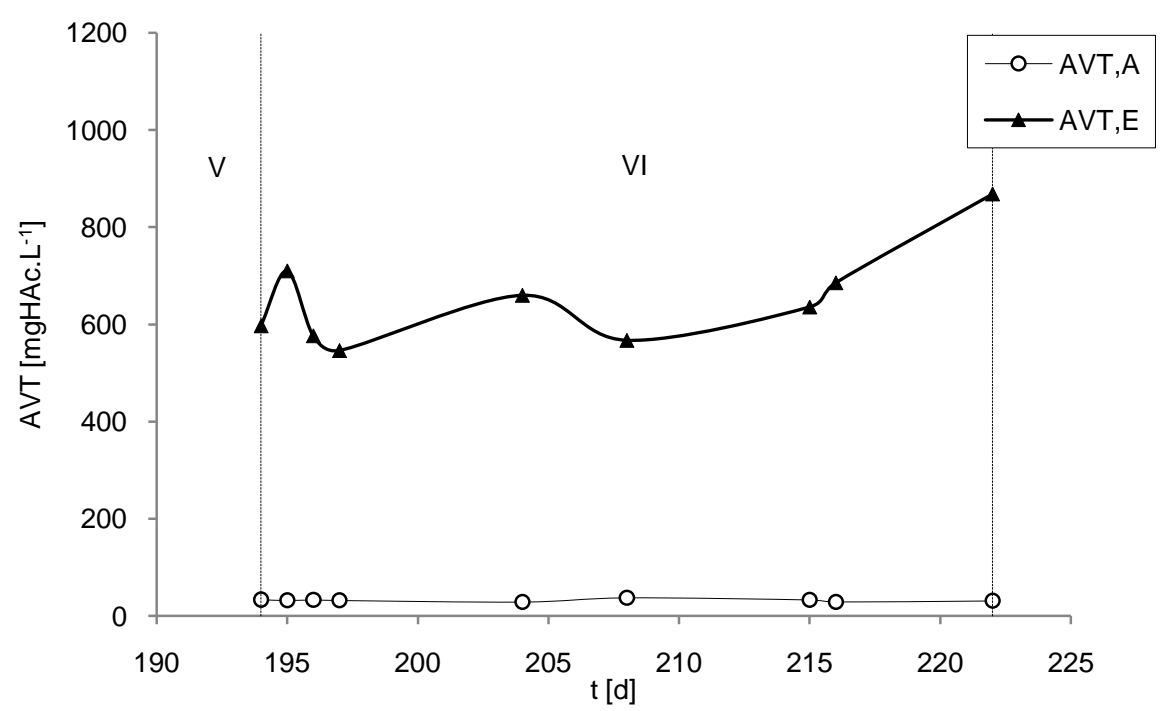

Figura 5.92- Concentrações em ácidos volateís totais por titulação no afluente e efluente - Condição VI.

Tabela 5.18 - Concentração média e composição dos compostos intermediários - Condição VI.

\begin{tabular}{|c|c|c|c|c|c|c|c|}
\hline \multirow{3}{*}{$\begin{array}{l}\text { Espécies } \\
\text { Acetona }\end{array}$} & \multicolumn{6}{|c|}{ Concentração média } & \multirow{3}{*}{$\begin{array}{c}\text { Repartição } \\
{[\%]}\end{array}$} \\
\hline & \multicolumn{3}{|c|}{$\left[\mathrm{mg} . \mathrm{L}^{-1}\right]$} & \multicolumn{3}{|c|}{$\left[\mathrm{mmol} . \mathrm{L}^{-1}\right]$} & \\
\hline & 0,0 & \pm & - & 0,0 & \pm & 0,0 & \\
\hline Metanol & 0,0 & \pm & - & 0,0 & \pm & 0,0 & 0,0 \\
\hline Etanol & 410,3 & \pm & 12,2 & 8,9 & \pm & 0,3 & 30,1 \\
\hline n-Butanol & 5,9 & \pm & 0,4 & 0,1 & \pm & 0,0 & 0,4 \\
\hline Acético & 576,5 & \pm & 62,5 & 9,6 & \pm & 1,0 & 42,3 \\
\hline Porpiônico & 78,8 & \pm & 2,5 & 1,1 & \pm & 0,0 & 5,8 \\
\hline Isobutírico & 8,6 & \pm & 2,1 & 0,1 & \pm & 0,0 & 0,6 \\
\hline Butírico & 176,5 & \pm & 28,5 & 2,0 & \pm & 0,3 & 13,0 \\
\hline Isovalérico & 11,0 & \pm & 0,7 & 0,1 & \pm & 0,0 & 0,8 \\
\hline Valérico & 24,3 & \pm & 1,3 & 0,2 & \pm & 0,0 & 1,8 \\
\hline Capróico & 69,5 & \pm & 11,0 & 0,6 & \pm & 0,1 & 5,1 \\
\hline
\end{tabular}




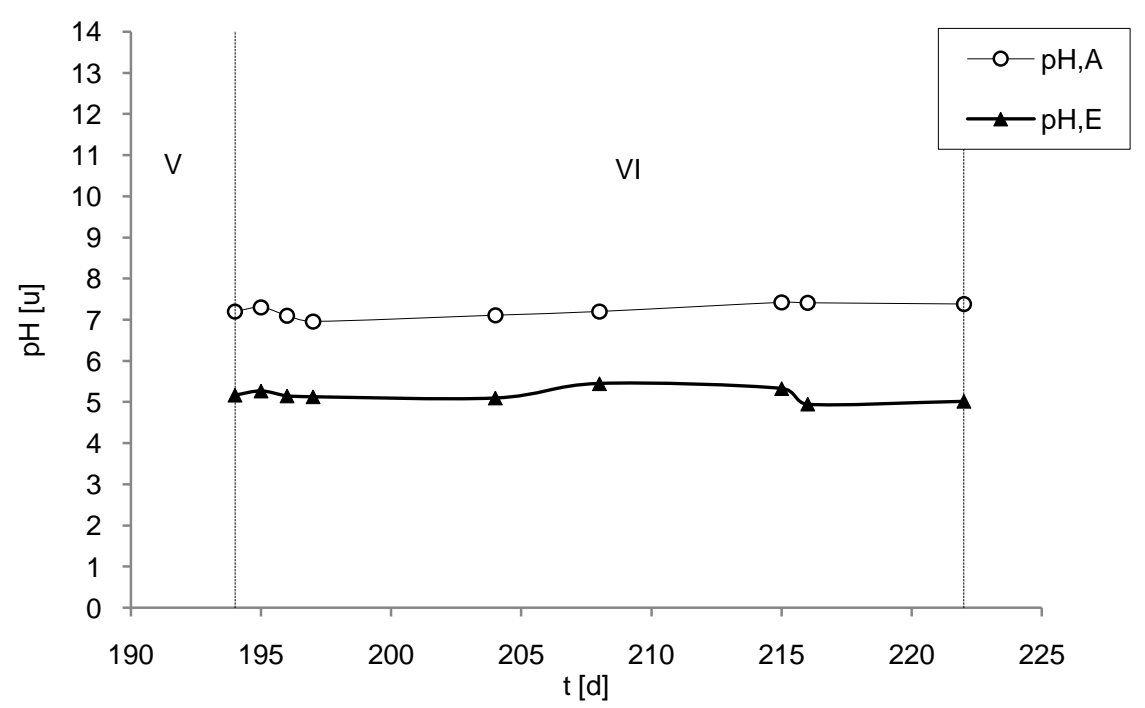

Figura 5.93- pH afluente e efluente - Condição VI.

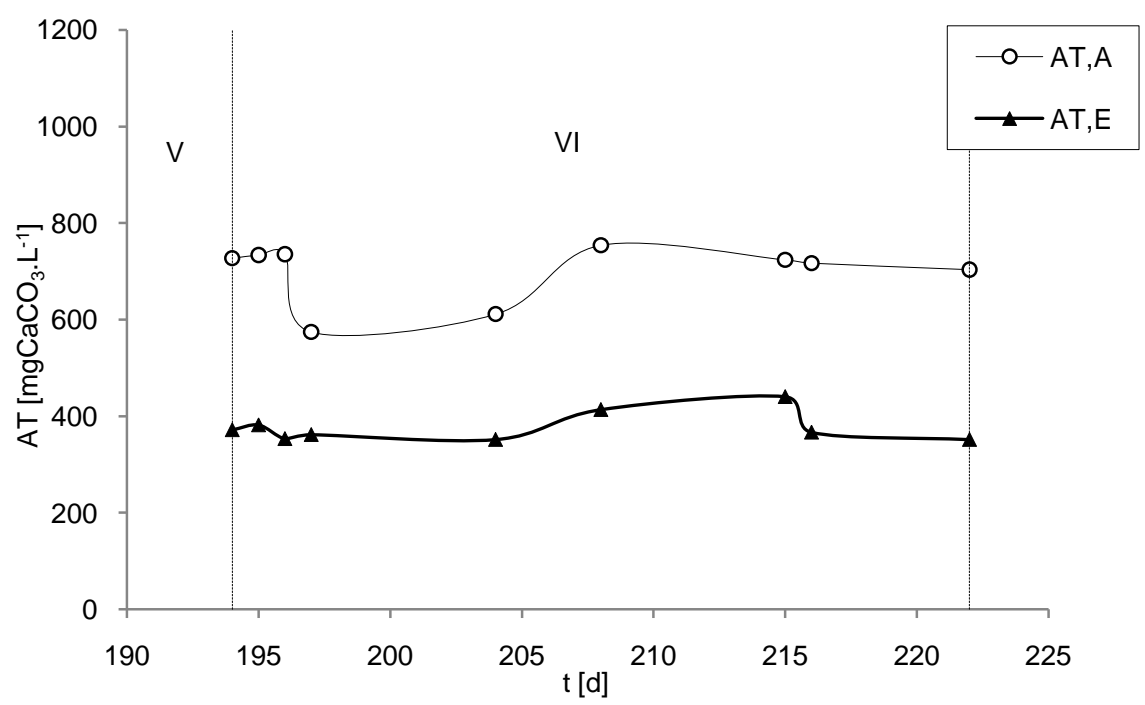

Figura 5.94- Alcalinidades totais por titulação no afluente e efluente - Condição VI. 


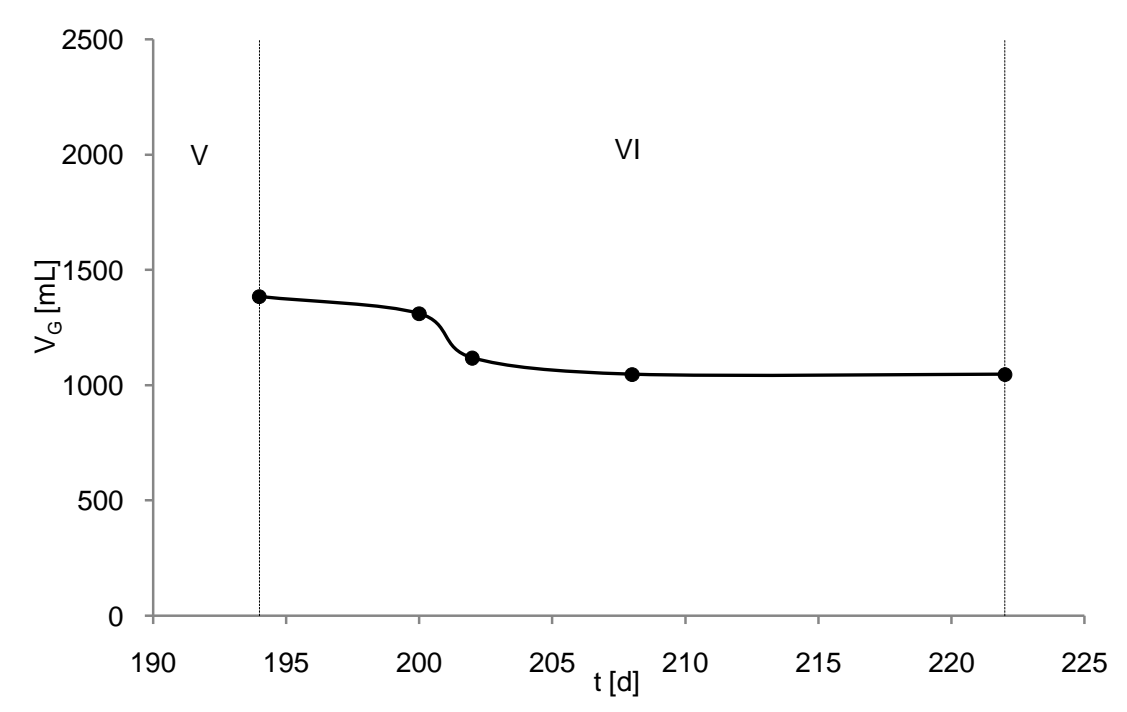

Figura 5.95- Variação da produção volumétrica de biogás durante um ciclo - Condição VI.

\subsubsection{Perfis ao longo do ciclo}

A Figura 5.96 mostra a evolução da concentração em carboidratos totais ao longo do ciclo. A Figura 5.97 mostra a evolução da concentração em DQO ao longo do ciclo, na qual pode ser observada uma remoção baixa em DQO ao longo do ciclo levando a uma alta concentração em DQO no volume residual.

A sacarose convertida em produtos intermediários do metabolismo anaeróbio leva a um acúmulo de ácidos voláteis conforme pode ser observado na Figura 5.98 sendo que a concentração em ácidos voláteis totais aumenta claramente durante a fase de reação para atingir um máximo no final do ciclo.

Os resultados da análise dos compostos intermediários por cromatografia em fase gasosa são apresentados na Figura 5.99, a qual permite observar uma predominância em ácido acético passando de uma concentração inicial de 231,0 mg.L $\mathrm{L}^{-1}$ até um máximo de 410,3 mg. $\mathrm{L}^{-1}$ no final do ciclo. 
$\mathrm{O}$ pH diminua instantaneamente com a diluição do afluente ao inicio do ciclo e permanece quase estável com ligeira diminuição ao longo da operação, provavelmente devido ao acúmulo de ácidos voláteis conforme representado na Figura 5.100. A estabilidade do $\mathrm{pH}$ mesmo com a produção de ácidos voláteis é devido ao tamponamento do sistema pelo consumo de alcalinidade ao longo do ciclo. A Figura 5.101 apresenta a evolução da alcalinidade total no reator ao longo do ciclo.

A produção volumétrica acumulada de biogás pode ser observada na Figura 5.102. A curva de produção tem comportamento crescente no inicio do ciclo e tende a se estabilizar no final. A caracterização qualitativa do biogás por cromatografia permite avaliar os volumes específicos de gases produzidos ao longo do ciclo. A Tabela 5.19 mostra uma produção acumulada de $206 \mathrm{~mL}$ de hidrogênio (15,4\%), $1127 \mathrm{~mL}$ de dióxido de carbono (84,3\%) e $4 \mathrm{~mL}$ de metano (0,3\%). As curvas relativas à produção de cada gás são apresentadas na Figura 5.103.

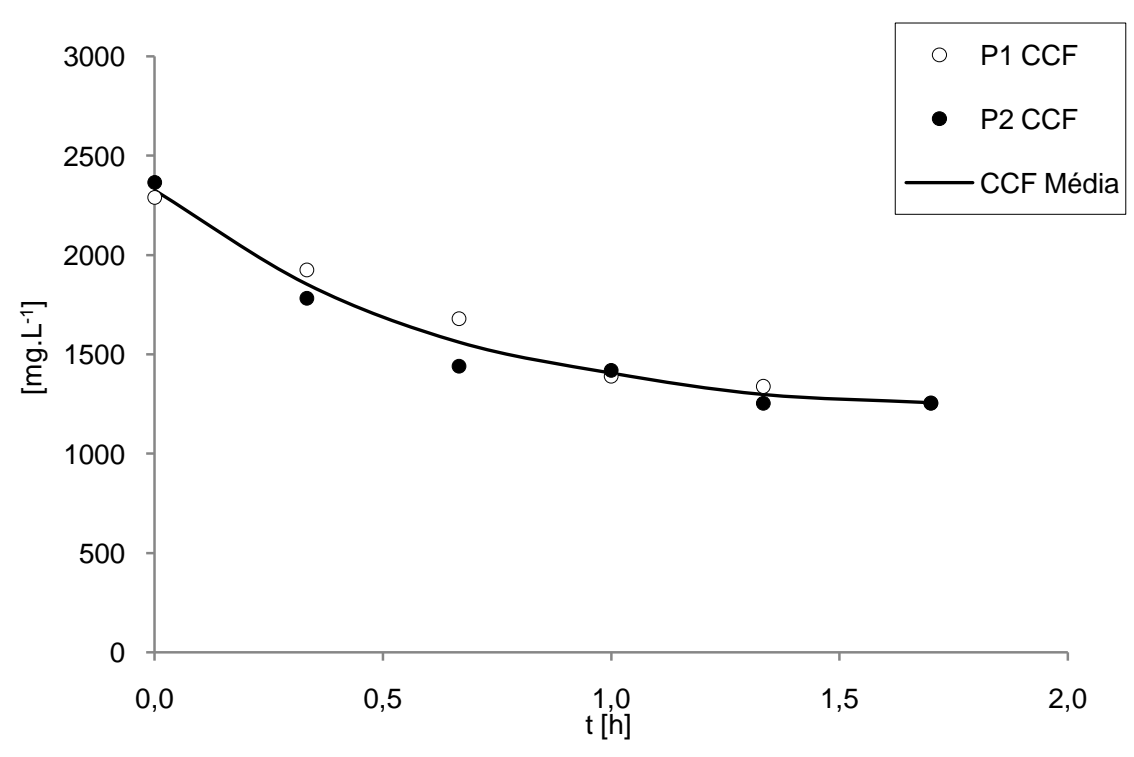

Figura 5.96- Perfil de evolução da concentração em carboidratos no reator - Condição VI. 


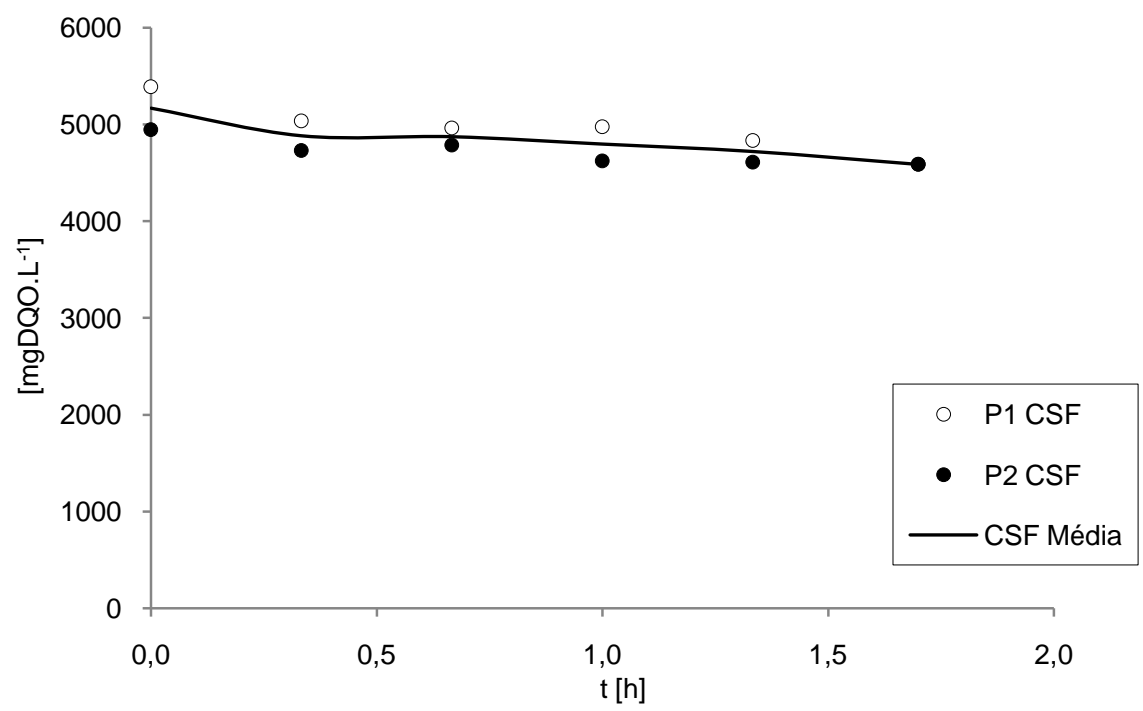

Figura 5.97- Perfil de evolução da concentração em DQO no reator- Condição VI.

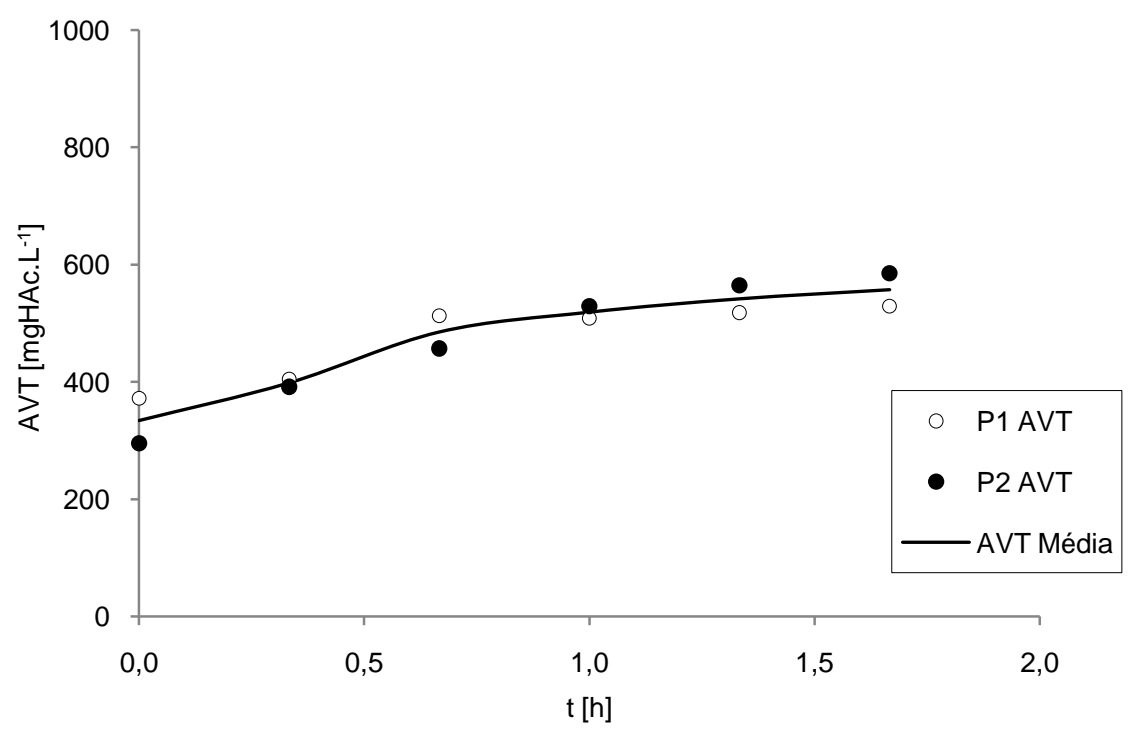

Figura 5.98- Perfil de evolução da concentração em ácidos volateís totais por titulação no reator - Condição VI. 


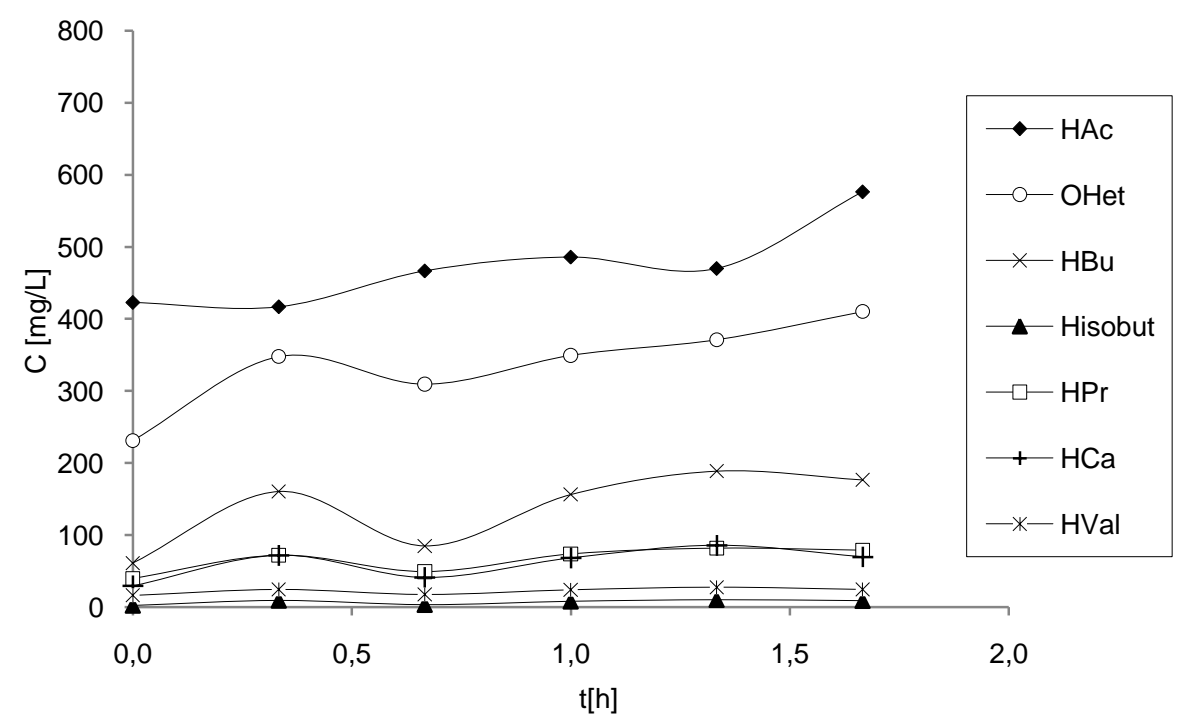

Figura 5.99 - Perfil de evolução das concentrações dos compostos intermediários - Condição VI.

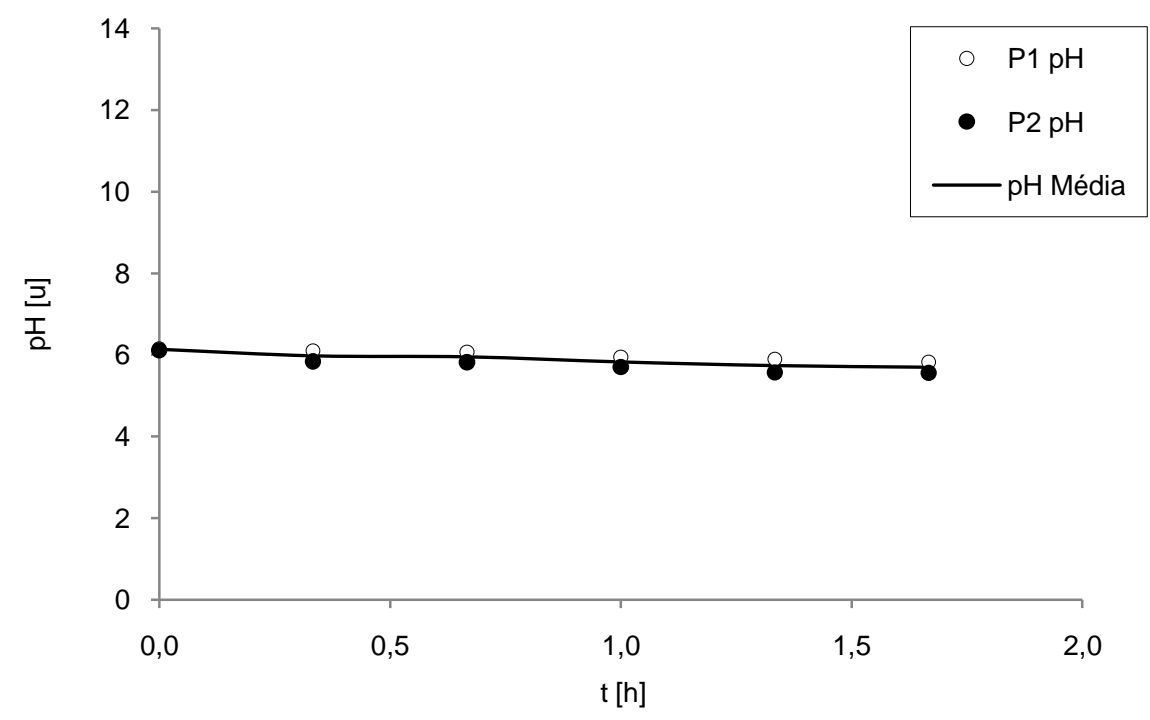

Figura 5.100- Perfil de evolução do pH no reator- Condição VI. 


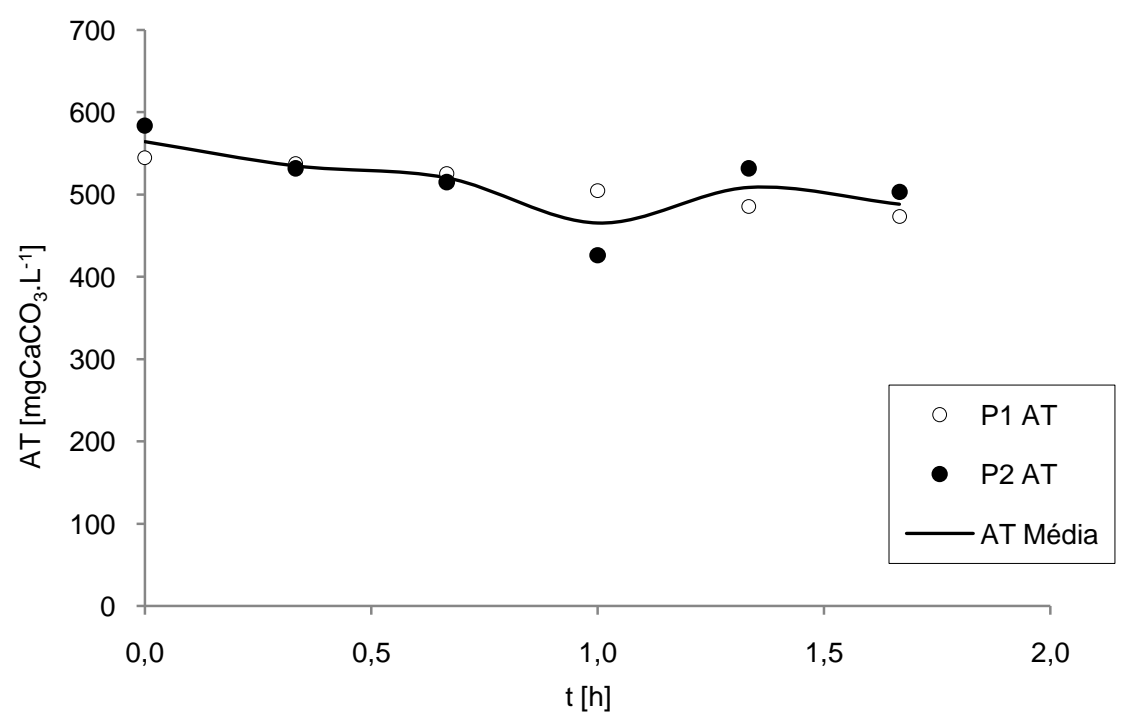

Figura 5.101- Perfil de evolução da alcalinidade total por titulação no reator - Condição VI.

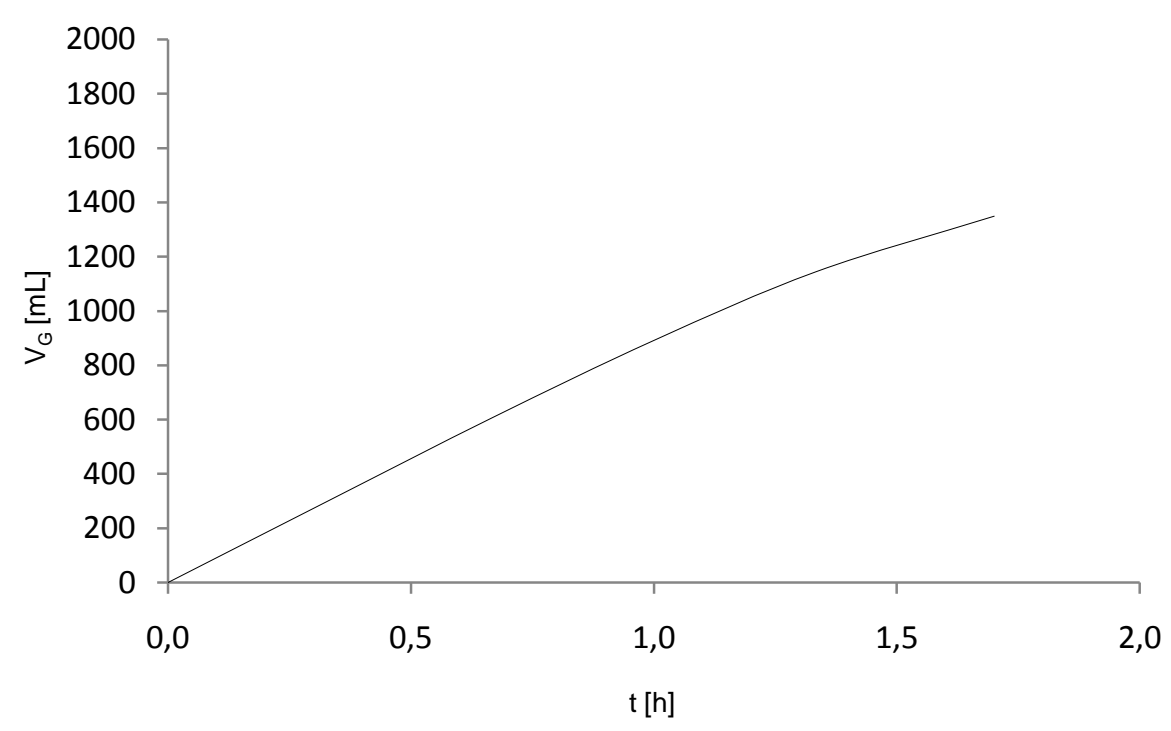

Figura 5.102- Perfil produção volumétrica acumulada de biogás Condição VI. 
Tabela 5.19 - Volumes específicos de gases acumulados e proporção de hidrogênio - Condição VI.

\begin{tabular}{|c|c|c|c|c|}
\hline \multirow{2}{*}{ Tempo } & \multicolumn{3}{|c|}{$\begin{array}{c}\text { Volumes específicos } \\
\text { acumulados }\end{array}$} & \multirow{2}{*}{$\begin{array}{c}\text { Proporção de hidrogênio } \\
\qquad \% \mathrm{H}_{2}\end{array}$} \\
\hline & $\mathrm{V}_{\mathrm{H} 2}$ & $\mathrm{~V}_{\mathrm{CO} 2}$ & $\mathrm{~V}_{\mathrm{CH} 4}$ & \\
\hline [h] & {$[\mathrm{mL}]$} & {$[\mathrm{mL}]$} & {$[\mathrm{mL}]$} & [\%] \\
\hline 0,0 & 0 & 0 & 0 & - \\
\hline 0,3 & 27 & 277 & 0 & 8,8 \\
\hline 0,7 & 66 & 535 & 5 & 10,8 \\
\hline 1,0 & 115 & 769 & 3 & 13,0 \\
\hline 1,3 & 163 & 969 & 4 & 14,4 \\
\hline 1,7 & 206 & 1127 & 4 & 15,4 \\
\hline
\end{tabular}

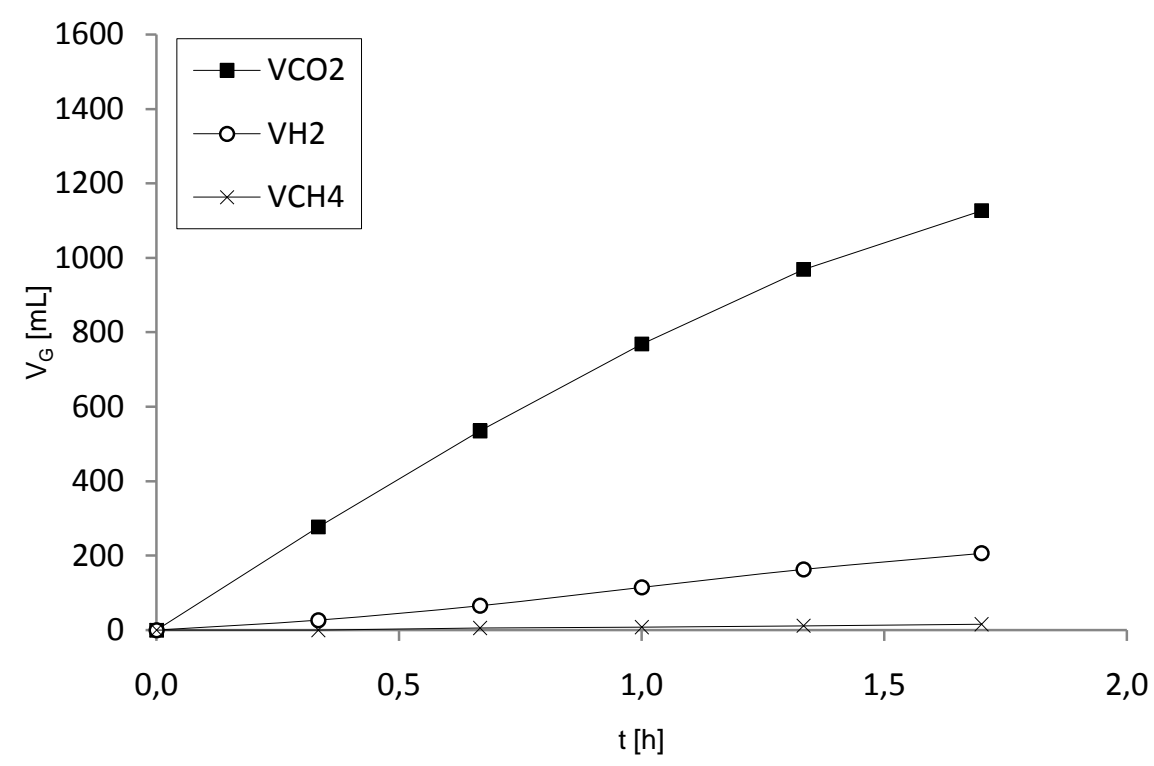

Figura 5.103 - Perfil produção volumétrica espécifica acumulada de gases - Condição VI. 


\subsection{Análise geral das condições experimentais estudadas}

\subsubsection{Desempenho do reator na conversão de substrato}

A variação do desempenho do reator pode ser analisada considerando três parâmetros: o aumento da carga orgânica aplicada (6 valores) e a variação dos dois parâmetros intrínsecos à carga orgânica: a diminuição do tempo de ciclo (3 valores) e o aumento da concentração afluente (2 valores).

Quanto à eficiência de remoção de matéria orgânica (DQO), verificou se uma grande estabilidade do reator que permaneceu próxima a um valor de 18\% (mínimo de 14 e máximo de $21 \%$ com desvio padrão médio de $4 \%$ ) sem apresentar nenhuma tendência significativa, como pode ser observado na Figura 5.104 e na Tabela 5.20 as quais representam as eficiências de remoção de matéria orgânica (DQO) ao longo da operação das seis condições. Dessa forma, esse parâmetro não é adequado para a análise do sistema, pois a conversão do substrato carboidrato (sacarose) no metabolismo fermentativo acidogênico não pode ser diferenciada pela análise de DQO.

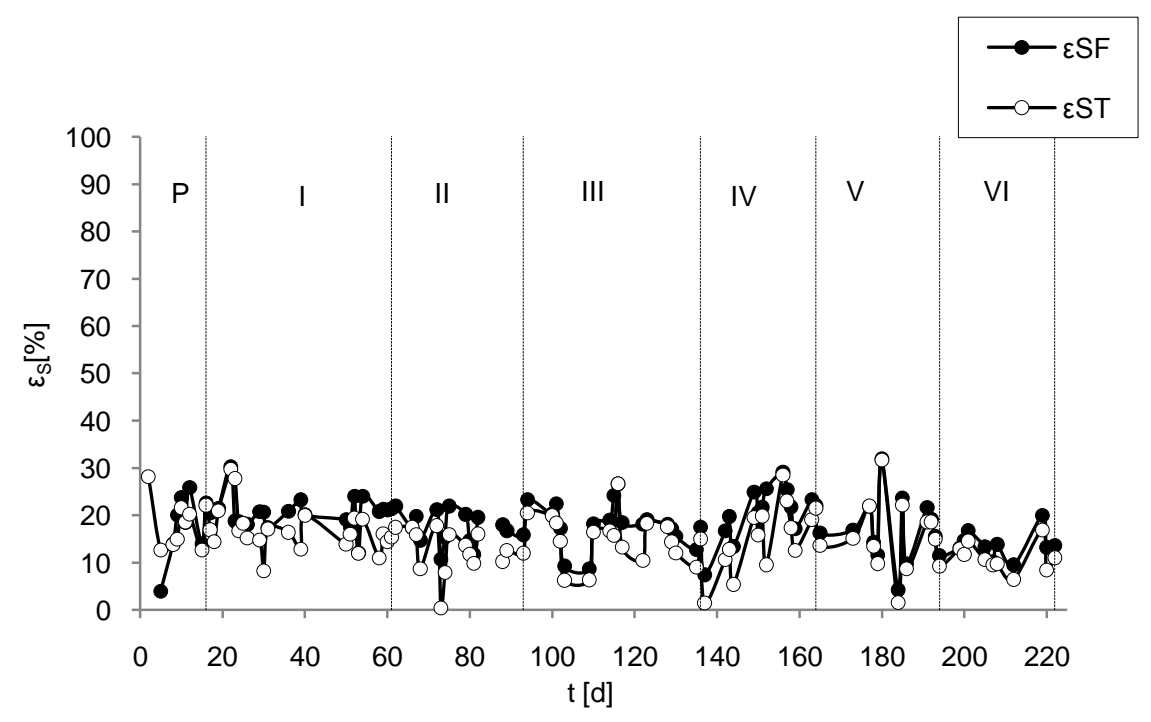

Figura 5.104 - Eficiências de remoção de matéria orgânica (DQO) nas formas não filtrada e filtrada - Todas Condições. 
Tabela 5.20 - Eficiências médias de conversão de matéria orgânica (DQO) e de carboidratos (sacarose) em função do aumento da carga orgânica aplicada.

\begin{tabular}{cccccc}
\hline Ensaio & Concentração & Tempo de ciclo & $\begin{array}{c}\text { Carga orgânica } \\
\text { volumétrica } \\
{\left[\mathrm{kgDQO}^{-3} \cdot \mathrm{d}\right]}\end{array}$ & $\begin{array}{c}\varepsilon_{\mathrm{CF}} \text { médio } \\
{[\%]}\end{array}$ & $\varepsilon_{\mathrm{SF}}$ médio \\
& {$\left[\mathrm{mgDQO} \cdot \mathrm{L}^{-1}\right]$} & {$[\mathrm{h}]$} & 9,0 & $97 \pm 2$ & $20 \pm 3$ \\
\hline I & 3600 & 4 & 12,0 & $97 \pm 2$ & $17 \pm 4$ \\
II & 3600 & 3 & 13,5 & $93 \pm 6$ & $18 \pm 8$ \\
III & 5400 & 4 & 18,0 & $88 \pm 5$ & $21 \pm 6$ \\
IV & 5400 & 3 & 18,0 & $89 \pm 8$ & $17 \pm 7$ \\
V & 3600 & 2 & 27,0 & $83 \pm 6$ & $14 \pm 3$ \\
VI & 5400 & 2 & &
\end{tabular}

Quanto à eficiência de conversão de carboidratos (sacarose), o reator apresentou um desempenho satisfatório ao longo da operação das seis condições entre 83 e 97\% (com desvio padrão médio de 5\%). A Tabela 5.20 e a Figura 5.105 representam as eficiências médias e diárias de conversão de carboidratos (sacarose) em função do aumento da carga orgânica aplicada, pelas quais se pode verificar uma diminuição do desempenho do reator com o aumento da carga orgânica aplicada, com os valores médios passando de $97 \%$ para $83 \%$ da condição I para a condição VI.

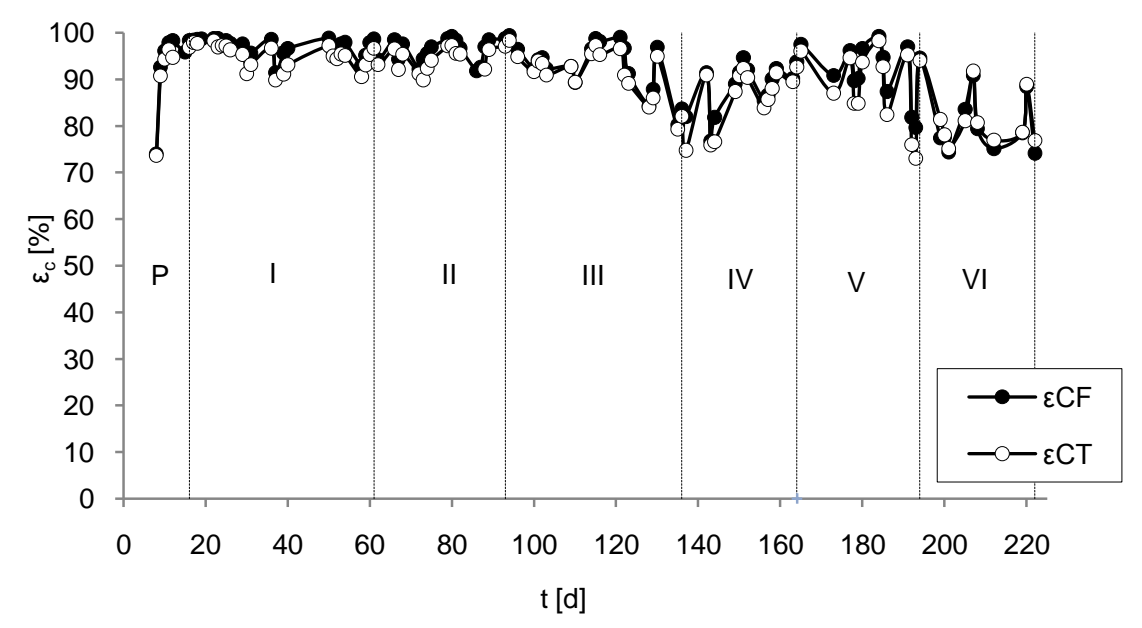

Figura 5.105 - Eficiências de conversão de carboidratos (sacarose) nas formas não filtrada e filtrada em função do aumento da carga orgânica aplicada - Todas Condições. 
Quanto à influência da concentração afluente sobre a conversão de carboidratos (sacarose), a Tabela 5.21 e a Figura 5.106 representam os mesmos resultados organizados em função do aumento da concentração afluente a fim de facilitar a comparação, podendo-se inferir que a concentração afluente tem efeito no desempenho do reator, pois de uma maneira geral valores diferentes (crescentes) de concentração afluente (e tempos de ciclo iguais) resultaram em eficiências menores de conversão. Vale destacar que o desvio padrão pode minimizar a importância dessa tendência.

Tabela 5.21 - Eficiências médias de conversão de matéria orgânica (DQO) e de carboidratos (sacarose) em função do aumento da concentração afluente.

\begin{tabular}{|c|c|c|c|c|c|}
\hline \multirow{2}{*}{ Ensaio } & Concentração & Tempo de ciclo & $\begin{array}{l}\text { Carga orgânica } \\
\text { volumétrica }\end{array}$ & $\varepsilon_{\mathrm{CF}}$ médio & $\varepsilon_{\mathrm{SF}}$ médio \\
\hline & {$\left[\mathrm{mgDQO} \cdot \mathrm{L}^{-1}\right]$} & {$[\mathrm{h}]$} & {$\left[\mathrm{kgDQO} . \mathrm{m}^{-3} . \mathrm{d}\right]$} & {$[\%]$} & {$[\%]$} \\
\hline $\mathrm{I}$ & 3600 & 4 & 9,0 & $97 \pm 2$ & $20 \pm 3$ \\
\hline II & 3600 & 3 & 12,0 & $97 \pm 2$ & $17 \pm 4$ \\
\hline $\mathrm{V}$ & 3600 & 2 & 18,0 & $89 \pm 8$ & $17 \pm 7$ \\
\hline III & 5400 & 4 & 13,5 & $93 \pm 6$ & $18 \pm 8$ \\
\hline IV & 5400 & 3 & 18,0 & $88 \pm 5$ & $21 \pm 6$ \\
\hline VI & 5400 & 2 & 27,0 & $83 \pm 6$ & $14 \pm 3$ \\
\hline
\end{tabular}

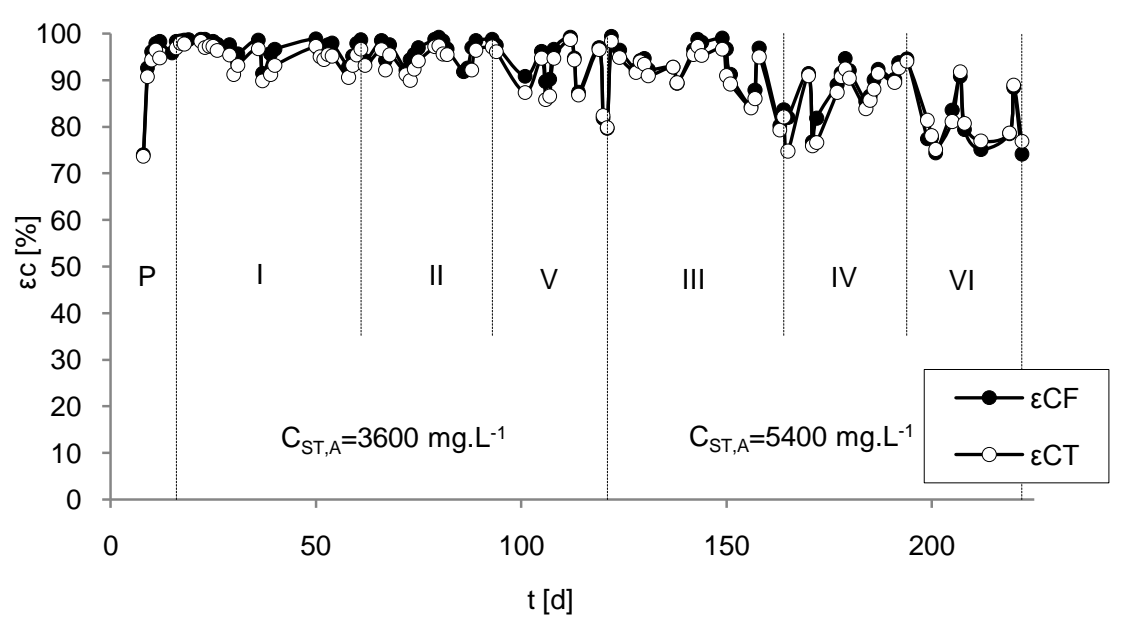

Figura 5.106 - Eficiências de conversão de carboidratos (sacarose) na forma não filtrada e filtrada em função do aumento da concentração afluente - Todas Condições. 
Quanto à influência do tempo de ciclo sobre a conversão de carboidratos (sacarose), a Tabela 5.22 e a Figura 5.107 representam os mesmos resultados organizados em função da diminuição do tempo de ciclo a fim de facilitar a comparação, podendo-se inferir que o tempo de ciclo apresenta um efeito no desempenho do reator, pois de uma maneira geral o desempenho foi menor e a instabilidade aumentou quando o tempo de ciclo diminuiu. Vale destacar novamente que o desvio padrão pode minimizar a importância dessa tendência.

Tabela 5.22 - Eficiências médias de conversão de matéria orgânica (DQO) e de carboidratos (sacarose) em função da diminuição do tempo de ciclo.

\begin{tabular}{cccccc}
\hline Ensaio & Concentração & Tempo de ciclo & $\begin{array}{c}\text { Carga orgânica } \\
\text { volumétrica } \\
{\left[\mathrm{kgDQO}^{-3} \mathrm{~m}^{-3} \mathrm{~d}\right]}\end{array}$ & {$[\%]$} & {$[\%]$} \\
\hline I & {$\left[\mathrm{mgDQO} . \mathrm{L}^{-1}\right]$} & {$[\mathrm{h}]$} & 9,0 & $97 \pm 2$ & $20 \pm 3$ \\
III & 3600 & 4 & 12,0 & $93 \pm 6$ & $18 \pm 8$ \\
II & 5400 & 4 & 18,0 & $97 \pm 2$ & $17 \pm 4$ \\
IV & 5600 & 3 & 13,5 & $88 \pm 5$ & $21 \pm 6$ \\
V & 5400 & 3 & 18,0 & $89 \pm 8$ & $17 \pm 7$ \\
VI & 3600 & 2 & 27,0 & $83 \pm 6$ & $14 \pm 3$ \\
\hline
\end{tabular}

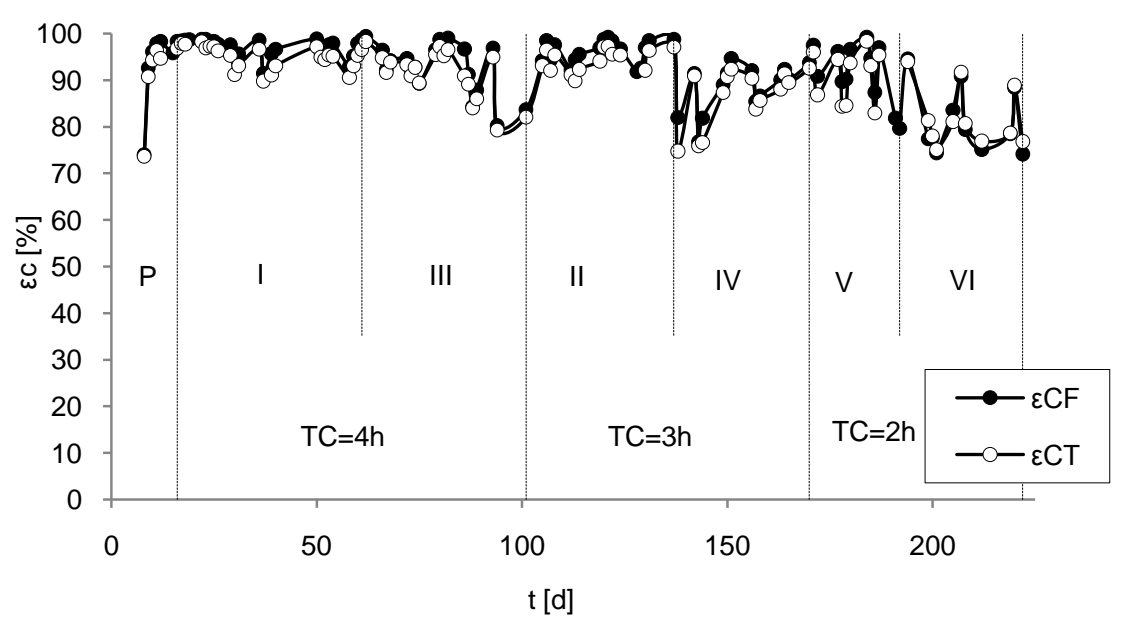

Figura 5.107 - Eficiências de conversão de carboidratos (sacarose) na forma não filtrada e filtrada em função da diminuição do tempo de ciclo - Todas Condições. 
Considerando estes elementos, pode-se inferir que a eficiência de conversão de carboidratos (sacarose) tem tendência a diminuir com o aumento de carga orgânica, sendo esta diminuição relacionada com o aumento da concentração afluente e com a diminuição do tempo de ciclo.

A Tabela 5.23 e a Figura 5.108 permitem avaliar a distribuição dos compostos intermediários, não sendo verificadas grandes mudanças ao longo da operação. A predominância do ácido acético foi verificada em cada condição e teve uma leve tendência a diminuir a favor de um aumento de ácidos butírico e propiônico com o aumento da carga orgânica. A produção de etanol não sofreu grande alteração com a mudança de condição, permanecendo quase constante em $30 \%$ dos compostos medidos.

Tabela 5.23 - Repartição dos compostos intermediários - Todas condições.

\begin{tabular}{ccccccc}
\hline \multirow{2}{*}{ Espécies } & \multicolumn{7}{c}{ Repartição [\%] } \\
& I & II & III & IV & V & VI \\
\hline Acetona & 0,0 & 0,0 & 0,0 & 0,0 & 0,0 & 0,0 \\
Metanol & 0,0 & 0,0 & 0,0 & 0,0 & 0,0 & 0,0 \\
Etanol & 31,3 & 24,8 & 27,6 & 33,5 & 29,5 & 30,1 \\
n-Butanol & 0,6 & 0,6 & 0,5 & 0,3 & 0,4 & 0,4 \\
ÁcidoAcético & 50,0 & 41,7 & 43,8 & 38,2 & 33,6 & 42,3 \\
Ácido Propiônico & 2,6 & 3,3 & 4,2 & 7,1 & 7,2 & 5,8 \\
Ácido Iso-Butírico & 3,8 & 5,6 & 3,5 & 3,1 & 2,8 & 0,6 \\
Ácido Butírico & 8,7 & 14,6 & 12,3 & 11,5 & 13,9 & 13,0 \\
Ácido Iso-Valérico & 0,5 & 0,6 & 2,0 & 0,6 & 0,9 & 0,8 \\
Ácido Valérico & 0,8 & 1,7 & 1,4 & 1,8 & 2,9 & 1,8 \\
Ácido Capróico & 1,6 & 7,1 & 4,7 & 4,1 & 8,8 & 5,1 \\
\hline
\end{tabular}




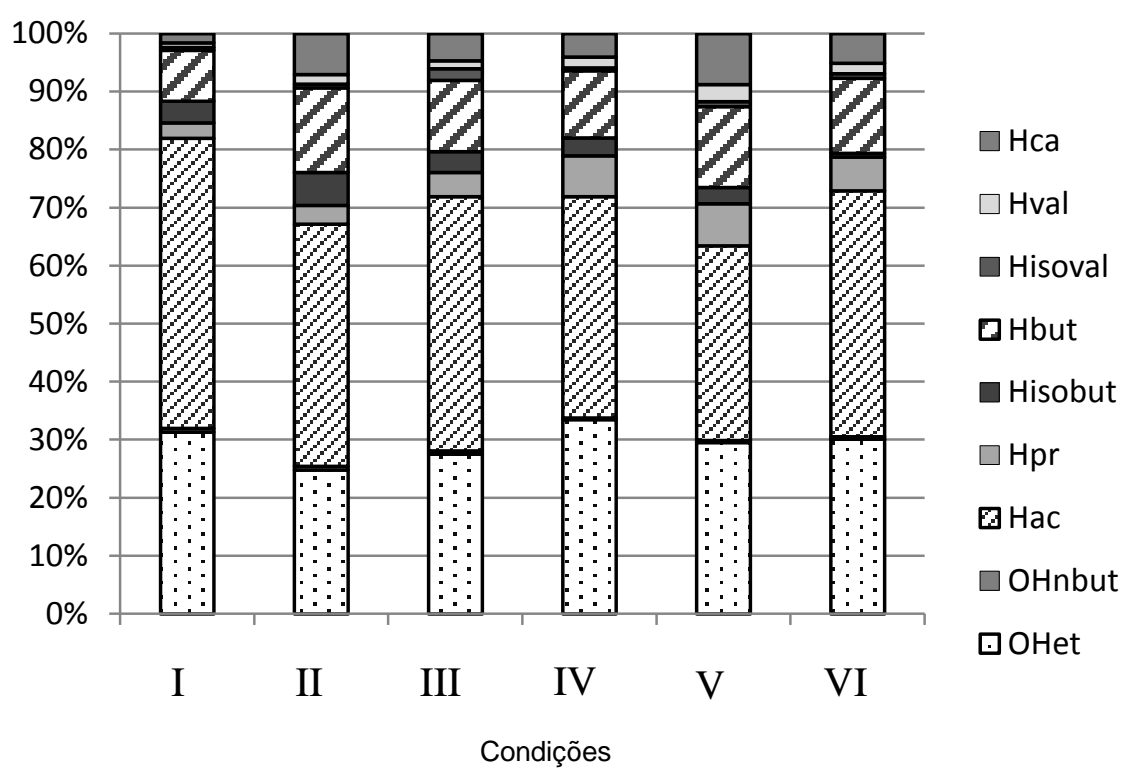

Figura 5.108 - Repartição dos compostos intermedíarios - Todas Condições. 


\subsubsection{Desempenho na produção de biogás}

A Figura 5.109 permite comparar a produção (volumétrica) quantitativa de biogás, verificando-se que a condição III (carga orgânica intermediária com maior concentração afluente e maior tempo de ciclo) apresentou os melhores resultados em termo de volume produzido.

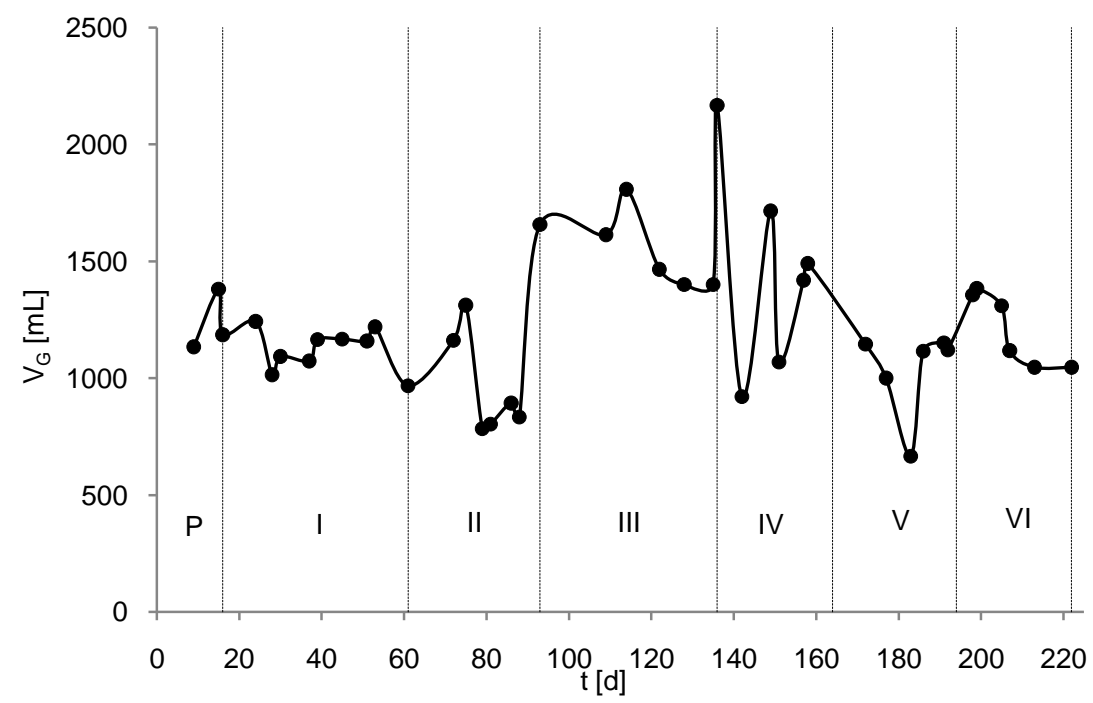

Figura 5.109 - Variação da produção volumétrica de biogás Todas Condições.

A análise qualitativa (composição) do biogás permitiu avaliar a distribuição média de cada composto, sendo apresentada na Tabela 5.24, na qual pode-se observar que a condições III e II (cargas orgânicas intermediárias com, respectivamente, maior e menor concentração afluente e maior e intermediário tempo de ciclo) apresentaram a maior concentração de hidrogênio no biogás.

Analisando a influência da concentração afluente para tempos de ciclo iguais (condições I/III, II/IV e V/VI) e a influência do tempo de ciclo para concentrações afluente iguais (condições I/II/V e III/IV/VI) não foi verificado uma tendência clara. As condições IV e V com mesma carga orgânica aplicada (e diferentes concentrações afluente e tempos de ciclo) apresentaram valores diferentes. Tais resultados ratificam a necessidade do estudo do comportamento do processo em função da carga orgânica aplicada e também das variáveis que definem a carga orgânica aplicada. 
Considerando estas médias ponderamos a curva de produção de biogás para obter a curva de produção específica molar ao longo do experimento representada na Figura 5.110. Esta curva permite visualizar a variação da produção de biogás considerando a hipótese de que a distribuição de cada gás permaneceu igual aos valores medidos na realização dos perfis.

Tabela 5.24 - Repartição dos gases produzidos - Todas Condições.

\begin{tabular}{ccccccc}
\hline $\begin{array}{c}\text { Proporção } \\
{[\%]}\end{array}$ & I & II & III & IV & V & VI \\
\hline $\mathrm{H}_{2}$ & 20,0 & 24,7 & 24,2 & 19,9 & 22,9 & 15,4 \\
$\mathrm{CO}_{2}$ & 79,8 & 75,0 & 75,2 & 79,8 & 76,9 & 84,3 \\
$\mathrm{CH}_{4}$ & 0,2 & 0,3 & 0,6 & 0,3 & 0,2 & 0,3 \\
\hline
\end{tabular}

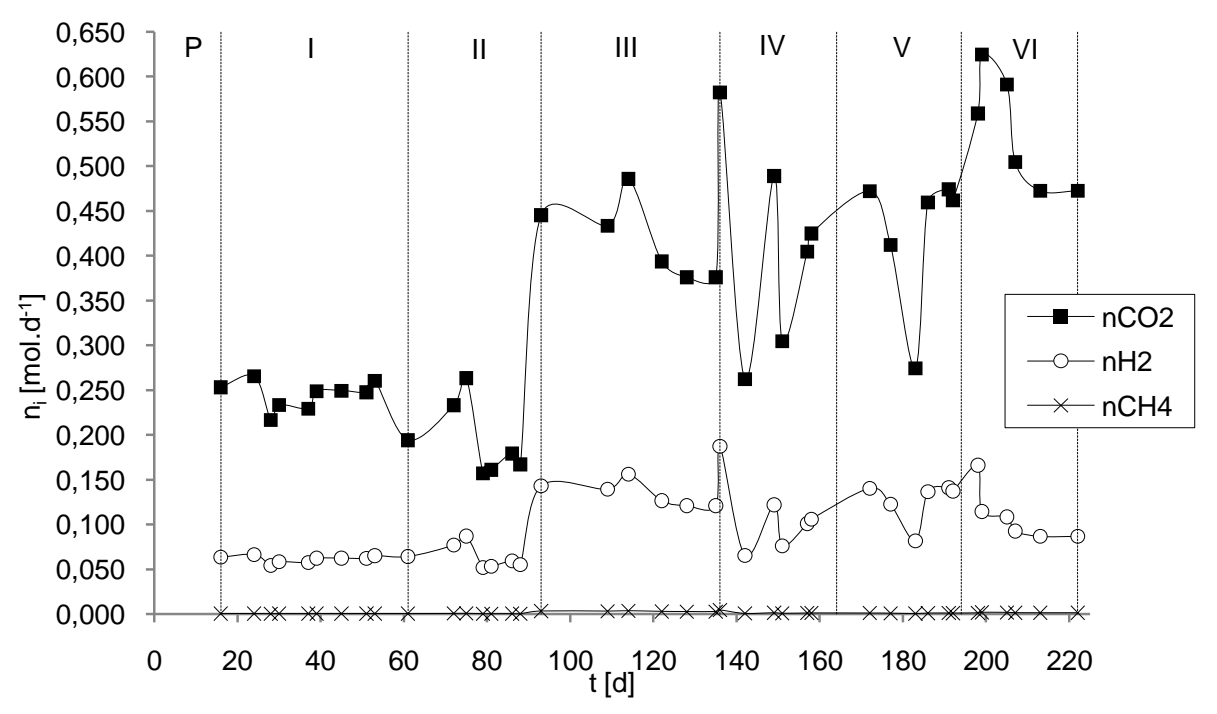

Figura 5.110 - Variação da produção molar específica de biogás - Todas Condições.

No intuito de interpretar melhor os resultados obtidos (produção de biohidrogênio e remoção de matéria orgânica e de carboidratos) em função das condições experimentais implementadas (carga orgânica, concentração afluente e tempo de ciclo), o desempenho do 
reator estudado nesse trabalho em termos de geração de biohidrogênio foi avaliado de modo sistemático considerando-se os indicadores apresentados na Tabela 5.25.

Tabela 5.25 - Indicadores de desempenho por unidade de massa em função do aumento da carga orgânica aplicada. - Todas Condições.

\begin{tabular}{cccccccc}
\hline \multirow{2}{*}{ Indicadores } & \multirow{2}{*}{ Unidades } & I & II & III & IV & V & VI \\
\hline $\mathrm{n}_{\mathrm{H} 2}$ & {$\left[\mathrm{~mol}_{\mathrm{d}} \mathrm{d}^{-1}\right]$} & 0,065 & 0,101 & 0,121 & 0,121 & 0,139 & 0,111 \\
$\mathrm{PrM}$ & {$\left[\mathrm{mol}_{\mathrm{m}}^{-3} \cdot \mathrm{d}^{-1}\right]$} & 10,0 & 15,6 & 18,7 & 18,6 & 21,4 & 17,0 \\
$\mathrm{PrME}$ & {$\left[\mathrm{mol}_{\mathrm{kgSVT}}^{-1} \cdot \mathrm{d}^{-1}\right]$} & 2,66 & 4,13 & 5,07 & 5,04 & 5,50 & 4,38 \\
$\mathrm{RMCA}_{\mathrm{C}, \mathrm{m}}$ & {$\left[\mathrm{molH}_{2} \cdot \mathrm{kgSAC}^{-1}\right]$} & 2,23 & 2,63 & 2,83 & 2,19 & 2,25 & 1,19 \\
$\mathrm{RMCA}_{\mathrm{S}, \mathrm{m}}$ & {$\left[\mathrm{molH}_{2} \cdot \mathrm{kgDQO}^{-1}\right]$} & 1,95 & 2,30 & 2,51 & 2,00 & 2,13 & 1,17 \\
$\mathrm{RMCR}_{\mathrm{C}, \mathrm{m}}$ & {$\left[\mathrm{molH}_{2} \cdot \mathrm{kgSAC}^{-1}\right]$} & 2,30 & 2,72 & 3,04 & 2,47 & 2,53 & 1,43 \\
$\mathrm{RMCR}_{\mathrm{S}, \mathrm{m}}$ & {$\left[\mathrm{molH}_{2} \cdot \mathrm{kgDQO}^{-1}\right]$} & 9,54 & 13,3 & 14,1 & 9,68 & 12,4 & 8,61 \\
\hline
\end{tabular}

A condição V (carga orgânica intermediária com concentração afluente mínima e tempo de ciclo mínimo) apresentou a maior quantidade de produção diária $\left(\mathrm{n}_{\mathrm{H} 2}\right)$ com 0,139 mol.d $\mathrm{d}^{-1}$. Observando-se o comportamento desse parâmetro de desempenho, pode-se concluir que este não deva ser utilizado em estudos de projeto, pois além de ser um parâmetro extensivo, ou seja, não está relacionado com alguma variável que caracterize o "tamanho/capacidade" do sistema, apresentou um valor máximo em condição diferente da máxima carga orgânica aplicada. Assim, deve haver alguma relação em função das variáveis de processo que indique uma de melhor forma o comportamento do sistema.

Nesse sentido, o volume do reator e a quantidade de biomassa são variáveis de processo que permitem o cálculo de parâmetros intensivos, pois relacionam o valor de volume de meio líquido e da massa de microrganismos presentes no biorreator. Entretanto, como tanto o volume quanto a biomassa sofreram poucas variações, esta condição $\mathrm{V}$ apresentou também os maiores valores de produtividade molar (PrM) e de produtividade molar específica (PrME) com valores respectivos de $21,4 \mathrm{~mol} \cdot \mathrm{m}^{-3} \cdot \mathrm{d}^{-1}$ e $5,50 \mathrm{~mol} \cdot \mathrm{kgSVT}^{-1} \cdot \mathrm{d}^{-}$ 
1. Assim, embora esses indicadores sejam intensivos, não permitiram interpretar de modo satisfatório o comportamento do sistema, pois novamente a maior carga orgânica aplicada não promoveu o maior valor nesses parâmetros.

Dessa forma, foram calculados os parâmetros de desempenho de produção de biohidrogênio por carga aplicada, tanto com base na matéria orgânica (DQO) quanto na de carboidratos (sacarose): $\mathrm{RMCA}_{\mathrm{C}, \mathrm{m}}$ em base de sacarose e $\mathrm{RMCA}_{\mathrm{S}, \mathrm{m}}$ em base de DQO, que permitiram estimar a capacidade de produção de biohidrogênio em função da carga implementada, ou seja, um parâmetro que pode ser admitido como intensivo. Assim, verificou-se que a condição III (carga orgânica intermediária com concentração afluente máxima e tempo de ciclo máximo) apresentou o maior valor desses parâmetros seguido de modo próximo pela condição II (carga orgânica intermediária com concentração afluente mínima e tempo de ciclo intermediário), ou seja, foram condições com cargas orgânicas próximas (e intermediárias) nas quais a maior concentração afluente (III em relação a II) foi compensada pelo maior tempo de ciclo (III em relação a II).

Portanto, notou-se que os parâmetros de desempenho que consideram a carga orgânica aplicada são mais efetivos para o projeto de reatores aplicados à produção de biohidrogênio. Entretanto, tais resultados podem ser influenciados pelos efeitos das conversões de matéria orgânica (DQO) e de carboidratos (sacarose) que, nesse caso, foram próximas, ou seja, o parâmetro de desempenho deve ser calculado por carga removida em detrimento a carga aplicada, tornando-se mais efetivo uma vez que considera a relação entre o biohidrogênio produzido e o substrato efetivamente consumido.

Nesse contexto, foram calculados os parâmetros de desempenho de produção de biohidrogênio por carga removida: $\mathrm{RMCR}_{\mathrm{C}, \mathrm{m}}$ em base de carboidratos (sacarose) e $\mathrm{RMCR}_{\mathrm{S}, \mathrm{m}}$ em base de matéria orgânica (DQO), os quais indicam o aproveitamento do substrato na biotransformação responsável pela produção de biogás. Assim, as melhores condições de desempenho foram III e II, ou seja, as mesmas obtidas anteriormente devido à 
já citada proximidade nas conversões de matéria orgânica e de carboidratos, que resultaram em comportamentos análogos em termos de cargas aplicada e removida.

Analisando a influência da concentração afluente para tempos de ciclo iguais (condições I/III, II/IV e V/VI) e a influência do tempo de ciclo para concentrações afluente iguais (condições I/II/V e III/IV/VI) não foi verificado novamente uma tendência clara. Portanto, verifica-se a importância do estudo da influência da carga orgânica, variando-se a concentração afluente o tempo de ciclo, sobre o rendimento de hidrogênio com base na carga removida, pois condições intermediárias podem otimizar o desempenho do sistema. Vale ressaltar que as condições IV e V que possuíam as mesmas cargas aplicadas, mas com concentrações afluente e tempos de ciclo distintos, apresentaram resultados em termos de produção de biohidrogênio por carga removida diferentes, o que ressalta o cuidado que se deve ter ao utilizar esse parâmetro (carga aplicada) em estudos de projeto, , ou seja, tais resultados tornam a ratificar a necessidade do estudo do comportamento do processo em função da carga orgânica aplicada e também das variáveis que definem a carga orgânica aplicada.

A comparação dos resultados obtidos com os valores teóricos, considerando as principais vias metabólicas de produção de hidrogênio a partir de sacarose, são apresentados na Tabela 5.26, pelos quais foram usados os rendimentos por carga molar aplicada para efetuar a conversão em carga mássica.

Tabela 5.26 - Rendimentos molares por carga aplicada potenciais por vias biológicas.

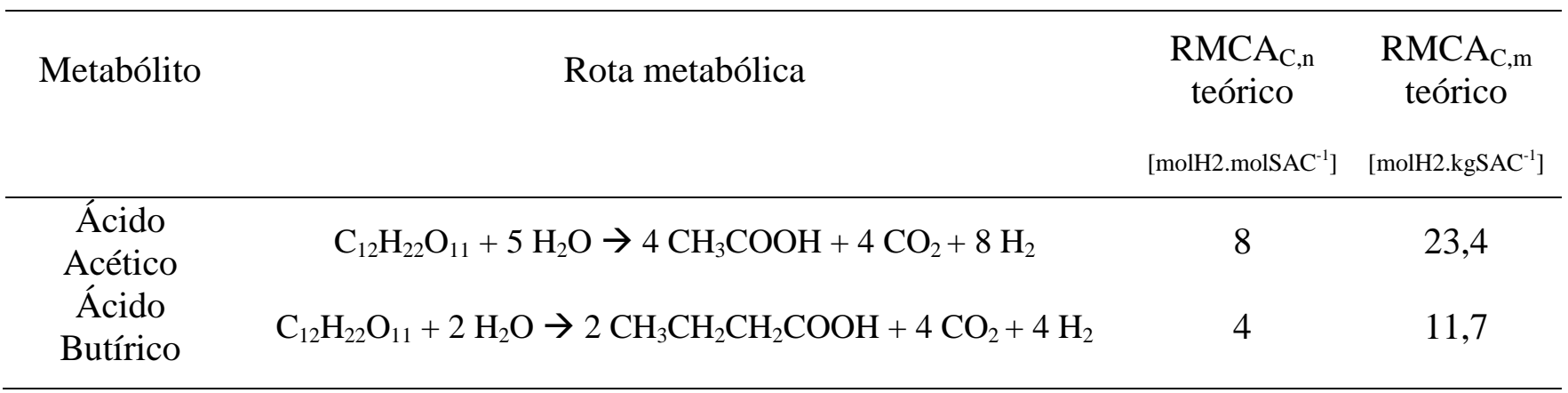


O diagrama de barra da variação dos indicadores apresentado na Figura 5.111 permite visualizar a melhor condição de operação, sendo a condição III, operada com carga orgânica nominal de $13,5 \mathrm{kgDQO} \cdot \mathrm{m}^{-3} \cdot \mathrm{d}^{-1}$, a que apresentou os melhores rendimentos. A Tabela 5.27 apresenta o desempenho porcentual do reator considerando sucessivamente como potencial máximo os rendimentos teóricos da rota de produção do ácido acético e do ácido butírico, sendo verificado que, em termo de desempenho, atingiu-se um máximo de $12 \%$ do potencial de produção da via do ácido acético ou de $24 \%$ da via do ácido butírico para a condição III.

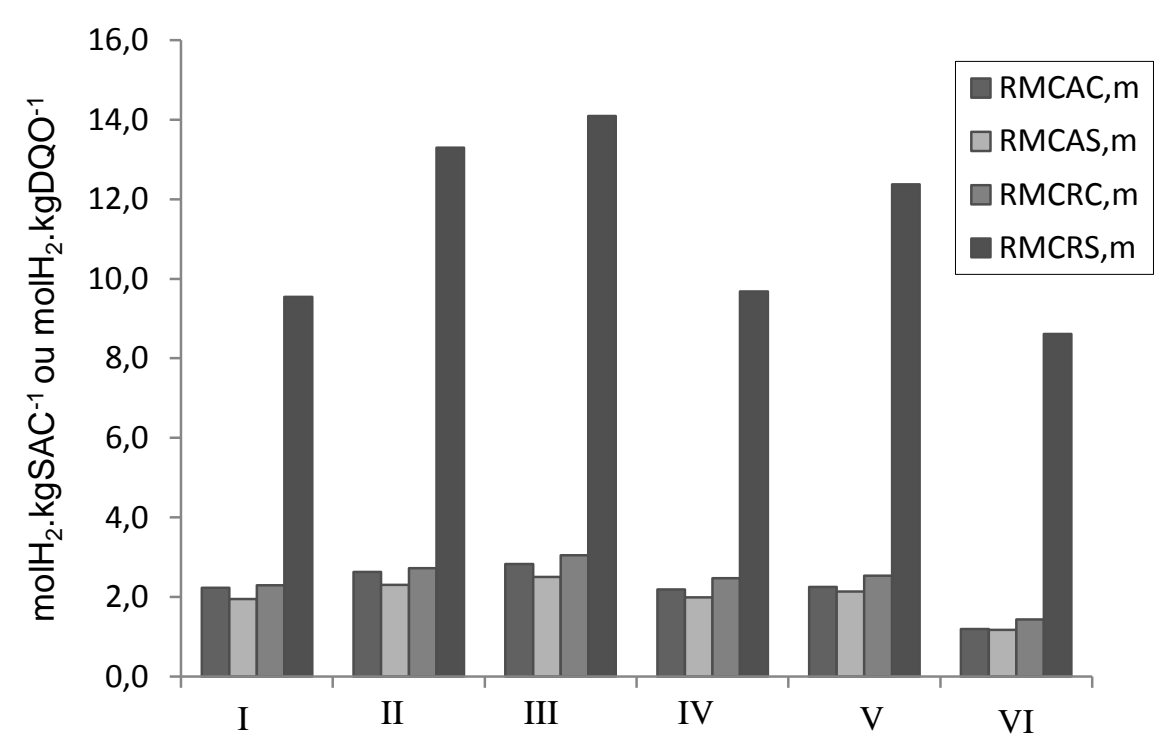

Figura 5.111 - Diagrama de barra dos indicadores de produção molar em função do aumento da carga orgânica aplicada.- Todas Condições.

Tabela 5.27 - Desempenho porcentual em função dos potenciais teòricos - Todas Condições.

\begin{tabular}{|c|c|c|c|c|c|c|c|c|}
\hline \multirow{2}{*}{ Indicadores } & \multirow{2}{*}{ Unidade } & \multirow{2}{*}{ Via } & \multicolumn{6}{|c|}{ Condições } \\
\hline & & & I & II & III & IV & $\mathrm{V}$ & VI \\
\hline $\mathrm{RMCA}_{\mathrm{C}, \mathrm{m}}$ & {$\left[\mathrm{molH}_{2} \cdot \mathrm{kgSAC}^{-1}\right]$} & Acético & $10 \%$ & $11 \%$ & $12 \%$ & $9 \%$ & $10 \%$ & $5 \%$ \\
\hline $\mathrm{RMCA}_{\mathrm{C}, \mathrm{m}}$ & {$\left[\mathrm{molH}_{2} \cdot \mathrm{kgSAC}^{-1}\right]$} & Butírico & $19 \%$ & $23 \%$ & $24 \%$ & $19 \%$ & $19 \%$ & $10 \%$ \\
\hline
\end{tabular}


A Tabela 5.28 apresenta alguns resultados de literatura para a produção de biohidrogênio a partir de diferentes fontes de substrato e sistemas operados em diferentes reatores. Os rendimentos obtidos no presente trabalho são um pouco abaixo dos rendimentos máximos observados no tratamento de efluente sintéticos, mas permanecem na mesma ordem de grandeza. 
Tabela 5.28 - Avaliações da produção de biohidrogênio em função da carga orgânica (Continua)

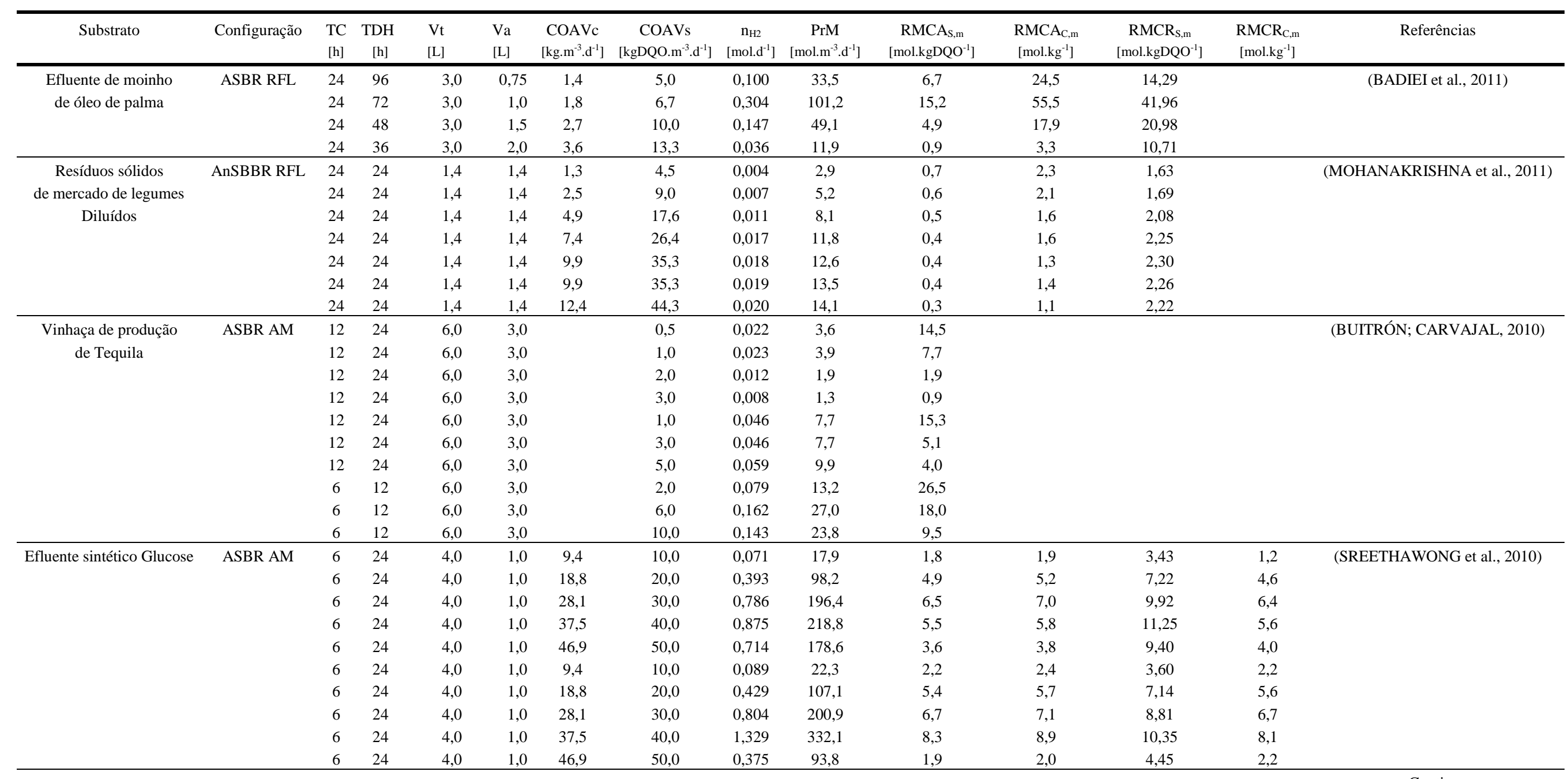


Tabela 5.28 - Avaliações da produção de biohidrogênio em função da carga orgânica (Continuação).

\begin{tabular}{|c|c|c|c|c|c|c|c|c|c|c|c|c|c|c|}
\hline Substrato & Configuração & $\begin{array}{l}\mathrm{TC} \\
{[\mathrm{h}]} \\
\end{array}$ & $\begin{array}{c}\mathrm{TDH} \\
{[\mathrm{h}]} \\
\end{array}$ & $\begin{array}{l}\mathrm{Vt} \\
{[\mathrm{L}]} \\
\end{array}$ & $\begin{array}{l}\mathrm{Va} \\
{[\mathrm{L}]} \\
\end{array}$ & $\begin{array}{c}\mathrm{COAVc} \\
{\left[\mathrm{kg} \cdot \mathrm{m}^{-3} \cdot \mathrm{d}^{-1}\right]} \\
\end{array}$ & $\begin{array}{c}\text { COAVs } \\
{\left[\mathrm{kgDQO} \cdot \mathrm{m}^{-3} \cdot \mathrm{d}^{-1}\right]} \\
\end{array}$ & $\begin{array}{c}\mathrm{n}_{\mathrm{H} 2} \\
{\left[\mathrm{mol.d}^{-1}\right]}\end{array}$ & $\begin{array}{c}\text { PrM } \\
{\left[\mathrm{mol} \cdot \mathrm{m}^{-3} \cdot \mathrm{d}^{-1}\right]} \\
\end{array}$ & $\begin{array}{c}\mathrm{RMCA}_{\mathrm{s}, \mathrm{m}} \\
{\left[\mathrm{mol}^{\left.-\mathrm{kgDQO}^{-1}\right]}\right]} \\
\end{array}$ & $\begin{array}{r}\mathrm{RMCA}_{\mathrm{C}, \mathrm{m}} \\
{\left[\mathrm{mol}^{\left.-\mathrm{kg}^{-1}\right]}\right]} \\
\end{array}$ & $\begin{array}{c}\mathrm{RMCR}_{\mathrm{S}, \mathrm{m}} \\
{\left[\mathrm{mol}^{\left.-1 . \mathrm{kgQO}^{-1}\right]}\right.} \\
\end{array}$ & 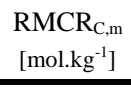 & Referências \\
\hline \multicolumn{15}{|l|}{ Continuação } \\
\hline Efluente sintético & ASBR AM & 4 & 16 & 3,0 & 0,75 & 20,1 & 22,5 & 0,319 & 106,2 & 4,7 & 5,3 & & 5,4 & (CHEN, W. et al., 2009) \\
\hline \multirow[t]{2}{*}{ Sacarose } & & 6 & 16 & 3,0 & 1,1 & 20,1 & 22,5 & 0,257 & 85,7 & 3,8 & 4,3 & & 4,4 & \\
\hline & & 8 & 16 & 3,0 & 1,5 & 20,1 & 22,5 & 0,188 & 62,8 & 2,8 & 3,1 & & 3,2 & \\
\hline \multirow[t]{6}{*}{ Amido de milho } & ASBR AM & 9 & 18 & 3,0 & 1,5 & 22,5 & 26,7 & 0,117 & 39,3 & 1,5 & 1,7 & & & (AROOJ et al., 2008) \\
\hline & & 8 & 15 & 3,0 & 1,5 & 27,0 & 32,0 & 0,240 & 79,5 & 2,5 & 3,0 & & & \\
\hline & & 6 & 12 & 3,0 & 1,5 & 33,8 & 40,0 & 0,319 & 114,7 & 2,7 & 3,1 & & & \\
\hline & & 5 & 9 & 3,0 & 1,5 & 45,0 & 53,3 & 0,292 & 96,4 & 1,8 & 2,2 & & & \\
\hline & & 3 & 6 & 3,0 & 1,5 & 67,5 & 80,0 & 0,550 & 183,9 & 2,3 & 2,7 & & & \\
\hline & & 2 & 4 & 3,0 & 1,5 & 101,3 & 120,0 & 0,113 & 39,3 & 0,3 & 0,4 & & & \\
\hline Efluente sintético Glucose & AnSBBR RFL & 24 & 32 & 2,0 & 1,6 & \multirow{3}{*}{1,6} & 6,3 & 0,024 & 11,9 & 1,9 & & & 13,4 & (VIJAYA BHASKAR et al., 2008) \\
\hline com efluente de indústria & & 24 & 32 & 2,0 & 2,0 & & 7,1 & 0,015 & 7,3 & 1,0 & & & 8,2 & \\
\hline química & & 24 & 32 & 2,0 & 1,6 & & 7,9 & 0,010 & 5,2 & 0,7 & & & 6,1 & \\
\hline \multirow[t]{3}{*}{ Efluente sintético Glucose } & ASBR AM & 8 & 16 & 2,6 & 1,3 & 37,5 & 32,0 & 0,250 & 96,3 & 2,6 & 3,0 & & & (CHEONG et al., 2007) \\
\hline & & 6 & 12 & 2,6 & 1,3 & 50,0 & 42,6 & 0,607 & 233,6 & 4,7 & 5,5 & & & \\
\hline & & 4 & 8 & 2,6 & 1,3 & 75,0 & 63,9 & 0,642 & 247,1 & 3,3 & 3,9 & & & \\
\hline Efluente sintético & ASBBR AM & 4 & 10 & 3,6 & 1,5 & 8,0 & 9,0 & 0,065 & 10,0 & 2,0 & 2,2 & 9,5 & 2,3 & (Presente Trabalho) \\
\hline \multirow[t]{5}{*}{ Sacarose } & & 3 & 7 & 3,6 & 1,5 & 10,7 & 12,0 & 0,101 & 15,6 & 2,3 & 2,6 & 13,3 & 2,7 & \\
\hline & & 4 & 10 & 3,6 & 1,5 & 12,0 & 13,5 & 0,121 & 18,7 & 2,5 & 2,8 & 14,1 & 3,0 & \\
\hline & & 3 & 7 & 3,6 & 1,5 & 16,0 & 18,0 & 0,121 & 18,6 & 2,0 & 2,2 & 9,7 & 2,5 & \\
\hline & & 2 & 5 & 3,6 & 1,5 & 16,0 & 18,0 & 0,139 & 21,4 & 2,1 & 2,3 & 12,4 & 2,5 & \\
\hline & & 2 & 5 & 3,6 & 1,5 & 24,0 & 27,0 & 0,111 & 17,0 & 1,2 & 1,2 & 8,6 & 1,4 & \\
\hline
\end{tabular}


Observa se que os máximos rendimentos molares por carga aplicada na base do substrato $\left(\mathrm{RMCA}_{\mathrm{C}, \mathrm{m}}\right)$ coincidem em todos os trabalhos com os máximos rendimentos molares por carga removida na base do substrato $\left(\mathrm{RMCR}_{\mathrm{C}, \mathrm{m}}\right)$, indicando que a capacidade de produção atinge um valor máximo quando ocorre o melhor aproveitamento da biotransformação na produção de biogás.

A Figura 5.112 apresenta de forma gráfica uma comparação da variação do rendimento por carga aplicada na base do substrato $\left(\mathrm{RMCA}_{\mathrm{C}, \mathrm{m}}\right)$ em função do aumento da carga orgânica volumétrica aplicada nos trabalhos realizados com efluentes sintéticos (sacarose e glicose). Aparece claramente que o rendimento por carga aplicada passa por um valor máximo quando o reator é operado nas condições ótimas de carga orgânica volumétrica o que confirma a hipótese do presente trabalho.

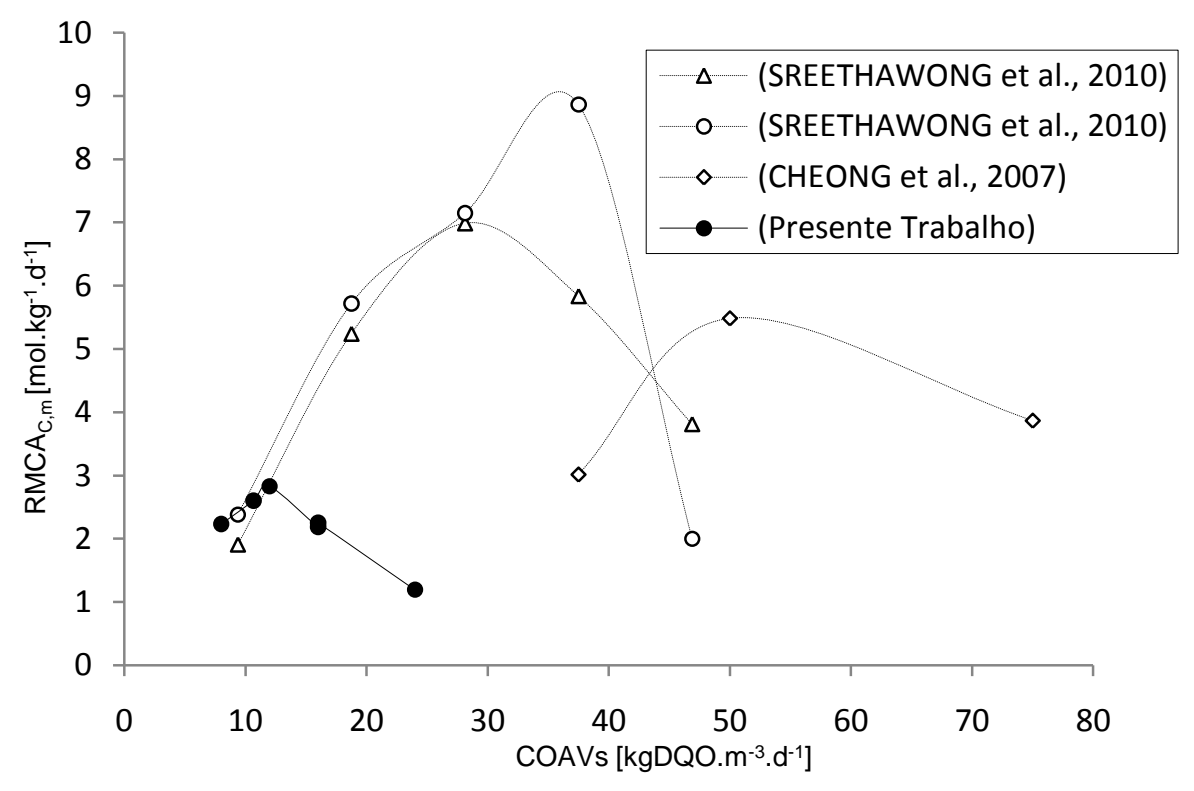

Figura 5.112 -Rendimentos molar por carga aplicada na base do substrato em em função da variação da carga orgânica aplicada Comparação com a literatura

O valor da carga orgânica ótima varia de um trabalho ao outro devido às diferencias de sistemas e de condições de operação investigadas. A ausência de pesquisa na literatura utilizado um reator de tipo AnSBBR com agitação mecânica e afluente sintético 
impossibilita a comparação do presente trabalho com outros resultados, mas podemos inferir que a carga orgânica ótima de operação desta configuração se encontra próxima a um valor de $13,5 \mathrm{kgDQO} . \mathrm{m}^{-3} \cdot \mathrm{d}^{-1}$ com concentração afluente de $5400 \mathrm{mgDQO} \cdot \mathrm{L}^{-1}$ e tempo de ciclo de 4 horas.

\subsubsection{Exames Microbiológicos}

As amostras de biomassa foram retiradas ao final de cada duas condições experimentais e conservadas para a realização de analises microbiológicas. Na Figura 5.113 podem ser observadas as microscopias óptica por luz comum, por contraste de fase e por fluorescência realizadas após a operação das condições I e II, na Figura 5.114 após a operação das condições III e IV e finalmente na Figura 5.115 após as condições V e VI.

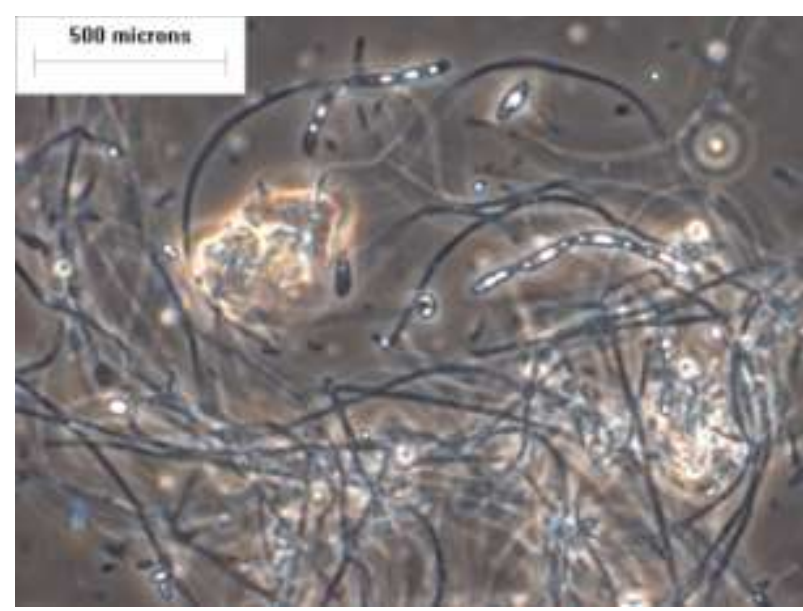

(a)

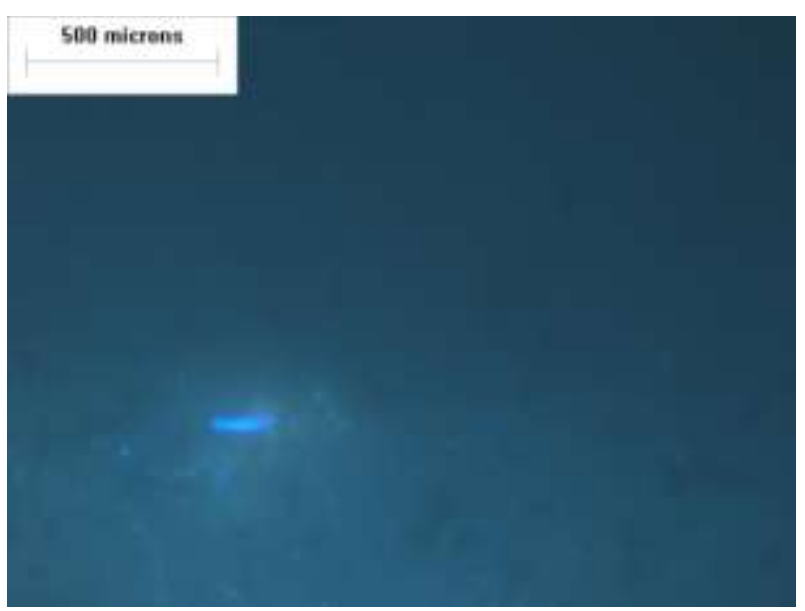

(b)

Figura 5.113 - Microscopias por luz comum e contraste de fase e por fluorescência - Condições I e II. 


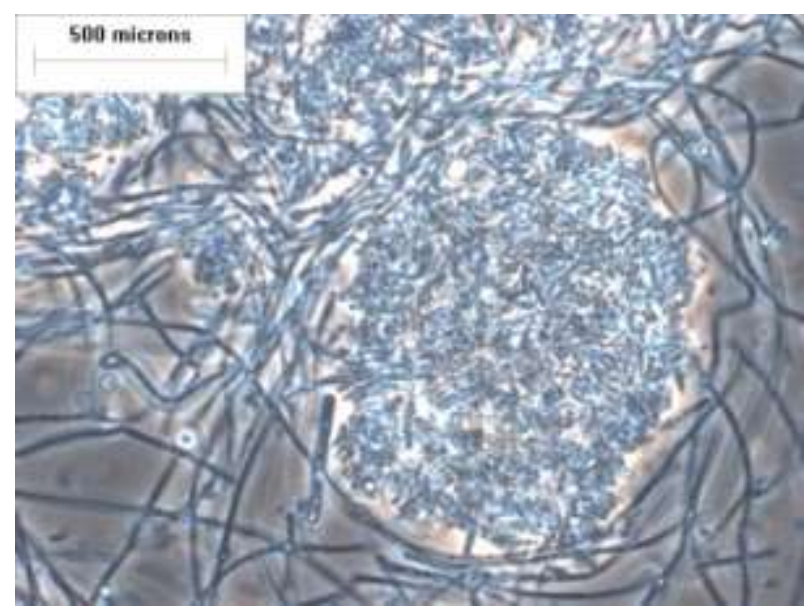

(a)

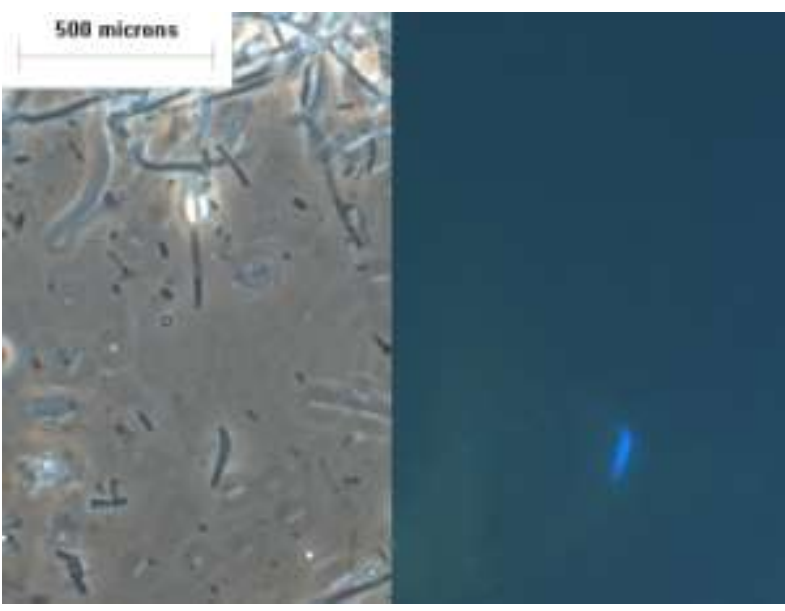

(b)

Figura 5.114 - Microscopias por luz comum e contraste de fase e por fluorescência - Condições III e IV.

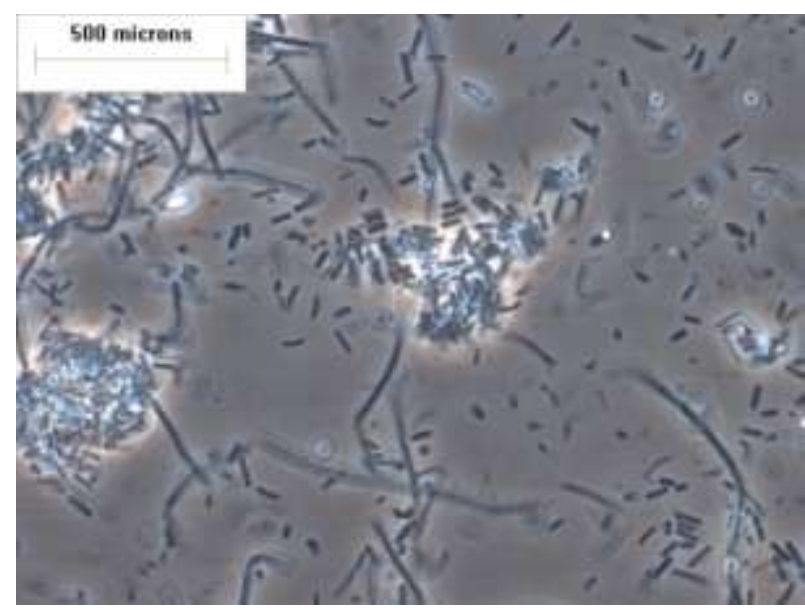

(a)

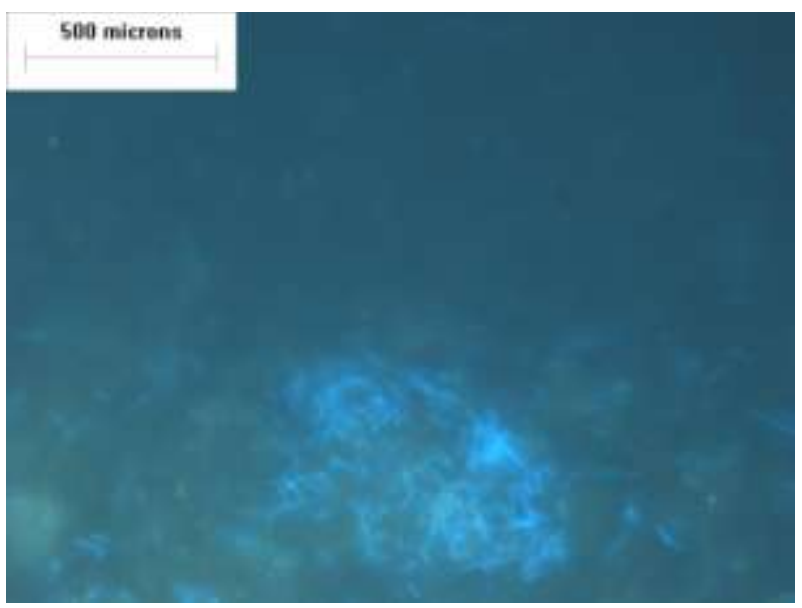

(b)

Figura 5.115 - Microscopias por luz comum e contraste de fase e por fluorescência - Condições V e VI.

As análises revelaram uma biomassa a caráter filamentosa provavelmente devido à geração de polímeros no metabolismo. Por análise da morfologia, pode-se inferir uma predominância de espécies de tipo bacilos, endósporos e bacilos com endósporos. Foram observadas espécies fluorescentes quando foram expostas à luz ultravioleta. As análises não permitiram constatar grandes diferenças morfológicas entre as três amostras. 


\subsubsection{Balanços de massa}

Realizou-se o balanço de massa de duas maneiras, considerando o elemento carbono nas entradas e saídas do sistema conforme mostrado na Tabela 5.29 e verificando a correspondência entre a DQO medida por análise direta e a DQO equivalente dos compostos intermediários quantificados por cromatografia em fase gasosa conforme mostrado na Tabela 5.30.

Foram consideradas as seguintes hipóteses: (i) os balanços foram realizados com base nas concentrações médias medidas na fase líquida (afluente e efluente) e gasosa durante o monitoramento e perfil de um ciclo; (ii) o bicarbonato de sódio não foi contabilizado como houve pouca variação de $\mathrm{pH}$; e (iii) a biomassa no efluente foi contabilizada na forma de sólidos suspensos voláteis.

O balanço de DQO foi realizado considerando a DQO equivalente de cada espécie quantificada pela cromatografia em fase gasosa segundo as seguintes equações:

$$
\begin{aligned}
& \mathrm{C}_{12} \mathrm{H}_{22} \mathrm{O}_{11} \text { (sacarose) }+12 \mathrm{O}_{2} \rightarrow 12 \mathrm{CO}_{2}+11 \mathrm{H}_{2} \mathrm{O} \\
& \mathrm{DQO}=1,123 \mathrm{~g} \mathrm{O}_{2} / \mathrm{g} \\
& \mathrm{C}_{2} \mathrm{H}_{6} \mathrm{O} \text { (etanol) }+2 \mathrm{O}_{2} \rightarrow 2 \mathrm{CO}_{2}+3 \mathrm{H}_{2} \mathrm{O} \\
& \text { DQO }=1,391 \mathrm{~g} \mathrm{O}_{2} / \mathrm{g} \\
& \mathrm{C}_{4} \mathrm{H}_{10} \mathrm{O} \text { (n-butanol) }+6 \mathrm{O}_{2} \rightarrow 4 \mathrm{CO}_{2}+5 \mathrm{H}_{2} \mathrm{O} \\
& \text { DQO }=2,590 \text { g O }{ }_{2} / \mathrm{g} \\
& \mathrm{C}_{2} \mathrm{H}_{4} \mathrm{O}_{2} \text { (ácido acético) }+2 \mathrm{O}_{2} \rightarrow 2 \mathrm{CO}_{2}+2 \mathrm{H}_{2} \mathrm{O} \\
& \text { DQO }=1,006 \text { g O } \mathrm{O}_{2} / \mathrm{g} \\
& \mathrm{C}_{3} \mathrm{H}_{6} \mathrm{O}_{2} \text { (ácido propiônico) }+7 / 2 \mathrm{O}_{2} \rightarrow 3 \mathrm{CO}_{2}+3 \mathrm{H}_{2} \mathrm{O} \\
& \text { DQO }=1,5135 \text { g O }{ }_{2} / \mathrm{g} \\
& \mathrm{C}_{4} \mathrm{H}_{8} \mathrm{O}_{2} \text { (ácido butírico) }+5 \mathrm{O}_{2} \rightarrow 4 \mathrm{CO}_{2}+4 \mathrm{H}_{2} \mathrm{O}
\end{aligned}
$$




$$
\begin{aligned}
& \mathrm{DQO}=1,818 \mathrm{~g} \mathrm{O}_{2} / \mathrm{g} \\
& \mathrm{C}_{5} \mathrm{H}_{10} \mathrm{O}_{2} \text { (ácido valérico) }+13 / 2 \mathrm{O}_{2} \rightarrow 5 \mathrm{CO}_{2}+5 \mathrm{H}_{2} \mathrm{O} \\
& \mathrm{DQO}=2,036 \mathrm{~g} \mathrm{O}_{2} / \mathrm{g} \\
& \mathrm{C}_{6} \mathrm{H}_{12} \mathrm{O}_{2} \text { (ácido capróico) }+8 \mathrm{O}_{2} \rightarrow 6 \mathrm{CO}_{2}+6 \mathrm{H}_{2} \mathrm{O} \\
& \mathrm{DQO}=2,196 \mathrm{~g} \mathrm{O} / \mathrm{g} \\
& \mathrm{C}_{5} \mathrm{H}_{9} \mathrm{O}_{3} \mathrm{~N} \text { (biomassa) }+11 / 2 \mathrm{O}_{2} \rightarrow 5 \mathrm{CO}_{2}+9 / 2 \mathrm{H}_{2} \mathrm{O} \\
& \mathrm{DQO}=1,343 \mathrm{~g} \mathrm{O}_{2} / \mathrm{g}
\end{aligned}
$$

As porcentagens de concordância indicam uma relativa baixa precisão dos balanços com uma concordância na ordem de $60 \%$ para o balanço considerando o elemento carbono nas entradas e saídas e na ordem de 75\% considerando a correlação entre as DQO na saída. Nos dois balanços, os valores considerando a quantificação da biomassa e a análise por cromatografia em fase gasosa foram inferiores aos valores considerando uma quantificação direta. Esta diferença entre entradas e saídas ou entre DQO direta e DQO equivalente pode ser atribuída à dificuldade de avaliação da biomassa arrastada ou à quantificação incompleta dos metabólitos por cromatografia.

O desenvolvimento de um novo método de quantificação da biomassa e a aplicação de uma quantificação dos metabólitos por cromatografia em fase líquida de alta performance (HPLC: "High Performane Liquid Chromatography”) poderiam permitir uma melhor assertividade na realização dos balanços de massa. 
Tabela 5.29 - Balanço de massa entre entrada e saída do elemento Carbono.

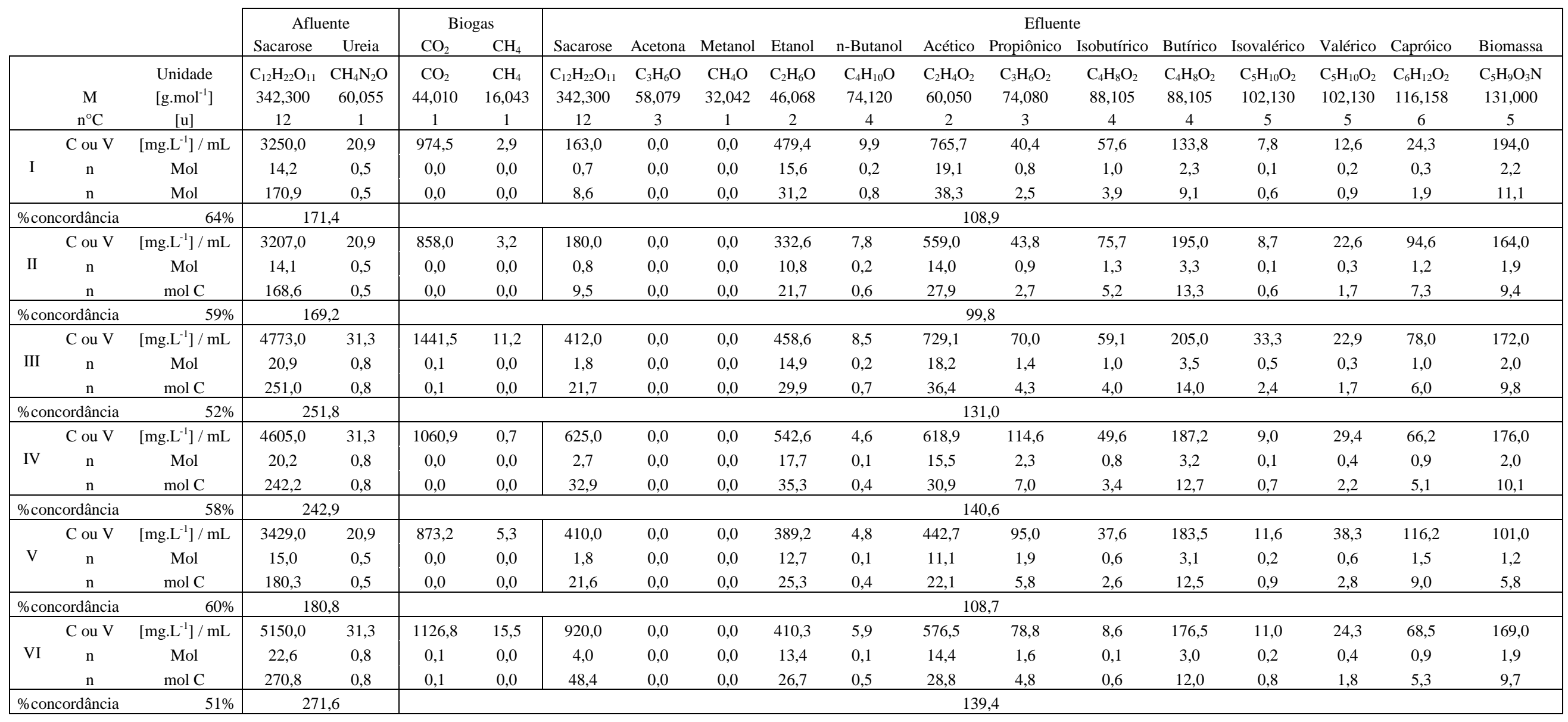


Tabela 5.30 - Balanço de massa de saída em termos de DQO.

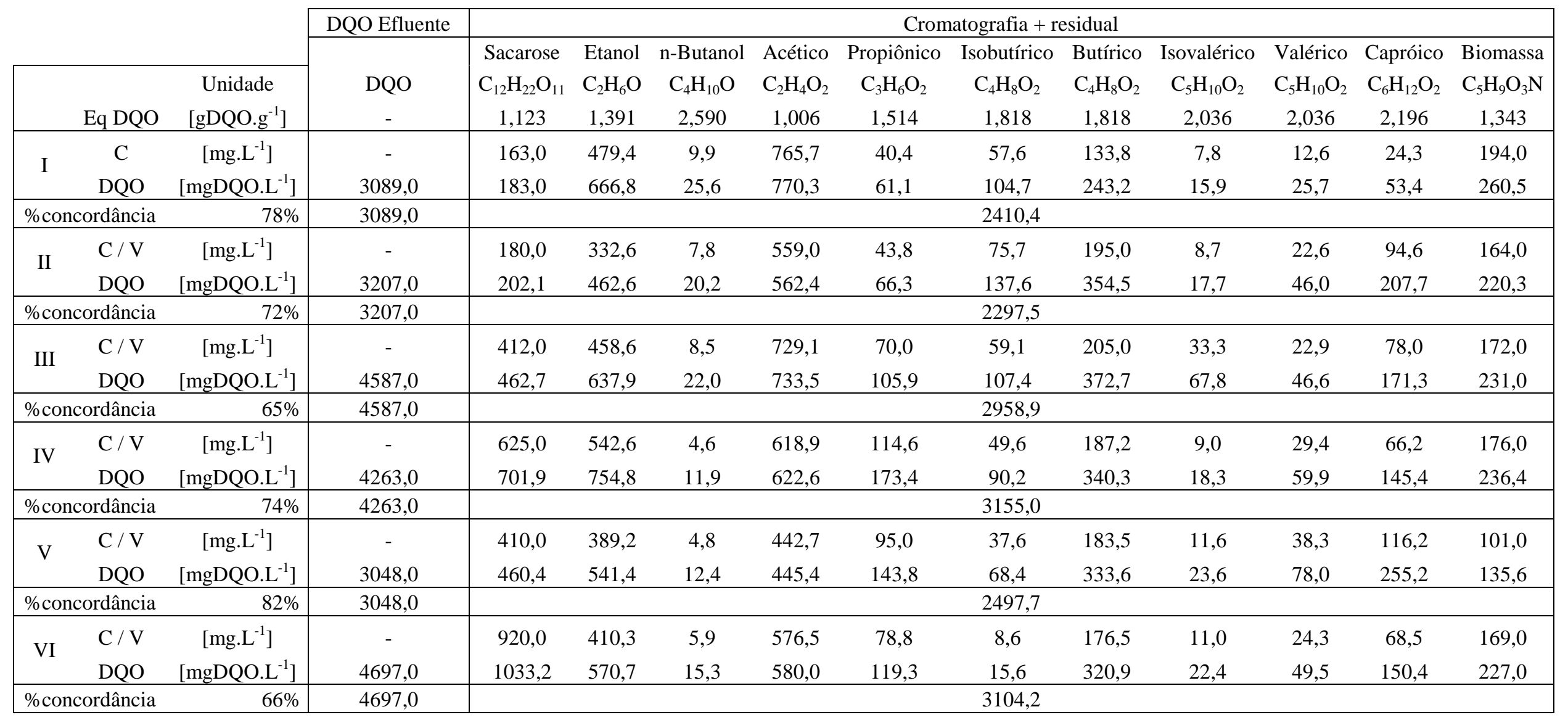




\subsubsection{Balanço de energia}

No contexto do estudo, é importante relacionar a produção de biohidrogênio com uma estimativa de produção de energia. Assim, utilizaram-se os valores de energia de combustão do hidrogênio e da gasolina convencional encontrados na literatura e apresentados na Tabela 5.31 (GRANOVSKII et al., 2006) para avaliar o calor que seria liberado pela combustão do biohidrogênio produzido pelo reator e depois fazer uma analogia com a gasolina que seria necessária para a produção da mesma quantidade de energia.

A curva de produção molar de hidrogênio diária previamente apresentada na Figura 5.110 foi então ponderada pelo calor de combustão liberado pelo hidrogênio o que permitiu avaliar o potencial de produção de energia diário do reator apresentado na Figura 5.116 e este potencial energético foi em seguida relacionado com o seu equivalente em massa de gasolina por combustão apresentado na Figura 5.117.

Tabela 5.31 - Calor de combustão dos combustiveis.

\begin{tabular}{cc}
\hline Carburante & Calor de combustão [MJ.kg $\left.{ }^{-1}\right]$ \\
\hline Hidrogênio & 121,0 \\
Gasolina convencional & 43,7 \\
\hline
\end{tabular}




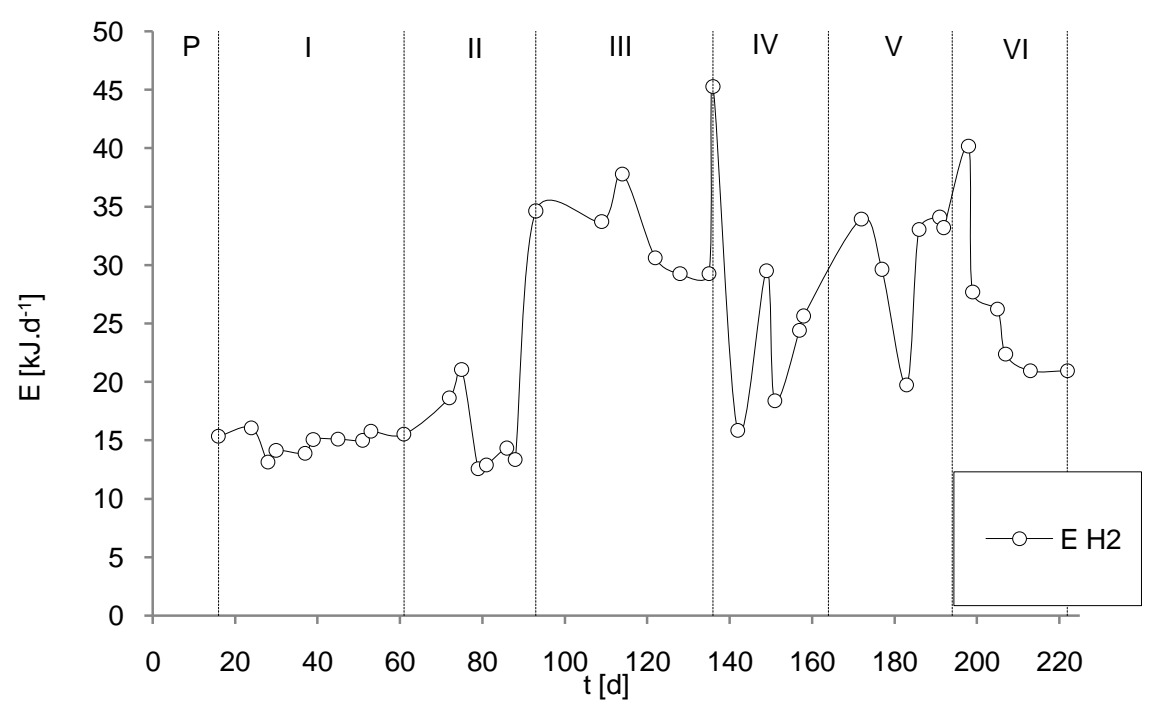

Figura 5.116 - Potencial energético por combustão - Todas Condições.

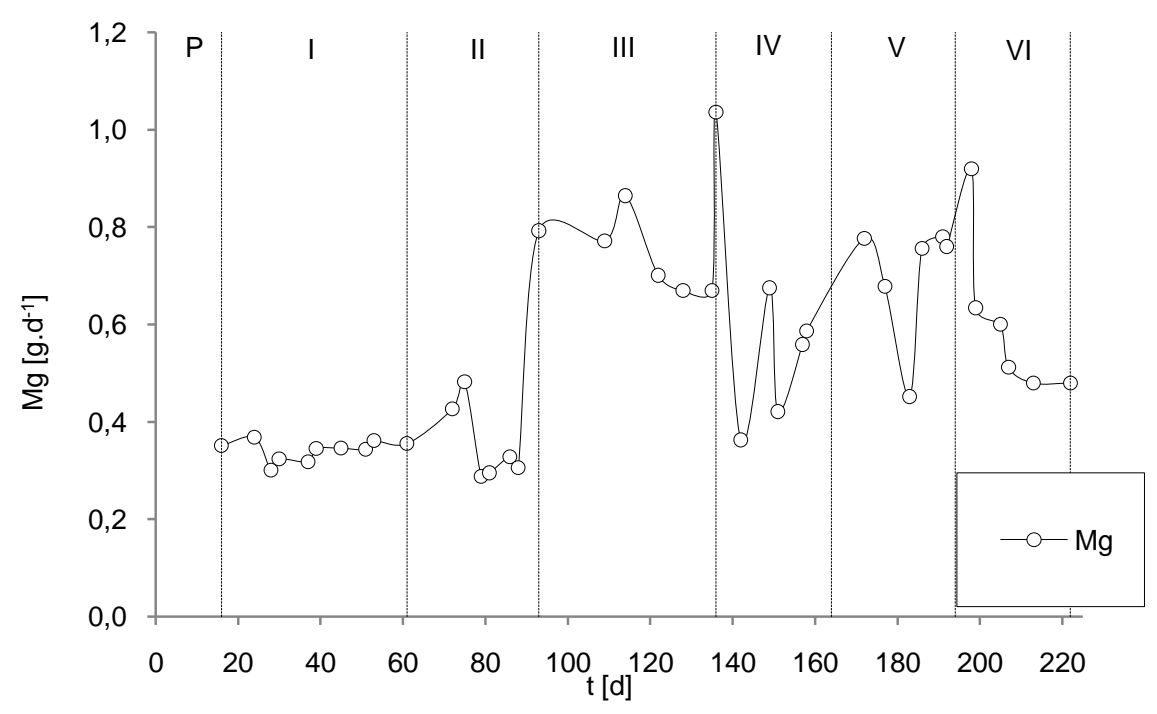

Figura 5.117 - Equivalente em grama de gasolina do potencial de energético por combustão - Todas Condições.

A Tabela 5.32 apresenta uma cotação realizada no mês de fevereiro 2012 dos preços do açúcar e da gasolina convencional pode se avaliar a viabilidade econômica do projeto. 
Tabela 5.32 - Cotação de preço da gasolina e do açúcar.

\begin{tabular}{ccccc} 
& Quantidade & Preço cotado & Preço $\left[\mathrm{R} \$ \mathrm{~g}^{-1}\right]$ & Fonte cotação \\
\hline Preço açúcar & $50 \mathrm{~kg}$ & $\mathrm{R} \$ 59,48$ & 0,001190 & $\begin{array}{c}\text { Indicador Açúcar Cristal } \\
\text { CEPEA/ESALQ - São Paulo }\end{array}$ \\
Preço Gasolina & $1 \mathrm{~L}$ & $\mathrm{R} \$ 2,74$ & $0,003648^{*}$ & $\begin{array}{c}\text { Agência Nacional do Petróleo, } \\
\text { Gás Natural e Biocombustível }\end{array}$ \\
\hline
\end{tabular}

Foi determinado o custo da energia produzido pelo reator considerando unicamente o custo do açúcar necessário para a fabricação do afluente. Este custo foi comparado ao custo de produção da mesma quantidade de energia por queima de gasolina convencional. Foram calculados em seguida os preços das energias produzidas, cujos resultados são apresentando na Tabela 5.33.

Tabela 5.33 - Estudo da viabilidade econômica do projeto.

\begin{tabular}{lccccccc}
\hline \multicolumn{1}{c}{ Parâmetro } & Unidade & \multicolumn{5}{c}{ Condições } \\
& & I & II & III & IV & V & VI \\
\hline Energia produzida & {$\left[\mathrm{kJ} \cdot \mathrm{d}^{-1}\right]$} & 15,8 & 24,5 & 29,4 & 29,2 & 33,6 & 26,8 \\
Massa de açúcar consumida & {$\left[\mathrm{g} \cdot \mathrm{d}^{-1}\right]$} & 28,9 & 38,5 & 43,0 & 57,9 & 57,9 & 86,8 \\
Massa de gasolina equivalente & {$\left[\mathrm{g} \cdot \mathrm{d}^{-1}\right]$} & 0,36 & 0,56 & 0,67 & 0,67 & 0,77 & 0,61 \\
\hline Preço açúcar consumido & {$\left[\mathrm{R} \$ . \mathrm{d}^{-1}\right]$} & 0,034 & 0,046 & 0,051 & 0,069 & 0,069 & 0,103 \\
Preço gasolina equivalente & {$\left[\mathrm{R} \$ . \mathrm{d}^{-1}\right]$} & 0,0013 & 0,0020 & 0,0025 & 0,0024 & 0,0028 & 0,0022 \\
\hline Preço energia biohidrogênio & {$\left[\mathrm{R} \$ . \mathrm{MJ}^{-1}\right]$} & 2,18 & 1,87 & 1,74 & 2,36 & 2,05 & 3,86 \\
Preço energia gasolina & {$\left[\mathrm{R} \$ . \mathrm{MJ}^{-1}\right]$} & 0,08 & 0,08 & 0,08 & 0,08 & 0,08 & 0,08 \\
Relação preços energias & {$[\mathrm{u}]$} & 26 & 22 & 21 & 28 & 25 & 46 \\
\hline
\end{tabular}

Esta cotação é ligada ás variações dos preços do açúcar e da gasolina no mercado, entretanto, pode-se inferir que atualmente o projeto não é economicamente viável. A energia produzida por queima de gasolina custa $\mathrm{R} \$ 0,08$ por $\mathrm{MJ}$ enquanto a bioenergia produzida pelo reator custa $\mathrm{R} \$ 1,74$ por MJ na condição de operação mais favorável (condição III), tornando a bioenergia 21 vezes mais cara hoje do que a queima de energia fóssil. Entretanto, a tendência do preço das energias fósseis é 
de aumentar com a escassez e o custo de operação do biorreator é reduzir com a utilização de efluentes industriais de baixo custo,

Portanto, a fim de viabilizar o projeto deve se focar na melhoria do desempenho do biorreator no tocante aos rendimentos alcançados que estão distantes dos máximos teóricos. É importante ressaltar também que a alimentação desta configuração com efluente sintético é apenas um passo na investigação das melhorias das condições de operação e não uma finalidade em si, ou seja, uma vez que as condições ótimas sejam identificadas poderão ser investigados outros substratos de menor custo podendo tornar o preço da bioenergia competitiva e justificando, assim, a importância desta linha de pesquisa. 


\section{CONCLUSÕES}

Os resultado obtidos na análise do efeito da carga orgânica no desempenho de um reator de tipo AnSBBR com biomassa imobilizada e agitação mecânica, tratando água residuária sintética a base de sacarose e visando a produção de biohidrogênio, permitem a elaboração das seguintes conclusões:

- $\quad$ A eficiência de remoção de matéria orgânica (DQO) permaneceu estável próximo a um valor de $18 \%$ (mínimo de 14 e máximo de $21 \%$ com desvio padrão médio de $4 \%$ ) sem apresentar nenhuma tendência significativa, ou seja, independentemente da variação da carga orgânica;

- $\quad$ O reator apresentou uma boa eficiência de conversão de carboidratos (sacarose) a qual permaneceu entre 83 e $97 \%$ (com desvio padrão médio de 5\%) ao longo da operação, podendo-se verificar uma diminuição do desempenho do reator com o aumento da carga orgânica aplicada, com os valores médios passando de 97\% para 83\% da condição I para a condição VI e, além disso, valores crescentes de concentração afluente (e tempos de ciclo iguais) e tempos de ciclo menores (e concentrações afluente iguais) resultaram em eficiências menores de conversão;

- Quanto aos metabólitos intermediários houve a predominância do ácido acético, com tendência a diminuir a favor de um aumento de ácidos butírico e propiônico com o aumento da carga orgânica, e de etanol em todas as condições;

- $\quad$ A produção volumétrica máxima de biogás foi atingida durante a operação da condição III (COAV de 13,5 kgDQO. $\mathrm{m}^{-3} \cdot \mathrm{d}^{-1}$ ), a concentração máxima de biohidrogênio no biogás (2425\%) foi atingida durante as operações das condições II e III (COAV de 12,0 e 13,5 kgDQO. $\left.\mathrm{m}^{-3} \cdot \mathrm{d}^{-1}\right)$; a vazão molar máxima de hidrogênio $\left(0,139 \mathrm{molH}_{2} \cdot \mathrm{d}^{-1}\right)$ foi atingida durante a operação da condição V (COAV de $\left.18 \mathrm{kgDQO} \cdot \mathrm{m}^{-3} \cdot \mathrm{d}^{-1}\right)$; 
- $\quad$ O desempenho do sistema na produção de biohidrogênio foi avaliado pelo uso combinado de indicadores que seguiram o mesmo comportamento de alguns trabalhos da literatura e tiveram tendência a passar por um máximo correspondente à condição ideal de operação, ou seja, nesta condição ótima de operação a capacidade de produção atingiu um valor máximo porque ocorreu o melhor aproveitamento da biotransformação do substrato consumido para a produção de biogás;

- Os melhores parâmetros de desempenho foram os que utilizaram o conceito intensivo de carga aplicada e removida, seja de matéria orgânica (DQO) ou de substrato (carboidratos sacarose), atingindo valores máximos na operação da condição III (COAV de 13,5 kgDQO.m $\left.{ }^{3} \cdot \mathrm{d}^{-1}\right)$ com $\mathrm{RMCA}_{\mathrm{c}, \mathrm{m}}$ de 2,83 $\mathrm{molH}_{2} \cdot \mathrm{kgSAC}^{-1}$ e $\mathrm{RMCR}_{\mathrm{c}, \mathrm{m}}$ de 3,04 molH $2 \cdot \mathrm{kgSAC}^{-1}$, correspondendo a um desempenho de $12 \%$ e $24 \%$ em relação aos máximos teóricos considerando as vias do ácido acético e do ácido butírico, respetivamente;

- Não se verificou uma tendência de modificação do rendimento de biohidrogênio do reator em função da concentração afluente para tempos de ciclo iguais e do tempo de ciclo para concentrações afluente iguais, ou seja, existe a necessidade do estudo do comportamento do processo em função da carga orgânica aplicada e também das variáveis que definem a carga orgânica aplicada.

- Os exames microbiológicos revelaram uma predominância de espécies do tipo bacilos, endósporos e bacilos com endósporos, sendo observadas espécies fluorescentes, entretanto, as análises não permitiram constatar grandes diferenças morfológicas entre as amostras obtidas nas diferentes condições;

- As porcentagens de concordância nos balanços de massa, na ordem $60 \%$ para o balanço considerando o elemento carbono nas entradas e saídas e na ordem de $75 \%$ considerando a correlação entre as DQO, indicaram uma relativa baixa precisão dos métodos de quantificação da biomassa e dos metabólitos. 
- $\quad$ O balanço de energia permitiu relacionar a produção de biohidrogênio à uma quantidade de energia produzida diariamente, sendo que a condição III apresentou os melhores resultados com uma produção média da ordem de $35 \mathrm{~kJ} . \mathrm{d}^{-1}$. 


\section{REFERÊNCIAS BIBLIOGRÁFICAS}

AGÊNCIA NACIONAL DO PETRÓLO, GÁS NATURAL E BIOCOMBUSTÍVEL $<$ http://www.anp.gov.br/preco/prc/Resumo_Semanal_Combustiveis.asp> acesso em 07/02/2012

ALZATE-GAVIRIA, L. M.; SEBASTIAN, P. J.; PÉREZ-HERNÁNDEZ, A.; EAPEN, D. Comparaison of two anaerobic systems for hydrogen production from the organic fraction of municipal solid waste and synthetic wastewater. International Journal of Hydrogen Energy, v. 32, n. 15, p. 3141-3146, 2007.

AROOJ, M.; HAN, S.; KIM, S.; KIM, D.; SHIN, H. Effect of HRT on ASBR converting starch into biological hydrogen. International Journal of Hydrogen Energy, v. 33, n. 22, p. 6509-6514, 2008. Elsevier Ltd.

BADIEI, M.; JAHIM, J. M.; ANUAR, N.; SHEIKH ABDULLAH, S. R. Effect of hydraulic retention time on biohydrogen production from palm oil mill effluent in anaerobic sequencing batch reactor. International Journal of Hydrogen Energy, v. 36, n. 10, p. 5912-5919, 2011. Elsevier Ltd.

BEZERRA, R. A.; RODRIGUES, J. A. D.; RATUSZNEI, S.; ZAIAT, M.; FORESTI, E. Whey Treatment by AnSBBR with Circulation: Effects of Organic Loading, Shock Loads, and Alkalinity Supplementation. Applied Biochemistry and Biotechnology, v. 143, n. 3, p. 257-275, 2007.

BORGES, A. C.; SIMAN, R. R.; RODRIGUES, J. A. D. et al. Stirred anaerobic sequencing batch reactor containing immobilized biomass: a behavior study when submitted to different fill times. Water science and technology : a journal of the International Association on Water Pollution Research, v. 49, n. 11-12, p. 311-8, 2004.

BUITRÓN, G.; CARVAJAL, C. Biohydrogen production from Tequila vinasses in an anaerobic sequencing batch reactor: Effect of initial substrate concentration, temperature and hydraulic retention time. Bioresource technology, v. 101, p. 9071-9077, 2010.

CENTRO DE ESTUDOS AVANÇADOS EM ECONOMIA APLICADA - ESALQ/USP <http://www.cepea.esalq.usp.br/acucar/> acesso em 07/02/2012

CAMARGO, E. F. M. DE; RATUSZNEI, S.; RODRIGUES, J. A. D.; ZAIAT, M.; BORZANI, W. Treatment of low-strength wastewater using immobilized biomass in a sequencing batch external loop reactor: influence of the medium superficial velocity on the stability and performance. Brazilian Journal of Chemical Engineering, v. 19, n. 3, p. 267 - 275, 2002.

CHEBEL, F. X.; RATUSZNEI, S.; RODRIGUES, J. A. D.; ZAIAT, M.; FORESTI, E. Analysis of performance of an Anaerobic sequencing batche reactor submitted to increasing organic load with different influenet concentrations and cycle lengths. Applied Biochemistry and Biotechnology, v. 133, p. 171-187, 2006.

CHEN, W.; SUNG, S.; CHEN, S. Biological hydrogen production in an anaerobic sequencing batch reactor: $\mathrm{pH}$ and cyclic duration effects. International Journal of Hydrogen Energy, v. 34, n. 1, p. 227-234, 2009. International Association for Hydrogen Energy. 
CHEONG, D.-YEOL; HANSEN, C. L. Acidogenesis characteristics of natural, mixed anaerobes converting carbohydrate-rich synthetic wastewater to hydrogen. Process Biochemistry, v. 41, n. 8 , p. 1736-1745, 2006.

CHEONG, D.-YEOL; HANSEN, C. L.; STEVENS, D. K. Production of Bio-Hydrogen by Mesophilic Anaerobic Fermentation in an Acid-Phase Sequencing Batch Reactor. Biotechnology, v. 96, n. 3, p. 421-432, 2007.

CUBAS, S. A. Influência do tamanho da biopartícula e da agitação no desempenho de reatores anaeróbios em bateladas sequenciais, contendo biomassa imobilizada, para tratamento de águas residuárias, 2004. USP-EESC.

DAMASCENO, L. H. S.; RODRIGUES, J. A. D.; RATUSZNEI, S.; ZAIAT, M.; FORESTI, E. Effects of feeding time and organic loading in an anaerobic sequencing batch biofilm reactor (ASBBR) treating diluted whey. Journal of environmental management, v. 85, n. 4, p. 927-35, 2007.

DAMASCENO, L. H. S.; RODRIGUES, J. A. D.; RATUSZNEI, S.; ZAIAT, M.; FORESTI, E. Effect of mixing mode on the behavior of an ASBBR with immobilized biomass in the treatment of cheese whey. Brazilian Journal of Chemical Engineering, v. 25, n. 2, p. 291 - 298, 2008.

DAS, D.; VEZIROGLU, T. N. Hydrogen production by biological processes : a survey of literature. International Journal of Hydrogen Energy, v. 26, p. 13-28, 2001.

DAVILA-VAZQUEZ, G.; ARRIAGA, S.; ALATRISTE-MONDRAGÓN, F. et al. Fermentative biohydrogen production: trends and perspectives. Reviews in Environmental Science and Bio/Technology, v. 7, n. 1, p. 27-45, 2007.

DEL NERY, V. Utilização de lodo anaeróbio imobilizado em gel no estudo de partida de reatores de fluxo ascendente com manta de lodo, Escola de Engenharia de São Carlos, USP; 1987.

DILALLO, R.; ALBERTSON, O.E. Volatile acids by direct titration. Journal of Water Pollution Control Federation, 3, 356-365, 1961.

DUBOIS, S.M.; GILLES, K.A.; HAMILTON, J.L.; REBERS, P.A.; SMITH, F. Colorimetric methods for determination of sugar and related substance. Analytical Chemistry, 228, 13-21, 1956

FERCHICHI, M.; CRABBE, E.; GIL, G.-H.; HINTZ, W.; ALMADIDY, A. Influence of initial pH on hydrogen production from cheese whey. Journal of biotechnology, v. 120, n. 4, p. 402-9, 2005.

FERNANDES, B. S. Produção de hidrogênio em reator anaeróbio de leito fixo, 2008. USPEESC.

FLÔRES, A. Avaliação da estabilidade e da eficiênça de um AnSBBR aplicado ao tratamento de água residuária de indústria metalúrgica, 2009. Escola de Engenharia Mauá do Centro Universitário do Instituto Mauá de Tecnologia.

FORESTI, E. Fundamentos do processo de digestão anaeróbia. Anais do III taller y seminario latino americano- Tratamento anaeróbio águas residuales. Anais... p.p97, 1994. Montevideo. 
FORESTI, E.; FLORENCIO, L.; VAN HAANDEL, A.; ZAIAT, M.; CAVALCANTI,P. Fundamentos do Tratamento Anaeróbio. Tratamento de esgotos sanitários por processo anaeróbio e disposição controlada no solo. Rio de Janeiro, ABES, 1999

GRANOVSKII, M.; DINCER, I.; ROSEN, M. A. Life cycle assessment of hydrogen fuel cell and gasoline vehicles. International Journal of Hydrogen Energy, v. 31, p. 337 - 352, 2006.

KAWAGOSHI, Y.; HINO, N.; FUJIMOTO, A. et al. Effect of inoculum conditioning on hydrogen fermentation and $\mathrm{pH}$ effect on bacterial community relevant to hydrogen production. Journal of bioscience and bioengineering, v. 100, n. 5, p. 524-30, 2005.

KHANAL, S.; CHEN, W.; SUNG, S. Biological hydrogen production: effects of $\mathrm{pH}$ and intermediate products. International Journal of Hydrogen Energy, v. 29, p. 1123 - 1131, 2003.

LEITE, J.; FERNANDES, B. S.; POZZI, E.; BARBOZA, M.; ZAIAT, M. Application of an anaerobic packed-bed bioreactor for the production of hydrogen and organic acids. International Journal of Hydrogen Energy, v. 33, n. 2, p. 579-586, 2008.

LI, C.; FANG, H. Fermentative Hydrogen Production From Wastewater and Solid Wastes by Mixed Cultures. Critical Reviews in Environmental Science and Technology, v. 37, n. 1, p. 1-39, 2007.

LIU, X.; ZHU, Y.; YANG, S. T. Butyric acid and hydrogen production by Clostridium tyrobutyricum ATCC 25755 and mutants. Enzyme and Microbial Technology, v. 38, n. 3-4, p. 521-528, 2006.

MICHELAN, R.; ZIMMER, T. R.; RODRIGUES, J. A. D. et al. Effect of impeller type and mechanical agitation on the mass transfer and power consumption aspects of ASBR operation treating synthetic wastewater. Journal of environmental management, v. 90, n. 3, p. 1357-64, 2009.

MOHANAKRISHNA, G.; VENKATA SUBHASH, G.; VENKATA MOHAN, S. Adaptation of biohydrogen producing reactor to higher substrate load: Redox controlled process integration strategy to overcome limitations. International Journal of Hydrogen Energy, v. 36, n. 15, p. 8943-8952, 2011. Elsevier Ltd.

MU, Y.; ZHENG, X.; YU, H.; ZHU, R. Biological hydrogen production by anaerobic sludge at various temperatures. International Journal of Hydrogen Energy, v. 31, n. 6, p. 780-785, 2006.

ORRA, A. A.; RATUSZNEI, S.; RODRIGUES, J. A. D.; FORESTI, E.; ZAIAT, M. Effects of feeding strategies on the performance of an anaerobic discontinuous reactor containing immobilized biomass with circulation system for liquid-phase mixing. Water science and technology: a journal of the International Association on Water Pollution Research, v. 49, n. 11-12, p. 303$10,2004$.

PINHEIRO, D. M.; RATUSZNEI, S.; RODRIGUES, J. A. D.; ZAIAT, M.; FORESTI, E. Fluidized ASBR treating synthetic wastewater: Effect of recirculation velocity. Chemical Engineering and Processing: Process Intensification, v. 47, n. 2, p. 184-191, 2008.

RATUSZNEI, S.; RODRIGUES, J. A. D.; CAMARGO, E. F. M. DE; ZAIAT, M.; BORZANI, W. Feasibility of a stirred anaerobic sequencing batch reactor containing immobilized biomass for wastewater treatment. Bioresource Technology, v. 75, n. 2, p. 127-132, 2000. 
RATUSZNEI, S.; RODRIGUES, J. A. D.; CAMARGO, E. F. M. DE; ZAIAT, M.; BORZANI, W. Influence of agitation rate on the performance of a stirred anaerobic sequencing batch reactor containing immobilized biomass. Water science and technology : a journal of the International Association on Water Pollution Research, v. 44, n. 4, p. 305-12, 2001.

REN, N.; GUO, W.; WANG, X. et al. Effects of different pretreatment methods on fermentation types and dominant bacteria for hydrogen production. International Journal of Hydrogen Energy, v. 33, n. 16, p. 4318-4324, 2008.

RIPLEY, L.E.; BOYLE, W.C.; CONVERSE, J.C. Improved Alkalimetric Monitoring for AnaerobicDigestor of High-Strength Wastes. Journal of Water Pollution Control Federation, 58, 406-411, 1986.

RODRIGUES, J. A. D.; PINTO, A. G.; RATUSZNEI, S.; ZAIAT, M.; GEDRAITE, R. Enhancement of the performance of an anaerobic sequencing batch reactor treating low-strength wastewater through implementation of a variable stirring rate program. Brazilian Journal of Chemical Engineering, v. 21, n. 3, p. 423 - 434, 2004

RODRIGUES, J. A. D.; RATUSZNEI, S.; FORESTI, E.; ZAIAT, M. New configurations and operations strategies of anaerobic biofilm bioreactors. In: P. .-58 Editor: Edwin C. Hearns (Ed.); Focus on Biotechnology Research. p.1-58, 2006. (C) 2006 Nova Science Publishers, Inc.

RODRIGUES, J. A. D.; RATUSZNEI, S.; ZAIAT, M. Fed-batch and batch operating mode analysis of a stirred anaerobic sequencing reactor with self-immobilized biomass treating lowstrength wastewater. Journal of Environmental Management, v. 69, n. 2, p. 193-200, 2003. Di

SIMAN, R. R.; BORGES, A. C.; RATUSZNEI, S. et al. Influence of organic loading on an anaerobic sequencing biofilm batch reactor (ASBBR) as a function of cycle period and wastewater concentration. Journal of environmental management, v. 72, n. 4, p. 241-7, 2004.

SREETHAWONG, T.; NIYAMAPA, T.; NERAMITSUK, H. et al. Hydrogen production from glucose-containing wastewater using an anaerobic sequencing batch reactor: Effects of COD loading rate, nitrogen content, and organic acid composition. Chemical Engineering Journal, v. 160, n. 1, p. 322-332, 2010. Elsevier B.V.

Standard Methods for the Examination of Water and Wastewater APHA, AWWA, WPCF. 19th edition, American Public Health Association, Washington, 1995

SUNG, S.; DAGUE, R. Laboratory studies on batch the anaerobic sequencing reactor. Water Environment Reserch, v. 67, n. 3, p. 294-301, 1995.

SUZUKI, Y. On hydrogen as fuel gas. International journal foir Hydrogen Energy, v. 7, n. 3, p. 227-230, 1982.

TANISHO, S. A scheme for developing the yield of hydrogen by fermentation. 2001.

TANISHO, S.; ISHIWATA, Y. Continuous hydrogen production from molasses by fermentation using urethane foam as a supprt of flocks. International Association for Hydrogen Energy, v. 20, n. I, p. 541-545, 1995. 
VENKATA MOHAN, S.; LALIT BABU, V.; SARMA, P. Anaerobic biohydrogen production from dairy wastewater treatment in sequencing batch reactor (AnSBR): Effect of organic loading rate. Enzyme and Microbial Technology, v. 41, n. 4, p. 506-515, 2007.

VIJAYA BHASKAR, Y.; VENKATA MOHAN, S.; SARMA, P. N. Effect of substrate loading rate of chemical wastewater on fermentative biohydrogen production in biofilm configured sequencing batch reactor. Bioresource technology, v. 99, n. 15, p. 6941-8, 2008.

WANG, J.; WAN, W. Factors influencing fermentative hydrogen production: A review. International Journal of Hydrogen Energy, v. 34, n. 2, p. 799-811, 2009. International Association for Hydrogen Energy.

WANG, X.; MONIS, P. T.; SAINT, C. P.; JIN, B. Biochemical kinetics of fermentative hydrogen production by Clostridium butyricum W5. International Journal of Hydrogen Energy, v. 34, n. 2, p. 791-798, 2009. Elsevier Ltd.

WANG, Y.; ZHAO, Q.; MU, Y. et al. Biohydrogen production with mixed anaerobic cultures in the presence of high-concentration acetate. International Journal of Hydrogen Energy, v. 33, n. 4, p. 1164-1171, 2008.

WU, K. J.; SARATALE, G. D.; LO, Y. C. et al. Simultaneous production of 2,3-butanediol, ethanol and hydrogen with a Klebsiella sp. strain isolated from sewage sludge. Bioresource technology, v. 99, n. 17, p. 7966-70, 2008.

WU, S. Y.; LIN, C. N.; CHANG, J. S. Hydrogen production with immobilized sewage sludge in three-phase fluidized-bed bioreactors. Biotechnology progress, v. 19, n. 3, p. 828-32, 2003.

WU, X.; YAO, W.; ZHU, J. Effect of $\mathrm{pH}$ on continuous biohydrogen production from liquid swine manure with glucose supplement using an anaerobic sequencing batch reactor. International Journal of Hydrogen Energy, v. 35, n. 13, p. 6592-6599, 2010. Elsevier Ltd.

ZAIAT, M.; CABRAL, A.K.A.; FORESTI, E. Reator Anaeróbio Horizontal de Leito Fixo Para Tratamento de Águas Residuárias: Concepção e Avaliação Preliminar de Desempenho. Revista Brasileira de Engenharia Caderno de Engenharia Química, v. 11, n. 2, p. 33-42, 1994.

ZAIAT, M.; RODRIGUES, J. A. D.; RATUSZNEI, S.; CAMARGO, E. F. M. DE; BORZANI, W. Anaerobic sequencing batch reactors for wastewater treatment: A developing technology. Applied Biochemestry and Biotechnology, v. 55, p. 29-35, 2001.

ZHANG, Z.; SHOW, K.; TAY, J. et al. Effect of hydraulic retention time on biohydrogen production and anaerobic microbial community. Process Biochemistry, v. 41, n. 10, p. 2118-2123, 2006.

ZIMMER, T. R.; MICHELAN, R.; CANTO, C. S. A. DO; RODRIGUES, J. A. D.; RATUSZNEI, S. Feed strategy study of a mechanically stirred anaerobic sequencing batch reactor ( ASBR ) equipped with a draft tube applied to whey treatment. Brazilian Journal of food technology, v. 11, p. 288-298, 2008. 
Tabela AI-1: Caracteristicas do Afluente em todas condições: concentrações em matéria orgânica DQO e substrato, $\mathrm{pH}$, alcalinidade total, alcalinidade a bicarbonato e ácidos voláteis totais do afluente.

\begin{tabular}{|c|c|c|c|c|c|c|c|c|c|c|}
\hline$\#$ & $\begin{array}{c}\text { Tempo de operação } \\
{[\mathrm{d}]}\end{array}$ & $\begin{array}{c}\mathrm{C}_{\mathrm{ST}, \mathrm{A}} \\
{\left[\mathrm{mgDQO} . \mathrm{L}^{-1}\right]}\end{array}$ & $\begin{array}{c}\mathrm{C}_{\mathrm{CT}, \mathrm{A}} \\
{\left[\mathrm{mg} \cdot \mathrm{L}^{-1}\right]}\end{array}$ & $\begin{array}{l}\mathrm{pH} \\
{[\mathrm{u}]}\end{array}$ & $\begin{array}{c}\mathrm{AP} \\
{\left[\mathrm{mgCaCO}_{3} \cdot \mathrm{L}^{-1}\right]}\end{array}$ & $\begin{array}{c}\mathrm{AI} \\
{\left[\mathrm{mgCaCO}_{3} \cdot \mathrm{L}^{-1}\right]}\end{array}$ & $\begin{array}{c}\mathrm{AT} \\
{\left[\mathrm{mgCaCO}_{3} \cdot \mathrm{L}^{-1}\right]}\end{array}$ & $\begin{array}{c}\mathrm{AI} / \mathrm{AP} \\
{[\mathrm{u}]}\end{array}$ & $\begin{array}{c}\mathrm{AB} \\
{\left[\mathrm{mgCaCO}_{3} \cdot \mathrm{L}^{-1}\right]}\end{array}$ & 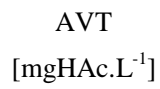 \\
\hline $\mathrm{Cp}$ & 1 & 3593 & - & 6,3 & 188,6 & 117,1 & 305,7 & 0,6 & 293,0 & 17,9 \\
\hline $\mathrm{Cp}$ & 2 & 3333 & - & 6,3 & 180,9 & 68,9 & 249,7 & 0,4 & 226,4 & 32,8 \\
\hline $\mathrm{Cp}$ & 3 & - & - & 6,2 & 196,3 & 124,9 & 321,2 & 0,6 & 299,3 & 30,7 \\
\hline $\mathrm{Cp}$ & 5 & 3708 & - & 6,2 & 157,7 & 105,6 & 263,2 & 0,7 & 237,7 & 36,0 \\
\hline $\mathrm{Cp}$ & 8 & 3749 & 3040 & 6,2 & 140,9 & 112,6 & 253,6 & 0,8 & 234,3 & 27,2 \\
\hline $\mathrm{Cp}$ & 9 & - & 3581 & 6,0 & 60,5 & 115,8 & 176,3 & 1,9 & 149,3 & 38,1 \\
\hline $\mathrm{Cp}$ & 10 & 3723 & 3116 & 6,2 & 103,0 & 92,0 & 195,0 & 0,9 & 165,4 & 41,7 \\
\hline $\mathrm{Cp}$ & 11 & 3825 & 3215 & 6,1 & 159,4 & 97,8 & 257,1 & 0,6 & 246,5 & 15,0 \\
\hline $\mathrm{Cp}$ & 12 & 3738 & 3259 & 6,0 & 108,4 & 136,0 & 244,4 & 1,3 & 231,8 & 17,7 \\
\hline $\mathrm{Cp}$ & 15 & 3575 & 3188 & 6,1 & 184,2 & 87,1 & 271,3 & 0,5 & 258,6 & 17,9 \\
\hline $\mathrm{Cp}$ & 16 & 3543 & 3494 & 6,1 & 121,8 & 126,1 & 247,9 & 1,0 & 234,6 & 18,8 \\
\hline I & 17 & 3596 & 3346 & - & - & - & - & - & - & - \\
\hline I & 18 & 3524 & 3504 & 6,4 & 277,2 & 142,3 & 419,5 & 0,5 & 405,1 & 20,3 \\
\hline I & 19 & 3590 & 3228 & 6,6 & 453,1 & 190,4 & 643,5 & 0,4 & 611,6 & 44,9 \\
\hline I & 22 & 3641 & 3325 & 6,8 & 521,4 & 154,8 & 676,2 & 0,3 & 657,0 & 27,1 \\
\hline I & 23 & 3810 & 3448 & 6,6 & 421,2 & 172,6 & 593,8 & 0,4 & 578,3 & 21,9 \\
\hline I & 24 & 3871 & 3325 & 6,4 & 309,7 & 140,6 & 450,3 & 0,5 & 437,1 & 18,7 \\
\hline I & 25 & 3703 & 3315 & 6,4 & 303,3 & 164,8 & 468,1 & 0,5 & 455,1 & 18,3 \\
\hline I & 26 & 3585 & 3254 & 6,7 & 380,7 & 142,8 & 523,5 & 0,4 & 507,8 & 22,1 \\
\hline I & 29 & 3596 & 3228 & 6,3 & 349,5 & 142,1 & 491,5 & 0,4 & 473,2 & 25,8 \\
\hline I & 30 & 3488 & 3519 & 6,7 & 216,6 & 66,1 & 282,7 & 0,3 & 260,9 & 30,7 \\
\hline I & 31 & 3728 & 3412 & - & - & - & - & - & - & - \\
\hline I & 36 & 3754 & 3325 & 6,3 & 167,8 & 82,8 & 250,6 & 0,5 & 234,2 & 23,1 \\
\hline I & 37 & - & 3320 & 6,5 & 182,4 & 91,2 & 273,6 & 0,5 & 258,2 & 21,6 \\
\hline I & 38 & - & - & 6,3 & 167,1 & 105,1 & 272,2 & 0,6 & 256,5 & 22,0 \\
\hline I & 39 & 3800 & 3560 & 6,2 & 151,0 & 110,7 & 261,7 & 0,7 & 248,7 & 18,3 \\
\hline I & 40 & 3570 & 2866 & 6,3 & 161,8 & 139,2 & 301,0 & 0,9 & 278,1 & 32,4 \\
\hline I & 50 & 3861 & 3106 & 6,4 & 192,9 & 93,0 & 285,9 & 0,5 & 272,2 & 19,2 \\
\hline I & 51 & 3794 & 3188 & 6,5 & 187,9 & 102,7 & 290,6 & 0,5 & 274,9 & 22,1 \\
\hline I & 52 & 3555 & 2774 & 6,5 & 201,9 & 81,8 & 283,6 & 0,4 & 269,9 & 19,4 \\
\hline I & 53 & 3840 & 3035 & 6,6 & 252,3 & 60,9 & 313,2 & 0,2 & 295,2 & 25,4 \\
\hline I & 54 & 3733 & 3167 & 6,5 & 193,2 & 83,5 & 276,7 & 0,4 & 263,6 & 18,4 \\
\hline I & 58 & 3896 & 3172 & 6,5 & 234,9 & 102,7 & 337,6 & 0,4 & 326,8 & 15,2 \\
\hline I & 59 & 3759 & 3259 & 6,5 & 212,3 & 87,0 & 299,3 & 0,4 & 288,9 & 14,6 \\
\hline I & 60 & 3825 & 3070 & 6,6 & 292,3 & 88,7 & 381,1 & 0,3 & 364,6 & 23,3 \\
\hline I & 61 & 3835 & 3259 & 6,9 & 337,6 & 120,3 & 457,9 & 0,4 & 445,7 & 17,3 \\
\hline II & 62 & 3789 & 3162 & - & - & - & - & - & - & - \\
\hline II & 65 & - & - & 7,3 & 452,9 & 132,0 & 585,0 & 0,3 & 565,8 & 27,0 \\
\hline II & 66 & 3580 & 3029 & 7,6 & 484,7 & 157,1 & 641,8 & 0,3 & 627,6 & 20,0 \\
\hline II & 67 & 3478 & 3131 & 7,3 & 464,6 & 108,6 & 573,3 & 0,2 & 558,7 & 20,5 \\
\hline II & 68 & 3718 & 3152 & 7,3 & 436,2 & 100,3 & 536,5 & 0,2 & 522,7 & 19,4 \\
\hline II & 72 & 3682 & 3218 & 7,3 & 427,9 & 103,6 & 531,5 & 0,2 & 518,5 & 18,3 \\
\hline II & 73 & 3437 & 3101 & 7,4 & 494,7 & 85,2 & 579,9 & 0,2 & 564,6 & 21,6 \\
\hline II & 74 & 3718 & 3009 & 7,6 & 444,6 & 75,2 & 519,8 & 0,2 & 509,1 & 15,1 \\
\hline II & 75 & 3626 & 3392 & 7,5 & 464,6 & 102,0 & 566,6 & 0,2 & 544,4 & 31,3 \\
\hline II & 79 & 3774 & 3111 & 7,2 & 426,2 & 95,3 & 521,5 & 0,2 & 505,4 & 22,7 \\
\hline II & 80 & 3738 & 3218 & 7,2 & 474,7 & 102,0 & 576,6 & 0,2 & 559,4 & 24,3 \\
\hline II & 81 & 4009 & 3366 & 7,3 & 501,4 & 115,3 & 616,7 & 0,2 & 602,5 & 20,0 \\
\hline II & 82 & 3509 & 3259 & 7,3 & 501,4 & 103,6 & 605,0 & 0,2 & 588,2 & 23,7 \\
\hline II & 86 & 0 & 0 & 0,0 & 0,0 & 0,0 & 0,0 & 0,0 & 0,0 & 0,0 \\
\hline II & 87 & 0 & 0 & 0,0 & 0,0 & 0,0 & 0,0 & 0,0 & 0,0 & 0,0 \\
\hline II & 88 & 3575 & 3152 & 7,4 & 451,3 & 117,0 & 568,3 & 0,3 & 554,1 & 20,0 \\
\hline II & 89 & 3631 & 3361 & 7,6 & 479,7 & 123,7 & 603,3 & 0,3 & 567,0 & 51,3 \\
\hline II & 93 & 3692 & 3437 & 7,3 & 553,2 & 112,0 & 665,2 & 0,2 & 649,1 & 22,7 \\
\hline
\end{tabular}


Tabela AI-1: Caracteristicas do Afluente em todas condições: concentrações em matéria orgânica DQO e substrato, $\mathrm{pH}$, alcalinidade total, alcalinidade a bicarbonato e ácidos voláteis totais do afluente.

\begin{tabular}{|c|c|c|c|c|c|c|c|c|c|c|}
\hline$\#$ & $\begin{array}{c}\text { Tempo de operação } \\
{[\mathrm{d}]}\end{array}$ & $\begin{array}{c}\mathrm{C}_{\mathrm{ST}, \mathrm{A}} \\
{\left[\mathrm{mgDQO} . \mathrm{L}^{-1}\right]}\end{array}$ & $\begin{array}{c}\mathrm{C}_{\mathrm{CT}, \mathrm{A}} \\
{\left[\mathrm{mg} \cdot \mathrm{L}^{-1}\right]}\end{array}$ & $\begin{array}{l}\mathrm{pH} \\
{[\mathrm{u}]}\end{array}$ & $\begin{array}{c}\mathrm{AP} \\
{\left[\mathrm{mgCaCO}_{3} \cdot \mathrm{L}^{-1}\right]}\end{array}$ & $\begin{array}{c}\mathrm{AI} \\
{\left[\mathrm{mgCaCO}_{3} \cdot \mathrm{L}^{-1}\right]}\end{array}$ & $\begin{array}{c}\mathrm{AT} \\
{\left[\mathrm{mgCaCO}_{3} \cdot \mathrm{L}^{-1}\right]}\end{array}$ & $\begin{array}{c}\mathrm{AI} / \mathrm{AP} \\
{[\mathrm{u}]}\end{array}$ & $\begin{array}{c}\mathrm{AB} \\
{\left[\mathrm{mgCaCO}_{3} \cdot \mathrm{L}^{-1}\right]}\end{array}$ & $\begin{array}{c}\text { AVT } \\
{\left[\mathrm{mgHAc} . \mathrm{L}^{-1}\right]}\end{array}$ \\
\hline III & 94 & 5681 & 4605 & 7,3 & 698,6 & 130,4 & 829,0 & 0,2 & 805,6 & 32,9 \\
\hline III & 100 & 5197 & 5151 & 7,3 & 656,8 & 123,7 & 780,5 & 0,2 & 761,7 & 26,4 \\
\hline III & 101 & 5248 & 5054 & 7,4 & 635,1 & 128,7 & 763,8 & 0,2 & 747,7 & 22,7 \\
\hline III & 109 & 6100 & 4381 & 7,4 & 712,0 & 125,3 & 837,3 & 0,2 & 812,1 & 35,6 \\
\hline III & 110 & 5314 & 5238 & 7,4 & 670,2 & 123,7 & 793,9 & 0,2 & 768,6 & 35,6 \\
\hline III & 114 & 5416 & 4284 & 7,6 & 687,3 & 154,9 & 842,2 & 0,2 & 822,8 & 27,3 \\
\hline III & 115 & 5024 & 3912 & 7,4 & 749,9 & 202,7 & 952,6 & 0,3 & 932,1 & 29,0 \\
\hline III & 116 & 4029 & 3779 & 7,2 & 675,8 & 164,8 & 840,6 & 0,2 & 818,1 & 31,7 \\
\hline III & 121 & 5370 & 4340 & - & - & - & - & - & - & - \\
\hline III & 122 & 5620 & 5365 & 7,4 & 555,4 & 133,5 & 688,9 & 0,2 & 665,7 & 32,8 \\
\hline III & 123 & 5620 & 4809 & 7,3 & 540,6 & 136,8 & 677,4 & 0,3 & 657,6 & 27,9 \\
\hline III & 128 & 5304 & 4855 & 7,4 & 515,9 & 133,7 & 649,6 & 0,3 & 634,7 & 21,0 \\
\hline III & 129 & 5452 & 4886 & 7,4 & 618,8 & 150,8 & 769,6 & 0,2 & 754,3 & 21,6 \\
\hline III & 130 & 5585 & 4799 & - & - & - & - & - & - & - \\
\hline III & 131 & - & - & 7,4 & 613,6 & 166,3 & 779,9 & 0,3 & 764,2 & 22,2 \\
\hline III & 135 & 6023 & 5304 & 7,0 & 543,4 & 138,8 & 682,2 & 0,3 & 664,5 & 24,9 \\
\hline III & 136 & 5238 & 5263 & 7,3 & 640,3 & 165,8 & 806,1 & 0,3 & 788,0 & 25,5 \\
\hline IV & 137 & 5304 & 4417 & - & - & - & - & - & - & - \\
\hline IV & 142 & 4590 & 4590 & 7,1 & 453,6 & 181,5 & 635,1 & 0,4 & 579,3 & 78,6 \\
\hline IV & 143 & 5202 & 5029 & 7,3 & 680,5 & 143,1 & 823,5 & 0,2 & 793,6 & 42,1 \\
\hline IV & 144 & 5350 & 4386 & 7,3 & 683,9 & 143,1 & 827,0 & 0,2 & 808,9 & 25,5 \\
\hline IV & 145 & - & - & 7,8 & 814,8 & 157,0 & 971,8 & 0,2 & 943,9 & 39,3 \\
\hline IV & 149 & 4804 & 4942 & 7,5 & 692,7 & 150,0 & 842,7 & 0,2 & 821,1 & 30,5 \\
\hline IV & 150 & 5222 & 4814 & 7,4 & 687,4 & 148,3 & 835,7 & 0,2 & 810,2 & 36,0 \\
\hline IV & 151 & 5141 & 4595 & 7,5 & 682,2 & 151,8 & 834,0 & 0,2 & 817,9 & 22,7 \\
\hline IV & 152 & 4804 & 4610 & 7,4 & 532,1 & 139,6 & 671,7 & 0,3 & 655,2 & 23,3 \\
\hline IV & 156 & 4641 & 4998 & 7,3 & 638,6 & 116,9 & 755,5 & 0,2 & 732,3 & 32,7 \\
\hline IV & 157 & 4845 & 4182 & 7,4 & 687,4 & 139,6 & 827,0 & 0,2 & 745,2 & 115,2 \\
\hline IV & 158 & 5243 & 4488 & 7,5 & 748,5 & 146,6 & 895,1 & 0,2 & 865,6 & 41,5 \\
\hline IV & 159 & 6171 & 4743 & 7,2 & 912,5 & 92,5 & 1005,0 & 0,1 & 949,1 & 78,6 \\
\hline IV & 163 & 4932 & 4488 & 7,4 & 656,0 & 106,4 & 762,5 & 0,2 & 736,5 & 36,6 \\
\hline IV & 164 & 4345 & 4182 & 7,3 & 666,5 & 117,2 & 783,7 & 0,2 & 758,8 & 35,1 \\
\hline V & 165 & 3779 & 3835 & 7,5 & 460,5 & 78,7 & 539,2 & 0,2 & 520,1 & 26,9 \\
\hline V & 173 & 3947 & 3825 & 7,3 & 463,9 & 103,8 & 567,7 & 0,2 & 517,0 & 71,3 \\
\hline V & 177 & 3468 & 3417 & 7,3 & 542,6 & 100,5 & 643,0 & 0,2 & 612,6 & 42,8 \\
\hline V & 178 & 3519 & 3162 & 7,2 & 550,9 & 75,4 & 626,3 & 0,1 & 599,4 & 37,9 \\
\hline V & 179 & 3672 & 3060 & 7,3 & 514,1 & 55,3 & 569,3 & 0,1 & 507,4 & 87,2 \\
\hline V & 180 & 3162 & 3060 & - & - & - & - & - & - & - \\
\hline V & 184 & 3738 & 3320 & 7,2 & 437,1 & 108,8 & 545,9 & 0,2 & 514,3 & 44,4 \\
\hline V & 185 & 3774 & 3902 & 7,2 & 463,9 & 108,8 & 572,7 & 0,2 & 556,7 & 22,5 \\
\hline V & 186 & 3774 & 3601 & 7,2 & 452,1 & 88,8 & 540,9 & 0,2 & 520,2 & 29,1 \\
\hline V & 187 & - & - & 7,3 & 435,4 & 119,4 & 554,7 & 0,3 & 538,0 & 23,5 \\
\hline V & 191 & 3366 & 3570 & 7,2 & 492,5 & 131,1 & 623,7 & 0,3 & 601,3 & 31,5 \\
\hline VI & 194 & 5375 & 5136 & - & - & - & - & - & - & - \\
\hline VI & 198 & - & - & 7,2 & 582,7 & 144,0 & 726,8 & 0,2 & 703,0 & 33,5 \\
\hline VI & 199 & 5365 & 5156 & 7,3 & 586,1 & 147,4 & 733,5 & 0,3 & 710,8 & 31,9 \\
\hline VI & 200 & 5100 & 5207 & 7,1 & 562,6 & 172,5 & 735,1 & 0,3 & 711,7 & 33,0 \\
\hline VI & 201 & 5115 & 5080 & 7,0 & 462,2 & 112,2 & 574,4 & 0,2 & 551,7 & 31,9 \\
\hline VI & 205 & 5615 & 5248 & - & - & - & - & - & - & - \\
\hline VI & 207 & 5610 & 5044 & - & - & - & - & - & - & - \\
\hline VI & 208 & 5421 & 5222 & 7,1 & 482,3 & 128,9 & 611,2 & 0,3 & 590,8 & 28,8 \\
\hline VI & 212 & 5304 & 5304 & 7,2 & 671,5 & 82,1 & 753,5 & 0,1 & 727,2 & 37,2 \\
\hline VI & 219 & 4605 & 5064 & 7,4 & 596,1 & 127,3 & 723,4 & 0,2 & 699,9 & 33,1 \\
\hline VI & 220 & 5115 & 5080 & 7,4 & 602,8 & 113,9 & 716,7 & 0,2 & 696,1 & 29,0 \\
\hline VI & 222 & 5131 & 5105 & 7,4 & 594,5 & 108,8 & 703,3 & 0,2 & 681,3 & 31,0 \\
\hline
\end{tabular}




\section{ANEXO II}

Tabela AII-1: Caracteristicas do efluente e desempenho do reator em todas condições: concentrações em DQO filtrada e total e substrato filtrado e total, eficiênças de remoção filtradas e totais.

\begin{tabular}{|c|c|c|c|c|c|c|c|c|c|}
\hline$\#$ & $\begin{array}{c}\text { Tempo de operação } \\
\text { [d] }\end{array}$ & $\begin{array}{c}\mathrm{C}_{\mathrm{SF}, \mathrm{E}} \\
{\left[\mathrm{mgDQO} \cdot \mathrm{L}^{-1}\right]}\end{array}$ & $\begin{array}{l}\varepsilon_{\mathrm{SF}} \\
{[\%]}\end{array}$ & $\begin{array}{c}\mathrm{C}_{\mathrm{ST}, \mathrm{E}} \\
{\left[\mathrm{mgDQO} . \mathrm{L}^{-1}\right]}\end{array}$ & $\begin{array}{l}\varepsilon_{S \mathrm{ST}} \\
{[\%]}\end{array}$ & $\begin{array}{c}\mathrm{C}_{\mathrm{CF}, \mathrm{E}} \\
{\left[\mathrm{mg} . \mathrm{L}^{-1}\right]}\end{array}$ & $\begin{array}{l}\varepsilon_{\mathrm{CF}} \\
{[\%]}\end{array}$ & $\begin{array}{c}\mathrm{C}_{\mathrm{CT}, \mathrm{E}} \\
{\left[\mathrm{mg} \cdot \mathrm{L}^{-1}\right]}\end{array}$ & $\begin{array}{l}\varepsilon_{\mathrm{CT}} \\
{[\%]}\end{array}$ \\
\hline $\mathrm{Cp}$ & 2 & 0 & 0,0 & 2618 & 28,1 & - & - & - & - \\
\hline $\mathrm{Cp}$ & 5 & 3500 & 3,9 & 3184 & 12,6 & - & - & - & - \\
\hline $\mathrm{Cp}$ & 8 & 3135 & 13,9 & 3142 & 13,8 & 848 & 74,1 & 861 & 73,7 \\
\hline $\mathrm{Cp}$ & 9 & 2912 & 20,1 & 3100 & 14,9 & 292 & 92,6 & 303 & 90,7 \\
\hline $\mathrm{Cp}$ & 10 & 2779 & 23,7 & 2858 & 21,5 & 154 & 96,1 & 185 & 94,3 \\
\hline $\mathrm{Cp}$ & 11 & 2969 & 18,5 & 2969 & 18,5 & 86 & 97,8 & 119 & 96,4 \\
\hline $\mathrm{Cp}$ & 12 & 2701 & 25,9 & 2906 & 20,2 & 68 & 98,3 & 173 & 94,7 \\
\hline $\mathrm{Cp}$ & 15 & 3134 & 14,0 & 3183 & 12,6 & 165 & 95,8 & 0 & 0,0 \\
\hline $\mathrm{Cp}$ & 16 & 2819 & 22,6 & 2838 & 22,1 & 67 & 98,3 & 102 & 96,9 \\
\hline I & 17 & 2951 & 20,5 & 3084 & 16,9 & 53 & 98,4 & 68 & 97,9 \\
\hline I & 18 & 2938 & 20,8 & 3178 & 14,4 & 47 & 98,5 & 74 & 97,7 \\
\hline I & 19 & 2915 & 21,5 & 2936 & 20,9 & 43 & 98,7 & 0 & 0,0 \\
\hline I & 22 & 2587 & 30,3 & 2609 & 29,7 & 40 & 98,8 & 56 & 98,3 \\
\hline I & 23 & 3015 & 18,8 & 2682 & 27,7 & 42 & 98,7 & 99 & 97,0 \\
\hline I & 24 & 3021 & 18,6 & 3092 & 16,7 & 59 & 98,2 & 89 & 97,3 \\
\hline I & 25 & 3033 & 18,3 & 3034 & 18,2 & 54 & 98,3 & 91 & 97,2 \\
\hline I & 26 & 3040 & 18,1 & 3147 & 15,2 & 75 & 97,7 & 120 & 96,3 \\
\hline I & 29 & 2940 & 20,8 & 3164 & 14,8 & 79 & 97,6 & 152 & 95,3 \\
\hline I & 30 & 2944 & 20,7 & 3407 & 8,2 & 139 & 95,7 & 286 & 91,2 \\
\hline I & 31 & 3067 & 17,4 & 3078 & 17,1 & 143 & 95,6 & 223 & 93,1 \\
\hline I & 36 & 2938 & 20,8 & 3104 & 16,4 & 46 & 98,6 & 108 & 96,7 \\
\hline I & 39 & 2848 & 23,3 & 3236 & 12,8 & 140 & 95,7 & 288 & 91,1 \\
\hline I & 40 & 2963 & 20,1 & 2971 & 19,9 & 109 & 96,6 & 224 & 93,1 \\
\hline I & 50 & 3003 & 19,1 & 3198 & 13,8 & 37 & 98,8 & 90 & 97,2 \\
\hline I & 51 & 3064 & 17,4 & 3119 & 16,0 & 130 & 96,0 & 163 & 95,0 \\
\hline I & 52 & 2819 & 24,0 & 2993 & 19,3 & 114 & 96,5 & 182 & 94,4 \\
\hline I & 53 & 3265 & 12,0 & 3269 & 11,9 & 77 & 97,6 & 149 & 95,4 \\
\hline I & 54 & 2819 & 24,0 & 3002 & 19,1 & 67 & 97,9 & 158 & 95,1 \\
\hline I & 58 & 2939 & 20,8 & 3304 & 11,0 & 232 & 92,9 & 307 & 90,6 \\
\hline I & 59 & 2921 & 21,3 & 3115 & 16,1 & 157 & 95,2 & 224 & 93,1 \\
\hline I & 60 & 2928 & 21,1 & 3178 & 14,4 & 69 & 97,9 & 152 & 95,3 \\
\hline I & 61 & 2918 & 21,4 & 3141 & 15,4 & 44 & 98,6 & 110 & 96,6 \\
\hline II & 62 & 2860 & 21,9 & 3026 & 17,4 & 185 & 94,2 & 220 & 93,1 \\
\hline II & 66 & 3027 & 17,4 & 3026 & 17,4 & 48 & 98,5 & 112 & 96,5 \\
\hline II & 67 & 2938 & 19,8 & 3082 & 15,9 & 183 & 94,3 & 253 & 92,1 \\
\hline II & 68 & 3125 & 14,7 & 3346 & 8,7 & 78 & 97,6 & 147 & 95,4 \\
\hline II & 72 & 2888 & 21,2 & 3013 & 17,8 & 252 & 92,1 & 284 & 91,1 \\
\hline II & 73 & 3273 & 10,7 & 3650 & 0,4 & 180 & 94,4 & 325 & 89,9 \\
\hline II & 74 & 3101 & 15,4 & 3376 & 7,9 & 143 & 95,5 & 246 & 92,3 \\
\hline II & 75 & 2860 & 21,9 & 3083 & 15,8 & 98 & 96,9 & 189 & 94,1 \\
\hline II & 79 & 2925 & 20,2 & 3165 & 13,6 & 40 & 98,8 & 91 & 97,2 \\
\hline II & 80 & 3128 & 14,6 & 3233 & 11,8 & 26 & 99,2 & 87 & 97,3 \\
\hline II & 81 & 3235 & 11,7 & 3304 & 9,8 & 52 & 98,4 & 142 & 95,6 \\
\hline II & 82 & 2947 & 19,6 & 3078 & 16,0 & 107 & 96,7 & 146 & 95,4 \\
\hline II & 86 & 3065 & 0,0 & 0 & 0,0 & 263 & 91,8 & 0 & 0,0 \\
\hline II & 87 & 2966 & 0,0 & 0 & 0,0 & 238 & 92,6 & 0 & 0,0 \\
\hline II & 88 & 3005 & 18,0 & 3290 & 10,2 & 97 & 97,0 & 252 & 92,1 \\
\hline II & 89 & 3050 & 16,7 & 3205 & 12,5 & 50 & 98,5 & 117 & 96,4 \\
\hline II & 93 & 3083 & 15,8 & 3226 & 11,9 & 40 & 98,8 & 94 & 97,1 \\
\hline
\end{tabular}

Tabela AII-1: Caracteristicas do efluente e desempenho do reator em todas condições: concentrações em DQO filtrada e total e substrato filtrado e total, eficiênças de remoção filtradas e totais. 


\begin{tabular}{|c|c|c|c|c|c|c|c|c|c|}
\hline$\#$ & $\begin{array}{l}\text { Tempo de operação } \\
\text { [d] }\end{array}$ & $\begin{array}{c}\mathrm{C}_{\mathrm{SF}, \mathrm{E}} \\
{\left[\mathrm{mgDQO} . \mathrm{L}^{-1}\right]}\end{array}$ & $\begin{array}{c}\varepsilon_{\mathrm{SF}} \\
{[\%]}\end{array}$ & $\begin{array}{c}\mathrm{C}_{\mathrm{ST}, \mathrm{E}} \\
{\left[\mathrm{mgDQO} \cdot \mathrm{L}^{-1}\right]}\end{array}$ & $\begin{array}{c}\varepsilon_{S \mathrm{~T}} \\
{[\%]}\end{array}$ & $\begin{array}{c}\mathrm{C}_{\mathrm{CF}, \mathrm{E}} \\
{\left[\mathrm{mg} \cdot \mathrm{L}^{-1}\right]}\end{array}$ & $\begin{array}{l}\varepsilon_{\mathrm{CF}} \\
{[\%]}\end{array}$ & $\begin{array}{c}\mathrm{C}_{\mathrm{CT}, \mathrm{E}} \\
{\left[\mathrm{mg} . \mathrm{L}^{-1}\right]}\end{array}$ & $\begin{array}{l}\varepsilon_{\mathrm{CT}} \\
{[\%]}\end{array}$ \\
\hline III & 94 & 4195 & 23,3 & 4354 & 20,4 & 30 & 99,4 & 80 & 98,3 \\
\hline III & 96 & - & - & - & - & 169 & 96,5 & 248 & 94,8 \\
\hline III & 100 & 4363 & 20,3 & 4384 & 19,9 & 370 & 92,3 & 400 & 91,6 \\
\hline III & 101 & 4244 & 22,4 & 4469 & 18,3 & 278 & 94,2 & 292 & 93,9 \\
\hline III & 102 & 4529 & 17,2 & 4682 & 14,4 & 254 & 94,7 & 317 & 93,4 \\
\hline III & 103 & 4967 & 9,2 & 5130 & 6,2 & 370 & 92,3 & 435 & 90,9 \\
\hline III & 110 & 4475 & 18,2 & 4573 & 16,4 & 512 & 89,3 & 507 & 89,4 \\
\hline III & 114 & 4433 & 19,0 & 4558 & 16,7 & 165 & 96,5 & 216 & 95,5 \\
\hline III & 115 & 4148 & 24,2 & 4613 & 15,7 & 61 & 98,7 & 132 & 97,2 \\
\hline III & 116 & 4016 & 26,6 & 4016 & 26,6 & 91 & 98,1 & 226 & 95,3 \\
\hline III & 117 & 4461 & 18,5 & 4749 & 13,2 & - & - & - & - \\
\hline III & 122 & 4480 & 18,1 & 4901 & 10,4 & 160 & 96,7 & 435 & 90,9 \\
\hline III & 123 & 4429 & 19,1 & 4472 & 18,3 & 420 & 91,2 & 519 & 89,1 \\
\hline III & 128 & 4480 & 18,1 & 4510 & 17,6 & 750 & 84,3 & 763 & 84,0 \\
\hline III & 129 & 4535 & 17,1 & 4687 & 14,3 & 579 & 87,9 & 669 & 86,0 \\
\hline III & 130 & 4622 & 15,5 & 4816 & 12,0 & 147 & 96,9 & 242 & 94,9 \\
\hline III & 135 & 4776 & 12,7 & 4980 & 9,0 & 945 & 80,2 & 990 & 79,3 \\
\hline III & 136 & 4514 & 17,5 & 4653 & 15,0 & 781 & 83,7 & 857 & 82,1 \\
\hline IV & 137 & 4670 & 7,4 & 4971 & 1,4 & 828 & 82,0 & 1162 & 74,8 \\
\hline IV & 142 & 4202 & 16,7 & 4510 & 10,6 & 396 & 91,4 & 418 & 90,9 \\
\hline IV & 143 & 4048 & 19,7 & 4400 & 12,7 & 1067 & 76,8 & 1111 & 75,9 \\
\hline IV & 144 & 4368 & 13,4 & 4773 & 5,3 & 836 & 81,8 & 1078 & 76,6 \\
\hline IV & 149 & 3788 & 24,9 & 4061 & 19,5 & 504 & 89,1 & 582 & 87,4 \\
\hline IV & 150 & 4004 & 20,6 & 4246 & 15,8 & 391 & 91,5 & 427 & 90,7 \\
\hline IV & 151 & 3949 & 21,7 & 4045 & 19,8 & 245 & 94,7 & 352 & 92,4 \\
\hline IV & 152 & 3753 & 25,6 & 4564 & 9,5 & 364 & 92,1 & 442 & 90,4 \\
\hline IV & 156 & 3575 & 29,1 & 3608 & 28,4 & 671 & 85,4 & 745 & 83,8 \\
\hline IV & 157 & 3762 & 25,4 & 3883 & 23,0 & 616 & 86,6 & 660 & 85,7 \\
\hline IV & 158 & 3945 & 21,8 & 4169 & 17,3 & 458 & 90,1 & 550 & 88,1 \\
\hline IV & 159 & 4180 & 17,1 & 4411 & 12,5 & 352 & 92,4 & 396 & 91,4 \\
\hline IV & 163 & 3869 & 23,3 & 4082 & 19,0 & 451 & 90,2 & 484 & 89,5 \\
\hline IV & 164 & 3929 & 22,1 & 3960 & 21,5 & 286 & 93,8 & 341 & 92,6 \\
\hline $\mathrm{V}$ & 165 & 3032 & 16,3 & 3127 & 13,6 & 116 & 97,5 & 138 & 96,0 \\
\hline $\mathrm{V}$ & 173 & 3010 & 16,9 & 3075 & 15,1 & 422 & 90,8 & 451 & 87,0 \\
\hline $\mathrm{V}$ & 177 & 2827 & 21,9 & 2827 & 21,9 & 176 & 96,2 & 187 & 94,6 \\
\hline $\mathrm{V}$ & 178 & 3102 & 14,3 & 3135 & 13,4 & 473 & 89,7 & 528 & 84,8 \\
\hline $\mathrm{V}$ & 179 & 3201 & 11,6 & 3267 & 9,8 & 451 & 90,2 & 528 & 84,8 \\
\hline $\mathrm{V}$ & 180 & 2464 & 31,9 & 2475 & 31,6 & 154 & 96,7 & 220 & 93,7 \\
\hline $\mathrm{V}$ & 184 & 3467 & 4,2 & 3566 & 1,5 & 37 & 99,2 & 59 & 98,3 \\
\hline $\mathrm{V}$ & 185 & 2764 & 23,6 & 2819 & 22,1 & 243 & 94,7 & 254 & 92,7 \\
\hline $\mathrm{V}$ & 186 & 3267 & 9,8 & 3307 & 8,7 & 581 & 87,4 & 612 & 82,4 \\
\hline $\mathrm{V}$ & 191 & 2838 & 21,6 & 2948 & 18,6 & 139 & 97,0 & 165 & 95,3 \\
\hline $\mathrm{V}$ & 192 & 2926 & 19,2 & 2948 & 18,6 & 836 & 81,8 & 836 & 75,9 \\
\hline $\mathrm{V}$ & 193 & 3058 & 15,5 & 3080 & 14,9 & 937 & 79,6 & 937 & 73,0 \\
\hline VI & 194 & 4650 & 11,4 & 4786 & 9,2 & 250 & 94,6 & 308 & 94,0 \\
\hline VI & 199 & 4563 & 13,1 & 4602 & 12,9 & 1038 & 77,4 & 959 & 81,4 \\
\hline VI & 200 & 4480 & 14,7 & 4662 & 11,7 & 1031 & 77,6 & 1130 & 78,1 \\
\hline VI & 201 & 4373 & 16,7 & 4519 & 14,5 & 1178 & 74,4 & 1282 & 75,1 \\
\hline VI & 205 & 4550 & 13,4 & 4716 & 10,6 & 756 & 83,6 & 972 & 81,1 \\
\hline VI & 207 & 4717 & 10,2 & 4773 & 9,5 & 422 & 90,8 & 425 & 91,8 \\
\hline VI & 208 & 4525 & 13,8 & 4762 & 9,7 & 947 & 79,4 & 993 & 80,7 \\
\hline VI & 212 & 4752 & 9,5 & 4928 & 6,4 & 1144 & 75,2 & 1188 & 76,9 \\
\hline VI & 219 & 4204 & 19,9 & 4400 & 16,9 & 987 & 78,6 & 1100 & 78,6 \\
\hline VI & 220 & 4557 & 13,2 & 4827 & 8,4 & 531 & 88,5 & 571 & 88,9 \\
\hline VI & 222 & 4538 & 13,6 & 4697 & 11,0 & 1188 & 74,2 & 1192 & 76,8 \\
\hline
\end{tabular}




\section{ANEXO III}

Tabela AIII-1: Caracteristicas do efluente em todas condições:, $\mathrm{pH}$, alcalinidade total, alcalinidade a bicarbonato e ácidos voláteis totais do afluente.

\begin{tabular}{|c|c|c|c|c|c|c|c|c|}
\hline$\#$ & $\begin{array}{c}\text { Tempo de operação } \\
{[\mathrm{d}]}\end{array}$ & $\begin{array}{l}\mathrm{pH} \\
{[\mathrm{u}]}\end{array}$ & $\begin{array}{c}\mathrm{AP} \\
{\left[\mathrm{mgCaCO}_{3} \cdot \mathrm{L}^{-1}\right]}\end{array}$ & $\begin{array}{c}\mathrm{AI} \\
{\left[\mathrm{mgCaCO}_{3} \cdot \mathrm{L}^{-1}\right]}\end{array}$ & $\begin{array}{c}\mathrm{AT} \\
{\left[\mathrm{mgCaCO}_{3} \cdot \mathrm{L}^{-1}\right]}\end{array}$ & $\begin{array}{c}\mathrm{AI} / \mathrm{AP} \\
{[\mathrm{u}]}\end{array}$ & $\begin{array}{c}\mathrm{AB} \\
{\left[\mathrm{mgCaCO}_{3} \cdot \mathrm{L}^{-1}\right]}\end{array}$ & $\begin{array}{c}\text { AVT } \\
{\left[\mathrm{mgHAc.L}^{-1}\right]}\end{array}$ \\
\hline $\mathrm{Cp}$ & 1 & 4,1 & 0,0 & 0,0 & 0,00 & - & 0,0 & 702,4 \\
\hline $\mathrm{Cp}$ & 2 & 4,4 & 0,0 & 28,3 & 28,32 & - & 0,0 & 663,0 \\
\hline $\mathrm{Cp}$ & 3 & 4,5 & 0,0 & 74,7 & 74,66 & - & 0,0 & 783,4 \\
\hline $\mathrm{Cp}$ & 5 & 4,6 & 0,0 & 105,6 & 105,55 & - & 0,0 & 568,9 \\
\hline $\mathrm{Cp}$ & 8 & 4,3 & 0,0 & 0,0 & 0,00 & - & 0,0 & 773,3 \\
\hline $\mathrm{Cp}$ & 9 & 4,4 & 0,0 & 21,9 & 21,88 & - & 0,0 & 832,9 \\
\hline $\mathrm{Cp}$ & 10 & 4,6 & 0,0 & 85,6 & 85,60 & - & 0,0 & 685,3 \\
\hline $\mathrm{Cp}$ & 11 & 4,1 & 0,0 & 0,0 & 0,00 & - & 0,0 & 762,6 \\
\hline $\mathrm{Cp}$ & 12 & 4,3 & 0,0 & 0,0 & 0,00 & - & 0,0 & 697,5 \\
\hline I & 15 & 3,9 & 0,0 & 0,0 & 0,00 & - & 0,0 & 683,1 \\
\hline I & 16 & 4,3 & 0,0 & 0,0 & 0,00 & - & 0,0 & 712,9 \\
\hline I & 17 & 4,4 & 0,0 & 40,9 & 40,86 & - & 0,0 & 773,9 \\
\hline I & 19 & 4,8 & 0,0 & 229,1 & 229,09 & - & 0,0 & 788,2 \\
\hline I & 22 & 5,1 & 0,0 & 382,1 & 382,14 & - & 0,0 & 674,3 \\
\hline I & 23 & 5,2 & 0,0 & 439,0 & 438,97 & - & 0,0 & 775,1 \\
\hline I & 24 & 5,1 & 0,0 & 365,1 & 365,09 & - & 0,0 & 668,8 \\
\hline I & 25 & 4,8 & 0,0 & 249,3 & 249,32 & - & 0,0 & 726,2 \\
\hline I & 26 & 4,7 & 0,0 & 203,1 & 203,15 & - & 0,0 & 718,4 \\
\hline I & 29 & 4,5 & 0,0 & 72,5 & 72,45 & - & 0,0 & 798,7 \\
\hline I & 30 & 4,9 & 0,0 & 299,7 & 299,75 & - & 0,0 & 839,8 \\
\hline I & 36 & 4,4 & 0,0 & 62,6 & 62,65 & - & 0,0 & 733,6 \\
\hline I & 37 & 4,2 & 0,0 & 0,0 & 0,00 & - & 0,0 & 766,8 \\
\hline I & 38 & 4,3 & 0,0 & 0,0 & 0,00 & - & 0,0 & 769,0 \\
\hline I & 39 & 4,3 & 0,0 & 0,0 & 0,00 & - & 0,0 & 757,1 \\
\hline I & 40 & 4,4 & 0,0 & 29,6 & 29,58 & - & 0,0 & 761,0 \\
\hline I & 50 & 4,5 & 0,0 & 77,5 & 77,50 & - & 0,0 & 737,1 \\
\hline I & 51 & 4,3 & 0,0 & 0,0 & 0,00 & - & 0,0 & 788,0 \\
\hline I & 52 & 4,3 & 0,0 & 0,0 & 0,00 & - & 0,0 & 769,6 \\
\hline I & 53 & 4,3 & 0,0 & 0,0 & 0,00 & - & 0,0 & 803,6 \\
\hline I & 54 & 4,3 & 0,0 & 5,2 & 5,22 & - & 0,0 & 751,5 \\
\hline I & 58 & 4,2 & 0,0 & 0,0 & 0,00 & - & 0,0 & 644,7 \\
\hline I & 59 & 4,4 & 0,0 & 52,2 & 52,20 & - & 0,0 & 645,3 \\
\hline I & 60 & 4,7 & 0,0 & 177,5 & 177,50 & - & 0,0 & 601,9 \\
\hline II & 61 & 4,6 & 0,0 & 128,7 & 128,69 & - & 0,0 & 615,0 \\
\hline II & 65 & 5,1 & 0,0 & 290,8 & 290,81 & - & 0,0 & 599,4 \\
\hline II & 66 & 5,2 & 0,0 & 334,3 & 334,27 & - & 14,0 & 451,0 \\
\hline II & 67 & 4,9 & 0,0 & 277,4 & 277,44 & - & 0,0 & 587,0 \\
\hline II & 68 & 4,9 & 0,0 & 237,3 & 237,33 & - & 0,0 & 564,3 \\
\hline II & 72 & 4,9 & 0,0 & 242,3 & 242,34 & - & 0,0 & 574,0 \\
\hline II & 73 & 5,2 & 0,0 & 406,1 & 406,13 & - & 0,0 & 824,2 \\
\hline II & 74 & 5,1 & 0,0 & 284,1 & 284,13 & - & 0,0 & 576,1 \\
\hline II & 75 & 5,0 & 0,0 & 297,5 & 297,50 & - & 0,0 & 746,0 \\
\hline II & 79 & 5,1 & 0,0 & 300,8 & 300,84 & - & 0,0 & 562,1 \\
\hline II & 80 & 5,2 & 0,0 & 372,7 & 372,69 & - & 0,0 & 563,2 \\
\hline II & 81 & 5,1 & 0,0 & 322,6 & 322,55 & - & 0,0 & 546,6 \\
\hline II & 82 & 5,0 & 0,0 & 330,9 & 330,91 & - & 0,0 & 670,1 \\
\hline II & 86 & 5,0 & 0,0 & 320,9 & 320,88 & - & 0,0 & 662,9 \\
\hline II & 87 & 5,1 & 0,0 & 215,6 & 215,59 & - & 0,0 & 562,7 \\
\hline II & 88 & 4,9 & 0,0 & 290,8 & 290,80 & - & 0,0 & 872,8 \\
\hline II & 89 & 4,9 & 0,0 & 279,1 & 279,10 & - & 0,0 & 708,9 \\
\hline
\end{tabular}


Tabela AIII-1: Caracteristicas do efluente em todas condições:, pH, alcalinidade total, alcalinidade a bicarbonato e ácidos voláteis totais do afluente.

\begin{tabular}{|c|c|c|c|c|c|c|c|c|}
\hline$\#$ & $\begin{array}{c}\text { Tempo de operação } \\
{[\mathrm{d}]}\end{array}$ & $\begin{array}{l}\mathrm{pH} \\
{[\mathrm{u}]}\end{array}$ & $\begin{array}{c}\mathrm{AP} \\
{\left[\mathrm{mgCaCO}_{3} \cdot \mathrm{L}^{-1}\right]}\end{array}$ & $\begin{array}{c}\mathrm{AI} \\
{\left[\mathrm{mgCaCO}_{3} \cdot \mathrm{L}^{-1}\right]}\end{array}$ & $\begin{array}{c}\mathrm{AT} \\
{\left[\mathrm{mgCaCO}_{3} \cdot \mathrm{L}^{-1}\right]}\end{array}$ & $\begin{array}{c}\mathrm{AI} / \mathrm{AP} \\
{[\mathrm{u}]}\end{array}$ & $\begin{array}{c}\mathrm{AB} \\
{\left[\mathrm{mgCaCO}_{3} \cdot \mathrm{L}^{-1}\right]}\end{array}$ & $\begin{array}{c}\text { AVT } \\
{\left[\mathrm{mgHAc} . \mathrm{L}^{-1}\right]}\end{array}$ \\
\hline III & 93 & 5,1 & 0,0 & 342,6 & 342,61 & - & 0,0 & 654,6 \\
\hline III & 94 & 5,1 & 0,0 & 357,7 & 357,66 & - & 0,0 & 527,1 \\
\hline III & 100 & 5,0 & 0,0 & 386,1 & 386,08 & - & 0,0 & 852,9 \\
\hline III & 101 & 5,0 & 0,0 & 417,8 & 417,83 & - & 0,0 & 955,4 \\
\hline III & 109 & 4,9 & 0,0 & 372,7 & 372,71 & - & 0,0 & 872,9 \\
\hline III & 110 & 5,0 & 0,0 & 379,4 & 379,39 & - & 0,0 & 973,8 \\
\hline III & 114 & 5,0 & 0,0 & 420,3 & 420,28 & - & 0,0 & 951,8 \\
\hline III & 115 & 5,0 & 0,0 & 402,2 & 402,15 & - & 0,0 & 902,6 \\
\hline III & 116 & 4,8 & 0,0 & 267,0 & 267,00 & - & 0,0 & 781,3 \\
\hline III & 122 & 4,9 & 0,0 & 331,3 & 331,28 & - & 0,0 & 817,9 \\
\hline III & 123 & 4,8 & 0,0 & 323,0 & 323,04 & - & 0,0 & 959,4 \\
\hline III & 128 & 4,9 & 0,0 & 419,9 & 419,94 & - & 0,0 & 1140,9 \\
\hline III & 129 & 5,0 & 0,0 & 377,1 & 377,09 & - & 0,0 & 842,9 \\
\hline III & 131 & 4,9 & 0,0 & 361,7 & 361,66 & - & 0,0 & 886,5 \\
\hline III & 135 & 4,9 & 0,0 & 440,5 & 440,51 & - & 0,0 & 700,8 \\
\hline III & 136 & 5,0 & 0,0 & 394,3 & 394,31 & - & 0,0 & 939,8 \\
\hline IV & 142 & 5,3 & 0,0 & 485,0 & 485,04 & - & 0,0 & 721,0 \\
\hline IV & 143 & 4,9 & 0,0 & 277,4 & 277,42 & - & 0,0 & 893,3 \\
\hline IV & 144 & 5,2 & 0,0 & 507,7 & 507,72 & - & 0,0 & 831,8 \\
\hline IV & 145 & 5,0 & 0,0 & 431,0 & 430,95 & - & 0,0 & 940,9 \\
\hline IV & 149 & 5,1 & 0,0 & 434,4 & 434,44 & - & 0,0 & 801,3 \\
\hline IV & 150 & 5,0 & 0,0 & 425,7 & 425,72 & - & 0,0 & 795,3 \\
\hline IV & 151 & 5,0 & 0,0 & 418,7 & 418,74 & - & 0,0 & 805,8 \\
\hline IV & 152 & 5,0 & 0,0 & 425,7 & 425,72 & - & 0,0 & 782,0 \\
\hline IV & 156 & 5,0 & 0,0 & 368,1 & 368,14 & - & 0,0 & 811,9 \\
\hline IV & 157 & 4,9 & 0,0 & 336,7 & 336,74 & - & 0,0 & 944,8 \\
\hline IV & 158 & 5,0 & 0,0 & 376,9 & 376,87 & - & 0,0 & 987,4 \\
\hline IV & 159 & 5,0 & 0,0 & 214,6 & 214,60 & - & 0,0 & 810,8 \\
\hline IV & 163 & 5,0 & 0,0 & 375,1 & 375,12 & - & 0,0 & 806,9 \\
\hline IV & 164 & 5,0 & 0,0 & 346,6 & 346,63 & - & 0,0 & 918,5 \\
\hline $\mathrm{V}$ & 165 & 5,4 & 0,0 & 338,3 & 338,26 & - & 0,0 & 565,2 \\
\hline $\mathrm{V}$ & 173 & 5,1 & 0,0 & 288,0 & 288,02 & - & 0,0 & 597,0 \\
\hline $\mathrm{V}$ & 177 & 5,4 & 0,0 & 346,6 & 346,63 & - & 0,0 & 616,7 \\
\hline $\mathrm{V}$ & 178 & 5,2 & 0,0 & 309,8 & 309,79 & - & 0,0 & 571,2 \\
\hline $\mathrm{V}$ & 179 & 5,1 & 0,0 & 289,7 & 289,70 & - & 0,0 & 628,3 \\
\hline $\mathrm{V}$ & 184 & 5,2 & 0,0 & 167,5 & 167,46 & - & 0,0 & 429,6 \\
\hline $\mathrm{V}$ & 185 & 5,3 & 0,0 & 284,7 & 284,67 & - & 0,0 & 460,4 \\
\hline $\mathrm{V}$ & 186 & 5,2 & 0,0 & 293,0 & 293,05 & - & 0,0 & 472,4 \\
\hline $\mathrm{V}$ & 187 & 5,2 & 0,0 & 289,1 & 289,14 & - & 0,0 & 474,7 \\
\hline $\mathrm{V}$ & 191 & 5,0 & 0,0 & 253,8 & 253,84 & - & 0,0 & 632,4 \\
\hline VI & 198 & 5,2 & 0,0 & 371,8 & 371,75 & - & 0,0 & 596,8 \\
\hline VI & 199 & 5,3 & 0,0 & 381,8 & 381,80 & - & 0,0 & 709,9 \\
\hline VI & 200 & 5,2 & 0,0 & 353,3 & 353,33 & - & 0,0 & 576,4 \\
\hline VI & 201 & 5,1 & 0,0 & 361,7 & 361,70 & - & 0,0 & 546,0 \\
\hline VI & 208 & 5,1 & 0,0 & 351,7 & 351,66 & - & 0,0 & 659,6 \\
\hline VI & 212 & 5,5 & 0,0 & 413,6 & 413,61 & - & 11,1 & 567,0 \\
\hline VI & 219 & 5,3 & 0,0 & 440,4 & 440,41 & - & 0,0 & 635,5 \\
\hline VI & 220 & 5,0 & 0,0 & 366,7 & 366,73 & - & 0,0 & 685,4 \\
\hline VI & 222 & 5,0 & 0,0 & 351,7 & 351,66 & - & 0,0 & 868,0 \\
\hline
\end{tabular}




\section{ANEXO IV}

Tabela AIV-1: Volume total e específicos do biogás em todas condições.

\begin{tabular}{|c|c|c|c|c|c|c|}
\hline$\#$ & $\begin{array}{c}\text { Tempo } \\
\text { [d] }\end{array}$ & $\begin{array}{ll} & \text { Pulsos } \\
{[\mathrm{u}]} & \\
\end{array}$ & $\begin{array}{c}\text { Volume corigido } \\
\text { [mL-CNTP] }\end{array}$ & $\begin{array}{c}\mathrm{VH} 2 \\
{[\mathrm{~mL}-\mathrm{CNTP}]}\end{array}$ & $\begin{array}{c}\mathrm{VCO} 2 \\
\text { [mL-CNTP] }\end{array}$ & $\begin{array}{c}\mathrm{VCH} 4 \\
\text { [mL-CNTP] }\end{array}$ \\
\hline $\mathrm{Cp}$ & 8 & & & & & \\
\hline $\mathrm{Cp}$ & 9 & 418,0 & 1134,2 & & & \\
\hline $\mathrm{Cp}$ & 15 & 509,0 & 1381,2 & & & \\
\hline I & 16 & 437,0 & 1185,8 & 1419,5 & 5678,4 & 16,8 \\
\hline I & 24 & 458,0 & 1242,8 & 1487,7 & 5951,3 & 17,6 \\
\hline I & 28 & 374,0 & 1014,8 & 1214,9 & 4859,8 & 14,4 \\
\hline I & 30 & 404,0 & 1093,1 & 1308,6 & 5234,7 & 15,5 \\
\hline I & 37 & 389,0 & 1073,4 & 1284,9 & 5140,1 & 15,2 \\
\hline I & 39 & 425,0 & 1164,8 & 1394,4 & 5578,1 & 16,5 \\
\hline I & 45 & 426,0 & 1167,6 & 1397,7 & 5591,2 & 16,6 \\
\hline I & 51 & 423,0 & 1159,4 & 1387,9 & 5551,8 & 16,5 \\
\hline I & 53 & 445,0 & 1219,7 & 1460,0 & 5840,6 & 17,3 \\
\hline II & 61 & 353,0 & 967,5 & 1436,0 & 4352,8 & 16,2 \\
\hline II & 72 & 424,0 & 1162,1 & 1724,8 & 5228,3 & 19,5 \\
\hline II & 75 & 479,0 & 1312,8 & 1948,5 & 5906,5 & 22,0 \\
\hline II & 79 & 286,0 & 783,9 & 1163,4 & 3526,7 & 13,1 \\
\hline II & 81 & 293,0 & 803,1 & 1191,9 & 3613,0 & 13,5 \\
\hline II & 86 & 326,0 & 893,5 & 1326,1 & 4019,9 & 15,0 \\
\hline II & 88 & 304,0 & 833,2 & 1236,6 & 3748,6 & 14,0 \\
\hline III & 93 & 605,0 & 1658,2 & 3206,0 & 9980,3 & 79,1 \\
\hline III & 109 & 589,0 & 1614,3 & 3121,3 & 9716,3 & 77,0 \\
\hline III & 114 & 660,0 & 1808,9 & 3497,5 & 10887,6 & 86,3 \\
\hline III & 122 & 535,0 & 1466,3 & 2835,1 & 8825,5 & 70,0 \\
\hline III & 128 & 511,0 & 1400,5 & 2707,9 & 8429,6 & 66,8 \\
\hline III & 135 & 511,0 & 1400,5 & 2707,9 & 8429,6 & 66,8 \\
\hline III & 136 & 791,0 & 2168,0 & 4191,7 & 13048,6 & 103,5 \\
\hline IV & 142 & 336,0 & 920,9 & 1466,0 & 5882,1 & 19,2 \\
\hline IV & 149 & 626,0 & 1715,7 & 2731,2 & 10958,8 & 35,9 \\
\hline IV & 151 & 390,0 & 1068,9 & 1701,6 & 6827,4 & 22,3 \\
\hline IV & 157 & 518,0 & 1419,7 & 2260,0 & 9068,2 & 29,7 \\
\hline IV & 158 & 544,0 & 1491,0 & 2373,5 & 9523,3 & 31,2 \\
\hline $\mathrm{V}$ & 172 & 418,0 & 1145,7 & 3141,9 & 10577,0 & 29,0 \\
\hline $\mathrm{V}$ & 177 & 365,0 & 1000,4 & 2743,5 & 9235,9 & 25,3 \\
\hline $\mathrm{V}$ & 183 & 243,0 & 666,0 & 1826,5 & 6148,8 & 16,8 \\
\hline $\mathrm{V}$ & 186 & 407,0 & 1115,5 & 3059,2 & 10298,7 & 28,2 \\
\hline $\mathrm{V}$ & 191 & 420,0 & 1151,1 & 3156,9 & 10627,6 & 29,1 \\
\hline $\mathrm{V}$ & 192 & 409,0 & 1121,0 & 3074,2 & 10349,3 & 28,3 \\
\hline $\mathrm{V}$ & 198 & 495,0 & 1356,7 & 3720,6 & 12525,4 & 34,3 \\
\hline VI & 199 & 505,0 & 1384,1 & 2564,4 & 13996,6 & 48,2 \\
\hline VI & 205 & 478,0 & 1310,1 & 2427,3 & 13248,3 & 45,6 \\
\hline VI & 207 & 408,0 & 1118,2 & 2071,8 & 11308,2 & 39,0 \\
\hline VI & 213 & 382,0 & 1047,0 & 1939,8 & 10587,6 & 36,5 \\
\hline VI & 222 & 382,0 & 1047,0 & 1939,8 & 10587,6 & 36,5 \\
\hline
\end{tabular}




\section{ANEXO V}

Tabela AV-1: Valores de Perfis da condição I.

\begin{tabular}{cccccccc}
\hline Tempo & $\begin{array}{c}\mathrm{C}_{\mathrm{SF}} \\
{\left[\mathrm{mgDQO} \cdot \mathrm{L}^{-1}\right]}\end{array}$ & $\begin{array}{c}\mathrm{C}_{\mathrm{CF}} \\
{\left[\mathrm{mgSAC} \cdot \mathrm{L}^{-1}\right]}\end{array}$ & $\begin{array}{c}\mathrm{AP} \\
{\left[\mathrm{mgCaCO}_{3} \cdot \mathrm{L}^{-1}\right]}\end{array}$ & $\begin{array}{c}\mathrm{AI} \\
{\left[\mathrm{mgCaCO}_{3} \cdot \mathrm{L}^{-1}\right]}\end{array}$ & $\begin{array}{c}\mathrm{AT} \\
{\left[\mathrm{mgCaCO}_{3} \cdot \mathrm{L}^{-1}\right]}\end{array}$ & $\begin{array}{c}\mathrm{AVT} \\
{\left[\mathrm{mgCaCO}_{3} \cdot \mathrm{L}^{-1}\right]}\end{array}$ & $\begin{array}{c}\mathrm{V}_{\text {biogás }} \\
{[\mathrm{mL}]}\end{array}$ \\
\hline 0,00 & 3285 & 1400 & 0 & 157 & 157 & 448 & 0 \\
0,50 & 3289 & 1165 & 0 & 159 & 159 & 460 & 397 \\
1,00 & 3202 & 964 & 0 & 144 & 144 & 665 & 661 \\
1,50 & 3086 & 757 & 0 & 117 & 117 & 645 & 849 \\
2,00 & 2989 & 625 & 0 & 100 & 100 & 611 & 997 \\
2,50 & 2939 & 463 & 0 & 96 & 96 & 659 & 1109 \\
3,00 & 2943 & 328 & 0 & 85 & 85 & 703 & 1176 \\
3,70 & 2891 & 219 & 0 & 31 & 31 & 738 & 1221 \\
\hline
\end{tabular}

Tabela AV-2: Valores de Perfis da condição II.

\begin{tabular}{cccccccc}
\hline Tempo & $\begin{array}{c}\mathrm{C}_{\mathrm{SF}} \\
{\left[\mathrm{mgDQO} . \mathrm{L}^{-1}\right]}\end{array}$ & $\begin{array}{c}\mathrm{C}_{\mathrm{CF}} \\
{\left[\mathrm{mgSAC} \cdot \mathrm{L}^{-1}\right]}\end{array}$ & $\begin{array}{c}\mathrm{AP} \\
{\left[\mathrm{mgCaCO}_{3} \cdot \mathrm{L}^{-1}\right]}\end{array}$ & $\begin{array}{c}\mathrm{AI} \\
{\left[\mathrm{mgCaCO}_{3} \cdot \mathrm{L}^{-1}\right]}\end{array}$ & $\begin{array}{c}\mathrm{AT} \\
{\left[\mathrm{mgCaCO}_{3} \cdot \mathrm{L}^{-1}\right]}\end{array}$ & $\begin{array}{c}\mathrm{AVT} \\
{\left[\mathrm{mgCaCO}_{3} \cdot \mathrm{L}^{-1}\right]}\end{array}$ & $\begin{array}{c}\mathrm{V}_{\text {biogás }} \\
{[\mathrm{mL}]}\end{array}$ \\
\hline 0,00 & 3631 & 1492 & 32 & 403 & 435 & 441 & 0 \\
0,50 & 3402 & 1119 & 0 & 403 & 403 & 483 & 315 \\
1,00 & 3249 & 811 & 0 & 377 & 377 & 481 & 590 \\
1,50 & 3144 & 652 & 0 & 365 & 365 & 574 & 809 \\
2,00 & 3071 & 439 & 0 & 332 & 332 & 580 & 984 \\
2,70 & 3015 & 250 & 0 & 325 & 325 & 602 & 1146 \\
\hline
\end{tabular}

Tabela AV-3: Valores de Perfis da condição III.

\begin{tabular}{cccccccc}
\hline Tempo & $\begin{array}{c}\mathrm{C}_{\mathrm{SF}} \\
{\left[\mathrm{mgDQO} \cdot \mathrm{L}^{-1}\right]}\end{array}$ & $\begin{array}{c}\mathrm{C}_{\mathrm{CF}} \\
{\left[\mathrm{mgSAC}^{-1}\right]}\end{array}$ & $\begin{array}{c}\mathrm{AP} \\
{\left[\mathrm{mgCaCO}_{3} \cdot \mathrm{L}^{-1}\right]}\end{array}$ & $\begin{array}{c}\mathrm{AI} \\
{\left[\mathrm{mgCaCO}_{3} \cdot \mathrm{L}^{-1}\right]}\end{array}$ & $\begin{array}{c}\mathrm{AT} \\
{\left[\mathrm{mgCaCO}_{3} \cdot \mathrm{L}^{-1}\right]}\end{array}$ & $\begin{array}{c}\mathrm{AVT} \\
{\left[\mathrm{mgCaCO}_{3} \cdot \mathrm{L}^{-1}\right]}\end{array}$ & $\begin{array}{c}\mathrm{V}_{\text {biogás }} \\
{[\mathrm{mL}]}\end{array}$ \\
\hline 0,00 & 5406 & 2374 & 136 & 507 & 642 & 522 & 0 \\
0,50 & 5133 & 2128 & 48 & 542 & 590 & 590 & 357 \\
1,00 & 4916 & 1849 & 0 & 553 & 553 & 614 & 658 \\
1,50 & 4921 & 1620 & 0 & 551 & 551 & 655 & 931 \\
2,00 & 4887 & 1399 & 0 & 550 & 550 & 727 & 1179 \\
2,50 & 4877 & 1212 & 0 & 526 & 526 & 680 & 1416 \\
3,00 & 4658 & 1012 & 0 & 518 & 518 & 776 & 1632 \\
3,70 & 4760 & 850 & 0 & 499 & 499 & 690 & 1876 \\
\hline
\end{tabular}


Tabela AV-4: Valores de Perfis da condição IV.

\begin{tabular}{cccccccc}
\hline Tempo & $\begin{array}{c}\mathrm{C}_{\mathrm{SF}} \\
{\left[\mathrm{mgDQO} \cdot \mathrm{L}^{-1}\right]}\end{array}$ & $\begin{array}{c}\mathrm{C}_{\mathrm{CF}} \\
{\left[\mathrm{mgSAC} \cdot \mathrm{L}^{-1}\right]}\end{array}$ & $\begin{array}{c}\mathrm{AP} \\
{\left[\mathrm{mgCaCO}_{3} \cdot \mathrm{L}^{-1}\right]}\end{array}$ & $\begin{array}{c}\mathrm{AI} \\
{\left[\mathrm{mgCaCO}_{3} \cdot \mathrm{L}^{-1}\right]}\end{array}$ & $\begin{array}{c}\mathrm{AT} \\
{\left[\mathrm{mgCaCO}_{3} \cdot \mathrm{L}^{-1}\right]}\end{array}$ & $\begin{array}{c}\mathrm{AVT} \\
{\left[\mathrm{mgCaCO}_{3} \cdot \mathrm{L}^{-1}\right]}\end{array}$ & $\begin{array}{c}\mathrm{V}_{\text {biogás }} \\
{[\mathrm{mL}]}\end{array}$ \\
\hline 0,00 & 4488 & 1877 & 129 & 467 & 596 & 487 & 0 \\
0,50 & 4066 & 1407 & 65 & 497 & 562 & 525 & 323 \\
1,00 & 3995 & 1184 & 0 & 539 & 539 & 698 & 608 \\
1,50 & 4006 & 1043 & 0 & 505 & 505 & 725 & 879 \\
2,00 & 3837 & 725 & 0 & 482 & 482 & 752 & 1125 \\
2,70 & 3837 & 523 & 0 & 471 & 471 & 828 & 1400 \\
\hline
\end{tabular}

Tabela AV-5: Valores de Perfis da condição V.

\begin{tabular}{cccccccc}
\hline Tempo & $\begin{array}{c}\mathrm{C}_{\mathrm{SF}} \\
{\left[\mathrm{mgDQO} \cdot \mathrm{L}^{-1}\right]}\end{array}$ & $\begin{array}{c}\mathrm{C}_{\mathrm{CF}} \\
{\left[\mathrm{mgSAC} \cdot \mathrm{L}^{-1}\right]}\end{array}$ & $\begin{array}{c}\mathrm{AP} \\
{\left[\mathrm{mgCaCO}_{3} \cdot \mathrm{L}^{-1}\right]}\end{array}$ & $\begin{array}{c}\mathrm{AI} \\
{\left[\mathrm{mgCaCO}_{3} \cdot \mathrm{L}^{-1}\right]}\end{array}$ & $\begin{array}{c}\mathrm{AT} \\
{\left[\mathrm{mgCaCO}_{3} \cdot \mathrm{L}^{-1}\right]}\end{array}$ & $\begin{array}{c}\mathrm{AVT} \\
{\left[\mathrm{mgCaCO}_{3} \cdot \mathrm{L}^{-1}\right]}\end{array}$ & $\begin{array}{c}\mathrm{V}_{\text {biogás }} \\
{[\mathrm{mL}]}\end{array}$ \\
\hline 0,00 & 3412 & 2088 & 170 & 257 & 427 & 322 & 0 \\
0,33 & 3386 & 1703 & 49 & 339 & 388 & 355 & 270 \\
0,67 & 3109 & 1396 & 18 & 342 & 359 & 437 & 531 \\
1,00 & 3044 & 1232 & 0 & 368 & 368 & 433 & 770 \\
1,33 & 3015 & 1090 & 0 & 346 & 346 & 448 & 976 \\
1,70 & 2992 & 887 & 0 & 364 & 364 & 481 & 1138 \\
\hline
\end{tabular}

Tabela AV-6: Valores de Perfis da condição VI.

\begin{tabular}{cccccccc}
\hline Tempo & $\begin{array}{c}\mathrm{C}_{\mathrm{SF}} \\
{\left[\mathrm{mgDQO} \cdot \mathrm{L}^{-1}\right]}\end{array}$ & $\begin{array}{c}\mathrm{C}_{\mathrm{CF}} \\
{\left[\mathrm{mgSAC} \cdot \mathrm{L}^{-1}\right]}\end{array}$ & $\begin{array}{c}\mathrm{AP} \\
{\left[\mathrm{mgCaCO}_{3} \cdot \mathrm{L}^{-1}\right]}\end{array}$ & $\begin{array}{c}\mathrm{AI} \\
{\left[\mathrm{mgCaCO}_{3} \cdot \mathrm{L}^{-1}\right]}\end{array}$ & $\begin{array}{c}\mathrm{AT} \\
{\left[\mathrm{mgCaCO}_{3} \cdot \mathrm{L}^{-1}\right]}\end{array}$ & $\begin{array}{c}\mathrm{AVT} \\
{\left[\mathrm{mgCaCO}_{3} \cdot \mathrm{L}^{-1}\right]}\end{array}$ & $\begin{array}{c}\mathrm{V}_{\text {biogás }} \\
{[\mathrm{mL}]}\end{array}$ \\
\hline 0,00 & 5169 & 3328 & 185 & 379 & 564 & 334 & 0 \\
0,33 & 4883 & 2854 & 137 & 397 & 535 & 398 & 304 \\
0,67 & 4874 & 2561 & 101 & 419 & 520 & 485 & 606 \\
1,00 & 4798 & 2406 & 59 & 406 & 466 & 519 & 892 \\
1,33 & 4721 & 2297 & 43 & 466 & 509 & 541 & 1144 \\
1,70 & 4587 & 2256 & 4 & 484 & 488 & 557 & 1349 \\
\hline
\end{tabular}

